\title{
Interaction of hepatic uptake transporters with antineoplastic compounds and regulation of the expression of organic cation transporter 3 in renal carcinoma cells
}

\section{Doctoral Thesis}

In partial fulfillment of the requirements for the degree "Doctor rerum naturalium (Dr. rer. nat.)" in the Molecular Medicine Study Program at the Georg-August University Göttingen

\author{
submitted by \\ Venkata V. V. R. Marada \\ born in Visakhapatnam, India
}

Göttingen 2014 
Members of the Thesis Committee:

\section{Supervisor:}

Prof. Dr. med. Gerhard Burckhardt

Institut für Vegetative Physiologie und Pathophysiologie

Universitätsmedizin Göttingen, Georg-August-Universität

Second member of the thesis committee

Prof. Dr. med. Jürgen Brockmöller

Abteilung Klinische Pharmakologie

Universitätsmedizin Göttingen, Georg-August-Universität

Third member of the thesis committee

Prof. Dr. med. Heidi Hahn

Institut für Humangenetik

Universitätsmedizin Göttingen, Georg-August-Universität

Date of Disputation: 


\title{
AFFIDAVIT
}

I hereby declare that my doctoral thesis entitled "Interaction of hepatic uptake transporters with antineoplastic compounds and regulation of the expression of organic cation transporter 3 in renal carcinoma cells" has been written independently with no other sources and aids than quoted.

\author{
Venkata V. V. R. Marada
}

November, 2014

Göttingen 


\section{Publications}

Venkata V. V. R. Marada , Saskia Flörl, Annett Kühne, Gerhard Burckhardt and Yohannes Hagos, Interaction of organic anion transporter 2 (OAT2) and sodium taurocholate cotransporting polypeptide (NTCP) with antineoplastic compounds, Pharmacol Res., 2014 (in press).

Venkata V. V. R. Marada , Saskia Flörl, Annett Kühne, Gerhard Burckhardt and Yohannes Hagos, Interaction of human Organic Anion Transporter transporting polypeptides 1B1 and 1B3 with antineoplastic compounds. Eur J Med Chem. (in revision).

Yohannes Hagos, Waja Wegner, Annett Kuehne, Saskia Floerl, Venkata V. V. R. Marada, Gerhard Burckhardt, Maja Henjakovic. HNF4 $\alpha$ Induced Chemosensitivity to Oxaliplatin and 5-FU Mediated by OCT1 and CNT3 in Renal Cell Carcinoma. J Pharm Sci. 2014 Oct; 103 (10):3326-34.

Yohannes Hagos, Philip Hundertmark, Volodymyr Shnitsar, Venkata V. V. R. Marada, Gerald Wulf, Gerhard Burckhardt. Renal Human Organic Anion Transporter 3 increases the Susceptibility of Lymphoma Cells to Bendamustine Uptake. Am J Physiol Renal Physiol (in revision). 


\begin{tabular}{|c|c|}
\hline \multicolumn{2}{|c|}{ Abbreviations } \\
\hline$\mu \mathrm{M}$ & Micromolar \\
\hline$\mu \mathrm{g}$ & Microgram \\
\hline$\mu \mathrm{L}$ & Microlitre \\
\hline${ }^{\circ} \mathrm{C}$ & Degree Celsius \\
\hline bp & Base pairs \\
\hline CCK-8 & Cholecystokinin octapeptide \\
\hline cDNA & Complementary DNA \\
\hline cGMP & Cyclic guanosine monophosphate \\
\hline $\mathrm{Ct}$ & Cycle of threshold \\
\hline DMSO & Dimethyl sulfoxide \\
\hline DNA & Deoxyribonucleic acid \\
\hline DNase & Deoxyribonuclease \\
\hline DTT & Dithiothreitol \\
\hline $\mathrm{ES}$ & Estrone-3-sulfate \\
\hline E. coli & Escherichia coli \\
\hline GAPDH & Glyceraldehyde 3-phosphate dehydrogenase \\
\hline $\mathrm{HCl}$ & Hydrogen chloride \\
\hline HDAC & Histone deacetylase \\
\hline HEK & Human embryonic kidney \\
\hline HPLC & High performance liquid chromatography \\
\hline $\mathrm{h}$ & Hour(s) \\
\hline ISP & Ion sphere particles \\
\hline$K_{m}$ & Michaelis-Menten constant \\
\hline$K_{i}$ & Inhibition constant \\
\hline $\mathrm{KCl}$ & Potassium chloride \\
\hline M & Molar \\
\hline
\end{tabular}




$\begin{array}{ll}\mathrm{MgCl}_{2} & \text { Magnesium chloride } \\ \mathrm{min} & \text { Minutes } \\ \mathrm{mL} & \text { Millilitre } \\ \text { mRNA } & \text { messenger RNA } \\ \mathrm{NaOH} & \text { Sodium hydroxide } \\ \mathrm{ng} & \text { Nanogram } \\ \mathrm{nM} & \text { Nanomolar } \\ \mathrm{nm} & \text { Nanometers } \\ \text { ntds } & \text { Nucleotides } \\ \text { NTCP } & \text { Sodium taurocholate cotransporting polypeptide } \\ \text { OAT2 } & \text { Organic anion transporter } 2\end{array}$

OATP1B1 Organic anion transporting polypeptide 1B1

OATP1B3 Organic anion transporting polypeptide 1B3

OCT3 Organic cation transporter 3

PBS Phosphate buffered saline

PCR Polymerase chain reaction

pmol Picomoles

qPCR Quantitative polymerase chain reaction

qRTPCR Quantitative reverse transcriptase polymerase chain reaction

RCCs Renal carcinoma cells

RNA Ribonucleic acid

RNase Ribonuclease

RPM Revolutions per minute

RFU Relative fluorescence units

s Second(s)

SEM Standard error mean

TBAHS Tetrabutylammonium hydrogen sulfate 
Tris Tris (hydroxymethyl) aminomethane

U Units of enzyme activity

UTR Untranslated region 


\section{Contents}

Abstract............................................................................................................................

List of figures.

XVII

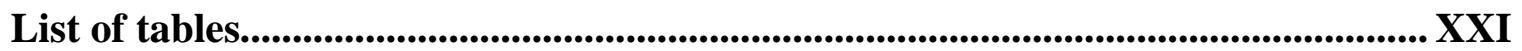

1. Introduction .................................................................................................................1

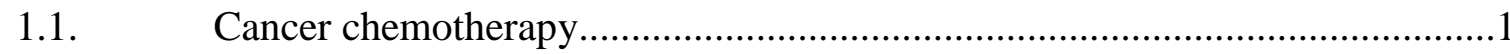

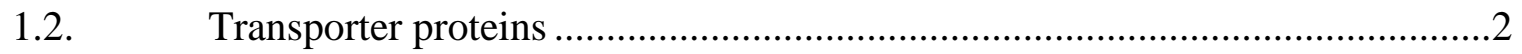

1.3. Importance of transporter proteins in metabolism of antineoplastic

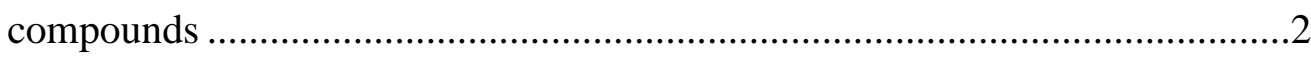

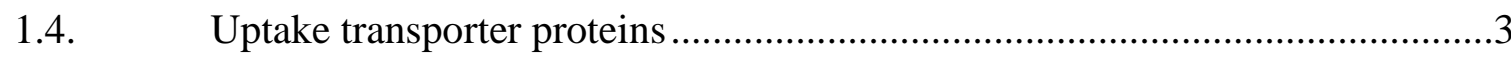

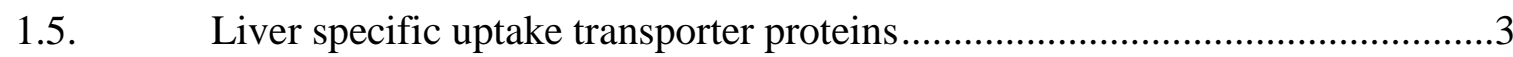

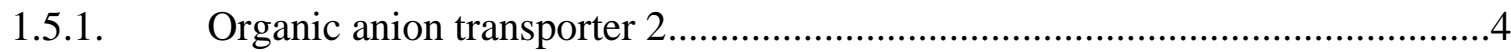

1.5.2. Sodium taurocholate cotransporting polypeptide .........................................4

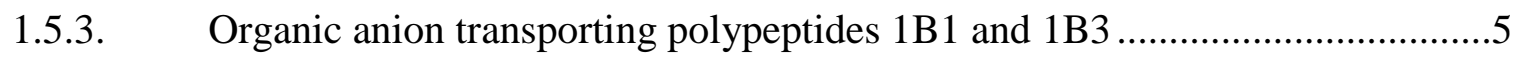

1.6. Interactions of transporter proteins with antineoplastic compounds ................5

1.7. Antineoplastic compounds used in the study and their mechanisms of

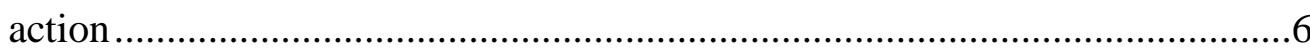

1.8. Therapeutic uses of antineoplastic compounds used in the study...................

1.9. Factors affecting contribution of transporter proteins to chemotherapy ...........9

1.9.1. Regulation of expression of genes at genetic and epigenetic levels ................9

1.9.2. Transcriptional regulation of gene expression ........................................... 14

1.9.3. MicroRNA based regulation of gene expression .........................................14

1.9.4. Post-translational mode of gene regulation................................................ 17

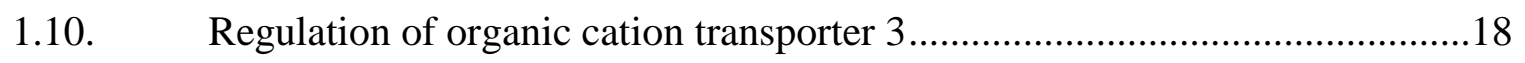




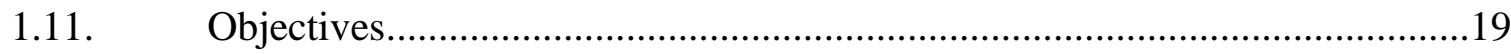

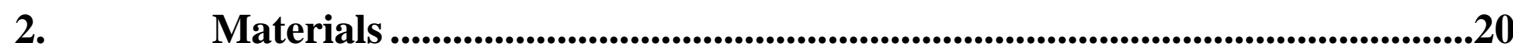

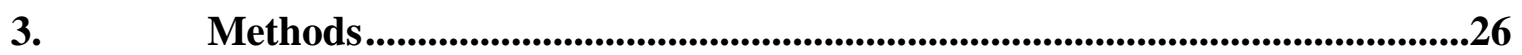

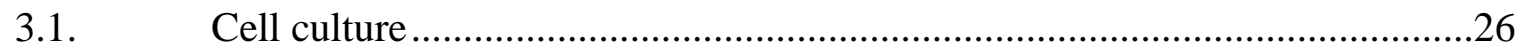

3.2. Substrate uptake experiments..................................................................26

3.2.1. Time dependent uptake of $\left[{ }^{3} \mathrm{H}\right]$ labeled substrates........................................27

3.2.2. Concentration dependent uptake of radiolabeled substrates and determination

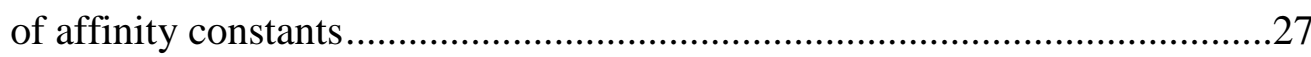

3.2.3. Inhibition of transporter activity by antineoplastic agents..............................27

3.2.4. Concentration dependent inhibition of uptake of substrates in the presence of

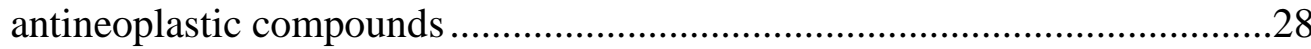

3.2.4.1. Concentration dependent inhibition of OAT2 activity by the compounds bendamustine, irinotecan and paclitaxel .........................................................28

3.2.4.2. Concentration dependent inhibition of OATP1B1 activity by vinblastine and paclitaxel .29

3.2.4.3. Concentration dependent inhibition of OATP1B3 activity by antineoplastic compounds .29

3.3. Apoptosis assay by determination of the Caspase-3 activity ...........................29

3.4. Evaluation the uptake of antineoplastic drugs in the cells by HPLC

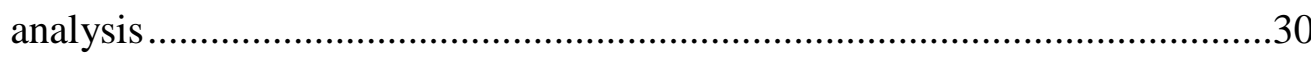

3.5. Determination of protein concentration …………........................................

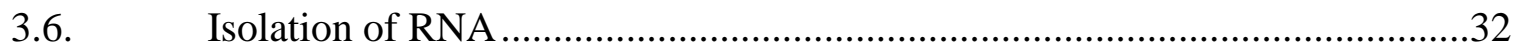

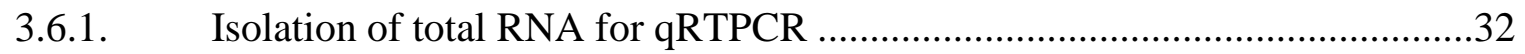

3.6.2. Isolation of total RNA using Trizol reagent..................................................33

3.6.3. Isolation of small RNA enriched fraction ........................................................ 


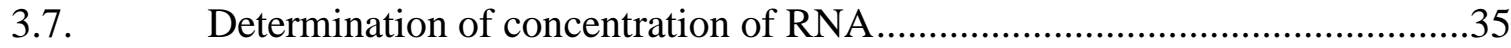

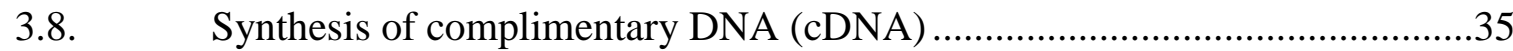

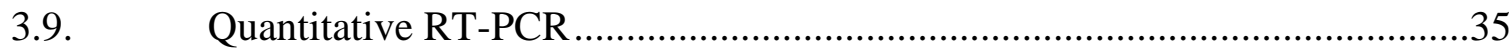

3.10. Disruption of DNA methylation using azacytidine ........................................36

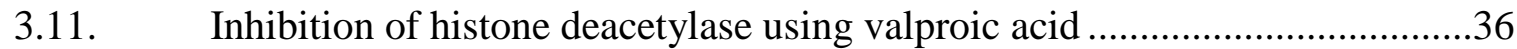

3.12. Analysis of methylation status of promoter of SLC22A3 gene by Ion Torrent

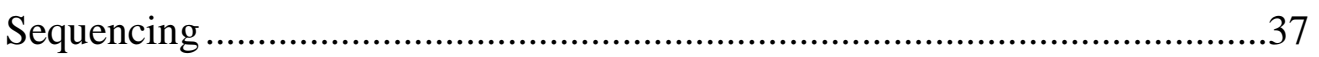

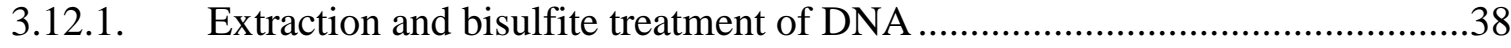

3.12.2. Amplification of desired fragments and library preparation...........................40

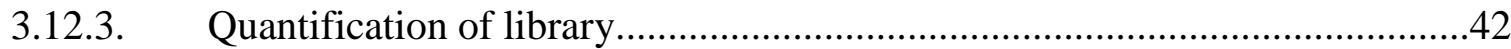

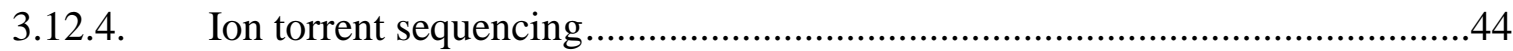

3.12.4.1. Preparation of template positive Ion Sphere Particles (ISPs) .........................44

3.12.4.2. Enrichment of template positive Ion Sphere Particles ...................................45

3.12.4.3. Sequencing the template positive Ion Sphere Particles .................................46

3.13. Computational algorithms used to predict microRNAs binding to $3^{\prime}$ UTR of OCT3 .46

3.14. Statistical analysis .47

3.15. Determination of molecular characteristics of the antineoplastic drugs using MarvinSketch software .47

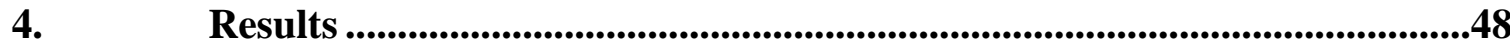

4.1. Interaction of Organic anion transporter 2 with antineoplastic compounds ...48

4.1.1. Inhibition of OAT2 mediated cGMP uptake by antineoplastic compounds ...48

4.1.1.1. Inhibition of OAT2 mediated cGMP uptake by alkylating agents ................48 
4.1.1.2. Inhibition of OAT2 mediated cGMP uptake by antimetabolites .49

4.1.1.3. Inhibition of OAT2 mediated cGMP uptake by intercalating agents and mitotic inhibitors .50

4.1.1.4. Inhibition of OAT2 mediated cGMP uptake by topoisomerase inhibitors and compounds targeting hormone receptors .51

4.1.2. Concentration dependent inhibition of antineoplastic compounds on OAT2 mediated $\left[{ }^{3} \mathrm{H}\right]$ cGMP uptake .53

4.1.2.1. Concentration dependent inhibition of OAT2 mediated $\left[{ }^{3} \mathrm{H}\right]$ cGMP uptake by bendamustine .53

4.1.2.2. Concentration dependent inhibition of OAT2 mediated $\left[{ }^{3} \mathrm{H}\right]$ cGMP uptake by irinotecan .54

4.1.2.3. Concentration dependent inhibition of OAT2 mediated $\left[{ }^{3} \mathrm{H}\right]$ cGMP uptake by paclitaxel .55

4.1.3. Evaluation of OAT2 mediated uptake of bendamustine by apoptosis .56

4.1.4. Evaluation of OAT2 mediated accumulation of irinotecan by HPLC analysis .57

4.1.4.1. Quantitation of OAT2 mediated uptake of irinotecan ..................................58

4.1.4.2. Time dependent OAT2 mediated uptake of irinotecan ................................59

4.1.4.3. Concentration dependent uptake of irinotecan by pcDNA and OAT2 cells...60

4.2. Interaction of sodium taurocholate cotransporting polypeptide (NTCP) with antineoplastic compounds

4.2.1. Functional characterization of NTCP 61

4.2.1.1. Time dependent uptake of $\left[{ }^{3} \mathrm{H}\right]$ estrone -3-sulfate by NTCP expressing cells 
4.2.1.2. Concentration dependent uptake of $\left[{ }^{3} \mathrm{H}\right]$ estrone-3-sulfate by NTCP expressing cells

4.2.2. Inhibition of NTCP mediated estrone-3-sulfate uptake by antineoplastic compounds

4.2.2.1. Inhibition of NTCP mediated estrone-3-sulfate uptake by alkylating agents .64

4.2.2.2. Inhibition of NTCP mediated estrone-3-sulfate uptake by antimetabolites....65

4.2.2.3. Inhibition of NTCP mediated estrone-3-sulfate uptake by intercalating agents and mitotic inhibitors .65

4.2.2.4. Inhibition of NTCP mediated estrone-3-sulfate uptake by topoisomerase inhibitors and compounds targeting hormone receptors .67

4.3. Interaction of organic anion transporting polypeptide 1B1 (OATP1B1) with antineoplastic compounds .68

4.3.1. Inhibition of OATP1B1 mediated estrone sulfate uptake by antineoplastic agents

4.3.1.1. Inhibition of OATP1B1 mediated estrone-3-sulfate uptake by alkylating agents .68

4.3.1.2. Inhibition of OATP1B1 mediated estrone-3-sulfate uptake by antimetabolites

4.3.1.3. Inhibition of OATP1B1 mediated estrone-3-sulfate uptake by intercalating agents and mitotic inhibitors

4.3.1.4. Inhibition of OATP1B1 mediated estrone-3-sulfate uptake by topoisomerase inhibitors and hormone receptor targeters .71

4.3.2. Concentration dependent inhibition of antineoplastic compounds on OATP1B1 mediated estrone-3-sulfate uptake .73 
4.3.2.1. Concentration dependent inhibition of vinblastine on OATP1B1 mediated estrone-3-sulfate uptake .73

4.3.2.2. Concentration dependent inhibition of paclitaxel on OATP1B1 mediated estrone-3-sulfate uptake .74

4.4. Interaction of organic anion transporting polypeptide 1B3 (OATP1B3) with antineoplastic compounds .75

4.4.1. Functional characterization of OATP1B3 transporter activity ......................75

4.4.1.1. Time dependent uptake of $\left[{ }^{3} \mathrm{H}\right]$ CCK-8 by OATP1B3 expressing cells .........75

4.4.1.2. Concentration dependent uptake of $\left[{ }^{3} \mathrm{H}\right] \mathrm{CCK}-8$ by OATP1B3 expressing cells .76

4.4.2. Inhibition of OATP1B3-mediated CCK-8 uptake by antineoplastic compounds .77

4.4.2.1. Inhibition of OATP1B3 mediated CCK-8 uptake by alkylating agents .........78

4.4.2.2. Inhibition of OATP1B3 mediated CCK-8 uptake by antimetabolites ............79

4.4.2.3. Inhibition of OATP1B3 mediated CCK-8 uptake by intercalating agents and mitotic inhibitors .80

4.4.2.4. Inhibition of OATP1B3 mediated CCK-8 uptake by topoisomerase inhibitors and hormone receptor targeters .81

4.4.3. Concentration dependent inhibition of antineoplastic compounds on OATP1B3 mediated cholecystokinin octapeptide uptake .82

4.4.3.1. Concentration dependent inhibition of chlorambucil on OATP1B3 mediated CCK-8 uptake .82

4.4.3.2. Concentration dependent inhibition of mitoxantrone on OATP1B3 mediated CCK-8 uptake .83 
4.4.3.3. Concentration dependent inhibition of vinblastine on OATP1B3 mediated CCK-8 uptake .84

4.4.3.4. Concentration dependent inhibition of vincristine on OATP1B3 mediated CCK-8 uptake .85

4.4.3.5. Concentration dependent inhibition of paclitaxel on OATP1B3 mediated CCK-8 uptake .86

4.4.3.6. Concentration dependent inhibition of etoposide on OATP1B3 mediated CCK-8 uptake .87

4.5. Expression of SLC22A3 in A498, ACHN, 786-O and LN 78 cells ..............88

4.6. Effect of inhibition of DNA methylation on expression of OCT3 _...............89

4.7. Effect of inhibition of histone deacetylation on the expression of OCT3 _....90

4.8. Determination of methylation status of $\mathrm{CpG}$ islands by Ion-Torrent sequencing of bisulfite treated DNA

4.9. $\quad$ qRTPCR of expression of selected microRNAs in A498 and ACHN cells....94

4.10. Manipulation of levels of hsa-mir-204 and hsa-mir-143 in A498 and ACHN cells using microRNA mimics and antimirs .95

4.11. Genome wide analysis of microRNA in A498, ACHN, 786-O and LN 78 cells

5. Discussion .99

5.1. Interaction of OAT2, NTCP, OATP1B1 and OATP1B3 with antineoplastic compounds .99

5.1.1. Bendamustine is a substrate of organic anion transporter $2 \ldots \ldots \ldots \ldots \ldots \ldots \ldots \ldots . . . . . . . .110$

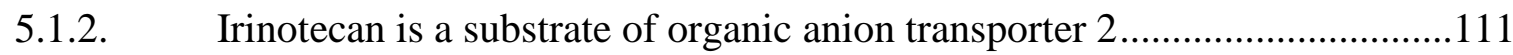

5.2. Regulation of organic cation transporter 3 in renal carcinoma cells.............113

5.2.1. Epigenetic regulation of OCT3 in renal carcinoma cells .............................114 
5.2.2. Impact of methylation of promoter region on the expression of organic cation transporter 3

5.2.3. Investigation of microRNA dependent post-transcriptional regulation of

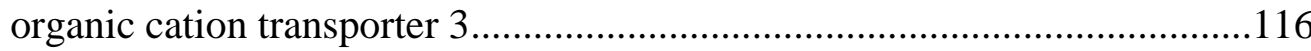

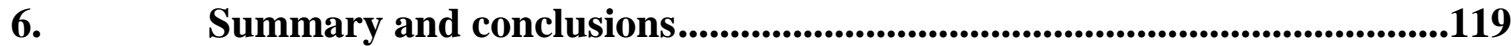

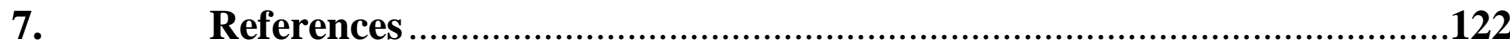

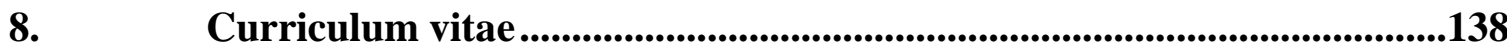




\section{Acknowledgements}

I would like to express my deepest sense of gratitude for Prof. Yohannes Hagos for giving me an opportunity to do $\mathrm{PhD}$ in his research group. The years of working here have been a great learning experience in many directions. I thank him for his patience in guiding me in this project and for his help and suggestions to overcome the hurdles I faced in the course of my research.

I am very thankful to Prof. Gerhard Burckhardt for his suggestions and guidance during the course of the project, for making sure that everything is done smoothly and timely, and for his constant support and encouragement for the experiments as well as for the formalities of the $\mathrm{PhD}$ program.

My gratitude goes to Prof. Jürgen Brockmöller and Prof. Heidi Hahn for being my thesis committee members. Their suggestions during the thesis committee meetings have been very insightful and expanded the scope of the project to its present shape.

I am thankful to the Graduate College Cancer Pharmacogenomics (GRK 1034) and Prof. Gerhard Burckhardt for the financial support.

It has been a great experience working with Dr. Mladen Tzvetkov and I thank him and his entire group, especially my colleague Sayed Mohammad Hasheminasab for his help with Ion Torrent Sequencing. I also thank our collaborator Dr. Gabriela Salinas-Riester and the staff of DNA deep sequencing and microarray facility in the university, especially Mr. Fabian Ludewig for the generation of microRNA expression data.

I thank Mr. Sören Petzke for his skilful assistance during this period. I learned a lot working with him, and his tips have been very productive for my experiments. I thank Dr. Saskia Flörl and Dr. Annett Kühne of PortaCellTec biosciences for providing me stably 
transfected cells. I also want to thank all my past and present colleagues in the department for their help and support with the experiments. I thank Mr. Sina Tadjerpisheh and Dr. Kotini for introducing me to the basics of HPLC and Ms. Judith Müller for helping me work with it. I thank Dr. Pantakani for help with transfections.

I thoroughly enjoyed and learned a lot from the various scientific presentations and I am thankful to Prof. Birgitta C. Burckhardt for organising Göttinger transporttage annually in the department and giving me an opportunity to present my data in it. I also thank Mr. Sven Müller and Dr. Erik Meskauskas for organising yearly retreats and coordinating the academic activities, and all my colleagues in GRK 1034 and the $\mathrm{PhD}$ program Molecular Medicine.

Finally, I want to thank all my friends and my family for their understanding, support, and encouragement. 


\section{Abstract}

The ability of a compound to exert its antineoplastic activity is determined by the amount of its accumulation inside the cell, a process largely dependent on the transporter proteins which are responsible for the passage of compounds into and out of the cell. The present study is focussed on the uptake transporter proteins; their interactions with antineoplastic compounds routinely used in cancer chemotherapy, and the regulation of expression of one such uptake transporter protein, organic cation transporter 3 (OCT3). The interactions of four such uptake transporters, that are predominantly expressed in liver namely, organic anion transporter 2 (OAT2), sodium taurocholate cotransporting polypeptide (NTCP), organic anion transporting polypeptides 1B1 and 1B3 (OATP1B1 and OATP1B3), were analysed in stably transfected human embryonic kidney cells. The transporter proteins were functionally characterized using $\left[{ }^{3} \mathrm{H}\right]$ model substrates and the uptake of this model substrate was followed in the presence of $100 \mu \mathrm{M}$ of the antineoplastic compounds. The antineoplastic compounds which were able to inhibit the uptake of model substrate by $60 \%$ of buffer control were chosen for further analysis of interaction. No compound could inhibit the NTCP mediated estrone-3-sulfate uptake by $60 \%$ of buffer control. The affinity ( $K_{i}$ value) of the transporter proteins for the compounds that inhibited the uptake of model substrate by $60 \%$ of buffer control was determined by Dixon-plot analysis. OAT2 was found to strongly interact with bendamustine, irinotecan and paclitaxel with $K_{i}$ values of $43.3 \mu \mathrm{M}, 26.4 \mu \mathrm{M}$, and 10.4 $\mu \mathrm{M}$, respectively. OATP1B1 interacted with vinblastine and paclitaxel, with $K_{i}$ values of $10.2 \mu \mathrm{M}$ and $0.84 \mu \mathrm{M}$, respectively. OATP1B3 interacted with chlorambucil, mitoxantrone, vinblastine, vincristine, paclitaxel, and etoposide with $K_{i}$ values of 37.4 $\mu \mathrm{M}, 3.1 \mu \mathrm{M}, 18.6 \mu \mathrm{M}, 17.6 \mu \mathrm{M}, 1.8 \mu \mathrm{M}$, and $13.5 \mu \mathrm{M}$, respectively. 
From the $\mathrm{IC}_{50}$ values generated, the possibility of these interactions to contribute to potential drug-drug interactions was calculated. Furthermore, as mentioned above, the regulation of expression of OCT3 in four renal carcinoma cells (A498, ACHN, 786-O, and LN78) with variable OCT3 expression, was analysed at the epigenetic and posttranscriptional levels. Using inhibitors for the processes of histone deacetylation and DNA methylation, the contribution of these processes was validated. It was found that they do not account for the huge difference of expression of OCT3 found between A498 and ACHN cells. In addition, the methylation status of the promoter region of OCT3 was analysed by Ion Torrent sequencing. There was no considerable difference between the methylation status of the promoter regions tested in the four renal carcinoma cell lines. The post-transcriptional regulation of OCT3 by microRNAs was also analysed. MicroRNAs that have the ability to bind to 3 ' untranslated region of OCT3 were obtained from in silico prediction programs and the expression of these microRNAs was analysed by qRTPCR. Two microRNAs, hsa-mir-204 and hsa-mir-143, were selected as they showed differential expression in A498 and ACHN cells. The levels of these microRNAs were altered in these cells using small molecules called microRNA mimics and antimirs, and the expression of OCT3 was followed. However, no correlation was observed between the expression levels of these microRNAs and OCT3. In this direction, the search for potential OCT3 regulators was pursued by the next generation sequencing of genome wide microRNA analysis. From the results it is clear that a many microRNAs are differentially expressed in the four renal carcinoma cells. To make more advances in the search for microRNAs which are directly or indirectly involved in the regulation of OCT3, transcriptome analysis from the same RNA samples is being performed. This approach is best suited to dissect any factors involved in the transcriptional as well as post-transcriptional regulation of OCT3. 


\section{List of figures}

1.1 Epigenetic control of a gene

1.3 Inhibition of DNA methylation by 5-aza-2'-deoxy-cytidine (AZA-CdR) .13

1.4 Multiple pathways of microRNA biogenesis

1.5 Post translational modifications (PTM) of proteins .18

2.1 Work flow of ion torrent sequencing .38

4.1 Inhibition of OAT2 mediated uptake of $\left[{ }^{3} \mathrm{H}\right]$ cGMP in the presence of alkylating agents

4.2 Inhibition of OAT2 mediated uptake of $\left[{ }^{3} \mathrm{H}\right]$ cGMP in the presence of antimetabolites

4.3 Inhibition of OAT2 mediated uptake of $\left[{ }^{3} \mathrm{H}\right]$ cGMP in the presence of intercalating agents and mitotic inhibitors

4.4 Inhibition of OAT2 mediated uptake of $\left[{ }^{3} \mathrm{H}\right]$ cGMP in the presence of topoisomerase inhibitors and compounds acting on hormone receptor targets

4.5 Determination of $K_{i}$ value of OAT2 for bendamustine by Dixon Plot analysis .53

4.6 Determination of $K_{i}$ value of OAT2 for irinotecan by Dixon Plot analysis .54

4.7 Determination of $K_{i}$ value of OAT2 for paclitaxel by Dixon - Plot analysis .55

4.8 Evaluation of OAT2- mediated apoptosis.

4.9 Evaluation of OAT2-mediated irinotecan uptake .58 


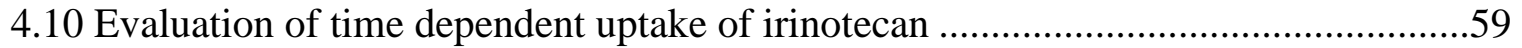

4.11 Evaluation of concentration dependent uptake of irinotecan...................................60

4.12 Time dependent uptake of NTCP mediated estrone-3-sulfate ...............................62

4.13 Concentration dependent uptake of estrone-3-sulfate by NTCP ............................62

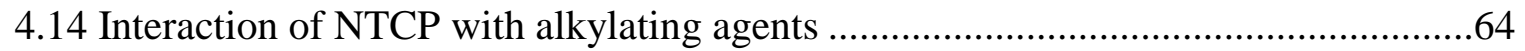

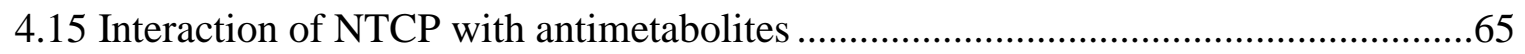

4.16 Interaction of NTCP with intercalating agents and mitotic inhibitors .....................66

4.17 Interaction of NTCP with topoisomerase inhibitors and hormone receptor targeters .67

4.18 Inhibition of OATP1B1 mediated estrone-3-sulfate uptake by alkylating agents .....69

4.19 Inhibition of OATP1B1 mediated estrone-3-sulfate uptake by antimetabolites........70

4.20 Inhibition of OATP1B1 mediated estrone-3-sulfate uptake by intercalating agents

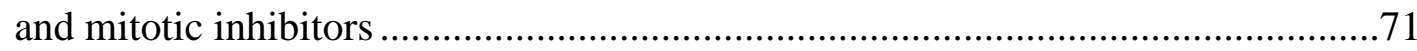

4.21 Inhibition of OATP1B1 mediated estrone-3-sulfate uptake by topoisomerase inhibitors and hormone receptor targeters

4.22 Concentration dependent inhibition of OATP1B1-mediated estrone-3-sulfate by vinblastine

4.23 Concentration dependent inhibition of OATP1B1-mediated estrone-3-sulfate by paclitaxel 
4.26 Inhibition of OATP1B3 mediated CCK-8 uptake by alkylating agents .78

4.27 Inhibition of OATP1B3 mediated CCK-8 uptake by antimetabolites .79

4.28 Inhibition of OATP1B3 mediated CCK-8 uptake by intercalating agents and mitotic inhibitors .80

4.29 Inhibition of OATP1B3 mediated CCK-8 uptake by topoisomerase inhibitors and hormone receptor targeters

4.30 Concentration dependent inhibition of OATP1B3 mediated CCK-8 uptake by chlorambucil .82

4.31 Concentration dependent inhibition of OATP1B3 mediated CCK-8 uptake by mitoxantrone .83

4.32 Concentration dependent inhibition of OATP1B3 mediated CCK-8 uptake by vinblastine .84

4.33 Concentration dependent inhibition of OATP1B3 mediated CCK-8 uptake by vincristine. .85

4.34 Concentration dependent inhibition of OATP1B3 mediated CCK-8 uptake by paclitaxel .86

4.35 Concentration dependent inhibition of OATP1B3 mediated CCK-8 uptake by etoposide .87

4.36 Expression of OCT3 in renal carcinoma cell lines .89

4.37 Expression of OCT3 in ACHN cells treated with 5-aza-2'-deoxy-cytidine .90 
4.38 Expression of OCT3 in ACHN cells treated with valproic acid ..............................91

4.39 Amplification of fragments 1 and 2 from the promoter region of SLC22A3 ...........92

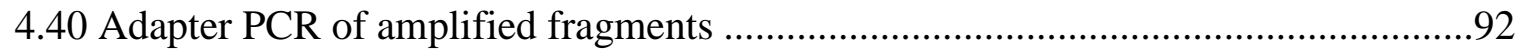

4.41 Analysis of methylation status of $\mathrm{CpG}$ islands in fragments 1 and 2 of the promoter

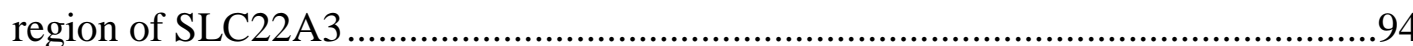

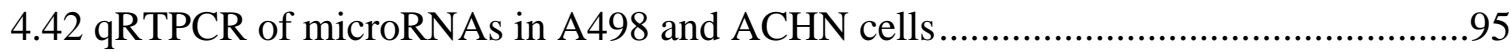

4.43 qRTPCR of SLC22A3 in A498 and ACHN cells upon transfection with microRNA

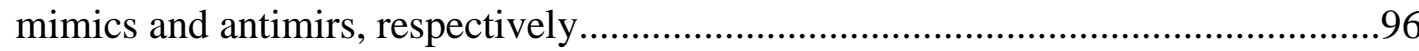

4.44 Number of differentially expressed microRNAs among the cell lines ....................97

4.45 Number of microRNAs highly expressed in ACHN (A) and with zero expression in

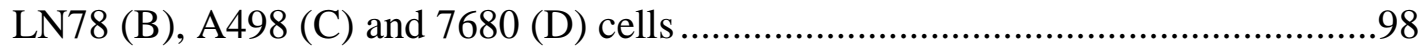

4.46 Number of microRNAs highly expressed in LN78 (B), A498 (C) and 7680 (D) cells

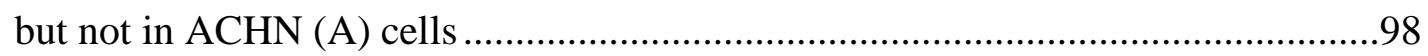

5.1 Correlation plots of inhibitory effect of antineoplastic compounds and their molecular parameters 109 


\section{List of tables}

1.1 Antineoplastic compounds and their therapeutic uses ..........................................

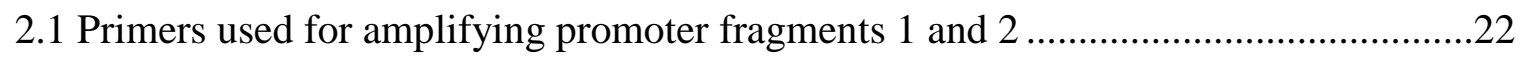

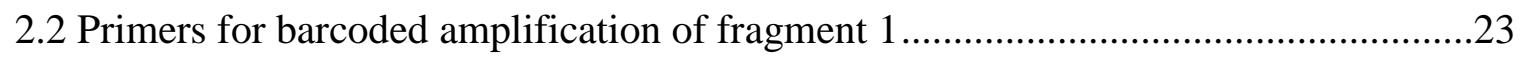

2.3 Primers for barcoded amplification of fragment 1 ..................................................24

3.1 Reaction mixture of gradient PCR for amplification of promoter regions 1 and 2 of SLC22A3

3.2 PCR conditions for the amplification of promoter regions 1 and 2 of SLC22A3 .41

3.3 Reaction mixture for adapter PCR 42

3.4 PCR conditions for the amplification of barcoded fragments of promoter regions 1 and 2 of SLC22A3 42

3.5 Reaction mixture for qPCR of amplified barcoded fragments .43

3.6 Reaction mixture for emulsion PCR to prepare template positive ISPs .44

5.1. Possibility of compounds to contribute to the transporter mediated drug-drug interactions .103

5.2 Molecular parameters of the compounds used in the study .105 


\section{Introduction}

\subsection{Cancer chemotherapy}

Cancer is of utmost health concerns and is one of the primary causes of deaths to humanity worldwide. This made cancer a hot topic of research and the scope of research has widened from therapy to the basic mechanisms of generation of cancer cells, including factors in cells which provide predisposition or risk of cancer and those which are responsible for suppressing the growth of such cells in vivo. However, with the complex ecosystem of today's world, the balance seems to have shifted towards factors causing the disease. Though the disease is characterized by a lot of pathways which seem to be commonly involved, it also has a diversity of mechanisms operating in parallel. This fact makes it hard to find a common treatment without understanding the origin of disease in detail. The discrepancies are found not only in origins but also in those processes which are crucial for treatment. Cancer therapy includes methods like radiotherapy, chemotherapy and surgery. However, any of the above methods individually, or in combination, have not been largely successful so far to yield a complete recovery and, at the most increase, the life span of the patients for varying periods of time, depending upon the organ affected. Cancer chemotherapy has the advantage among the treatment options that the side effects of such a therapy would not, in most cases, last long. Compounds which are used in the treatment of cancer are referred to as antineoplastic compounds. Antineoplastic compounds have varying mechanisms of action, while some cause abnormalities in the DNA metabolism; others cause abnormalities in cytoskeletal processes and so on. The ability of an antineoplastic drug to exert its cytostatic effect depends largely on the balance between its uptake into and extrusion from the cancer cells. The uptake transport proteins are involved in the transport of the compounds into 
the cells, without the involvement of a direct energy coupling, whereas the efflux transporters drive the compound out the cells coupled with the hydrolysis of ATP.

\subsection{Transport proteins}

The proteins involved in the transport of antineoplastic compounds are expressed on the surface of cells. The efflux transport proteins are grouped into the ABC (ATP binding cassette) superfamily of proteins which, by virtue of their ability to hydrolyze ATP, drive the molecules out of the cell [1]. They include the proteins P-gp (multidrug resistance protein, MDR1 or $\mathrm{ABCB} 1$ ), breast cancer resistance protein (BCRP) etc. These proteins have been a focal point of extensive research as they are shown to be key determinants of chemoresistance in cells [2;3]. On the other hand, a relatively less studied group of proteins, which also hold key to chemoresistance of a cell are the uptake transport proteins, grouped under the SLC superfamily. They are shown to be involved in the uptake of a number of foreign compounds and influence the initial stages of the absorption, distribution, and metabolism (ADME) of endogens and exogenous compounds.

\subsection{Importance of transporter proteins in metabolism of antineoplastic compounds}

Most of the antineoplastic compounds in the circulation exist as a protein bound fraction and a free fraction. The free fraction largely represents the active compound and the ability of the compound to exert its cytostatic effects would largely depend on the local concentration of its free fraction achieved in the tumor cells. This process underlines the importance of transporter proteins as they form a determining factor of this process, infact, the efficacy of an antineoplastic compound is determined by the uptake 
transporters and efflux transporters as mentioned above [4;5]. Furthermore, abnormalities in the expression of many of the transporter proteins have been associated with discrepancies with the metabolism of an antineoplastic compound and effectiveness of a drug in chemotherapy.

\subsection{Uptake transporter proteins}

The uptake transporter proteins belong to a vast superfamily of proteins referred to as the SLC (solute carrier) superfamily which is further classified into 53 families, containing almost 400 genes [4]. The classification of this superfamily is based on the sequence similarity of the transporter proteins. The physiological role of these proteins is unrelated to their ability to transport exogenous molecules, suggesting that there is no specific family which is exclusively involved in the uptake of foreign substances. This issue is the basis for an increasing number of studies aimed at finding out which transporter is involved in the transport of which foreign compound [6-8]. It is noteworthy to mention here that any interaction with a foreign compound might potentially cause an alteration in the physiological function of that particular transporter protein and homeostasis of the physiologically relevant endogenous substrates.

\subsection{Liver specific uptake transporter proteins}

The uptake transport proteins expressed in the liver play a pivotal role in the body as liver is the organ concerned with modification and excretion of endogenous as well as exogenous substances including drugs and their metabolites. Hepatic excretion of drugs

invariably involves their uptake transporter mediated absorption from the sinusoidal blood into the hepatocytes wherein they are metabolized and converted to a nontoxic or conjugated form which is excreted. The uptake transport proteins expressed in the liver 
include organic cation transporter 1 (OCT1), organic anion transporter 2 (OAT2), OAT7, sodium taurocholate cotransporting polypeptide (NTCP), organic anion transporting polypeptide 1B1 (OATP1B1), OATP1B3, and OATP2B1. The current work deals with the investigation of the ability of four of these proteins, OAT2, NTCP, OATP1B1, and OATP1B3, to interact with some antineoplastic compounds routinely being used in cancer chemotherapy.

\subsubsection{Organic anion transporter 2}

The organic anion transporter 2 (OAT2), encoded by the gene SLC22A7, is involved in the transport of various organic substances of both endogenous and exogenous origin. It has been shown to be expressed predominantly in liver, and to a lesser extent in kidney, lung and various other tissues in humans [9;10]. Its substrates include many endogenous substances like cGMP, estrone-3-sulfate, dehydroepiandrosterone sulfate, prostaglandin E2, purine analogs, glutamate, orotic acid, uric acid, and exogenous substrates including tetracycline, antiviral compounds like acyclovir, ganciclovir, zidovudine, and paclitaxel among others [11-15]. Two splice variants have been reported for this transporter which differed by 6 ntds, the shorter variant was found to be functional demonstrated by its ability to transport cGMP [11]. The functional splice variant was used in this study.

\subsubsection{Sodium taurocholate cotransporting polypeptide}

The sodium taurocholate cotransporting polypeptide (NTCP) encoded by the gene SLC10A1, is exclusively expressed in hepatocytes. NTCP is mainly involved in the sodium dependent uptake of bile acids and thus in the enterohepatic circulation [16]. Other than bile acids, its substrates include thyroid hormones, estrone-3-sulfate and drugs like rosuvastatin, pitavastatin [17-19]. A recent report implicated NTCP as the receptor 
for Hepatitis B and Hepatitis D viruses, undermining its clinical importance, and hence an inhibitor of NTCP is of high clinical relevance [20].

\subsubsection{Organic anion transporting polypeptides $1 \mathrm{~B} 1$ and $1 \mathrm{B3}$}

The organic anion transporting polypeptide $1 \mathrm{~B} 1$ and $1 \mathrm{~B} 3$ are encoded by the genes SLCO1B1 and SLCO1B3 genes, respectively. They are involved in the transport of a variety of substances, most of which are amphipathic high molecular weight compounds, and the list includes endogenous substances like bile salts, both conjugated as well as unconjugated bilirubin, leukotrienes, prostaglandins, thyroid hormones and exogenous compounds like statins and certain drugs [21]. Members of OATP1 family were shown to interact with a variety of compounds, and some of these compounds have been proven to be substrates of these proteins. Both these proteins are specifically expressed in the sinusoidal membranes of liver [22;23] and are involved in the hepatic uptake of bile salts, bile pigments, and also a variety of exogenous substances like rosuvastatin, pitavastatin, and hence, play a crucial role in xenobiotic metabolism and regulation of the cholesterol homeostasis.

\subsection{Interactions of transporter proteins with antineoplastic compounds}

There are various observations citing the involvement of abnormalities in the expression of transporters in the ineffectiveness of substrate uptake [24;25]. This makes it very important to know which transporter proteins are involved in the uptake and efflux of an antineoplastic compound. In literature, there are a lot of studies that focus on the interaction of antineoplastic compounds with transporter proteins. All these studies have a common objective of providing individual therapy which is a prerequisite in the treatment of a disease as complex as cancer. 


\subsection{Antineoplastic compounds used in the study and their mechanisms of action}

In our study we tested several antineoplastic drugs that are routinely used in the treatment of cancer including alkylating agents (melphalan, bendamustine, chlorambucil, cyclophosphamide, trofosfamide, ifosfamide, busulfan, treosulfan, and thio TEPA), antimetabolites (methotrexate, cytosinarabinoside, gemcitabine, 5 fluorouracil, fluoroadenine, cladribine, and fludarabine), intercalating agents (doxorubicin and mitoxantrone), topoisomerase inhibitors (irinotecan and etoposide), mitotic inhibitors (vinblastine, vincristine, and paclitaxel) and those having hormone receptors as targets (tamoxifen, prednisone, and clodronic acid).

Alkylating agents follow the common principle of addition of alkyl groups onto the guanine nucleotides in DNA. This process leads to errors during replication and consequently the DNA repair pathways are set in to repair the damaged or altered base, and failure to do so leads to cell death by apoptosis. There are differences in the mechanism of action of alkylating agents; some compounds like melphalan, bendamustine, chlorambucil, cyclophosphamide, ifosfamide, and trofosfamide lead to the alkylation of only one guanosine residue whereas the compounds busulfan and treosulfan alkylate two guanosine residues causing interstrand or intrastrand crosslinks leading to the DNA being arrested in a locked form inaccessible for replication, forcing the cells to either repair or apoptosis [26-28]. The nucleoside analogs cause cytotoxicity upon incorporation into DNA, leading to the accumulation of DNA breaks and subsequently apoptosis [29;30]. 5-fluorouracil, on the other hand, inhibits the enzyme thymidylate synthase enzyme resulting in low levels of dTMP and this imbalance causes DNA damage [31]. Topoisomerases are enzymes that are crucial for the separation of DNA 
strands during replication and transcription. The antineoplastic compounds, irinotecan and etoposide, inhibit these enzymes causing extensive accumulation of DNA breaks and consequently cell death. Similarly, the intercalating compounds doxorubicin and mitoxantrone also contribute to the inhibition of topoisomerases [32]. The mitotic inhibitors, vinblastine, vincristine, and paclitaxel alter the structural protein tubulin and consequently spindle dynamics, forcing the cells to arrest the cell division, and to undergo apoptosis [33;34]. The mechanisms of the antineoplastic compounds are diverse as described in this section, but this diversity is made use of in the formulation of treatment regimens involving a combination of the compounds to achieve an effective means to treat various types of cancer as listed below. Furthermore, the success of a treatment regimen depends on the functional expression of the corresponding uptake transport proteins.

\subsection{Therapeutic uses of antineoplastic compounds used in the study}

Many of these compounds are being used either alone or in combination as front line drugs in chemotherapy of various cancers. A summary of the studies that explore the therapeutic potential of these compounds in clinical trials of specific malignancies and relevant literature is provided in Table 1.1. 


\begin{tabular}{|c|c|c|}
\hline Compound & Type of cancer & References \\
\hline \multicolumn{3}{|l|}{ Alkylating agents } \\
\hline Melphalan & multiple myeloma, retinoblastoma & {$[35 ; 36]$} \\
\hline Bendamustine & $\begin{array}{l}\text { chronic lymphocytic leukemia, } \\
\text { Non-Hodgkin Lymphoma }\end{array}$ & {$[37]$} \\
\hline Chlorambucil & chronic lymphocytic leukemia & {$[38 ; 39]$} \\
\hline Cyclophosphamide & breast cancer, B-cell lymphoma & {$[40-43]$} \\
\hline Trofosfamide & non-small cell lung cancer & [44] \\
\hline Ifosfamide & non-small cell lung cancer, anal cancer & {$[45 ; 46]$} \\
\hline Busulfan & leukemia & [47] \\
\hline Treosulfan & Malignant melanoma, uveal melanoma & {$[48 ; 49]$} \\
\hline thioTEPA & Acute leukemia & {$[50]$} \\
\hline \multicolumn{3}{|l|}{ Antimetabolites } \\
\hline Methotrexate & $\begin{array}{l}\text { Bladder cancer, } \mathrm{T} \text { cell lymphoma, B-cell } \\
\text { lymphoma }\end{array}$ & {$[43 ; 51 ; 52]$} \\
\hline Cytosine arabinoside & $\begin{array}{l}\text { Acute myeloid leukemia, } \\
\text { lymphoma, follicular lymphoma }\end{array}$ & {$[43 ; 53-55]$} \\
\hline Gemcitabine & Pancreatic cancer, renal cell carcinoma & {$[45 ; 48 ; 49 ; 56 ; 57]$} \\
\hline 5-Fluorouracil & Pancreatic cancer, colorectal cancer & [58;59] \\
\hline \multicolumn{3}{|l|}{ Fluoroadenine } \\
\hline Fludarabine & Chronic lymphocytic leukemia & {$[60]$} \\
\hline Cladribine & Hairy cell leukemia & {$[61 ; 62]$} \\
\hline \multicolumn{3}{|l|}{ Intercalating agents } \\
\hline Doxorubicin & $\begin{array}{l}\text { breast cancer, bladder cancer, renal cell } \\
\text { carcinoma }\end{array}$ & {$[41 ; 51 ; 57]$} \\
\hline Mitoxantrone & Acute myeloid leukemia & [54] \\
\hline \multicolumn{3}{|l|}{ Mitotic inhibitors } \\
\hline Vinblastine & Bladder cancer & {$[51]$} \\
\hline Vincristine & Large B-cell lymphoma & [43] \\
\hline Paclitaxel & Pancreatic cancer & [63] \\
\hline \multicolumn{3}{|c|}{ Topoisomerase inhibitors } \\
\hline Irinotecan & Pancreatic cancer, colorectal cancer & {$[58 ; 59]$} \\
\hline Etoposide & T cell lymphoma, & {$[52]$} \\
\hline \multicolumn{3}{|c|}{ Hormone receptor targeters } \\
\hline Prednisone & Follicular lymphoma & {$[55]$} \\
\hline Clodronic acid & Malignant bone metastases & {$[64]$} \\
\hline Tamoxifen & breast cancer & [41] \\
\hline
\end{tabular}

Table 1.1 Antineoplastic compounds and their therapeutic uses. 


\subsection{Factors effecting impact of transporter proteins on chemotherapy}

There are two main factors which cause considerable variability in the effect of transport proteins on chemotherapy. One of the factors is the widely studied phenomenon of drugdrug interactions. It originates in combinatorial chemotherapies wherein the interaction of the first drug with its transporter causes changes in the effectiveness of a second drug, either decreasing or increasing the bioavailability of the second drug and is associated with ineffective drug therapy or drug mediated cytotoxicity, respectively. There have been a lot of incidences of drug-drug interactions mediated by the OATP and OCT transporters [65]. Since drug-drug interactions can lead to drastic effects during chemotherapy, many models have been put forward which would predict the possibility of drug-drug interactions. Some of the models take into account the interactions of the transporter proteins with the compounds in vitro, specifically, the affinity of a transporter protein for the compounds in question [66-69]. The other factor is the alteration in the transport of the antineoplastic compound by the transporter protein. This may arise due to abnormalities in the localization of the protein on the membrane or an aberration in the expression of the transporter protein leading to a loss of its function or specificity for the compound. There are a myriad of mechanisms that influence the expression of a gene operating at various levels such as genetic, epigenetic, transcriptional, post-transcriptional and post-translational levels.

\subsubsection{Regulation of expression of genes at genetic and epigenetic levels}

Since transporter genes are physiologically important and are at the forefront of cancer chemotherapy, a small change in the nucleotide sequence might cause a magnified effect. Such changes were characterized for many genes as single nucleotide polymorphisms (SNPs) which might lead to the incorporation of a different amino acid into the protein. A 
lot of such changes have been mentioned for many transport genes, which were associated with altered substrate recognition or transport $[25 ; 70 ; 71]$. Normally, DNA is closely bound together and wrapped around histone proteins to form structures called nucleosomes. For the expression of genes, the DNA needs to be made accessible to the synthesizing machinery; a process achieved by chemical modifications on histones. The most common modifications of histones are methylation and acetylation brought about by the histone methyl transferases and histone acetyl transferases. Methylation of histones can be of varied extents such as mono, di or tri-methylation, can occur on the same lysine residue and each one of these methylated states can have a different function. However, acetylation invariably leads to only one conclusion, the conversion of a dense heterochromatin to a loosely bound euchromatin. This happens by virtue of the negatively charged acetyl groups disturbing the interactions between positively charged (lysine and arginine) histone proteins and the negative phosphodiester DNA backbone, thus providing access to the synthesizing machinery. The reversal of these processes is performed by the enzymes histone demethylase and histone deacetylase. Histone deacetylases remove the acetyl residues on the lysine residues of histones making them wound back to DNA converting it into densely packed complex as represented in fig. 1.1 [72-74]. In addition to the contribution of these modifications to differential expression of genes, investigations revealed that they might be associated with the development of cancer by altering the expression of tumor suppressor genes. In addition to these modifications on histone proteins, modifications also occur on DNA as methylation. The process of methylation occurs on $\mathrm{CpG}$ sites and is brought about by the enzyme DNA methyltransferase. These mechanisms are topics of intense research as many studies highlighted the role of them in carcinogenesis. 


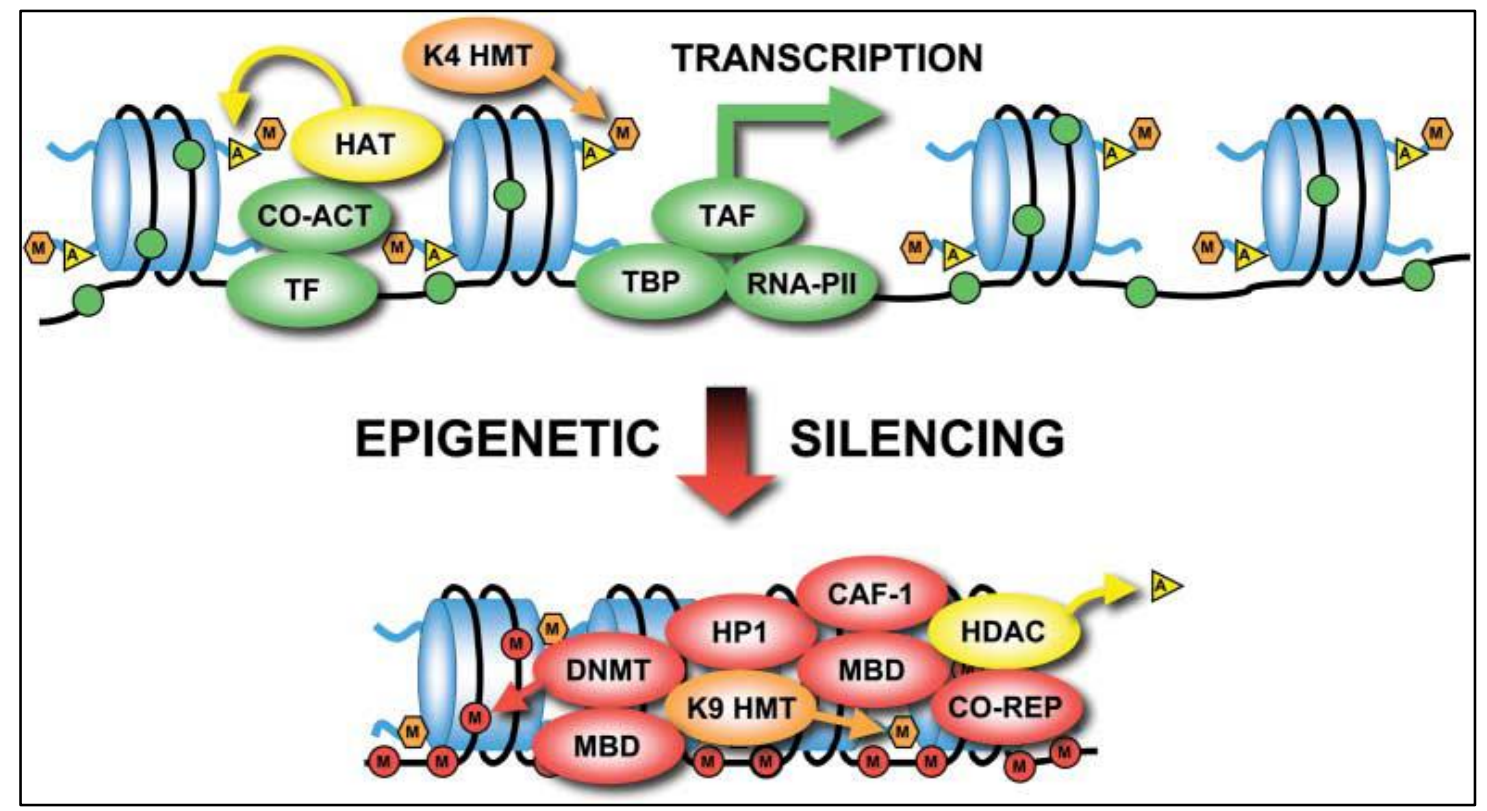

\section{Figure 1.1 Epigenetic regulation of a gene}

Proteins involved in the transcriptional activation and repression of a gene. Transcription factors (TF), co-activators (CO-ACT), histone acetyltransferase (HAT), lysine 4 histone methyltransferase (K4 HMT), TATA binding protein (TBP), TBP-associated factor (TAF) and RNA polymerase II (RNA-PII) are associated with transcriptional activation. DNA methyltransferase (DNMT), methyl-binding domain protein (MBD), heterochromatin protein 1 (HP1), histone 3 lysine 9 (K9 HMT), chromatin assembly factor-1 (CAF-1), histone deacetylases (HDAC), and co-repressor (CO-REP) are associated with transcriptional repression [74].

Molecules that could inhibit the above mentioned processes were used to study the mechanistic details of the epigenetic modifications and to cause changes leading to arrest the growth of cancer cells. Valproic acid is a compound that inhibits histone deacetylase enzyme, and has been extensively studied for its antineoplastic properties [75-78]. 


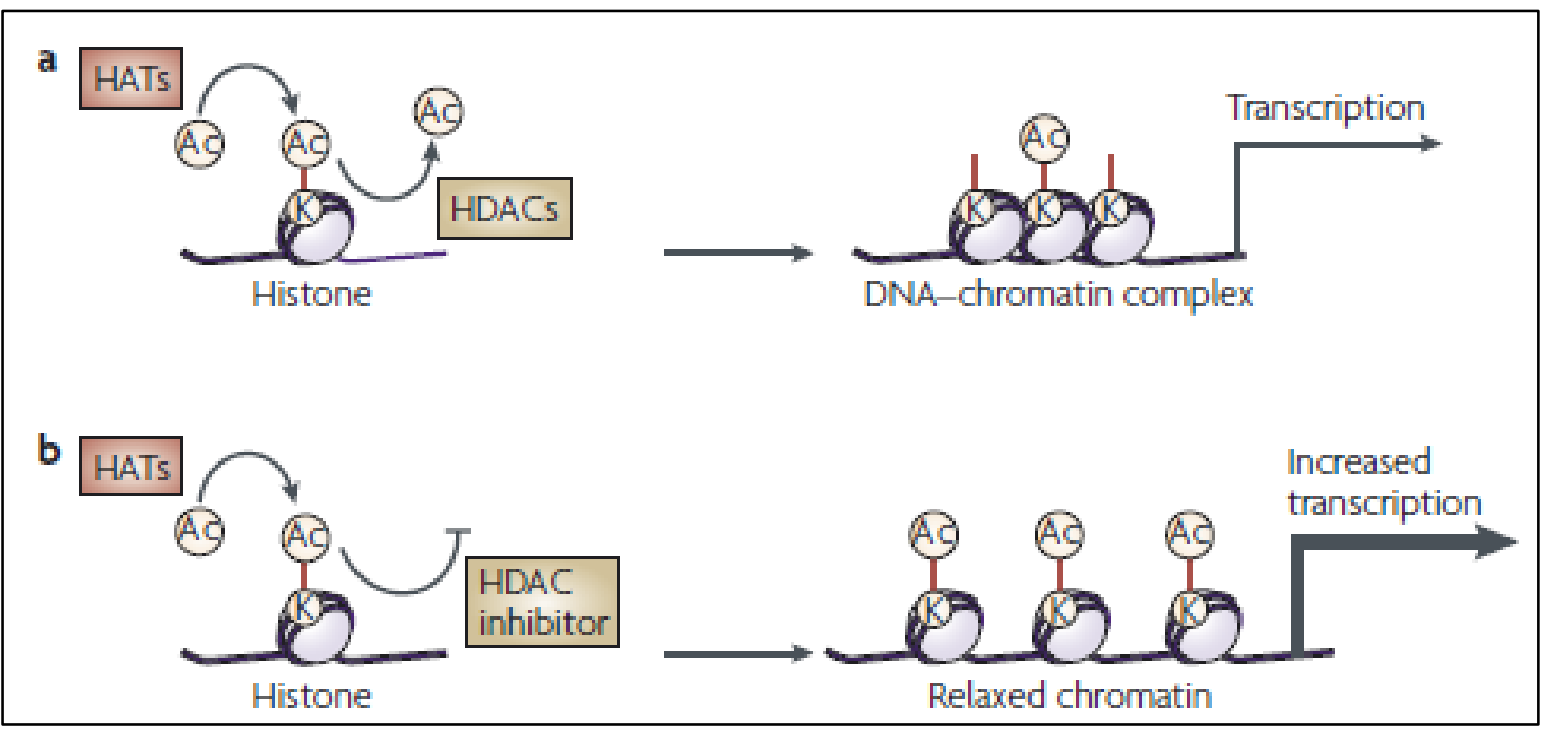

\section{Figure 1.2 Impact of acetylation of histones on transcription}

Equilibrium between acetylation and deacetylation effects the transcription of a gene. The acetylation of lysine (K) residues by histone acetyltransferase (HAT) and the selective removal of these acetyl groups by histone deacetylase (HDAC) results in an appropriate level of acetylation of histones which leads to the formation of a proper DNA-chromatin complex associated with transcription of selected genes (a). Inhibition of the deacetylation process leads to increased transcription (b) [79].

Similarly, a nucleoside analogue of cytidine, 5-azacytidine, has been found to be functionally active against DNA methylation process by inhibiting the enzyme DNA methyltransferase [80;81]. Azacytidine is converted to the compound 5-aza-2'-deoxycytidine (decitabine) which is the active compound responsible for this activity. 


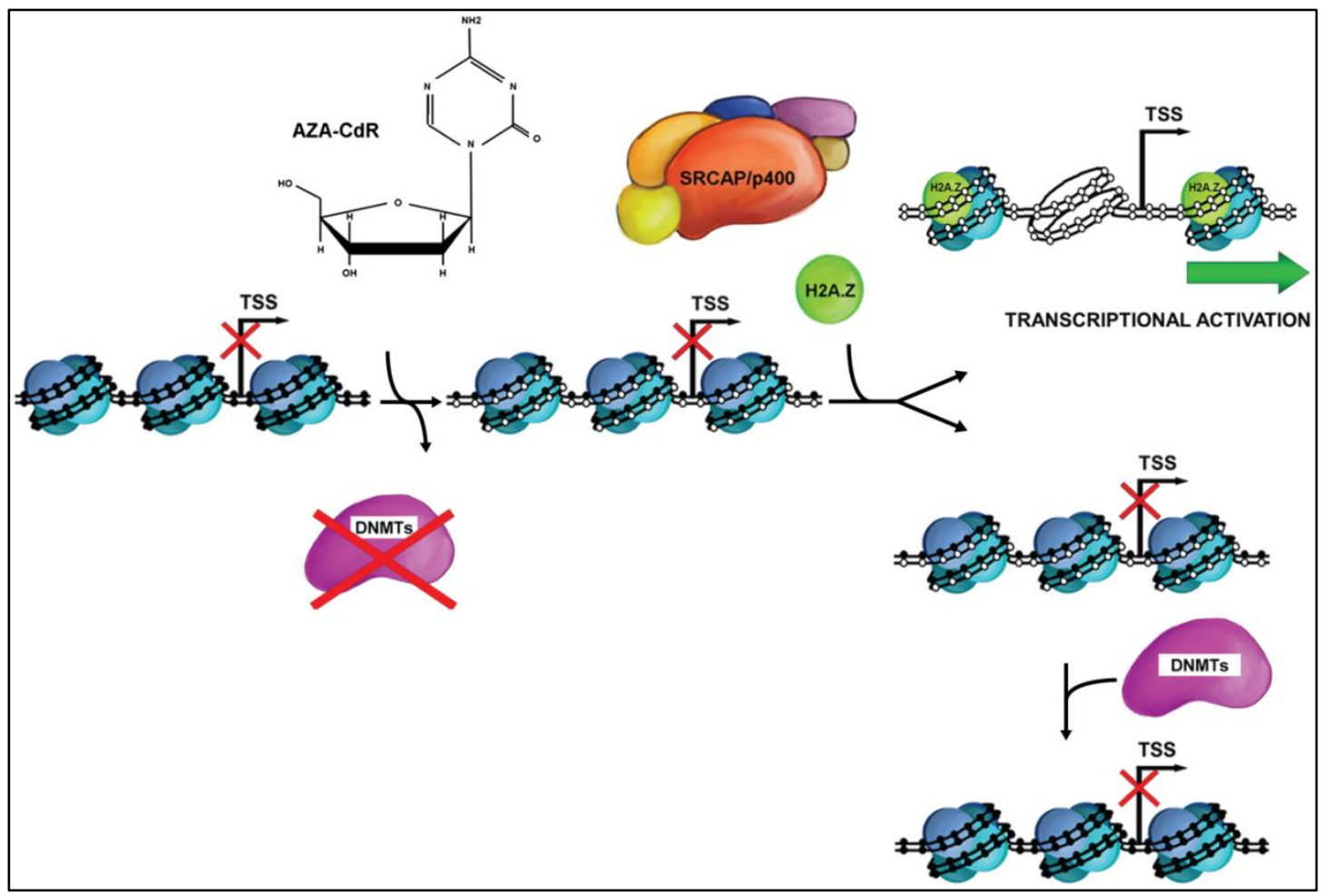

Figure 1.3 Inhibition of DNA methylation by 5-aza-2'-deoxy-cytidine (AZA-CdR)

Demethylation of a gene caused by inhibition of DNA methyltransferases (DNMTs) by 5-aza-2'deoxy-cytidine (AZA-CdR) leads to the recruitment of proteins involved in gene reactivation such as the histone variant H2A.Z. H2A.Z recruitment at promoter regions is performed by the Snf2related CBP activator protein (SRCAP) complex [82].

Apart from the methylation patterns on the whole DNA, methylation occurring specifically at the promoter region has been shown to effect the expression of a gene. Hypermethylation of promoter regions has been associated with lower expression of the gene [83-85]. Infact, the methylation patterns were found to be altered in cancer, wherein hypomethylation was observed in sequences of most of the genome while the genes involved in regulating processes crucial for normal growth patterns like cell cycle were effectively silenced by hypermethylation [86].

Such mechanisms have been reported to influence the uptake of therapeutically important molecules. Promoter methylation was reported to influence the expression of the uptake 
transporter organic cation/carnitine transporter 2 (OCTN2) [87]. Similarly, DNA methylation repressed the promoter activity of organic anion transporter 3 (OAT3) [88].

\subsubsection{Transcriptional regulation of gene expression}

Epigenetic level of regulation of gene expression is followed by the transcriptional level, many times as a consequence of changes at the epigenetic level. As described above, conversion of a closed chromatin to an open one in most cases is followed by binding of proteins of the transcription machinery. Transcription factors are small proteins that bind to specific regions in the DNA around the start site of transcription. They are classified based on the sequences they recognize and bind to, and on the basis of their protein structure. They bind to sequences such as promoters, activators or silencers and this binding induces or hinders the formation of an active transcription complex [89-91]. Deviations in this tightly controlled mechanism have been implicated in various diseases including cancer [92]. The involvement of a lot of factors in contributing to the expression of a gene upon diverse stimuli made them one of the strategies for cancer treatment [93]. The involvement of transcription factors in the regulation of uptake transporters is a topic of intense research. Organic cation transporter 1, organic anion transporters 1 and 2 were shown to be activated by hepatocyte nuclear factor- $4 \alpha$ (HNF4a) [94-96]. Similarly the organic anion transporters 5 and 7 were activated by HNF-1 $\alpha$ [97]. The transcription factor BCL6 was found to activate the expression OAT2 [98].

\subsubsection{MicroRNA based regulation of gene expression}

At the post-transcriptional level, the level and translation of the messenger RNA are greatly influenced by a group of non-coding RNAs referred to as microRNAs. MicroRNAs are transcribed either from their own discrete genes or generated during the 
splicing of the messenger RNAs [99]. There are multiple pathways of microRNA biogenesis including the canonical and noncanonical pathways. The microRNAs are transcribed as pri-microRNAs in the canonical pathway which undergo processing by Drosha and other proteins to become pre-microRNAs containing a stem-loop structure and are exported to the cytoplasm. These immature microRNAs are bound by Dicer and other proteins, culminating in the formation of a mature RNA induced silencing complex (RISC) [100;101].

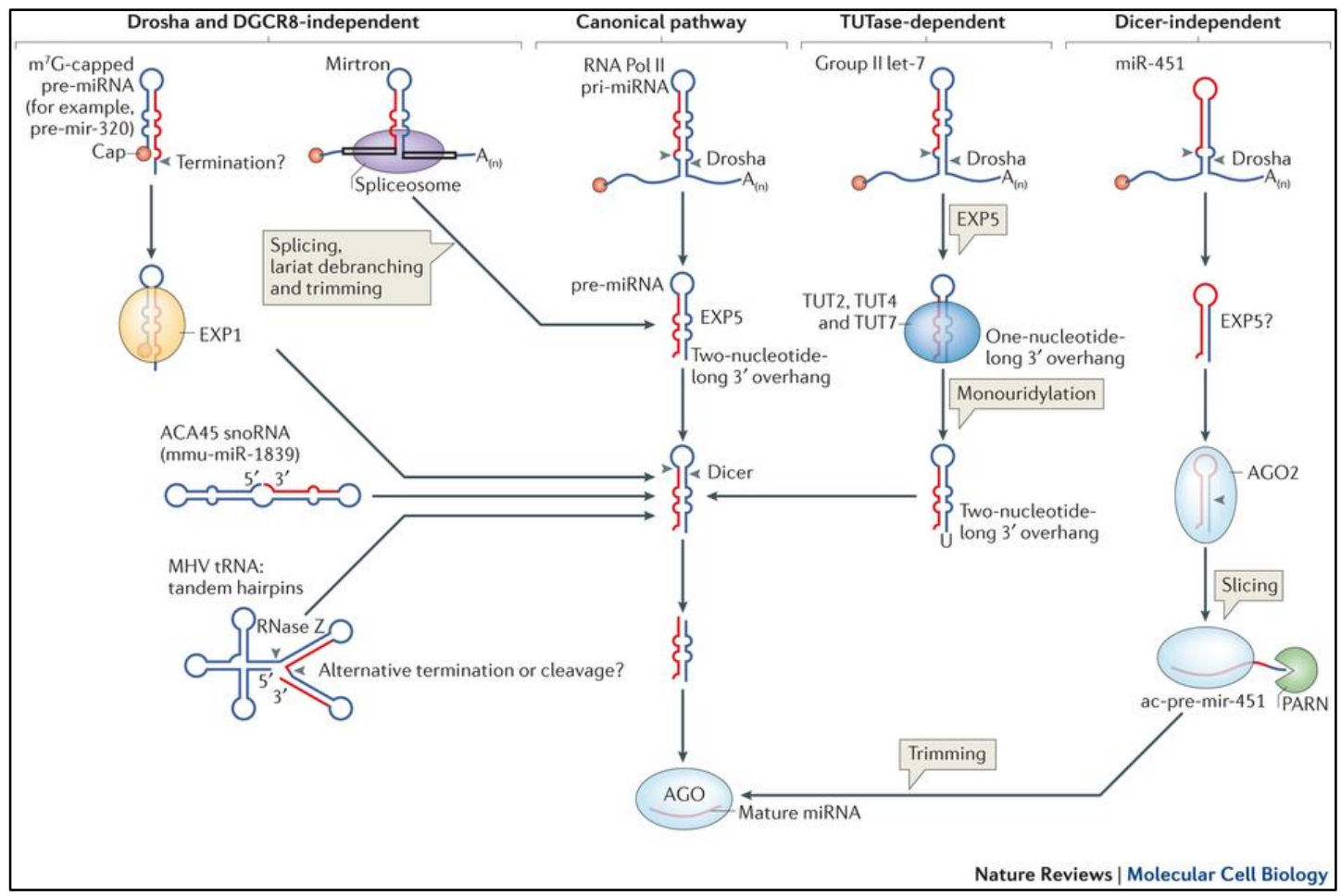

\section{Figure 1.4 Multiple pathways of microRNA biogenesis}

MicroRNAs are transcribed in the canonical pathway as primary microRNAs (pri-miRNA) with a cap, stem-loop and poly(A) tail. They are converted into pre-miRNA by the microprocessor complex (Drosha, DGCR8) in the nucleus and exported into the cytoplasm wherein the enzyme, Dicer, processes it further into miRNA duplex, one strand of this duplex is loaded onto RNA induced silencing complex (RISC). Some microRNAs are generated directly from transcription, while some are generated by splicing from mirtrons (generated from introns of mRNA of other 
genes), and exported without the involvement of processing proteins in a Drosha and DGCR8independent pathway. Some microRNAs are synthesized short and require additional action of a terminal uridylyl transferase (TUTase), a step required for efficient DICER action in TUTase dependent pathway. In yet another pathway independent of Dicer, mir-451 is generated as a stemloop structure by Drosha and processed by Ago2 and poly(A)-specific ribonuclease (PARN) enzyme to a mature microRNA [101].

The mature microRNAs in the RISC are shown to bind to the $5^{\prime}$ or $3^{\prime}$ untranslated regions or even in the coding regions of messenger RNAs with complete or incomplete complementarity and this binding either triggers the degradation of mRNA or causes translational repression [99;102-104]. Degradation of mRNA was found to take place in specialized structures called P- bodies or cytoplasmic bodies [105;106]. Alternately, microRNA has also been shown to upregulate translation of mRNA [107-109]. It is worthwhile to mention here that the effect caused by microRNA in most of the cases is rather fine tuning the timing and expression level of the mRNA [110]. It has been seen that microRNA can have more than one target messenger RNAs [111] and likewise an mRNA can be regulated by more than one microRNA [112]. The binding of microRNA to messenger RNA in most cases was reported to be with incomplete complementarity. This makes it difficult to pinpoint which microRNA would bind to which messenger RNA and this quest led to the development of prediction algorithms. Many prediction programs were developed after studying the observed interactions between microRNA seed sequence and evolutionary conserved target sequence on mRNAs and algorithms were developed. Some of the prediction programs routinely used include TargetScan [113], DIANA-microT [114], miRanda [115], and PicTar [116]. A comparison of such algorithms revealed the accuracy of the prediction algorithms and that some programs have high correlation between the predicted targets with those experimentally found [117- 
120]. Simultaneously, a number of experimental procedures were also developed and employed to judge the accuracy of the predictions made using in silico programs [121].

MicroRNA based regulation of expression is an emerging field of research and studies focused on the impact of such a regulation on the uptake transporters and hence cancer chemotherapy is being currently looked into as well. The microRNA mir-195-5p was shown to suppress the expression of the glucose transporter GLUT3 [122]. Similarly microRNA miR-133 was shown to regulate the expression of GLUT4 [123].

\subsubsection{Post-translational mode of gene regulation}

Once a protein is synthesized from messenger RNA, it often undergoes a series of changes including formation of a functional 3 dimensional structure with the aid of chaperones. Post-translational modifications confer operational regulation on a protein by phosphorylation, acetylation, glycosylation etc. Protein phosphorylation and dephosphorylation are the most common mechanisms employed by the cellular machinery during signal transduction. Phosphorylation, glycosylation, ubiquitination and other post-translational modifications have been shown to affect the function of many transporter proteins like OCT2, NTCP etc. [124-129]. The other area of intense research, involving post translational modifications and protein-protein interactions, is the maintenance of the transporters on the plasma membrane in structures known as lipid rafts. Transporter membranes were often found to be localized to specialized areas on plasma membrane, regions rich in sphingolipids and cholesterol called lipid rafts and changes in constituents of lipid rafts altered their transport activity in vitro [130;131]. Protein-protein interactions with adaptor proteins like PDZK2 have been implicated in modulation of transporter activity [132;133]. 


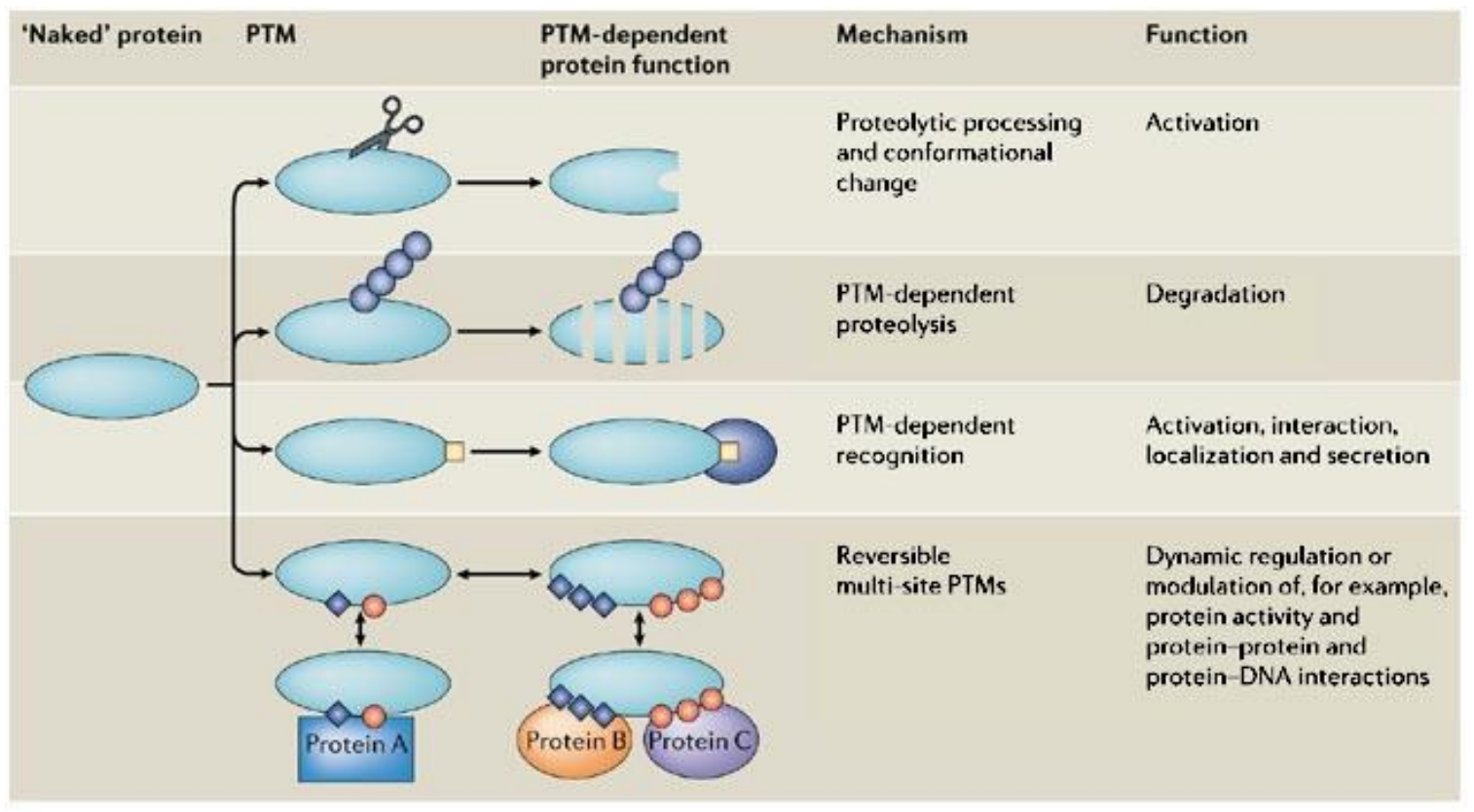

Copyright $@ 2006$ Nature Publishing Group Nature Reviews | Molecular Cell Biology

\section{Figure 1.5 Post-translational modifications (PTM) of proteins}

Post-translational modifications of proteins lead to a variety of consequences such as activation, degradation, interaction with specific partners, either protein or DNA, secretion etc. [134].

\subsection{Regulation of organic cation transporter 3}

Organic cation transporter 3, encoded by the gene SLC22A3, is involved in the transport of positively charged molecules in a sodium independent manner. Considerable work has been done assessing the ability of OCT3 to transport physiologically and therapeutically important compounds. It is found to be expressed predominantly in kidney, liver, placenta, heart and skeletal tissues and to a lesser extent in brain and lung in humans [135-138]. It is involved in the uptake of physiological substances like histamine, serotonin, and exogenous substances like MPP, TEA, and ASP [139]. It was found to contribute to the regulation of salt-intake [140], uptake of the antineoplastic compounds melphalan, irinotecan, and vincristine [141], oxaliplatin [142], antipsychotic drug amisulpride [143], and also shown to interact with many antidepressants [144]. There 
were changes in the expression of OCT3 in various carcinomas $[141 ; 145]$ and this factor, in addition to the important physiological role it plays, made the quest of mechanism of regulation of OCT3 expression, a matter of considerable interest. The changes in expression of OCT3 were observed to affect the transporter mediated accumulation of antineoplastic drugs in renal cell carcinoma [141].

The contribution of single nucleotide polymorphisms [146], methylation patterns [147] and the effects of kinases and other proteins on the expression and function of OCT3 were studied in detail [148-150]. However, the regulation of OCT3 by microRNAs and the impact of such a regulation on the function of OCT3 have not been looked into yet.

\subsection{Objectives of the thesis}

The objectives of this work are

1) To analyze the interactions of antineoplastic compounds with the SLC transporter proteins specifically expressed in hepatocytes namely, organic anion transporter 2 (OAT2), sodium taurocholate cotransporting polypeptide (NTCP), and organic anion transporting polypeptides 1B1 and 1B3 (OATP1B1 and OATP1B3).

2) To find out the possible factors responsible for the variable expression of organic cation transporter 3 in the renal carcinoma cells A498; ACHN, 786-O, and LN78. 


\section{Materials}

\section{Reagents for cell culture}

Poly D-lysine

FBS

Trypsin

Phosphate buffered saline

Antibiotics

Penicillin

Streptomycin

Hygromycin B

\section{Media}

Quantum 286 medium

Quantum 263 medium

DMEM HG medium

RPMI-1640 medium

\section{Transport buffer (Hank's Buffer)}

Hank's Balanced Salt Solution (HBSS)

HEPES buffer
Sigma-Aldrich

Gibco

Biochrom

Biochrom

PAA

PAA

PAA

PAA

PAA

Sigma-Aldrich

Sigma-Aldrich

PAA; Biochrom

Biochrom 


\section{$\left[{ }^{3} \mathrm{H}\right]$ labeled compounds}

$\left[{ }^{3} \mathrm{H}\right] 3^{\prime}$ - 5' cyclic guanosine monophosphate Perkin Elmer

$\left[{ }^{3} \mathrm{H}\right]$ estrone 3-sulfate

Perkin Elmer

$\left[{ }^{3} \mathrm{H}\right]$ cholecystokinin octapeptide

Perkin Elmer

Rotiszint eco plus scintillation solution

Carl Roth

\section{Compounds for HPLC analysis}

Irinotecan hydrochloride

Sigma-Aldrich

Camptothecin

TCI

Methanol

Sigma-Aldrich

Tetra butyl ammonium hydrogen sulfate

Sigma-Aldrich

Ammonium acetate

Merck

Kits

RNA isolation kit

Qiagen

SuperScript reverse transcriptase

Life technologies

$10 \mathrm{mM}$ dNTPs

Life technologies

$10 \mathrm{mM}$ oligo dT

Eurofins

Complete buffer

Applichem

TaqMan Universal master mix

Life technologies

TaqMan primers

Life technologies 
mirVana microRNA isolation kit

microRNA reverse transcription kit

TaqMan Universal master mix no UNG

microRNA mimics and antimirs

DNA ladder
Qiagen

Life technologies

Life technologies

Qiagen

Rapidozyme

\section{Primers}

\begin{tabular}{|l|l|l|}
\hline Primer & Primer ID & Sequence \\
\hline 1 & OCT_frag1_f & AAGGTTTTGGAGAAAAGTGAGT \\
\hline 2 & OCT_frag1_r & ACCAAACCTAATACAAACCTCC \\
\hline 3 & OCT_frag1_r_2 & AAAACCAAACCTAATACAAACCTC \\
\hline 4 & OCT_frag2_f & GTAAGGGTTAAGGGTTGGAG \\
\hline 5 & OCT_frag2_r & TCCCTACCAACAACCTACTCTA \\
\hline 6 & OCT_frag2_r_2 & ACCTACTCTACAATCAACCCCA \\
\hline
\end{tabular}

Table 2.1 Primers used for amplifying promoter fragments 1 and 2

\section{Software used}

SigmaPlot 11

Microsoft Excel

MarvinSketch (version 14.7.28.0) from ChemAxon

Reference Manager 


\begin{tabular}{|c|c|c|c|c|c|c|c|c|}
\hline 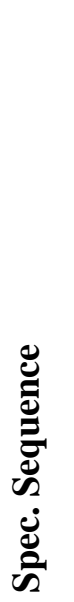 & 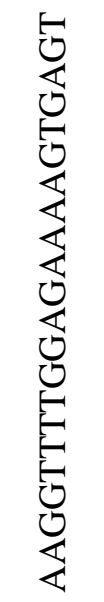 & 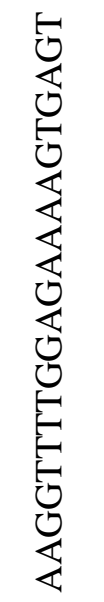 & 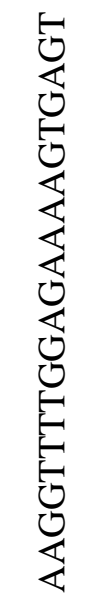 & 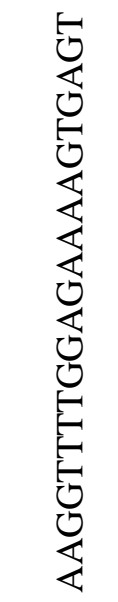 & 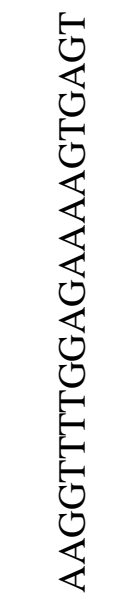 & 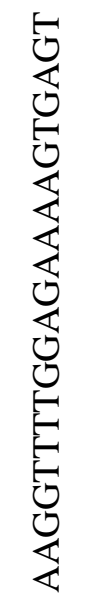 & 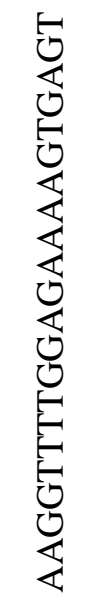 & 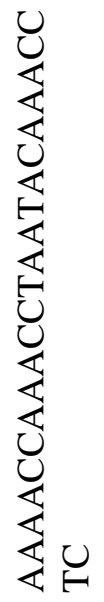 \\
\hline$\frac{\grave{0}}{\frac{a}{a}}$ & 帠 & 导 & 芯 & 芯 & 导 & 芯 & 惢 & \\
\hline 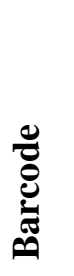 & 岕 & 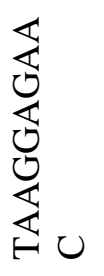 & 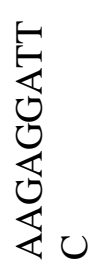 & 悹 & U & 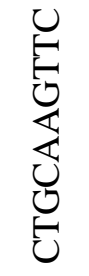 & 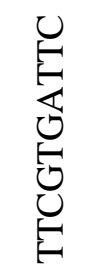 & \\
\hline 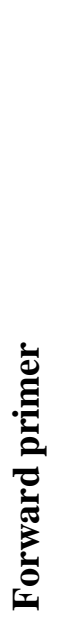 & 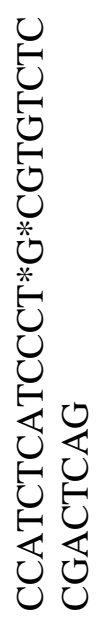 & 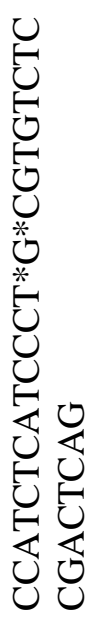 & 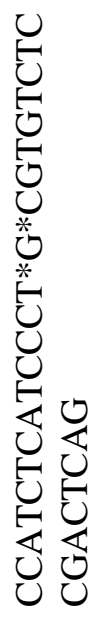 & 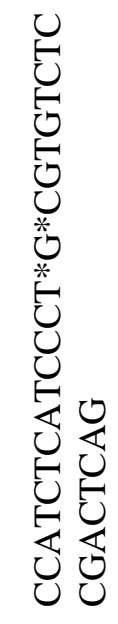 & 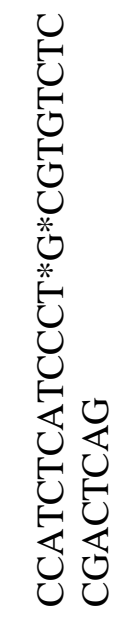 & 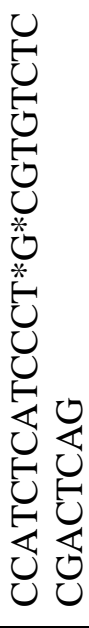 & 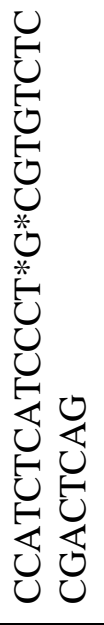 & 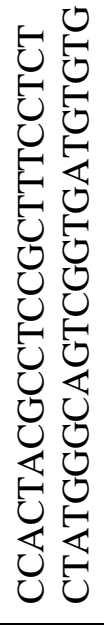 \\
\hline 当 & 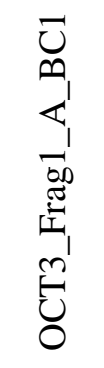 & 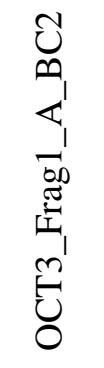 & 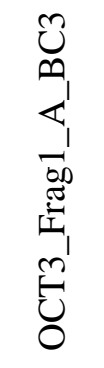 & 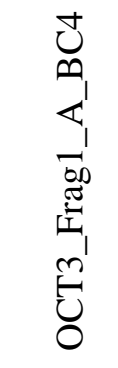 & 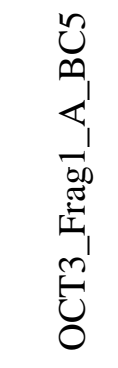 & 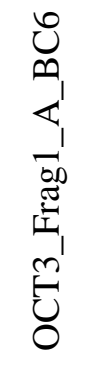 & 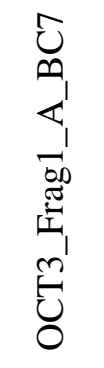 & 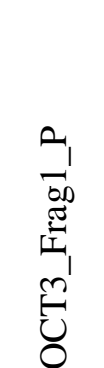 \\
\hline
\end{tabular}

Table 2.2 Primers for barcoded amplification of fragment 1 


\begin{tabular}{|c|c|c|c|c|c|c|c|c|}
\hline 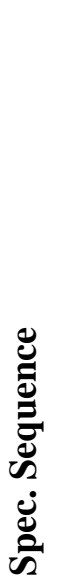 & 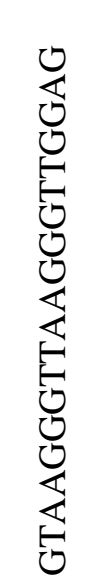 & 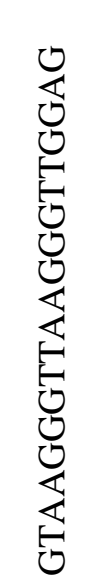 & 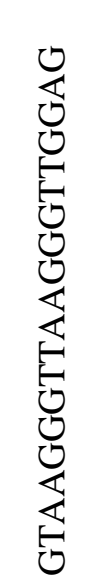 & 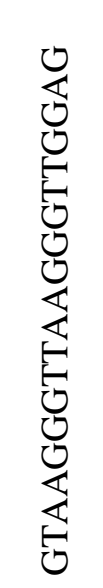 & 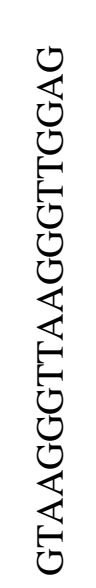 & 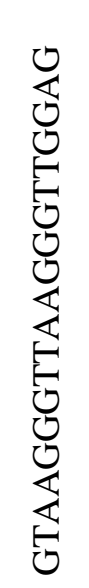 & 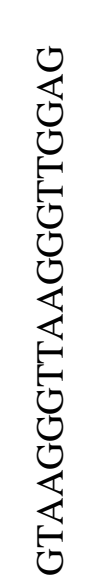 & 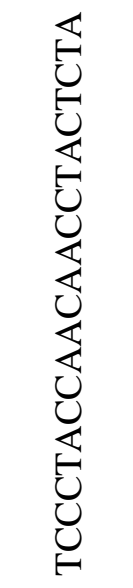 \\
\hline 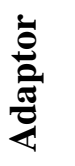 & 导 & 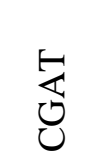 & 芯 & 芯 & 芯 & 芯 & 式 & \\
\hline 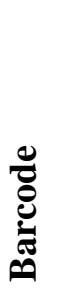 & 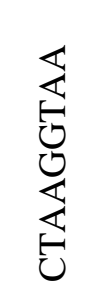 & 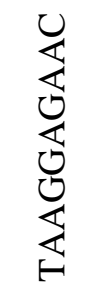 & 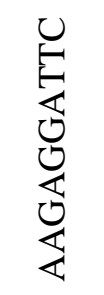 & 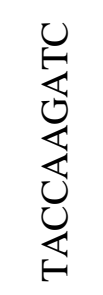 & 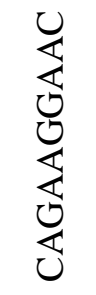 & 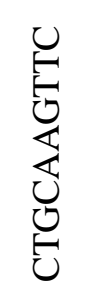 & 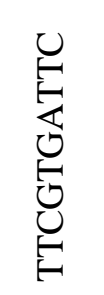 & \\
\hline 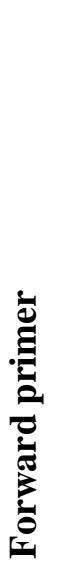 & 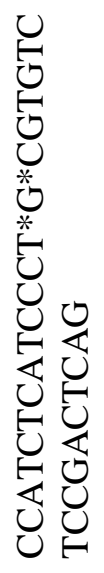 & 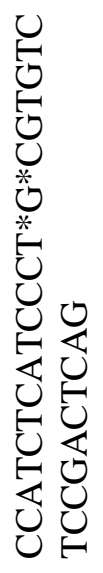 & 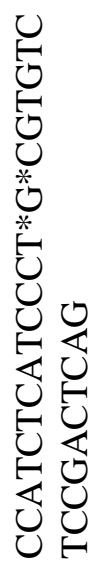 & 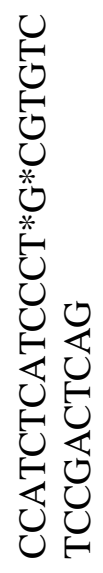 & 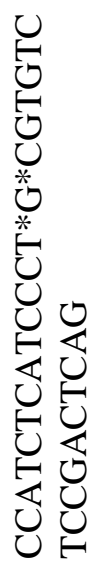 & 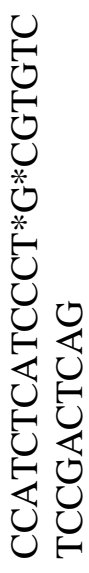 & 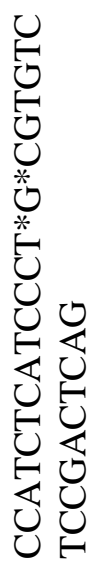 & 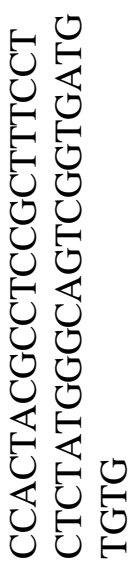 \\
\hline 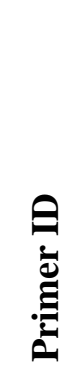 & 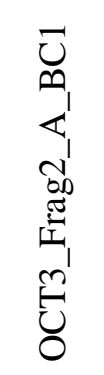 & 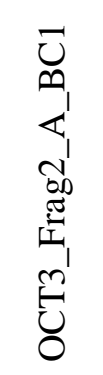 & 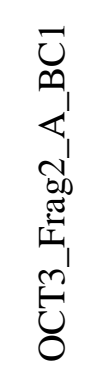 & 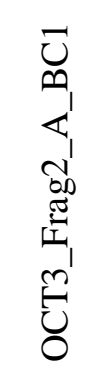 & 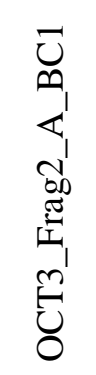 & 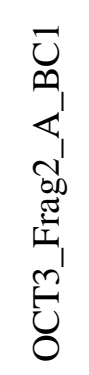 & 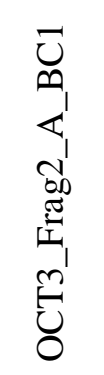 & 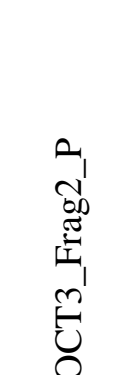 \\
\hline
\end{tabular}

Table 2.3 Primers for barcoded amplification of fragment 2 


\section{Equipment}

Liquid scintillation counter

HPLC system

Nanophotometer

Spectrophotometer

Gel electrophoresis unit

Gel documentation system

$\mathrm{pH}$ meter

Circulating water bath incubator

Microplate reader

qRTPCR system

Thermocycler

Ultrasonicator (degasser)

Sonicator

Centrifuges
TriCarb 2910TR (Perkin Elmer)

Agilent technologies 1100

GeneQuant II, Pharmacia Biotech

Biometra

Biorad Fluor-S multiplier system

inoLab

Haake

Berthold Technologies Mithras LB 940

Stratagene

Peltier thermocycler PTC200,

Bio-Rad C1000

L\&R Ultrasonics

Labsonic 2000

Biofuge (Heraeus) 


\section{Methods}

\subsection{Cell culture}

Human embryonic cells stably transfected with organic anion transporter 2 (OAT2), sodium taurocholate cotransporting polypeptide (NTCP), organic anion transporting polypeptides 1B1 or 1B3 were cultured in DMEM high glucose medium. Renal carcinoma cells (RCCs) were grown in Q263 medium.

All the cells were cultivated in an incubator maintained at $37^{\circ} \mathrm{C}$ with $5 \% \mathrm{CO}_{2}$. At confluency, cells were washed with $3 \mathrm{~mL}$ of PBS and then incubated with $3 \mathrm{~mL}$ of trypsin-EDTA solution at $37^{\circ} \mathrm{C}$ for $5 \mathrm{~min}$ (RCCs) or for $2 \mathrm{~min}$ at room temperature for HEK based cells. The cells were pipetted into a $15 \mathrm{~mL}$ falcon containing $3 \mathrm{~mL}$ of medium and centrifuged at $1000 \mathrm{RPM}$ for $5 \mathrm{~min}$ at room temperature. The supernatant was discarded and the cells were supplemented with $1 \mathrm{~mL}$ of fresh medium. Depending upon the need they were either split for the next passage of culture or used for RNA isolation. For storage, cells were resuspended with ice cold medium containing 10\% DMSO and transferred onto ice for $30 \mathrm{~min}$ and later stored in $-80^{\circ} \mathrm{C}$ and liquid nitrogen.

\subsection{Substrate uptake experiments}

HEK293 cells carrying the vector alone (pcDNA) or the corresponding transporter gene were seeded at a density of $2 \times 10^{5}$ cells per well in poly-D-lysine coated 24 well plates and grown for $72 \mathrm{~h}$ in Quantum 286 medium containing penicillin and streptomycin. All substrate uptake assays were performed at $37^{\circ} \mathrm{C}$ in Hank's buffer solution containing Hank's balanced salt solution and 20 mM HEPES, pH 7.4 adjusted with $1 \mathrm{~N} \mathrm{NaOH}$. Prior to the experiment, the cells were washed twice with PBS and then incubated in Hank's buffer until the start of experiment. The substrate solutions were prepared in Hank's 
buffer, and along with the cells, were prewarmed for 5 min at $37^{\circ} \mathrm{C} .5 \mu \mathrm{L}$ of the substrate solution was taken as a standard to calculate the specific activity of the substrate.

After the desired time point, the uptake was terminated by washing thrice with ice cold PBS and the cells were lysed by incubation with $1 \mathrm{~N} \mathrm{NaOH}$ for $1 \mathrm{~h}$ at room temperature. The lysates were transferred to scintillation vials and $2.5 \mathrm{ml}$ of Rotiszint eco plus scintillation solution was added. The counts were obtained from a liquid scintillation counter TriCarb 2910TR. Data was analyzed using Microsoft Excel and SigmaPlot 11.

\subsubsection{Time dependent uptake of $\left[{ }^{3} \mathrm{H}\right]$ labeled substrates}

The uptake of $\left[{ }^{3} \mathrm{H}\right]$ labeled substrate was followed over a period of time in Hank's buffer containing a mixture of labeled and unlabeled substrate amounting to a desired concentration.

\subsubsection{Concentration dependent uptake of radiolabeled substrates and determination of affinity constants}

The uptake of radiolabeled substrate was measured at increasing concentrations of unlabeled substrate, and the affinity of the transporter protein for its respective substrate was calculated from the uptake values obtained. From three such experiments, the Michaelis-Menten constant, $K_{m}$ was calculated.

\subsubsection{Inhibition of transporter activity by antineoplastic agents}

The ability of an antineoplastic compound to inhibit the uptake of the corresponding substrate of the transporter protein was used as an index to find out potential interactions between the compound and the transporter protein. The inhibition studies were performed with $100 \mu \mathrm{M}$ of the antineoplastic compounds wherein the uptake was measured with a 
substrate concentration of $1 / 10^{\text {th }}$ of the $K_{m}$ value of the transporter protein for the corresponding substrate.

\subsubsection{Concentration dependent inhibition of uptake of substrates in the presence of antineoplastic compounds}

The affinity of the transporter protein for the antineoplastic compound was calculated from Dixon plot analysis. The uptake of the radiolabeled substrate was measured in buffer solutions containing two different concentrations of substrate both having identical concentrations of labeled substrate and an increasing amount of the antineoplastic compound.

\subsubsection{Concentration dependent inhibition of OAT2 activity by the compounds bendamustine, irinotecan and paclitaxel}

To determine the affinity of the transporter proteins for those antineoplastic compounds which inhibited the uptake of the corresponding substrate to less than $40 \%$ of buffer control, the Dixon plot analysis was performed. For Dixon plot analysis of inhibition of OAT2 mediated uptake of $\left[{ }^{3} \mathrm{H}\right]$ cGMP, the transport was performed at two different concentrations of cGMP; $1 \mu \mathrm{M}\left(10 \mathrm{nM}\left[{ }^{3} \mathrm{H}\right]\right.$ labeled cGMP and $990 \mathrm{nM}$ cold cGMP) and $10 \mu \mathrm{M}$ cGMP (10 nM $\left[{ }^{3} \mathrm{H}\right]$ labeled cGMP and $9.99 \mu \mathrm{M}$ cold cGMP) in the presence of increasing concentrations of the respective cytostatic compound. The concentrations used for bendamustine and irinotecan were $0,5 \mu \mathrm{M}, 10 \mu \mathrm{M}, 20 \mu \mathrm{M}, 40 \mu \mathrm{M}, 70 \mu \mathrm{M}, 100 \mu \mathrm{M}$ and $130 \mu \mathrm{M}$, and for paclitaxel, the concentrations were $0,2.5 \mu \mathrm{M}, 5 \mu \mathrm{M}, 7.5 \mu \mathrm{M}, 10$ $\mu \mathrm{M}, 12.5 \mu \mathrm{M}, 15 \mu \mathrm{M}$ and $20 \mu \mathrm{M}$. 


\subsubsection{Concentration dependent inhibition of OATP1B1 activity by vinblastine and paclitaxel}

The uptake of $\left[{ }^{3} \mathrm{H}\right]$ estrone-3-sulfate was measured in Hank's buffer solution containing $20 \mathrm{nM}\left[{ }^{3} \mathrm{H}\right]$ estrone-3-sulfate and either $230 \mathrm{nM}$ or $2.48 \mu \mathrm{M}$ unlabeled estrone-3-sulfate for $5 \mathrm{~min}$ in the presence of $0,10 \mu \mathrm{M}, 25 \mu \mathrm{M}, 50 \mu \mathrm{M}, 75 \mu \mathrm{M}, 100 \mu \mathrm{M}, 125 \mu \mathrm{M}$, and 150 $\mu \mathrm{M}$ of vinblastine, and $0,0.1 \mu \mathrm{M}, 0.25 \mu \mathrm{M}, 0.5 \mu \mathrm{M}, 0.75 \mu \mathrm{M}, 1 \mu \mathrm{M}, 1.5 \mu \mathrm{M}$, and $2 \mu \mathrm{M}$ of paclitaxel.

\subsubsection{Concentration dependent inhibition of OATP1B3 activity by antineoplastic compounds}

In the case of OATP1B3, the uptake of $\left[{ }^{3} \mathrm{H}\right] \mathrm{CCK}-8$ was monitored in Hank's buffer solution containing $5 \mathrm{nM}$ of $\left[{ }^{3} \mathrm{H}\right] \mathrm{CCK}-8$ and either $995 \mathrm{nM}$ or $9.995 \mu \mathrm{M}$ unlabeled CCK-8 in the presence of increasing concentration of the corresponding antineoplastic compound. The concentrations of $0,10 \mu \mathrm{M}, 25 \mu \mathrm{M}, 50 \mu \mathrm{M}, 75 \mu \mathrm{M}, 100 \mu \mathrm{M}, 125 \mu \mathrm{M}$ and $150 \mu \mathrm{M}$ were used for chlorambucil and vinblastine, $0,1 \mu \mathrm{M}, 2 \mu \mathrm{M}, 3 \mu \mathrm{M}, 4 \mu \mathrm{M}, 5$ $\mu \mathrm{M}, 7.5 \mu \mathrm{M}$ and $10 \mu \mathrm{M}$ for mitoxantrone; $0,5 \mu \mathrm{M}, 10 \mu \mathrm{M}, 20 \mu \mathrm{M}, 40 \mu \mathrm{M}, 70 \mu \mathrm{M}, 100$ $\mu \mathrm{M}$ and $130 \mu \mathrm{M}$ for vincristine, $0,0.25 \mu \mathrm{M}, 0.5 \mu \mathrm{M}, 1 \mu \mathrm{M}, 2 \mu \mathrm{M}, 3 \mu \mathrm{M}, 4 \mu \mathrm{M}$, and $5 \mu \mathrm{M}$ for paclitaxel and $0,1 \mu \mathrm{M}, 2.5 \mu \mathrm{M}, 5 \mu \mathrm{M}, 7.5 \mu \mathrm{M}, 10 \mu \mathrm{M}, 15 \mu \mathrm{M}$ and $20 \mu \mathrm{M}$ for etoposide, respectively.

\subsection{Apoptosis assay by determination of the Caspase-3 activity}

Caspases are a family of enzymes that play an important role in the complex process of apoptosis. Most of the antineoplastic compounds used in this study invariably lead to cell death by apoptosis. To find whether the strong interactions observed in cis-inhibition experiments are associated with to the uptake of the antineoplastic compounds into the 
cells, a specific assay for measuring the caspase-3 activity was performed. Bendamustine is an alkylating agent and is known to be cause apoptosis in cells. So, an apoptosis assay was performed using the EnzChek Caspase 3-Assay kit as per the manufacturer's protocol with some modifications. Briefly, $2 \times 10^{5}$ cells were seeded in 24 well plates, grown for $72 \mathrm{~h}$, and were incubated further with $100 \mu \mathrm{M}$ bendamustine in the culture medium for 12 $\mathrm{h}$ alone or in combination with $100 \mu \mathrm{M}$ probenecid. Cells were washed in PBS, trypsinised, and pelleted from the spent medium, PBS wash fraction, trypsinized fraction and pooled together to avoid possible loss of any cells. They were lysed in $50 \mu 1$ of lysis buffer (supplied in the kit) and subjected to a freeze thaw cycle with 5 min incubation in liquid nitrogen. After a spin at 5,000 rpm for $5 \mathrm{~min}$, the supernatant was collected. $40 \mu \mathrm{l}$ of this supernatant was added to the substrate and incubated for $20 \mathrm{~min}$ in a dark place. The remaining $10 \mu \mathrm{l}$ was used for protein concentration determination by the Bradford method (Section 2.5). Fluorescence was measured in $80 \mu 1$ of the 1:10 diluted product in a Multi-plate reader Mithras LB 940. The relative fluorescence units (RFU) were normalized to protein concentrations obtained from Bradford estimation and the data is represented as \% caspase- 3 activity wherein the RFU obtained with untreated pcDNA cells was taken as $100 \%$. Similar assays were also conducted with irinotecan and paclitaxel.

\subsection{Evaluation the uptake of antineoplastic drugs in the cells by HPLC analysis}

High performance liquid chromatography is a tool used for the separation of compounds based on the differential properties of the compounds in interacting with substances or phases differently, as judged by their partition coefficients. This method is highly sensitive and has been successfully used as a very reliable method to quantify various metabolites in cells. Fluorescence based detection of compounds in HPLC analysis of cell 
lysates has the added advantage of specificity with a minimal background contribution to the signal observed.

The HPLC analysis was essentially performed as the uptake experiments mentioned earlier, albeit, in $100 \mathrm{~mm}$ plates. $3 \times 10^{6}$ cells were seeded in poly D-lysine coated plates and allowed to grow to confluency. Cells were washed with PBS thrice and incubated with Hank's buffer solution containing $100 \mu \mathrm{M}$ irinotecan or a mixture of $100 \mu \mathrm{M}$ irinotecan and $100 \mu \mathrm{M}$ cGMP in a $37^{\circ} \mathrm{C}$ water bath for 5 min. The transport was terminated by placing the plates in ice cold water and then aspirating the buffer followed by three washes with ice-cold PBS. The cells were scrapped using $1 \mathrm{~mL}$ of the mobile phase (40\% methanol: $60 \% \quad 0.1 \mathrm{M}$ ammonium acetate and $0.01 \mathrm{M}$ TBAHS pH 5.5) containing $20 \mu \mathrm{M}$ of the internal standard, camptothecin. The cell suspensions were lysed by sonication. $20 \mu \mathrm{L}$ of the lysates was separated for protein estimation and the rest was centrifuged at $13,000 \mathrm{rpm}$ at $4^{\circ} \mathrm{C}$ for $20 \mathrm{~min}$. The supernatants were filtered through 0.2 $\mu \mathrm{M}$ syringe filters and subjected to HPLC analysis using a Zorbax Eclipse XDB-C8 column with $5 \mu \mathrm{L}$ injections. Irinotecan (CPT-11) and camptothecin (CPT) were detected by fluorescence with excitation maximum of $355 \mathrm{~nm}$ and emission maximum of $515 \mathrm{~nm}$ in a mobile phase containing 40\% methanol: $60 \% 0.1 \mathrm{M}$ ammonium acetate and $0.01 \mathrm{M}$ TBAHS pH 5.5. Standard curves were plotted using increasing concentrations of the pure compounds irinotecan and camptothecin.

For measuring time dependent uptake of irinotecan, confluent cells in $100 \mathrm{~mm}$ culture dishes were washed twice with PBS and incubated in Hank's buffer solution containing $100 \mu \mathrm{M}$ irinotecan for $2,4,6,8$ or $10 \mathrm{~min}$. The buffer was removed, the cells were washed with ice cold PBS three times, and the cells were collected by scraping them in 1 $\mu L$ of mobile phase and analyzed as described above. 


\subsection{Determination of Protein concentration}

To normalize the amount of cell mass contributing to the observed effect, the amount of protein in the cell lysates was measured by Bradford method [151] with some modifications. Briefly, the lysates were diluted 1:20 with distilled water and $20 \mu 1$ of this solution was added to a 96 well plate followed by the addition of $200 \mu \mathrm{l}$ of Bradford reagent. The absorbance was measured at $595 \mathrm{~nm}$ in a Multi-plate reader Mithras LB 940. A standard curve was plotted from absorbance of $0,50 \mu \mathrm{g}, 75 \mu \mathrm{g}, 100 \mu \mathrm{g}, 150 \mu \mathrm{g}, 200$ $\mu \mathrm{g}, 250 \mu \mathrm{g}$ and $300 \mu \mathrm{g}$ of BSA and the protein concentration of each test sample was calculated using the plotted standard curve of BSA, which is integrated in an evaluation table of Microsoft Excel.

\subsection{Isolation of RNA}

RNA was isolated from cells using the Qiagen RNA isolation kit or by Trizol method based on the experiment where it is used later.

\subsubsection{Isolation of total RNA for qRTPCR}

Qiagen kit based RNA isolation was performed for RNA that was later used in qRTPCR reactions. After the cells are confluent, they were pelleted as mentioned above. The cells were counted and $2 \times 10^{6}$ cells were used for the process. The cells were washed twice with PBS and were lysed with $350 \mu \mathrm{L}$ of lysis buffer (RLT buffer) containing $1 \%$ Bmercapto ethanol. The suspension was vortexed and an equal amount of $70 \%$ ethanol was added to it. The solution was transferred to a Qiagen filter column and was spun down at 10,000 RPM at room temperature for $15 \mathrm{~s}$. The flow through was discarded and the column was washed with $700 \mu \mathrm{L}$ of wash buffer 1 (RW-1) and centrifuged at 10,000 RPM for $15 \mathrm{~s}$. It was followed by a couple of washing steps with $500 \mu \mathrm{L}$ of wash buffer 2 
(RW2) and spun down for 15s and 2 min, respectively. A high speed centrifugation step at 13,000 RPM for 1 min was applied to remove any residual wash solution. Then $30 \mu \mathrm{L}$ of RNase free water was added to the center of the column and the RNA bound to the column was eluted during a centrifugation step of 10,000 RPM for $30 \mathrm{~s}$.

\subsubsection{Isolation of total RNA using Trizol reagent}

The Trizol method of isolation of RNA was performed for genome wide sequencing of microRNAs in the renal carcinoma cells A498, ACHN, 786-O and LN78 cells. Cells were seeded at a suitable density to yield ca. $3 \times 10^{6}$ cells at confluency. After washing twice with PBS, the cells were lysed on the culture dish itself by the addition of $3 \mathrm{~mL}$ of Trizol reagent ( $1 \mathrm{~mL}$ of Trizol per $1 \times 10^{6}$ cells). The suspension was thoroughly mixed, split into 2 parts into two separate $2 \mathrm{~mL}$ tubes and centrifuged at 11,300 RPM $(12,000 \mathrm{x}$ $\mathrm{g}$ ) in a table top centrifuge at $4^{\circ} \mathrm{C}$ for $10 \mathrm{~min}$. The supernatant was transferred into a fresh tube and left to stand at room temperature for $5 \mathrm{~min}$. After $5 \mathrm{~min}, 0.3 \mathrm{~mL}$ of chloroform was added to the solution and the tubes were sealed tight and shaken vigorously for ca. $15 \mathrm{~s}$ and incubated at room temperature for a further $5 \mathrm{~min}$. The samples were spun down at $11,300 \mathrm{RPM}$ for $15 \mathrm{~min}$ at $4^{\circ} \mathrm{C}$ and the upper (aqueous) phase containing RNA was carefully transferred to a fresh tube without disturbing the white interphase (protein). The RNA present in the solution was precipitated by the addition of $0.75 \mathrm{~mL}$ of isopropanol and $1 \mu \mathrm{L}$ of GlycoBlue (a dye used to stain the RNA pellet). The samples were then incubated overnight in $-20^{\circ} \mathrm{C}$. They were centrifuged at $11,300 \mathrm{RPM}$ for $30 \mathrm{~min}$ at $4^{\circ} \mathrm{C}$. The supernatant was removed by pipetting and the pellet was washed with $1.5 \mathrm{~mL}$ of $75 \%$ ethanol and centrifuged at $11,300 \mathrm{RPM}$ for $5 \mathrm{~min}$ at $4^{\circ}$ C. The wash step was repeated again and the RNA pellet obtained was dried at $37^{\circ} \mathrm{C}$. The dry pellet was dissolved later by pipetting in $50 \mu \mathrm{L}$ of RNase-free water. 


\subsubsection{Isolation of small RNA enriched fraction}

The small RNA fraction of the RNA pool was specifically enriched using the mirVana miRNA isolation kit. Confluent cells were harvested and. 2 × $10^{6}$ cells were separated for small RNA enrichment. The cells were washed twice in PBS and the cell pellets were resuspended in $600 \mu \mathrm{L}$ of lysis/binding buffer supplied in the kit and thoroughly vortexed. To this suspension, $60 \mu \mathrm{L}$ of microRNA homogenate additive is added and mixed by vortexing. After an incubation of $10 \mathrm{~min}$ on ice, $600 \mu \mathrm{L}$ of acid-phenol: chloroform mixture was added and vortexed for $45 \mathrm{~s}$ to mix. The mixture was centrifuged at 13,000 RPM for $5 \mathrm{~min}$ at room temperature. The upper aqueous phase was removed without disturbing the lower phase into a fresh tube and the volume was measured. To this solution, $1 / 3^{\text {rd }}$ volume of $100 \%$ ethanol was added and thoroughly vortexed. This mixture was passed through a filter cartridge ( $700 \mu \mathrm{L}$ at a time) and the flow through was collected after a centrifugation step of 10,000 RPM for $15 \mathrm{~s}$. The volume of the filtrate was measured and $2 / 3^{\text {rd }}$ volumes of $100 \%$ ethanol was added to this mixture which contains the small RNAs and mixed thoroughly. This solution is passed through a second filter cartridge and centrifuged at 10,000 RPM for $15 \mathrm{~s}$ and the filtrate is discarded. Both the filter membranes were then washed to retrieve the larger length RNAs and the smaller length RNAs, respectively. The filter cartridges were washed with $700 \mu \mathrm{L}$ of microRNA wash solution 1 and centrifuged for $10 \mathrm{~s}$ at 10,000 RPM followed by two washes with $500 \mu \mathrm{L}$ of wash solution $2 / 3$ and centrifugation steps of $10,000 \mathrm{RPM}$ for $10 \mathrm{~s}$. The cartridges were given a spin to remove residual liquid and the RNA bound to the filters was later eluted by the addition of $100 \mu \mathrm{L}$ of sterile water preheated to $95^{\circ} \mathrm{C}$ and a centrifugation at 13,000 RPM for $30 \mathrm{~s}$. 


\subsection{Determination of concentration of RNA}

$1 \mu \mathrm{L}$ of RNA was added to $9 \mu \mathrm{L}$ of sterile water and the absorbance ratio of $\mathrm{A}_{260 / 280}$ and the concentration was measured thrice for each sample. The average of the three readings was calculated as the total RNA concentration for future experiments.

\subsection{Synthesis of complimentary DNA (cDNA)}

$2 \mu \mathrm{g}$ of RNA was used to prepare cDNA in a volume of $7 \mu \mathrm{L}$ in a $200 \mu \mathrm{L}$ PCR tube. $1 \mu \mathrm{L}$ of $10 \mathrm{mM}$ oligo dT primer was added to the PCR tube and the mixture was subjected to annealing at $70^{\circ} \mathrm{C}$ for $10 \mathrm{~min}$ and then at room temperature. Meanwhile, a master mix was prepared with $4 \mu \mathrm{L}$ of complete buffer containing $(250 \mathrm{mM}$ Tris $\mathrm{HCl} \mathrm{pH} 8.3,500$ $\mathrm{mM} \mathrm{KCl}, 15 \mathrm{mM} \mathrm{MgCl}$, and $50 \mathrm{mM}$ DTT), $1 \mu \mathrm{L}$ of dNTPs, a volume containing $200 \mathrm{U}$ of Superscript reverse transcriptase and $6.6 \mu \mathrm{L}$ of sterile water to a total volume of $12 \mu \mathrm{L}$ per reaction. The mixture was calculated for $n+1$ reactions, where $n$ is the number of reactions in the assay. The reaction mixture was mixed well by pipetting and was transferred to the annealing mixture and subjected to cDNA synthesis step with conditions of $37^{\circ} \mathrm{C}$ for $1 \mathrm{~h}$ and $70^{\circ} \mathrm{C}$ for $10 \mathrm{~min}$. The cDNA obtained was either stored in $-20^{\circ} \mathrm{C}$ or used immediately for the qRTPCR reaction.

\subsection{Quantitative RT-PCR}

To measure the expression of the gene of interest, a qRTPCR reaction was performed using the cDNA synthesized. For all experiments aimed at finding the expression of OCT3, GAPDH was used as an internal control. Similarly, for experiments with objective of evaluating the expression status of microRNAs in the cells, the small nucleolar RNA, RNU43 and the microRNA hsa-mir-103 were used as internal controls. The $20 \mu \mathrm{L}$ cDNA prepared was diluted to a volume of $63 \mu \mathrm{L} .1 \mu \mathrm{L}$ of primer of the corresponding gene was 
added to $10 \mu \mathrm{L}$ of $10 \mathrm{X}$ TaqMan master mix followed by $9 \mu \mathrm{L}$ of the diluted cDNA. The reaction mixture was mixed well by pipette, briefly centrifuged and then subjected to qRTPCR with conditions of $50^{\circ} \mathrm{C}$ for $10 \mathrm{~min}, 95^{\circ} \mathrm{C}$ for $2 \mathrm{~min}$, followed by 40 cycles of $95^{\circ} \mathrm{C}$ for $15 \mathrm{~s}$ and $60^{\circ} \mathrm{C}$ for $1 \mathrm{~min}$. The plate sample values were obtained from the MxPro software and the data was plotted using Microsoft Excel.

\subsection{Disruption of DNA methylation using azacytidine}

Methylation of a DNA in vivo confers it to remain transcriptionally silent. There are many synthetic compounds which can block this process thus making the genes active; azacytidine is one such compound. Since the ACHN cells have less expression of OCT3, we performed the azacytidine based inhibition of DNA methylation on these cells, to check whether a transcriptional block is responsible for the low expression.

A498 and ACHN cells were seeded in 6 well plates at a density of $3 \times 10^{5}$ cells per well in $4 \mathrm{~mL}$ medium. After $24 \mathrm{~h}, \mathrm{ACHN}$ cells were treated with $5 \mu \mathrm{M}, 15 \mu \mathrm{M}$ and $25 \mu \mathrm{M}$ of 5 Aza 2' deoxy-cytidine. The medium was changed with fresh 5 Aza 2' deoxy-cytidine every $24 \mathrm{~h}$ for a total of $72 \mathrm{~h}$ as the compound is highly unstable. RNA was isolated (Section 2.6.1) from these cells along with the untreated A498 and ACHN cells and cDNA was prepared, followed by a qRTPCR reaction to check the levels of expression of OCT3 in them (Section 2.8 and 2.9).

\subsection{Inhibition of histone deacetylase using valproic acid}

Addition of acetyl groups on the lysine residues of histones renders them less affine to the negative phosphodiester backbone of DNA making the gene transcriptionally active and reversal of this process by histone deacetylases (HDACs) leads to a transcriptionally 
inactive state of the gene. Inhibition of histone deacetylases using compounds such as valproic acid has been widely used for inhibition of HDACs.

Inhibition of histone deacetylases was performed using valproic acid in ACHN cells which have low OCT3 expression to check whether this results in higher expression of OCT3.

A498 and ACHN cells were seeded at a density of $3 \times 10^{5}$ cells per well in 4 mL medium and grown for $72 \mathrm{~h}$ in 6 well plates. They were incubated for a further $24 \mathrm{~h}$ with $0.5 \mathrm{mM}$, $5 \mathrm{mM}$ or $10 \mathrm{mM}$ valproic acid. The cells were harvested and the RNA was isolated from them along with untreated A498 and ACHN cells. cDNA was prepared from the RNA and a qRTPCR reaction was performed to check the levels of expression of OCT3.

\subsection{Analysis of methylation status of promoter of SLC22A3 gene by Ion Torrent Sequencing}

The methylation status of a promoter is an indication of whether a gene is transcriptionally active or not. There are various methods to determine the methylation status of a gene. Recent advances in the sequencing methods led to the development of high throughput processes aimed to achieve high sensitivity and a simpler work flow. One such method is the Ion torrent sequencing. The work flow is illustrated in fig. 2.1. As depicted in the figure, the method involves the construction of library, followed by preparation of template for sequencing followed by sequencing. Prior to the construction of the library, the whole DNA was extracted and bisulfite treated, followed by the amplification of desired fragments. 

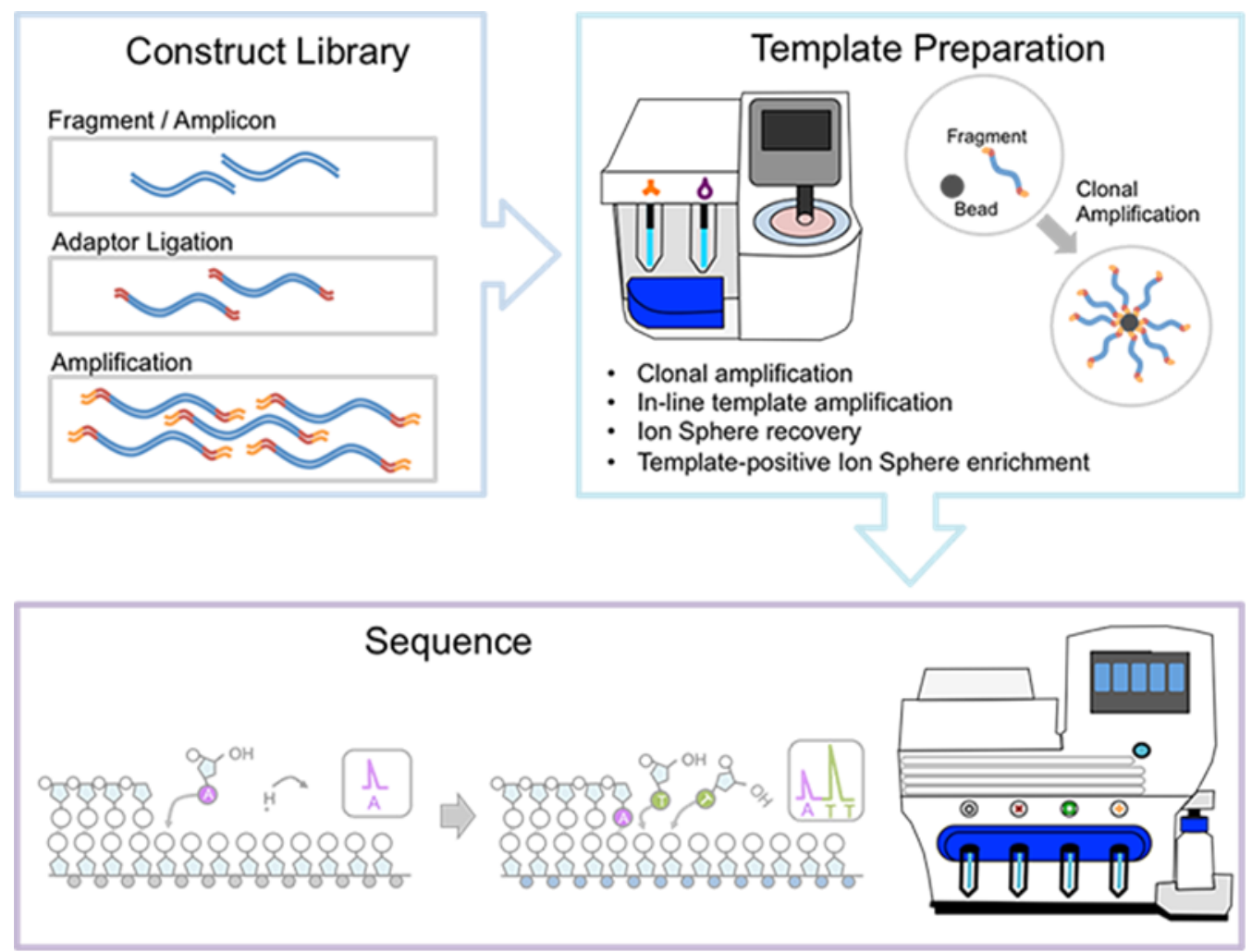

adapted from sunnybrook.ca

\section{Figure 2.1 Work flow of ion torrent sequencing}

The desired fragments are amplified by emulsion PCR on the ion sphere particles and loaded onto a chip. During sequencing the nucleotides are sequentially flushed into and out of the wells. Whenever a nucleotide is added, there is a release of proton leading to the local change of $\mathrm{pH}$ that is detected by a sensor and this signal is converted into a digital signal.

\subsubsection{Extraction and bisulfite treatment of DNA}

Bisulfite treatment of total DNA is the core step of many of the procedures aimed at finding the methylation status of a gene, the underlying mechanism being sodium bisulfite treatment would convert all unmethylated cytosines into uracil. When sequenced, 
this converted DNA would reveal which cytosines were methylated and which ones were unmethylated.

$2 \times 10^{6}$ cells of all the four RCCs were harvested and along with the human renal cortical epithelial cell pellet were subjected to DNA extraction protocol using an automated QIAcube system. The extracted DNA was estimated in a nanophotometer. $3 \mu \mathrm{L}$ of eluted DNA was used for the estimation. $1 \mu \mathrm{g}$ of the isolated DNA was taken into a fresh tube and the volume was raised to $20 \mu \mathrm{L}$ with sterile double distilled water, followed by the addition of $85 \mu \mathrm{L}$ of bisulfite solution and $35 \mu \mathrm{L}$ of DNA protect buffer.

This mixture was vortexed and subjected to a bisulfite reaction in the QIAcube automated system using the protocol supplied by the manufacturer. The reaction was performed in the following steps; a denaturation step at $95^{\circ} \mathrm{C}$ for $5 \mathrm{~min}$, an incubation at $60^{\circ} \mathrm{C}$ for 15 min followed by another denaturation step at $95^{\circ} \mathrm{C}$ for 5 min followed by an incubation for $15 \mathrm{~min}$ at $60^{\circ} \mathrm{C}$ and then at room temperature until the next step.

The treatment was soon followed by the cleanup procedure of bisulfite treated DNA. This process was performed in the QIAcube automated system under the protocol "cleanup of bisulfite converted DNA". The process involves immobilizing the DNA on the Qiagen spin columns and removing all the reaction constituents of the bisulfite reaction. It involved the following steps: the bisulfite treated DNA was transferred into a $1.5 \mathrm{~mL}$ tube, followed by the addition of $250 \mu \mathrm{L}$ of $100 \%$ ethanol and pulse vortexed for $15 \mathrm{~s}$. After a brief spin, the mixture was passed through a MinElute DNA spin columns by centrifugation at full speed for 1 min. The column was washed with $500 \mu \mathrm{L}$ of wash buffer (BW) followed by centrifugation at full speed for 1 min. It was followed by a desulfonation step wherein the columns were incubated with $500 \mu \mathrm{L}$ of desulfonation buffer (BD) for $15 \mathrm{~min}$ at room temperature. After a full speed centrifugation step for 1 
min, the columns were washed twice with $500 \mu \mathrm{L}$ of BW, followed by the addition of 250 $\mu \mathrm{L}$ of $100 \%$ ethanol to the columns and centrifuged at full speed for $1 \mathrm{~min}$. The columns were transferred into fresh $2 \mathrm{~mL}$ tubes and centrifuged at full speed for $1 \mathrm{~min}$ to remove any residual liquid. The DNA bound to the columns was then eluted by incubating the columns with $15 \mu \mathrm{L}$ of elution buffer at room temperature for $1 \mathrm{~min}$, followed by centrifugation of the columns at 12,000 RPM for $1 \mathrm{~min}$. The eluted DNA was measured in a nanophotometer.

\subsubsection{Amplification of desired fragments and library preparation}

The primers were designed using the software Methyl Primer Express software. $3 \mu \mathrm{L}$ of the bisulfite DNA obtained in each sample was pooled and the $15 \mu \mathrm{L}$ was subjected to a gradient PCR in the range of $50^{\circ} \mathrm{C}$ to $70^{\circ} \mathrm{C}$, with the primers designed to regions 1 and 2 of the promoter of OCT3. The composition of the reaction mixture for 3 reactions was

\begin{tabular}{|l|l|}
\hline Component & volume \\
\hline 2X HotStart master mix & $15 \mu \mathrm{L}$ \\
\hline Forward primer $(10 \mu \mathrm{M})$ & $1.2 \mu \mathrm{L}$ \\
\hline Reverse primer $(10 \mu \mathrm{M})$ & $1.2 \mu \mathrm{L}$ \\
\hline Water & $5.6 \mu \mathrm{L}$ \\
\hline Bisulfite treated DNA & $7 \mu \mathrm{L}$ \\
\hline Total volume & $30 \mu \mathrm{L}$ \\
\hline
\end{tabular}

Table 3.1 Reaction mixture of gradient PCR for amplification of promoter regions 1 and 2 of SLC22A3 
$10 \mu \mathrm{L}$ of the mixture was loaded in wells and PCR reaction was performed in the following steps

\begin{tabular}{|l|l|l|l|}
\hline Step & No. of cycles & Temperature & Duration \\
\hline Step 1 & 1 & $95^{\circ} \mathrm{C}$ & $15 \mathrm{~min}$ \\
\hline \multirow{3}{*}{ Step 2 } & \multirow{3}{*}{50} & 95 & $30 \mathrm{~s}$ \\
\cline { 3 - 4 } & & $50-70$ & $30 \mathrm{~s}$ \\
\cline { 3 - 4 } Step 3 & 1 & 65 & $2 \mathrm{~min}$ \\
\hline Step 4 & 1 & 65 & 1 min \\
\hline
\end{tabular}

Table 3.2 PCR conditions for the amplification of promoter regions 1 and 2 of SLC22A3

After the reaction is completed, the PCR products were mixed with $2 \mu \mathrm{L}$ of loading dye and analyzed in a $2 \%$ agarose gel. After the annealing temperature was set, $19 \mathrm{ng}$ of bisulfite treated DNA from each sample was used to amplify the regions of interest and the PCR products were analyzed in a $2 \%$ agarose gel. Once all the amplified products were obtained, a library was prepared using 1:200 dilution of the obtained PCR product. Library preparation confers to the identification of each fragment of amplified DNA from each sample as a unique entity by the sequencer. To achieve this process, the amplified fragments were subjected to further PCR reactions with primers containing sequences called barcode and adaptor sequences. The barcode is specific for each fragment and is of 9 or 10 nucleotides length, followed by an adaptor which is 4 nucleotides length and is the same sequence for all the primers which is the start point for the amplification. This sequence is followed by specific sequence of forward and reverse primers of fragments 1 and 2 respectively. With the primers, an adapter PCR reaction was performed. The reaction mixture for this reaction for a single reaction was as follows 


\begin{tabular}{|l|l|}
\hline Component & volume \\
\hline 2X HotStart master mix & $15 \mu \mathrm{L}$ \\
\hline Barcoded forward primer $(10 \mu \mathrm{M})$ & $1.2 \mu \mathrm{L}$ \\
\hline Reverse primer $(10 \mu \mathrm{M})$ & $1.2 \mu \mathrm{L}$ \\
\hline Water & $5.6 \mu \mathrm{L}$ \\
\hline PCR product $(1: 200$ diluted $)$ & $7 \mu \mathrm{L}$ \\
\hline Total volume & $30 \mu \mathrm{L}$ \\
\hline
\end{tabular}

Table 3.3 Reaction mixture for adapter PCR

The reaction mixture was subjected to a PCR reaction containing the following steps

\begin{tabular}{|l|l|l|l|}
\hline Step & No. of cycles & Temperature & Duration \\
\hline Step 1 & 1 & $95^{\circ} \mathrm{C}$ & $15 \mathrm{~min}$ \\
\hline \multirow{3}{*}{ Step 2 } & \multirow{3}{*}{14} & 95 & $30 \mathrm{~s}$ \\
\cline { 3 - 4 } & & 50 & $30 \mathrm{~s}$ \\
\cline { 3 - 4 } & 65 & $2 \mathrm{~min}$ \\
\hline Step 3 & 1 & 65 & 5 min \\
\hline Step 4 & 1 & 8 & infinite \\
\hline
\end{tabular}

Table 3.4 PCR conditions for the amplification of barcoded fragments of promoter regions 1 and 2 of SLC22A3

The products from this PCR were also analyzed on a $2 \%$ agarose gel.

\subsubsection{Quantification of library}

$7 \mu \mathrm{L}$ of the each adaptor PCR product from each fragment was separately pooled followed by the addition of $10 \mu \mathrm{L}$ of loading dye and the mixture was resolved on a $2 \%$ agarose gel. The fragments 1 and 2 were excised from the gel and then extracted from the 
gel using the protocol of gel extraction of DNA in the QIAcube automated system. The two fragments were pooled and quantified by a quantitative PCR reaction.

The pooled PCR products were diluted to 1:2000 and 1:20000 by the dilution scheme:

$5 \mu \mathrm{L}$ of product $+495 \mu \mathrm{L}$ of water

$1: 100$ dilution

$50 \mu \mathrm{L}$ of $1: 100$ diluted product

$+950 \mu \mathrm{L}$ of water

1:20 dilution (used as 1:2000

template)

$10 \mu \mathrm{L}$ of 1:2000 template

$+90 \mu \mathrm{L}$ of water

1:10 dilution (used as 1:20000 template)

Using the diluted templates, the qPCR reaction was set up. The master mix was prepared such that each reaction was performed in triplicates along with the control library (E. coli DH10B control supplied with the kit). The number of reactions required was calculated accordingly and the reaction was set up with the following composition for 1 reaction

\begin{tabular}{|l|l|}
\hline Component & volume \\
\hline RNase-/DNase - free water & $3.86 \mu \mathrm{L}$ \\
\hline GeneRead qPCR SYBR green Mastermix & $5.68 \mu \mathrm{L}$ \\
\hline Primer mix $(10 \mu \mathrm{M})$ & $0.45 \mu \mathrm{L}$ \\
\hline Final volume & $10 \mu \mathrm{L}$ \\
\hline Template & $3 \mu \mathrm{L}$ \\
\hline
\end{tabular}

Table 3.5 Reaction mixture for qPCR of amplified barcoded fragments

The plate was sealed with an adhesive tape and the PCR was run with an SDS 2.4 application template PCR program. Using the software the concentration of template was obtained which was then multiplied to the dilution factor and a factor of 0.000198 
(corresponding to a library of average size of $300 \mathrm{bp}$ ) and the concentration of the library was obtained as $\mathrm{ng} / \mu \mathrm{L}$.

\subsubsection{Ion torrent sequencing}

For the next generation sequencing protocol of Ion Torrent sequencing, the templates are to be adhered onto ion sphere particles which are then loaded onto a chip in which the sequencing by synthesis reaction is performed.

\subsubsection{Preparation of template positive Ion Sphere Particles (ISPs)}

The template positive ion sphere particles were prepared using the Ion One Touch system. The process involves an emulsion PCR where in a DNA molecule is amplified on an ion sphere particle in an emulsion containing all the components required for DNA synthesis, and multiple cycles of this process leads to clonal amplification of the desired fragments on the ion sphere particle. All the reactions components were added sequentially as per the manufacturer's protocol as depicted in the following table

\begin{tabular}{|l|l|}
\hline Component & volume \\
\hline Nuclease free water & $280 \mu \mathrm{L}$ \\
\hline Ion One Touch 2x reagent mix & $500 \mu \mathrm{L}$ \\
\hline Ion One Touch enzyme mix & $100 \mu \mathrm{L}$ \\
\hline Diluted library & $20 \mu \mathrm{L}$ \\
\hline Total volume & $900 \mu \mathrm{L}$ \\
\hline
\end{tabular}

Table 3.6 Reaction mixture for emulsion PCR to prepare template positive ISPs 
To this mixture, $100 \mu \mathrm{L}$ of Ion One Touch Ion Sphere Particles were added and the mixture was mixed well and loaded into the sample port of the Ion One Touch reaction filter assembly. Then $1 \mathrm{~mL}$ of Ion One Touch reaction oil was added into the sample port, followed by the addition of another $500 \mu \mathrm{L}$ of the oil. After performing the run, the samples were centrifuged and the template positive ISPs were recovered. The template positive ISPs were transferred into $1.5 \mu \mathrm{L}$ LoBind tubes. The supernatant was carefully removed leaving a $50 \mu \mathrm{L}$ volume and the pellets were resuspended slowly with pipette, pooled and the volume was raised to $1 \mathrm{~mL}$ with wash buffer and centrifuged at 15,500 $\mathrm{g}$ for 2.5 min removing all but $100 \mu \mathrm{L}$ of the supernatant. The pellet was vortexed and proceeded further for the enrichment of the ISPs.

\subsubsection{Enrichment of template positive Ion Sphere Particles}

Enrichment of template positive ISPs is performed to remove the unbound DNA and ghost ion sphere particles (which have no DNA bound to them) and potentially enrich those ISPs which have amplified DNA bound to them. This is achieved by incubation of the template positive ISPs (with biotinylated primers) with streptavidin beads and later washing them off after enrichment. A fresh melt off solution was prepared by mixing 865 $\mu \mathrm{L}$ of nuclease free water, $125 \mu \mathrm{L}$ of $1 \mathrm{M} \mathrm{NaOH}$, and $10 \mu \mathrm{L}$ of $10 \%$ Tween 20 solution. The Dynabeads MyOne streptavidin C1 beads were resuspended in $130 \mu \mathrm{L}$ of MyOne beads wash solution. All the solutions were all placed in their designated wells in an 8 well strip and the run was performed resulting in the collection of enriched template positive ISPs. The collected suspension was spun down at $15,500 \mathrm{x} g$ for $1.5 \mathrm{~min}$, washed with $200 \mu \mathrm{L}$ of Ion One Touch wash solution, mixed well with pipette and centrifuged at $15,500 \mathrm{x} g$ for $1.5 \mathrm{~min}$. After making sure that there are no beads left, the supernatant was removed leaving $10 \mu \mathrm{L}$ of it with the pellet. The volume was raised to $100 \mu \mathrm{L}$ with Ion 
One Touch wash solution and the pellet was resuspended and ready to be loaded onto the chip for the run.

\subsubsection{Sequencing the template positive Ion Sphere Particles}

Meanwhile, the Ion Torrent PGM sequencer was initialized as per the manufacturer's instructions. Half of the volume of obtained enriched template positive ISPs was transferred to a fresh $0.2 \mathrm{~mL}$ tube followed by the addition of $5 \mu \mathrm{L}$ of control Ion Sphere Particles. The solution was centrifuged at $15,500 \mathrm{x} g$ for 2 min and the supernatant was removed leaving $3 \mu \mathrm{L}$ with the pellet. $3 \mu \mathrm{L}$ of sequencing primer was added and the pellet was suspended with pipette. The tube was placed in a thermocycler and a run was performed with $95^{\circ} \mathrm{C}$ for $2 \mathrm{~min}$ and $37^{\circ} \mathrm{C}$ for $2 \mathrm{~min}$. Meanwhile, a check was performed on the chip which is to be loaded with the template positive ISPs as per the guidelines provided in the protocol. To the reaction mixture, $1 \mu \mathrm{L}$ of Ion PGM sequencing $200 \mathrm{v} 2$ polymerase was added to a final volume of $7 \mu \mathrm{L}$, mixed and incubated for 5 min at room temperature. The solution was loaded onto an Ion 314 chip at a rate of ca. $1 \mu \mathrm{L} / \mathrm{s}$ and the chip was centrifuged for $30 \mathrm{~s}$. The solution was pipetted in and out of chip, centrifuged and all the liquid was removed from the chip. Then the run was performed.

\subsection{Computational algorithms used to predict microRNAs binding to $3^{\prime}$ UTR of OCT3}

There are many prediction programs which predict microRNAs binding to the $3^{\prime}$ and $5^{\prime}$ untranslated regions (UTRs) of mRNA of gene of interest. The prediction programs used for data mining were PICTAR, DIANA microT V3.0, TargetScan Human V 5.2, microRNA.org and EIMMo. All the microRNA species which were predicted to bind to the $3^{\prime}$ UTR of OCT3 mRNA were collected as a data pool and such microRNA species 
which were predicted by more than 2 of these programs were shortlisted for further experimentation.

\subsection{Statistical analysis}

All the statistical analysis was done using Microsoft Excel 2010 and SigmaPlot 11. $p$ values were calculated using the paired samples student's $t$ test.

\subsection{Determination of molecular characteristics of the antineoplastic drugs using MarvinSketch software}

MarvinSketch (version 14.7.28.0), 2014, from ChemAxon (https://www.chemaxon.com) was used to determine the molecular characteristics of the antineoplastic compounds used in the study. All the molecular structures were downloaded as molfiles, available from the chEMBL database. The parameters obtained using the software, which recognizes molfiles, include polar surface area, $\log \mathrm{P}$ value, $\log \mathrm{D}$ value, existence of a compound in various ionization states, their percentages, and net charge at different $\mathrm{pH}$ values. 


\section{Results}

\subsection{Interaction of Organic anion transporter 2 with antineoplastic compounds}

Functionally characterized HEK cells stably expressing OAT2 were obtained from Dr. Saskia Flörl, PortaCellTec GmbH. From initial experiments conducted by PortaCellTec, the time of cGMP uptake chosen was 5 min and the $K_{m}$ value was calculated to be 101.4 $\mu \mathrm{M}$. So, the inhibition studies were performed wherein the uptake time was 5 min and the concentration of substrate was $10 \mu \mathrm{M}$.

\subsubsection{Inhibition of OAT2 mediated cGMP uptake by antineoplastic compounds}

The uptake of $\left[{ }^{3} \mathrm{H}\right]$ labeled cGMP into OAT2-HEK cells was measured in the presence of $100 \mu \mathrm{M}$ of the antineoplastic drugs for $5 \mathrm{~min}$. Uptake of $\left[{ }^{3} \mathrm{H}\right]$ cGMP in the absence of any antineoplastic compounds was calculated to be $62.4 \pm 1.3 \mathrm{pmol} / 5 \mathrm{~min}$. This absolute value was regarded, in each independent experiment, as $100 \%$ and the uptake value in the presence of antineoplastic compounds is represented as percentage of this value. Significant changes were observed in the uptake of $\left[{ }^{3} \mathrm{H}\right]$ labeled cGMP into OAT2-HEK cells in the presence of many of the antineoplastic drugs tested and are presented as interactions with different classes of antineoplastic compounds based on their mechanism of action.

\subsubsection{Inhibition of OAT2 mediated cGMP uptake by alkylating agents}

Among alkylating agents, melphalan inhibited the uptake significantly by $20.7 \pm 1.9 \%$, bendamustine by $86.7 \pm 0.7 \%$, chlorambucil by $38.9 \pm 1.2 \%$ and busulfan by $21.7 \pm 2.1$ $\%$ of its buffer control (Fig. 4.1). The compounds cyclophosphamide, trofosfamide, 
ifosfamide, treosulfan and thioTEPA did not cause any significant change in the uptake compared to the buffer control.

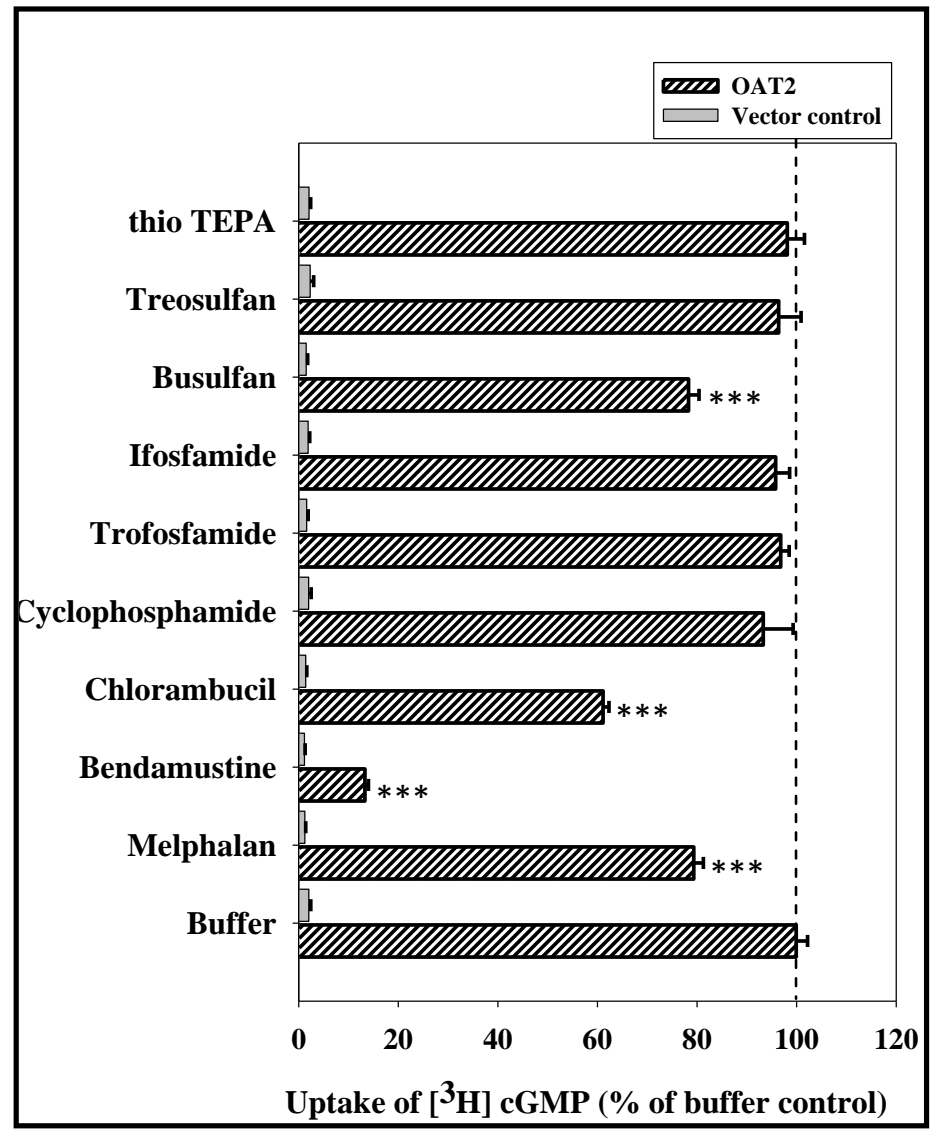

Figure 4.1 Inhibition of OAT2 mediated uptake of $\left[{ }^{3} \mathrm{H}\right]$ cGMP in the presence of alkylating agents. The uptake of $\left[{ }^{3} \mathrm{H}\right]$ cyclic GMP was monitored in a buffer system containing $10 \mathrm{nM}\left[{ }^{3} \mathrm{H}\right]$ cyclic GMP and $990 \mathrm{nM}$ unlabeled cGMP in the presence or absence of $100 \mu \mathrm{M}$ of the alkylating compounds in OAT2 transfected HEK cells and vector transfected HEK cells. Data represent mean \pm SEM of 3 independent experiments with 3 repeats each. $* * *$ represents $p$ value $<0.001$

\subsubsection{Inhibition of OAT2 mediated cGMP uptake by antimetabolites}

Among the antimetabolites, the compounds, methotrexate, gemcitabine and fluoroadenine reduced the uptake of OAT2 mediated uptake of $\left[{ }^{3} \mathrm{H}\right]$ cGMP significantly by $25.6 \pm 2.9 \%$, $9.5 \pm 2.3 \%$ and $23.1 \pm 1.9 \%$ of buffer control, respectively (Fig. 4.2). The 
antimetabolites cytosine arabinoside, 5-fluorouracil, fludarabine and cladribine did not affect the transport activity.

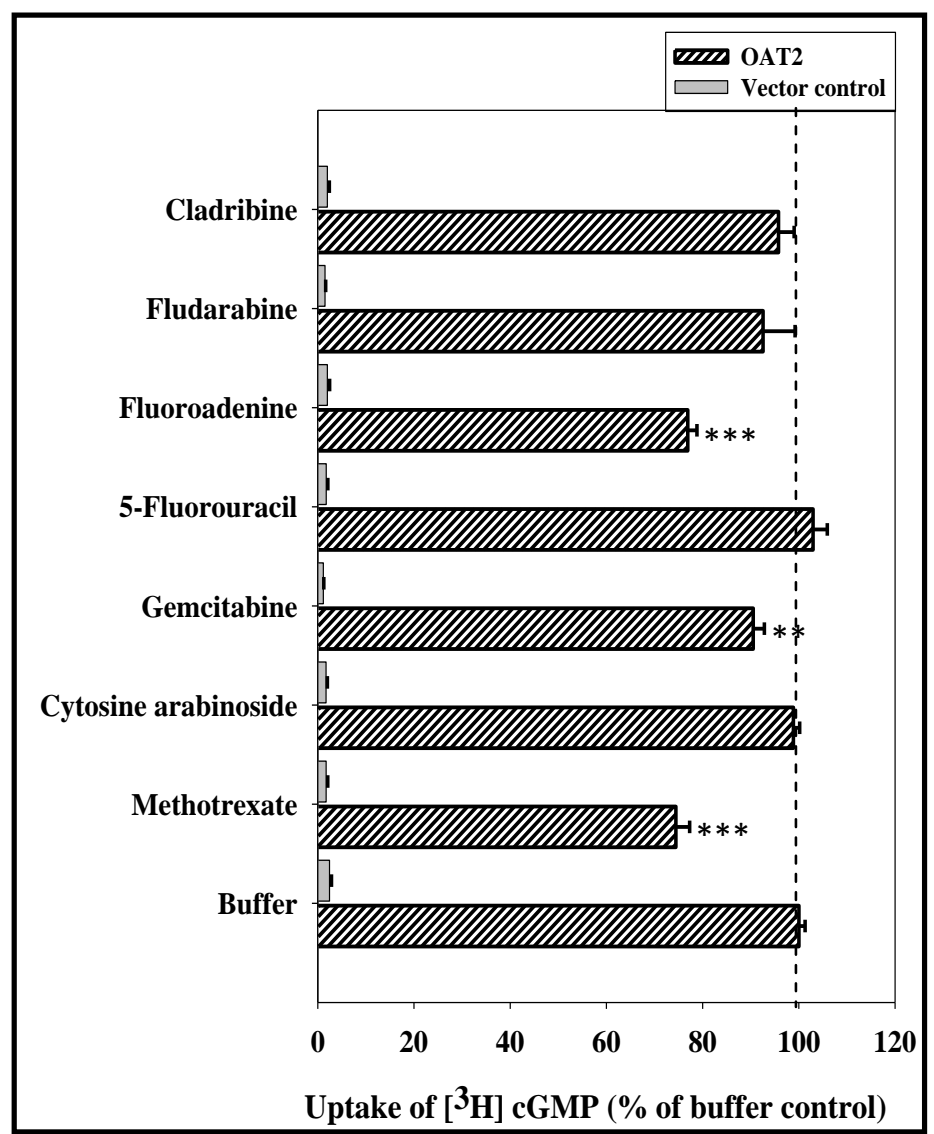

Figure 4.2 Inhibition of OAT2 mediated uptake of $\left[{ }^{3} \mathrm{H}\right]$ cGMP in the presence of antimetabolites. The uptake of $\left[{ }^{3} \mathrm{H}\right]$ cGMP was monitored in a buffer system containing $10 \mathrm{nM}\left[{ }^{3} \mathrm{H}\right]$ cyclic GMP and $990 \mathrm{nM}$ unlabeled cGMP in the presence or absence of $100 \mu \mathrm{M}$ of the antimetabolites in OAT2 transfected HEK cells and vector transfected HEK cells. Data represent the mean \pm SEM of 3 independent experiments with 3 repeats each. ** represents $p$ value $<0.01, * * *$ represents $p$ value $<0.001$

\subsubsection{Inhibition of OAT2 mediated cGMP uptake by intercalating agents and mitotic inhibitors}

Incubation of the cells with doxorubicin, mitoxantrone and vinblastine did not cause any significant effect on the OAT2 mediated uptake of $\left[{ }^{3} \mathrm{H}\right]$ cGMP whereas vincristine caused 
a marginal increase of the uptake by $5.0 \pm 1.5 \%$ whereas paclitaxel caused a strong inhibition of the uptake by $83.7 \pm 0.5 \%$ of buffer control (Fig. 4.3).

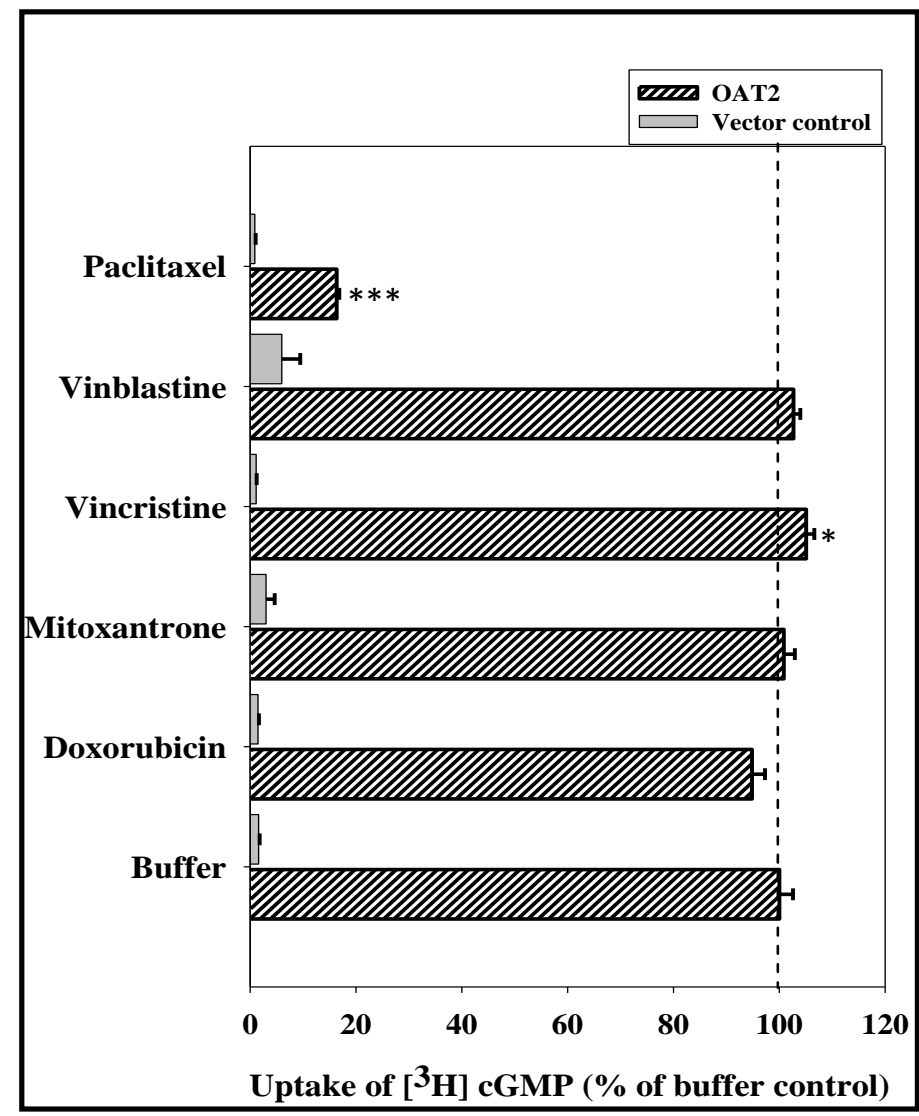

Figure 4.3 Inhibition of OAT2 mediated uptake of $\left[{ }^{3} \mathrm{H}\right]$ cGMP in the presence of intercalating agents and mitotic inhibitors. The uptake of $\left[{ }^{3} \mathrm{H}\right]$ cGMP was monitored in a buffer system containing $10 \mathrm{nM}\left[{ }^{3} \mathrm{H}\right]$ cyclic GMP and $990 \mathrm{nM}$ unlabeled cGMP in the presence or absence of $100 \mu \mathrm{M}$ of the intercalating agents and mitotic inhibitors in OAT2 transfected HEK cells and vector transfected HEK cells. Data represent the mean \pm SEM of 3 independent experiments with 3 repeats each. * represents $p$ value $<0.05, * * *$ represents $p$ value $<0.001$.

\subsubsection{Inhibition of OAT2 mediated cGMP uptake by topoisomerase inhibitors and compounds targeting hormone receptors}

The topoisomerase inhibitors irinotecan and etoposide reduced the uptake by $87.8 \pm 0.4$ $\%$ and $32 \pm 1.2 \%$ respectively. Tamoxifen caused an inhibition of OAT2 mediated 
uptake of cGMP by $12.7 \pm 2.2 \%$ of buffer control while the compounds prednisone and clodronic acid did not cause any significant effect (Fig. 4.4).

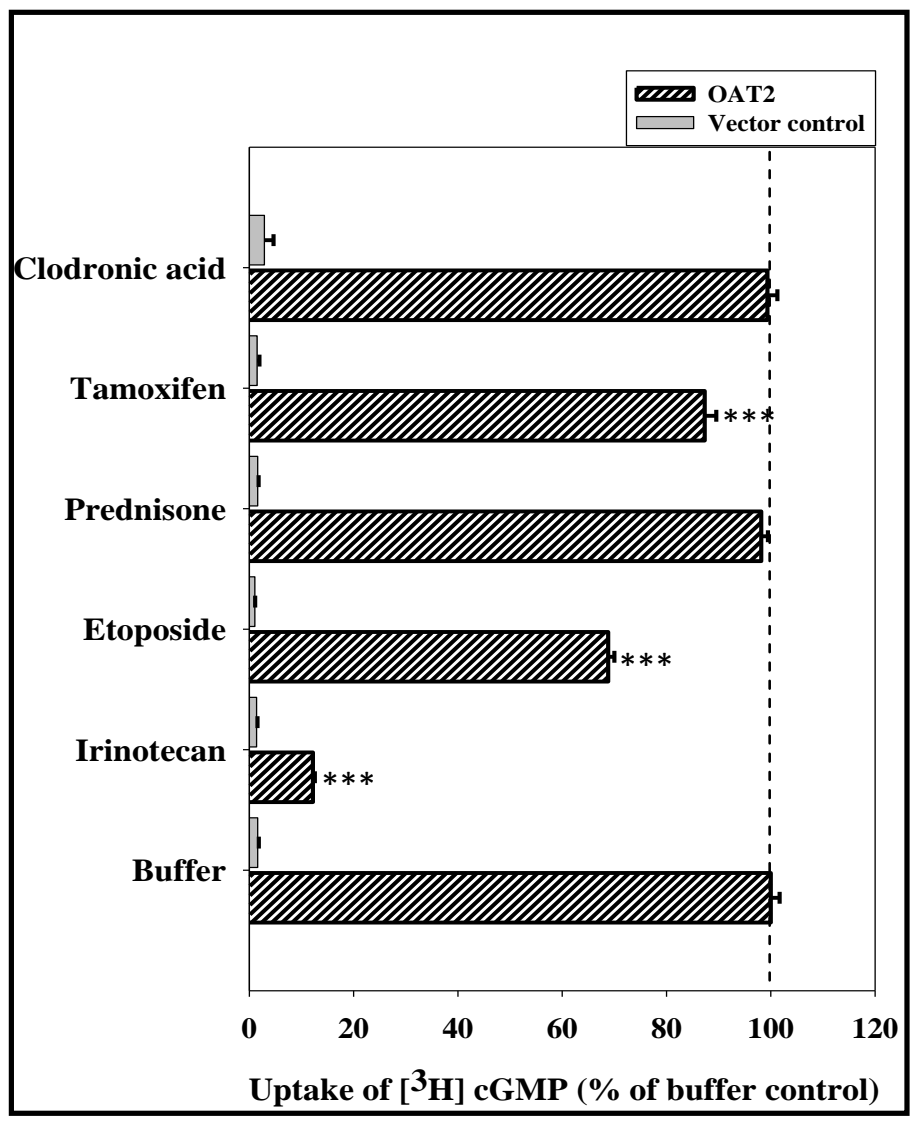

Figure 4.4 Inhibition of OAT2 mediated uptake of $\left[{ }^{3} \mathrm{H}\right]$ cGMP in the presence of topoisomerase inhibitors and compounds acting on hormone receptor targets. The uptake of $\left[{ }^{3} \mathrm{H}\right]$ cGMP was monitored in a buffer system containing $10 \mathrm{nM}\left[{ }^{3} \mathrm{H}\right]$ cyclic GMP and $990 \mathrm{nM}$ unlabeled cGMP in the presence or absence of $100 \mu \mathrm{M}$ of topoisomerase inhibitors and hormone receptor targeters in OAT2 transfected HEK cells and vector transfected HEK cells. Data represent the mean \pm SEM of 3 independent experiments with 3 repeats of each sample. $* * *$ represents $p$ value $<0.001$. 


\subsubsection{Concentration dependent inhibition of antineoplastic compounds on OAT2 mediated $\left[{ }^{3} \mathbf{H}\right]$ cGMP uptake}

In order to determine the affinity of OAT2 for selected antineoplastic drugs, which inhibited uptake to less than $40 \%$ of buffer control, we employed the Dixon plot analysis. Measurement of the uptake of $\left[{ }^{3} \mathrm{H}\right]$ labeled cGMP at $1 \mu \mathrm{M}$ and $10 \mu \mathrm{M}$ cGMP was performed in the presence of increasing concentrations of the corresponding compound.

\subsubsection{Concentration dependent inhibition of OAT2 mediated [ $\left.{ }^{3} \mathrm{H}\right]$ cGMP uptake by bendamustine}

For measuring the affinity of OAT2 for bendamustine, the uptake was measured in the presence of increasing concentrations of bendamustine in the range of $0-130 \mu \mathrm{M}$. Plots of the reciprocal of velocity of uptake on $\mathrm{Y}$ axis over the concentration of the antineoplastic compound on X axis revealed the $K_{i}$ value of OAT2 for bendamustine to be $43.3 \pm 4.33 \mu \mathrm{M}$ (Fig. 4.5).

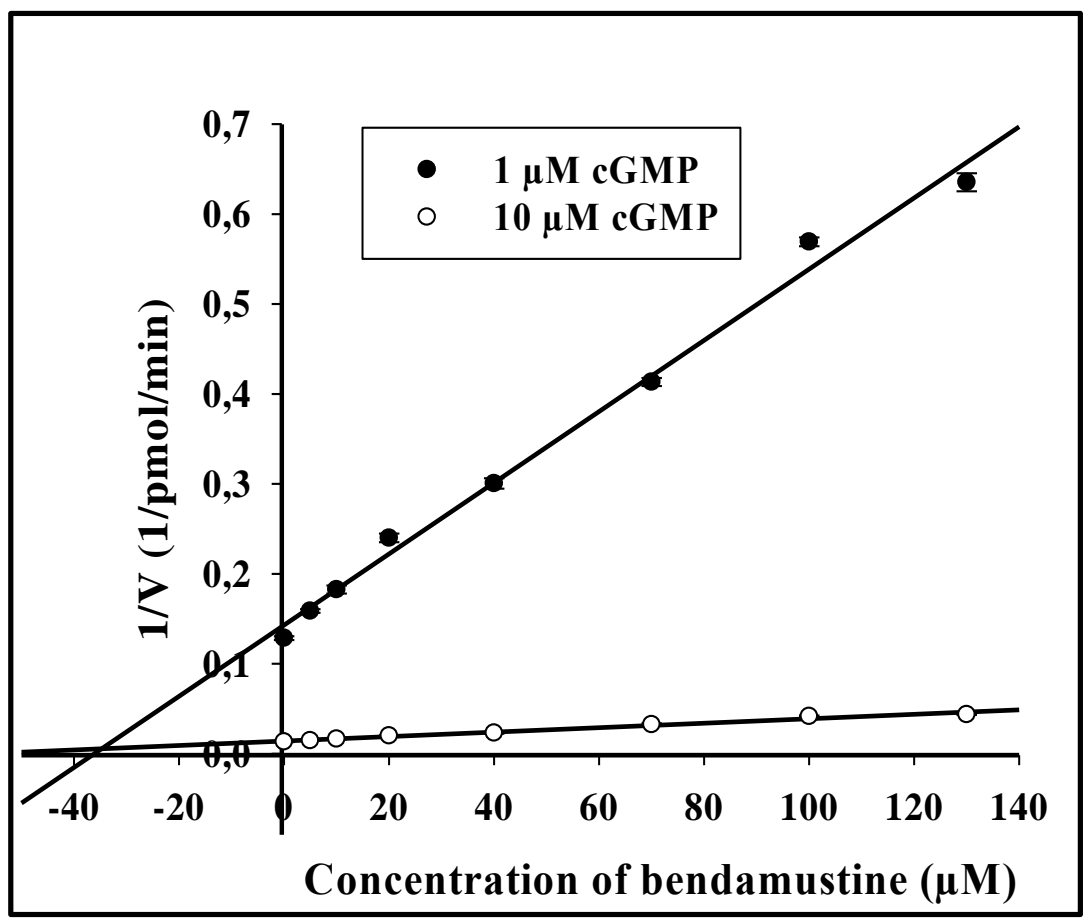


Figure 4.5 Determination of $K_{i}$ value of OAT2 for bendamustine by Dixon Plot analysis. The uptake of $\left[{ }^{3} \mathrm{H}\right]$ cyclic GMP was monitored in a buffer system containing $10 \mathrm{nM}$ $\left[{ }^{3} \mathrm{H}\right] \mathrm{cGMP}$ and $990 \mathrm{nM}$ or $9.99 \mu \mathrm{M}$ cGMP in the presence of $0,5 \mu \mathrm{M}, 10 \mu \mathrm{M}, 20 \mu \mathrm{M}, 40 \mu \mathrm{M}, 70$ $\mu \mathrm{M}, 100 \mu \mathrm{M}$, and $130 \mu \mathrm{M}$ bendamustine. Data are means \pm SEMs of 3 independent experiments with three repeats of each sample. Figure is representative and the $K_{i}$ value was calculated from three individual experiments.

\subsubsection{Concentration dependent inhibition of OAT2 mediated [ $\left.{ }^{3} \mathrm{H}\right]$ cGMP uptake by irinotecan}

The affinity of OAT2 for irinotecan was calculated from experiments wherein the uptake was measured in the presence of increasing concentrations of irinotecan in the range of 0 $-130 \mu \mathrm{M}$. Plots of the reciprocal of velocity of uptake on $\mathrm{Y}$ axis over the concentration of the antineoplastic compound on X axis revealed $K_{i}$ value of OAT2 for irinotecan to be $26.4 \pm 2.34 \mu \mathrm{M}$ (Fig. 4.6)

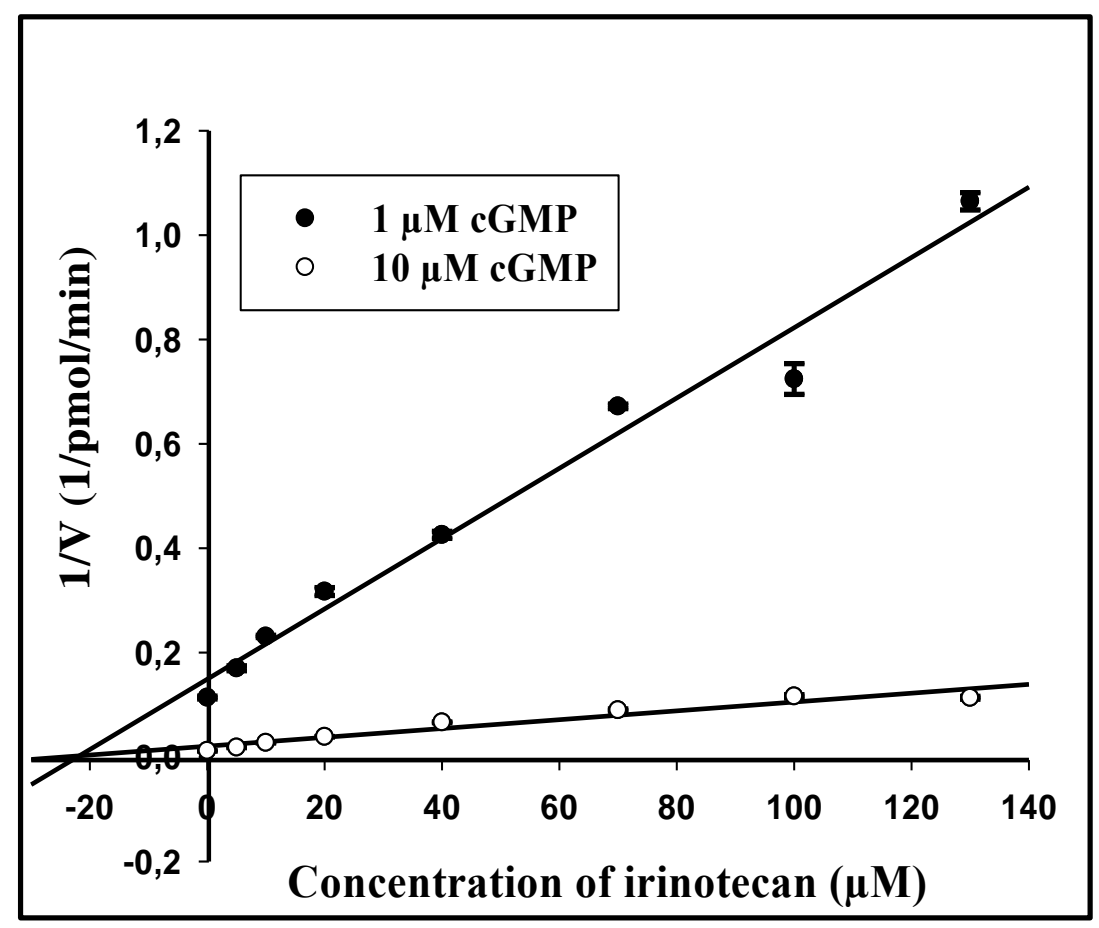

Figure 4.6 Determination of $K_{i}$ value of OAT2 for irinotecan by Dixon Plot analysis. The uptake of $\left[{ }^{3} \mathrm{H}\right]$ cyclic GMP was monitored in a buffer system containing $10 \mathrm{nM}\left[{ }^{3} \mathrm{H}\right]$ cGMP 
and $990 \mathrm{nM}$ or $9.99 \mu \mathrm{M}$ cGMP in the presence of $0,5 \mu \mathrm{M}, 10 \mu \mathrm{M}, 20 \mu \mathrm{M}, 40 \mu \mathrm{M}, 70 \mu \mathrm{M}, 100$ $\mu \mathrm{M}$, and $130 \mu \mathrm{M}$ irinotecan. Data are means \pm SEMs of 3 independent experiments with three repeats of each sample. Figure is representative and the $K_{i}$ value was calculated from three individual experiments.

\subsubsection{Concentration dependent inhibition of OAT2 mediated $\left[{ }^{3} \mathrm{H}\right]$ cGMP uptake by paclitaxel}

The affinity of OAT2 for paclitaxel was calculated from experiments wherein the uptake was measured in the presence of increasing concentrations of paclitaxel in the range of 0 $-20 \mu \mathrm{M}$. Plots of the reciprocal of velocity of uptake on $\mathrm{Y}$ axis over the concentration of the antineoplastic compound on X axis revealed $K_{i}$ value of OAT2 for paclitaxel to be $10.4 \pm 0.45 \mu \mathrm{M}$ (Fig. 4.7).

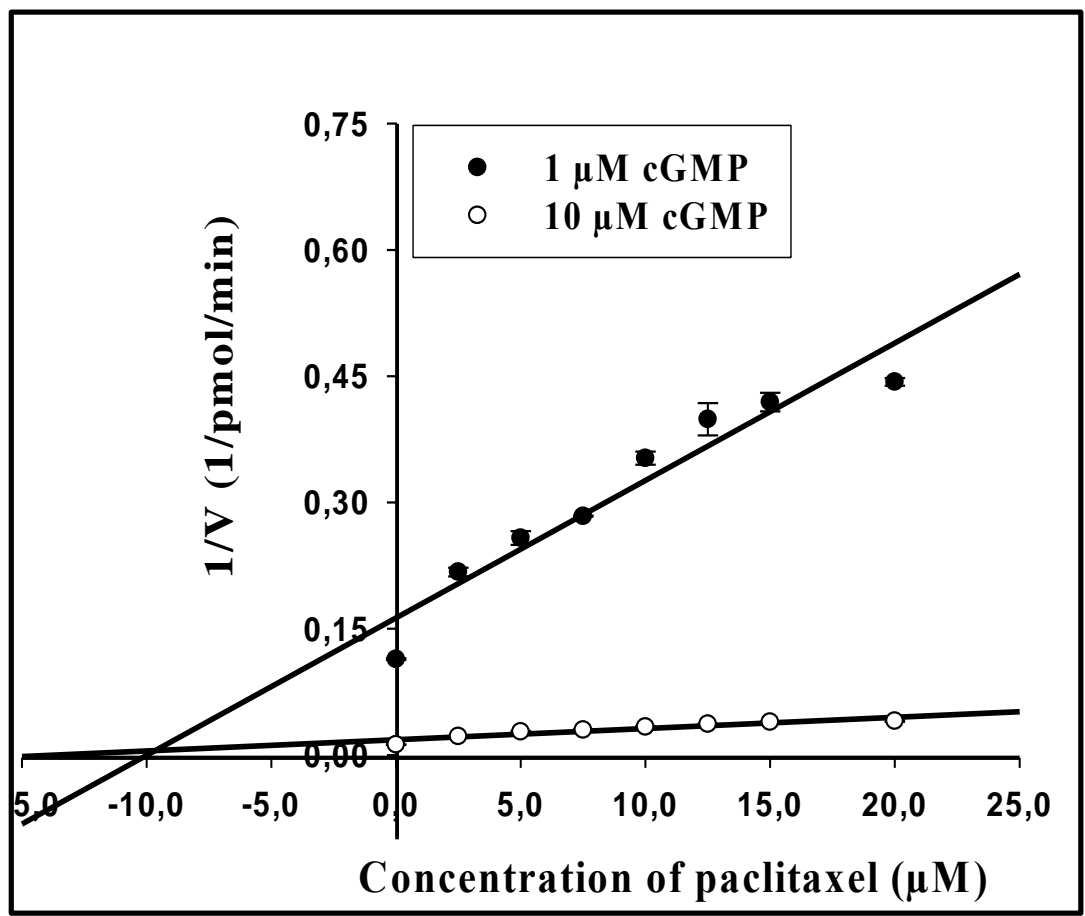

Figure 4.7 Determination of $K_{i}$ value of OAT2 for paclitaxel by Dixon - Plot analysis. The uptake of $\left[{ }^{3} \mathrm{H}\right]$ cyclic GMP was monitored in a buffer system containing $10 \mathrm{nM}$ $\left[{ }^{3} \mathrm{H}\right] \mathrm{cGMP}$ and $990 \mathrm{nM}$ or $9.99 \mu \mathrm{M}$ cGMP in the presence of $0,2.5 \mu \mathrm{M}, 5 \mu \mathrm{M}, 7.5 \mu \mathrm{M}, 10 \mu \mathrm{M}$, $12.5 \mu \mathrm{M}, 15 \mu \mathrm{M}$, and $20 \mu \mathrm{M}$ paclitaxel from 0 to $20 \mu \mathrm{M}$. Data are means \pm SEMs of 3 
independent experiments with three repeats of each sample. Figure is representative and the $K_{i}$ value was calculated from three individual experiments.

\subsubsection{Evaluation of OAT2 mediated uptake of bendamustine by apoptosis}

To find out, indirectly, whether bendamustine is transported by OAT2, an enzymatic assay measuring the activity of caspase- 3 enzyme, a key enzyme in the cascade of apoptosis, was performed. The assay is based on the ability of the caspase- 3 enzyme in cell lysates to cleave the substrate bound to a fluorescent dye, releasing the fluorophore which was then estimated. Incubation of OAT2 expressing cells with $100 \mu \mathrm{M}$ bendamustine showed an increase in the caspase- 3 activity by ca. $16 \%$ of untreated pcDNA while the activity in control cells did not change significantly. This increase in caspase-3 activity was completely diminished when the bendamustine treatment was performed in combination with $100 \mu \mathrm{M}$ probenecid, an OAT2 inhibitor (Fig. 4.8). 


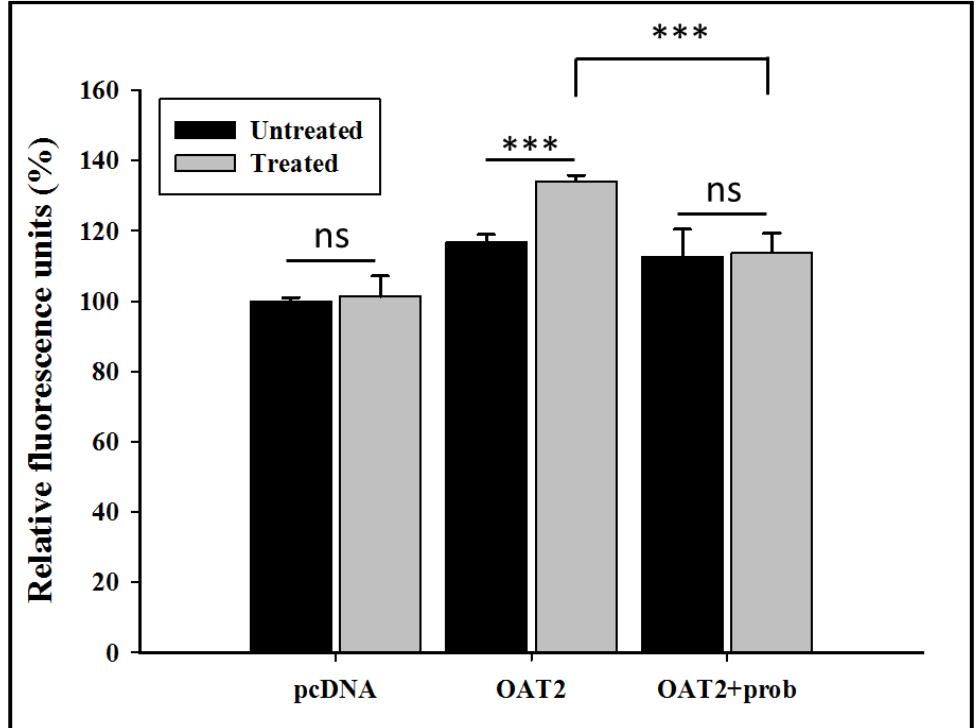

Figure 4.8 Evaluation of OAT2 mediated apoptosis. Caspase-3 activity was monitored in OAT2 expressing cells and pcDNA cells incubated with $100 \mu \mathrm{M}$ bendamustine for $12 \mathrm{~h}$ alone or in the presence of $100 \mu \mathrm{M}$ probenecid. The relative fluorescence unit values obtained in the experiment were normalized with protein levels and expressed as $\%$ of the value obtained in control pcDNA cells. Data are means \pm SEMs of two individual experiments with two technical repeats each. $* * *$ indicates $p$ value $<0.001$; ns - not significant.

\subsubsection{Evaluation of OAT2 mediated accumulation of irinotecan by HPLC analysis}

The OAT2 uptake of irinotecan was determined by HPLC analysis. A working protocol was established and standardized prior to the assay. The characteristic peaks for each compound were obtained by injections of pure substances in the same conditions of the experimental run. Standard curves were plotted for both irinotecan as well as camptothecin (internal standard) in the range of 15 pmol to 500 pmol. The results from three independent runs show that the retention times of irinotecan and camptothecin were 
ca. $5.7 \mathrm{~min}$ and $11.6 \mathrm{~min}$ respectively. Using them as reference in each experiment, uptake amount was quantified.

\subsubsection{Quantitation of OAT2 mediated uptake of irinotecan}

From the standard curve, the amount of irinotecan found in lysates of OAT2 expressing cells was approximately $86 \mathrm{pmol} / 5 \mathrm{~min}$ which was regarded as $100 \%$. Accumulation of irinotecan in mock pcDNA cells was $57.4 \% \pm 7.5 \%$ of irinotecan found in OAT2 expressing cells (Fig. 4.9). The uptake of irinotecan was strongly inhibited by $100 \mu \mathrm{M}$ cGMP to $68.6 \pm 12.2 \%$ in OAT2 expressing cells whereas the irinotecan uptake was not significantly changed in pcDNA treated with $100 \mu \mathrm{M}$ cGMP $(49.7 \% \pm 12.1 \%)$ confirming the cGMP induced reduction in the accumulation of irinotecan is specific to transport by OAT2.

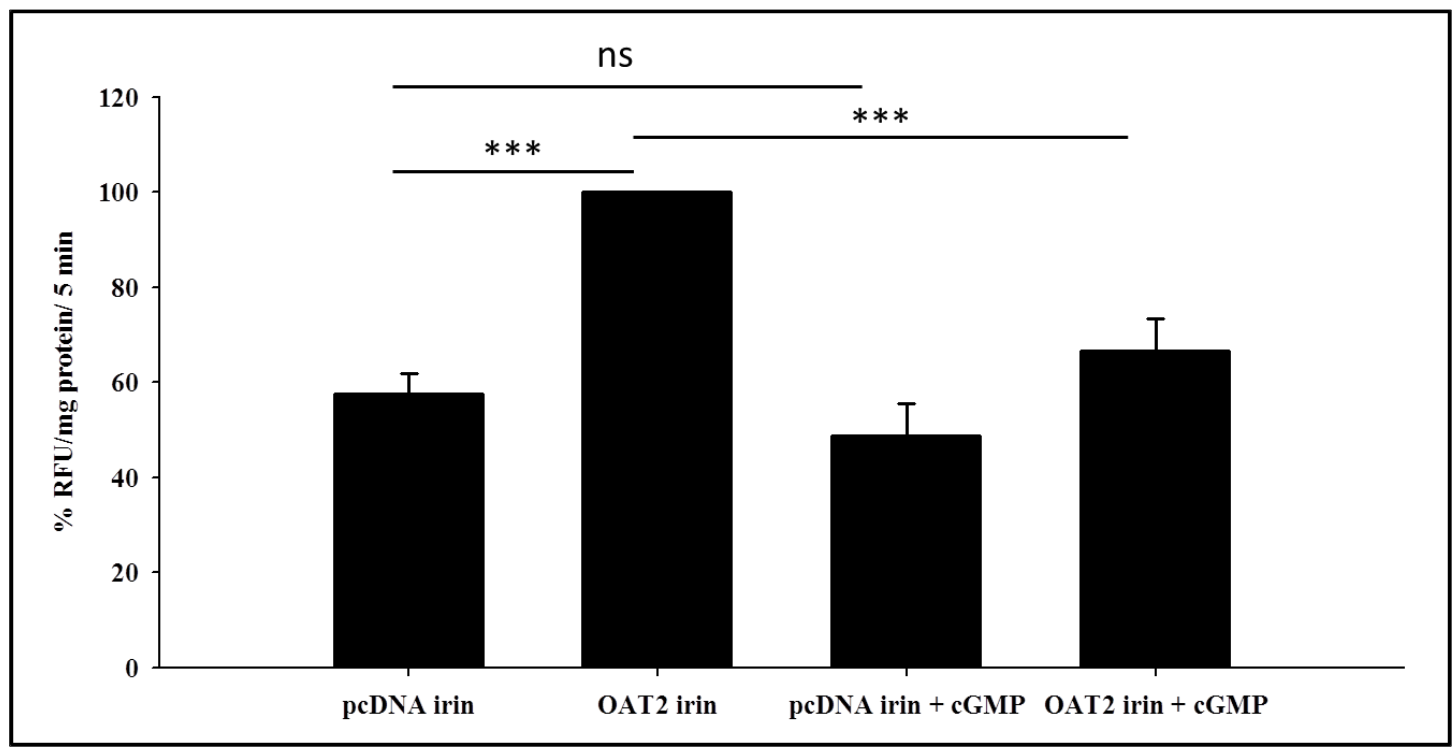

Figure 4.9 Evaluation of OAT2 mediated irinotecan uptake. Irinotecan uptake was monitored by HPLC analysis in pcDNA and OAT2 expressing cells treated with $100 \mu \mathrm{M}$ irinotecan alone or in combination with $100 \mu \mathrm{M}$ cGMP. The amount of irinotecan found was normalized with internal standard and as well to protein concentration and expressed as uptake per mg protein. Irinotecan uptake in OAT2 expressing cells treated with irinotecan alone is taken 
as $100 \%$ and the other conditions are represented as percentage of that value. Data are means \pm SEMs of three individual experiments. RFU - relative fluorescence units. *** indicates $p$ value < $0.001 ;$ ns - not significant.

\subsubsection{Time dependent OAT2 mediated uptake of irinotecan}

The amount of irinotecan in the cells was analyzed in pcDNA and OAT2 cells incubated with $100 \mu \mathrm{M}$ irinotecan for increasing periods of time. There was an increase both in the OAT2 dependent as well as nonspecific uptake into the cells, however, the OAT2 mediated uptake was far more pronounced as can be seen from the net uptake plotted against time (Fig.4.10).

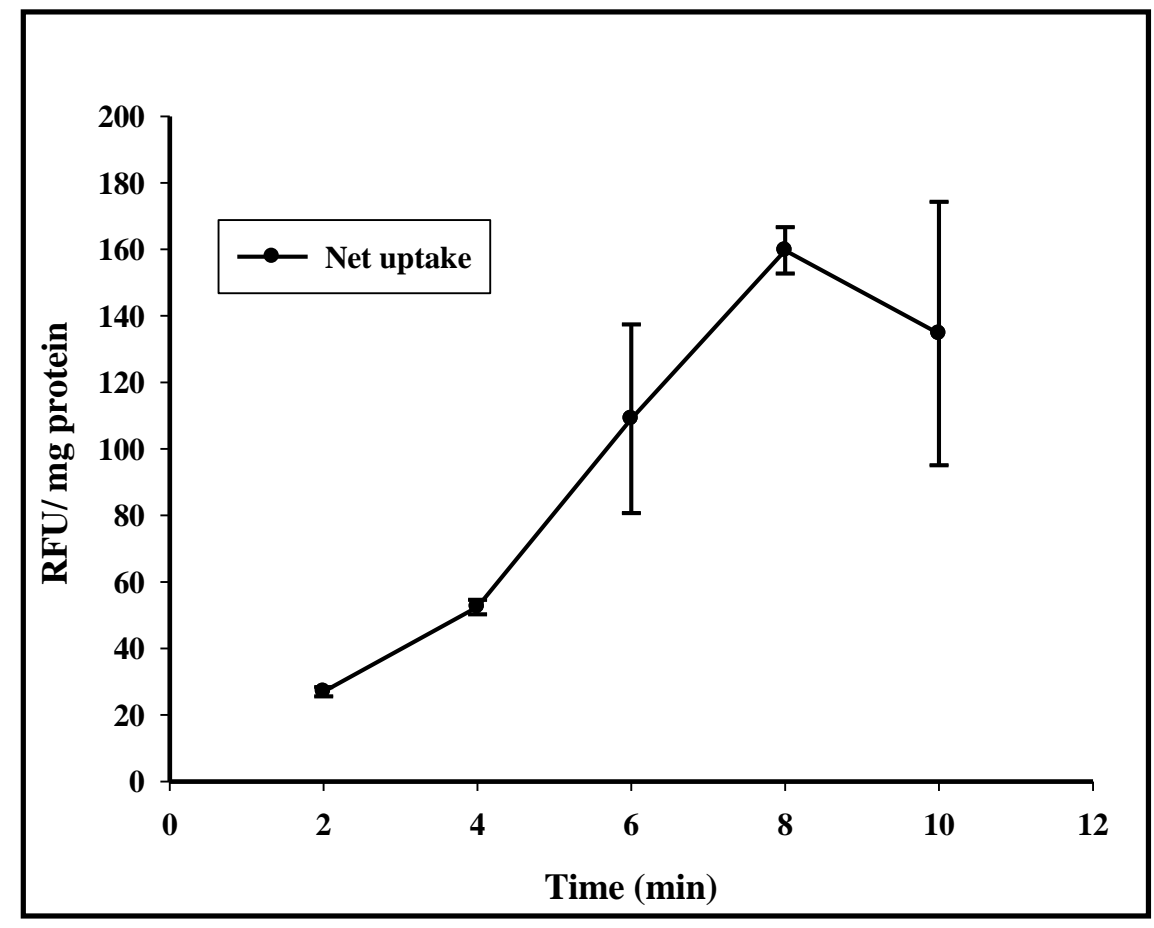

Figure 4.10 Evaluation of time dependent uptake of irinotecan. Irinotecan uptake was monitored in pcDNA and OAT2 cells after incubation with irinotecan for 2, 4, 6, 8 and 10 min. The uptake was normalized to the internal standard and the protein amount and the net uptake was calculated by subtracting the irinotecan values of pcDNA from OAT2 cells and expressed as relative fluorescence units (RFU)/ mg protein. 


\subsubsection{Concentration dependent uptake of irinotecan by pcDNA and OAT2 cells}

Accumulation of irinotecan was followed by performing HPLC analyses of lysates of cells incubated with increasing amounts of irinotecan in Hank's buffer solution. Similar to time course experiments, with increase in concentration of irinotecan in the transport buffer, an increase in the amount of irinotecan was observed in the lysates. The $K_{m}$ value was calculated to be $42.37 \pm 6.4 \mu \mathrm{M}$ from two such experiments (Fig. 4.11).

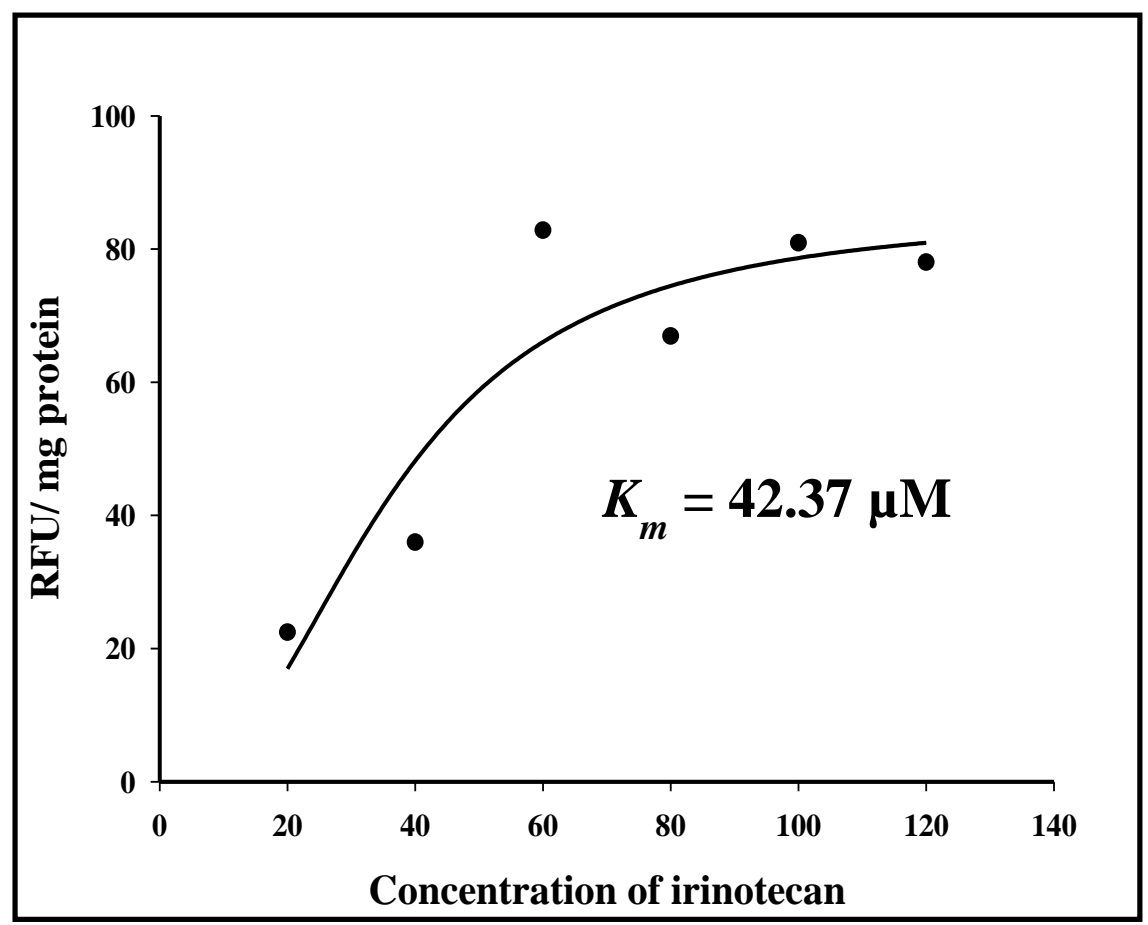

Figure 4.11 Evaluation of concentration dependent uptake of irinotecan. Irinotecan uptake was monitored in pcDNA and OAT2 cells after incubation with $20 \mu \mathrm{M}, 40 \mu \mathrm{M}, 60 \mu \mathrm{M}, 80$ $\mu \mathrm{M}, 100 \mu \mathrm{M}$, and $120 \mu \mathrm{M}$ irinotecan for $5 \mathrm{~min}$. The uptake was normalized to the internal standard and the protein amount, and the net uptake was calculated by subtracting the irinotecan values of pcDNA from OAT2 cells and expressed as relative fluorescence units (RFU)/ mg protein. Figure is representative of one of the experiments and the $K_{m}$ value was calculated from two such experiments. 
4.2. Interaction of sodium taurocholate cotransporting polypeptide (NTCP) with antineoplastic compounds

A functional characterization of NTCP cells stably transfected into HEK cells was performed prior to the interaction studies of NTCP with antineoplastic compounds.

\subsubsection{Functional characterization of NTCP}

Using estrone-3-sulfate as substrate, the transporter activity of NTCP was evaluated. Uptake experiments were performed with $\left[{ }^{3} \mathrm{H}\right]$ estrone-3-sulfate for time dependency and calculation of affinity of NTCP for estrone-3-sulfate.

\subsubsection{Time dependent uptake of $\left[{ }^{3} \mathrm{H}\right]$ estrone -3-sulfate by NTCP expressing cells}

A time course experiment was conducted with NTCP-HEK cells and vector transfected HEK cells where the uptake of $1 \mu \mathrm{M}$ estrone-3-sulfate was measured over a period of 30 min. From the plot, 3 min was chosen as the time for further experiments as this was in the linear phase of curve (Fig. 4.12).

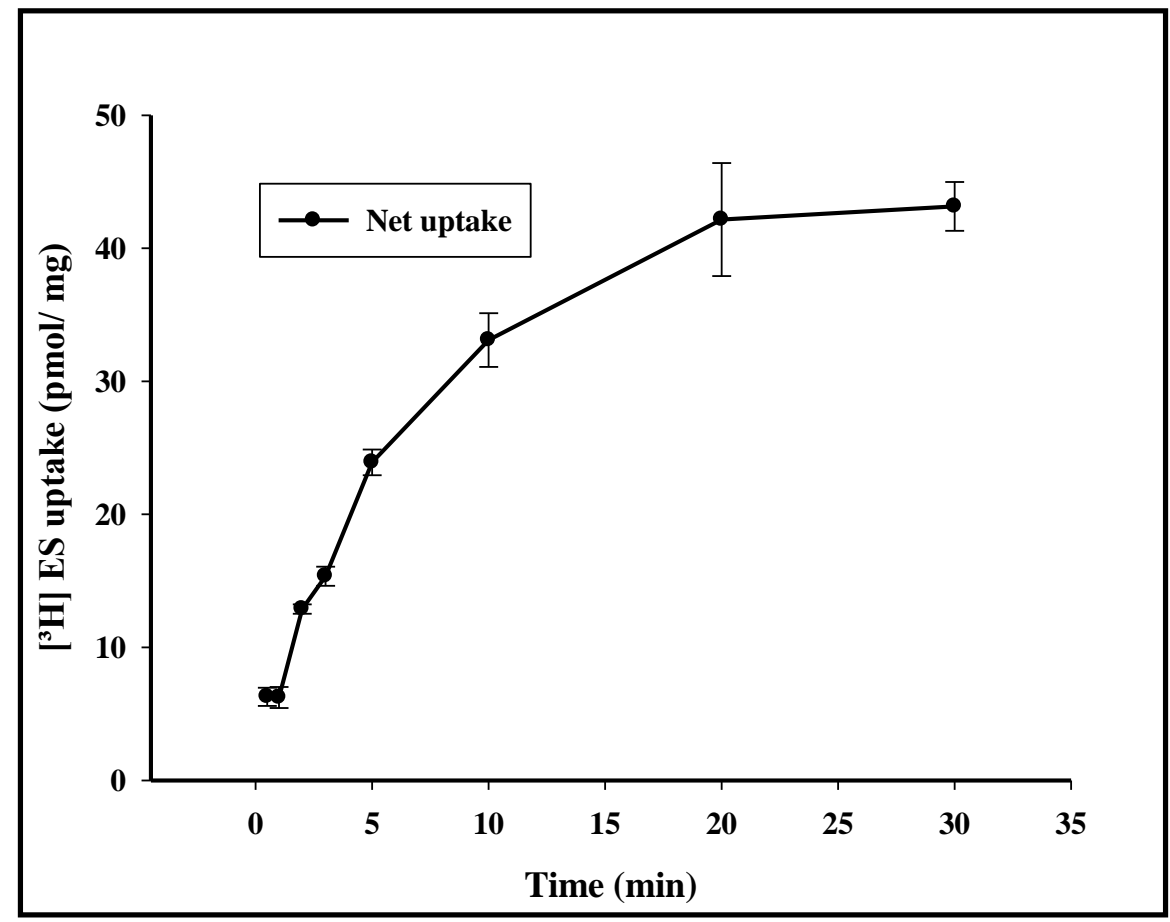


Figure 4.12 Time dependent uptake of NTCP mediated estrone-3-sulfate. The uptake

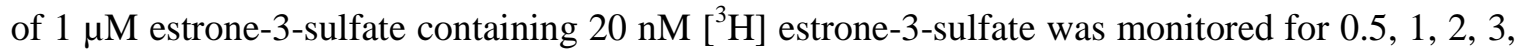
5, 10, 20, and 30 min in NTCP expressing HEK cells and vector transfected HEK cells. Net uptake was calculated by subtracting the uptake values of control cells from NTCP expressing cells. Data is the means \pm SEMs of triplicates obtained from three identical experiments and expressed as $\mathrm{pmol} / \mathrm{mg}$ of protein.

\subsubsection{Concentration dependent uptake of $\left[{ }^{3} \mathrm{H}\right]$ estrone-3-sulfate by NTCP expressing cells}

The affinity of NTCP for estrone-3-sulfate was determined by calculating the MichaelisMenten constant $\left(K_{m}\right)$. Uptake experiments in buffer containing $20 \mu \mathrm{M}$ labeled $\left[{ }^{3} \mathrm{H}\right]$ estrone-3-sulfate and increasing concentrations of unlabeled estrone sulfate for $3 \mathrm{~min}$ revealed the $K_{m}$ value to be $217.4 \pm 12.3 \mu \mathrm{M}$ (Fig. 4.13).

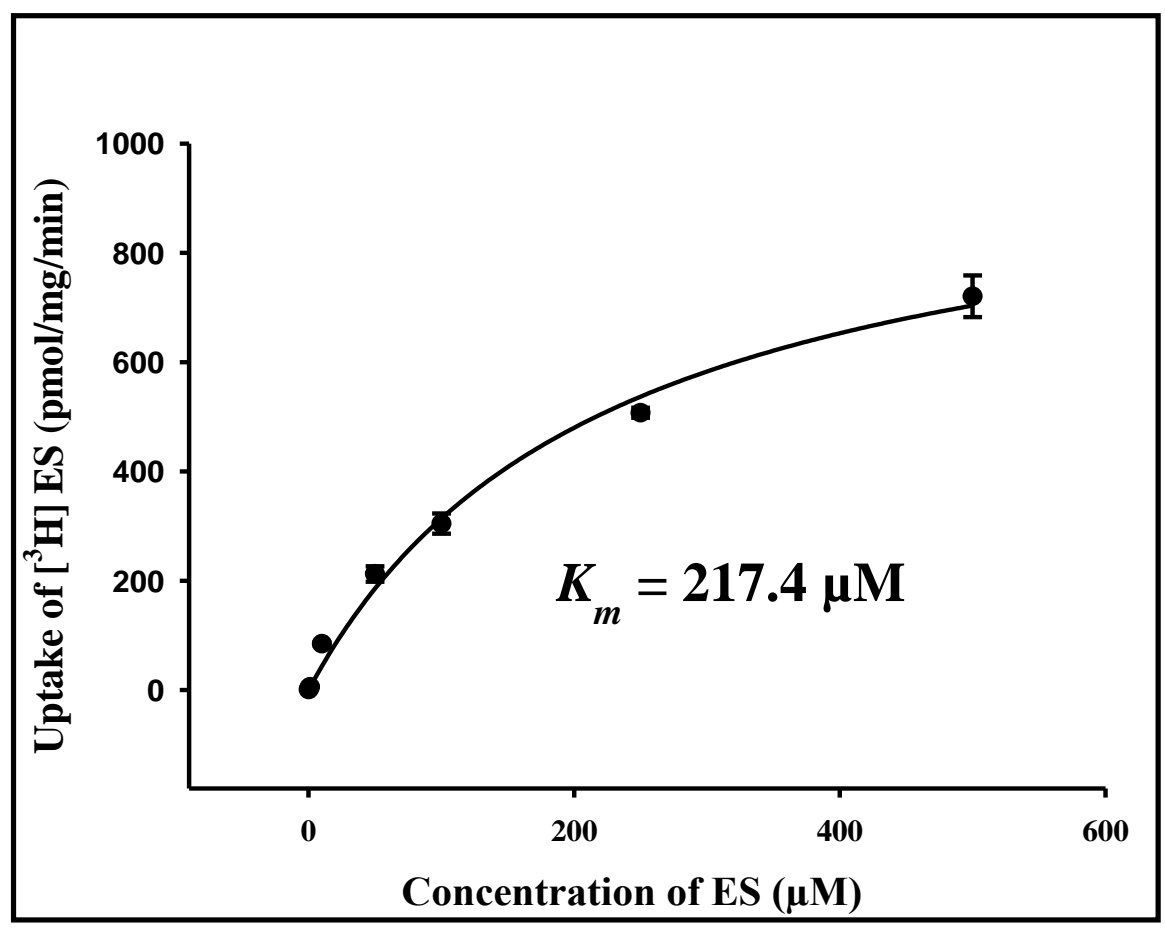

Figure 4.13 Concentration dependent uptake of estrone-3-sulfate by NTCP. The uptake of $\left[{ }^{3} \mathrm{H}\right]$ estrone-3-sulfate was monitored in a buffer system containing $20 \mathrm{nM}\left[{ }^{3} \mathrm{H}\right]$ estrone3 -sulfate and unlabeled estrone-3 sulfate amounting to a final concentration of $0.1 \mu \mathrm{M}, 0.5 \mu \mathrm{M}, 1$ 
$\mu \mathrm{M}, 10 \mu \mathrm{M}, 50 \mu \mathrm{M}, 100 \mu \mathrm{M}, 250 \mu \mathrm{M}$, and $500 \mu \mathrm{M}$ for $3 \mathrm{~min}$. Net uptake was calculated by subtracting the uptake of $\left[{ }^{3} \mathrm{H}\right]$ estrone-3-sulfate in vector cells from the uptake in NTCP-HEK cells. Data are represented as means \pm SEMs of triplicates. The $K_{m}$ value was calculated from three such experiments. The data is expressed as $\mathrm{pmol} / \mathrm{min} / \mathrm{mg}$ of protein.

\subsubsection{Inhibition of NTCP mediated estrone-3-sulfate uptake by antineoplastic compounds}

The uptake of $\left[{ }^{3} \mathrm{H}\right]$ estrone-3-sulfate was measured in the presence of $100 \mu \mathrm{M}$ of antineoplastic compounds for $3 \mathrm{~min}$. Uptake values are represented as $\%$ of the uptake of substrates in the absence of any antineoplastic compound (buffer control) which was determined for NTCP to be $212.2 \pm 6.2 \mathrm{pmol}$ estrone-3-sulfate/ $3 \mathrm{~min}$. Only a few significant changes in the uptake of $\left[{ }^{3} \mathrm{H}\right]$ labeled estrone-3-sulfate by antineoplastic drugs were observed compared to buffer control.

\subsubsection{Inhibition of NTCP mediated estrone-3-sulfate uptake by alkylating agents}

The alkylating agents, chlorambucil and busulfan reduced significantly the uptake of estrone-3-sulfate by $27.8 \pm 2.5 \%$ and $10.2 \pm 1.8 \%$, respectively, whereas an increase in the uptake was observed with bendamustine by $20.9 \pm 3.9 \%$ of buffer control. No significant interactions were observed with the other alkylating agents melphalan, cyclophosphamide, trofosfamide, ifosfamide, treosulfan, and thioTEPA (Fig. 4.14). 


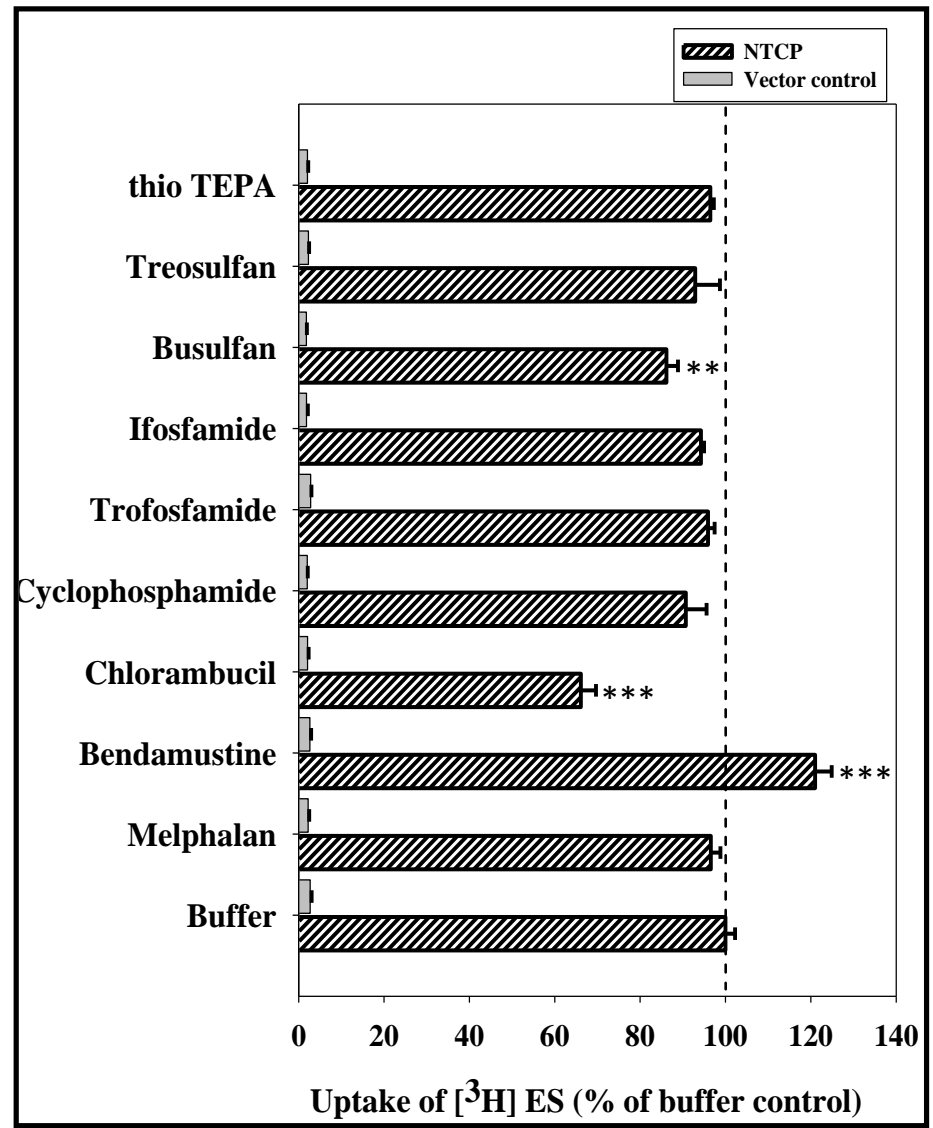

Figure 4.14. Interaction of NTCP with alkylating agents. The uptake of $\left[{ }^{3} \mathrm{H}\right]$ estrone-3sulfate was monitored in a buffer system containing $20 \mathrm{nM}\left[{ }^{3} \mathrm{H}\right]$ estrone-3-sulfate and $19.98 \mu \mathrm{M}$ estrone-3-sulfate in the presence or absence of $100 \mu \mathrm{M}$ of the respective alkylating compound in NTCP transfected HEK cells and vector transfected HEK cells. Data are means \pm SEMs of three individual experiments with three repeats each. ${ }^{* *}$ represents $p$ value $<0.01, * * *$ represents $p$ value $<0.001$

\subsubsection{Inhibition of NTCP mediated estrone-3-sulfate uptake by antimetabolites}

None of the antimetabolites tested were able to cause any significant interaction in the uptake of NTCP mediated $\left[{ }^{3} \mathrm{H}\right]$ estrone-3-sulfate (Fig. 4.15). 


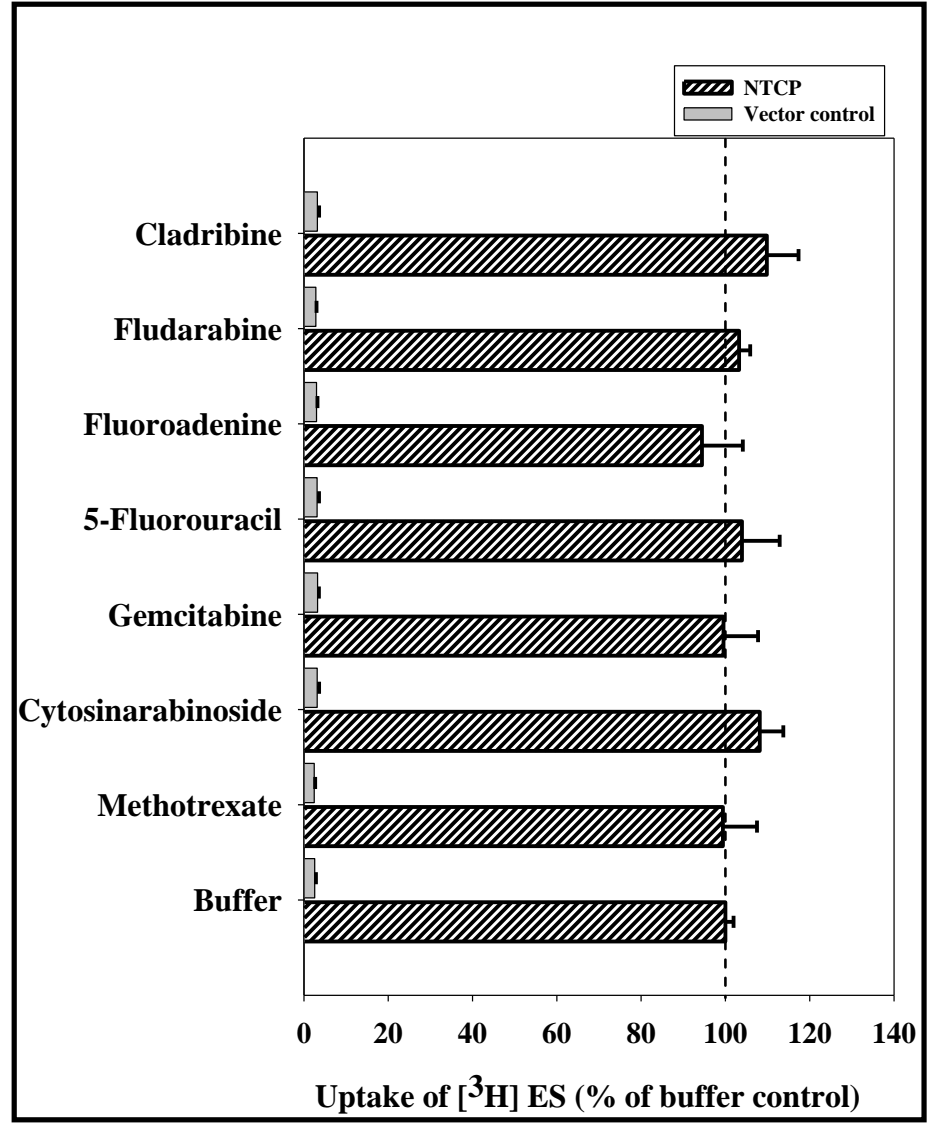

Figure 4.15. Interaction of NTCP with antimetabolites. The uptake of $\left[{ }^{3} \mathrm{H}\right]$ estrone-3sulfate was monitored in a buffer system containing $20 \mathrm{nM}\left[{ }^{3} \mathrm{H}\right]$ estrone-3-sulfate and $19.98 \mu \mathrm{M}$ estrone-3-sulfate in the presence or absence of $100 \mu \mathrm{M}$ of the respective antimetabolite in NTCP transfected HEK cells and vector transfected HEK cells. Data are means \pm SEMs of three individual experiments with three repeats each.

\subsubsection{Inhibition of NTCP mediated estrone-3-sulfate uptake by intercalating agents and mitotic inhibitors}

Among the intercalating agents, mitoxantrone significantly reduced the uptake of NTCP mediated estrone-3-sulfate by $10.6 \pm 2.4 \%$ whereas doxorubicin did not alter the uptake. Among the mitotic inhibitors, vincristine and paclitaxel caused an inhibition of uptake by $13.7 \pm 3 \%$ and $53.3 \pm 1.9 \%$ of buffer control, respectively. The other mitotic inhibitor tested, vinblastine, did not cause any significant change in the uptake (Fig. 4.16). 


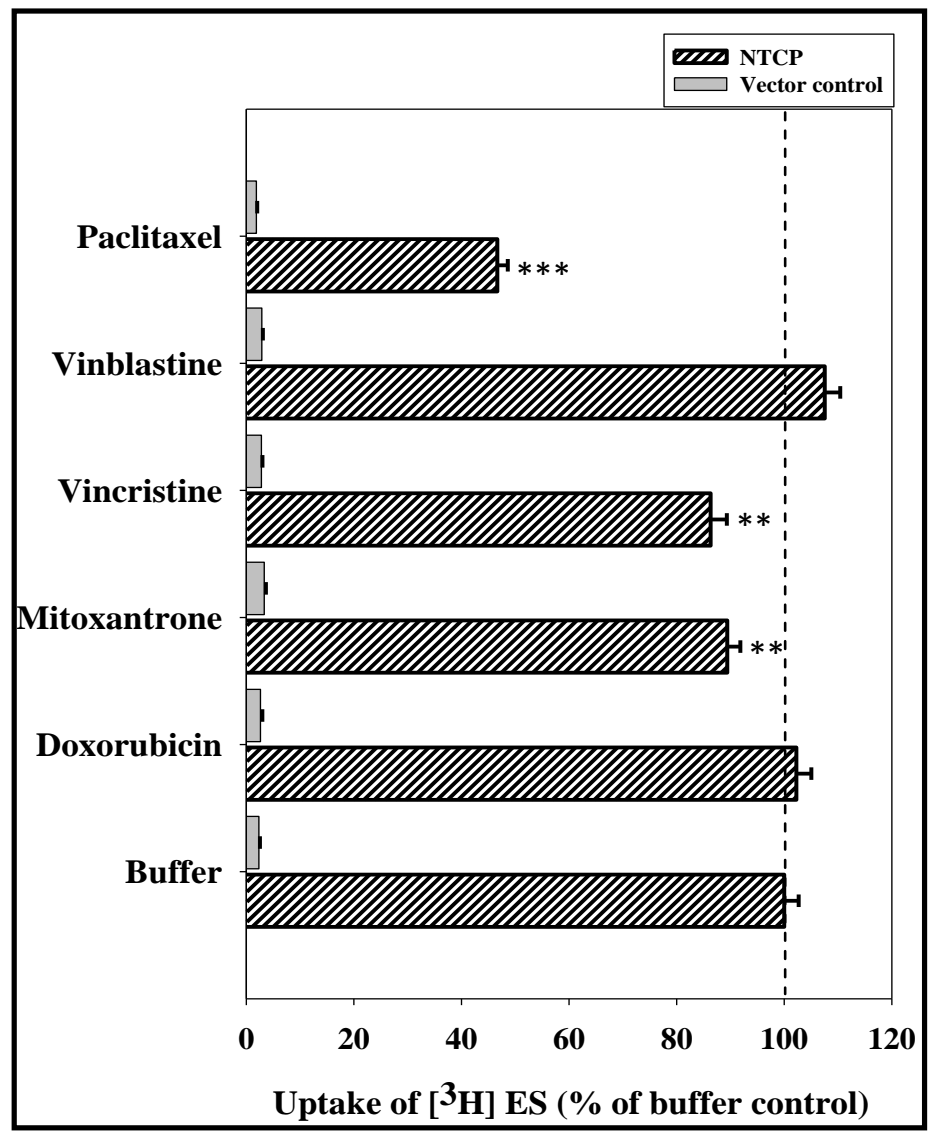

Figure 4.16. Interaction of NTCP with intercalating agents and mitotic inhibitors. The uptake of $\left[{ }^{3} \mathrm{H}\right]$ estrone-3-sulfate was monitored in a buffer system containing $20 \mathrm{nM}\left[{ }^{3} \mathrm{H}\right]$ estrone-3-sulfate and $19.98 \mu \mathrm{M}$ estrone-3-sulfate in the presence or absence of $100 \mu \mathrm{M}$ of the respective compound in NTCP transfected HEK cells and vector transfected HEK cells. Data are means \pm SEMs of three individual experiments with three repeats each. $* *$ represents $p$ value $<$ $0.01, * * *$ represents $p$ value $<0.001$ 


\subsubsection{Inhibition of NTCP mediated estrone-3-sulfate uptake by topoisomerase inhibitors and compounds targeting hormone receptors}

None of the topoisomerase inhibitors or the antineoplastic drugs targeting hormone receptors caused any significant interaction to the uptake of estrone-3-sulfate by NTCPHEK cells (Fig. 4.17).

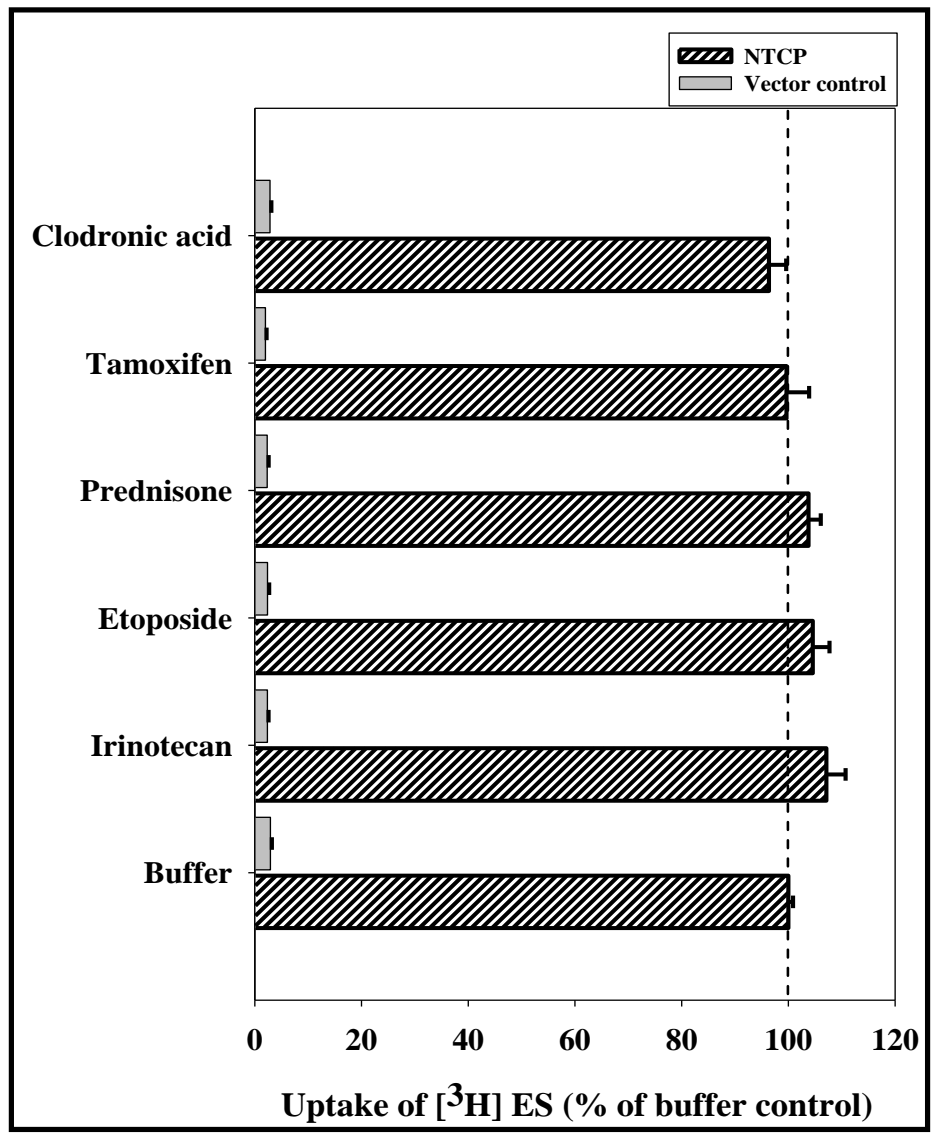

Figure 4.17. Interaction of NTCP with topoisomerase inhibitors and hormone receptor targeters. The uptake of $\left[{ }^{3} \mathrm{H}\right]$ estrone-3-sulfate was monitored in a buffer system containing $20 \mathrm{nM}\left[{ }^{3} \mathrm{H}\right]$ estrone-3-sulfate and $19.98 \mu \mathrm{M}$ estrone-3-sulfate in the presence or absence of $100 \mu \mathrm{M}$ of the respective compound in NTCP transfected HEK cells and vector transfected HEK cells. Data are means \pm SEMs of three individual experiments with three repeats each. 


\subsection{Interaction of organic anion transporting polypeptide 1B1 (OATP1B1) with antineoplastic compounds}

Functionally characterized HEK cells stably expressing OATP1B1 were obtained from Dr. Saskia Flörl, PortaCellTec GmbH. Estrone-3-sulfate was used as the substrate for the study of transporter activity of OATP1B1. From initial experiments, 5 min was chosen as the time of uptake for further experiments and the $K_{m}$ value was calculated to be $0.23 \mu \mathrm{M}$. So, the inhibition studies were performed with the uptake time of 5 min and the substrate concentration of $0.23 \mu \mathrm{M}$.

\subsubsection{Inhibition of OATP1B1 mediated estrone sulfate uptake by antineoplastic agents}

The uptake of $\left[{ }^{3} \mathrm{H}\right]$ estrone-3-sulfate was monitored in the presence of $100 \mu \mathrm{M}$ antineoplastic compounds in OATP1B1 expressing cells and vector transfected cells. Uptake values are represented as \% of the uptake of substrates in the absence of any antineoplastic compound which was determined for OATP1B1 to be $118.2 \pm 6.5 \mathrm{pmol}$ estrone 3- sulfate/ 5 min. The absolute uptake value without drugs in each individual experiment was regarded as $100 \%$ and uptake under all other conditions is represented as percentage of this value. Significant changes were observed in the interaction studies with many of the antineoplastic compounds.

\subsubsection{Inhibition of OATP1B1 mediated estrone-3-sulfate uptake by alkylating agents}

Among the alkylating agents, a weak but significant stimulation of OATP1B1 mediated uptake of $\left[{ }^{3} \mathrm{H}\right]$ estrone-3-sulfate was observed in cells incubated with chlorambucil by $18.8 \pm 2.4 \%$, cyclophosphamide by $5.6 \pm 0.98 \%$, trofosfamide by $13.1 \pm 1.2 \%$, 
ifosfamide by $7.4 \pm 1.9 \%$ and thio TEPA by $11.9 \pm 0.59 \%$. Any inhibitory effect of alkylating agents on OATP1B1 mediated uptake was not observed (Fig. 4.18)

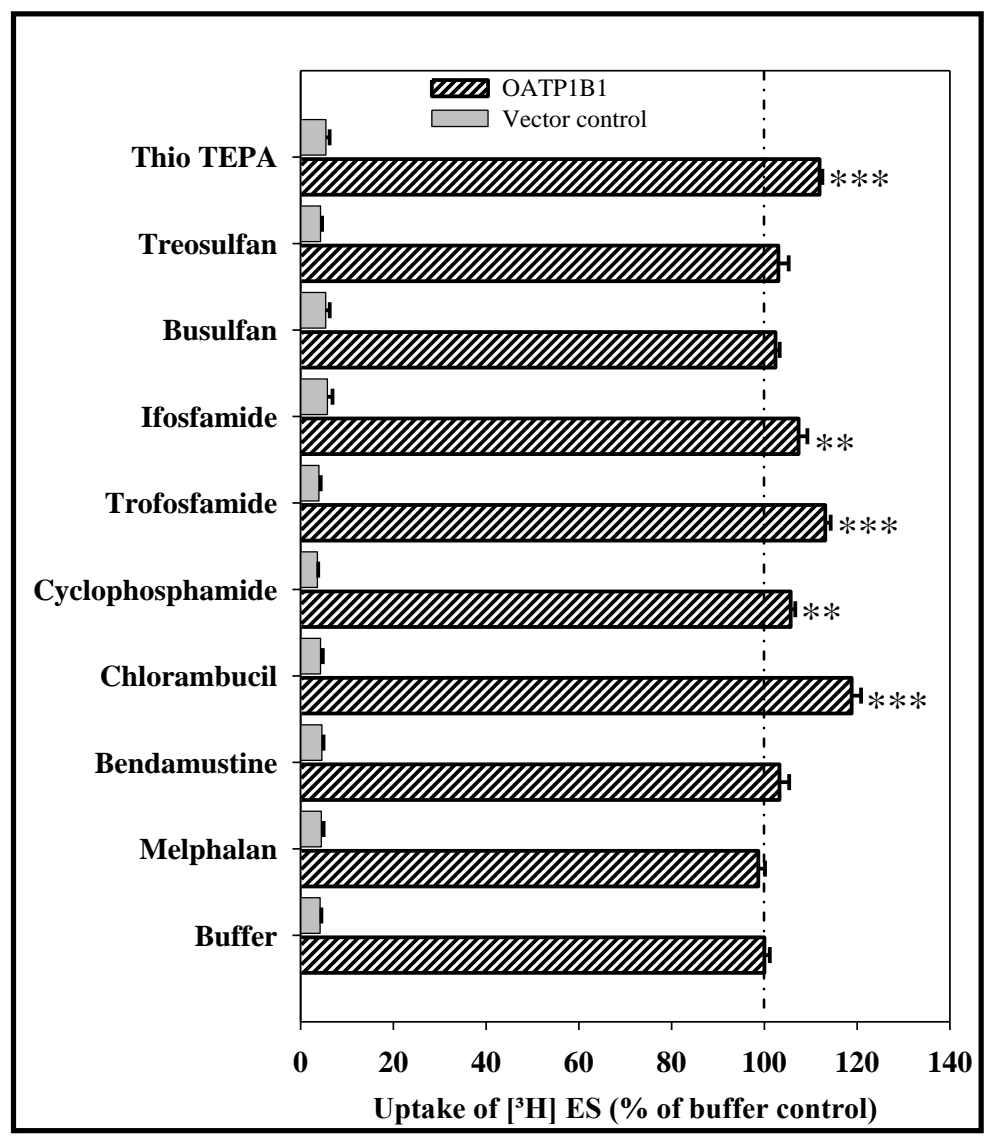

Figure 4.18 Inhibition of OATP1B1 mediated estrone-3-sulfate uptake by alkylating agents. The uptake of $\left[{ }^{3} \mathrm{H}\right]$ estrone-3-sulfate was followed in the presence of $100 \mu \mathrm{M}$ of alkylating agents. Data is represented as percentage of uptake observed in the absence of any compounds and are means \pm SEM of three individual experiments with three repeats each. * represents $p$ value $<0.05^{* *}$ represents $p$ value $<0.01$, *** represents $p$ value $<0.001$.

\subsubsection{Inhibition of OATP1B1 mediated estrone-3-sulfate uptake by antimetabolites}

Among antimetabolites, cladribine alone caused a significant change in the uptake of estrone-3-sulfate by OATP1B1; it stimulated the uptake by $15.9 \pm 3.8 \%$ of buffer 
control. None of the remaining antimetabolites caused any effect on the OATP1B1 mediated uptake (Fig. 4.19).

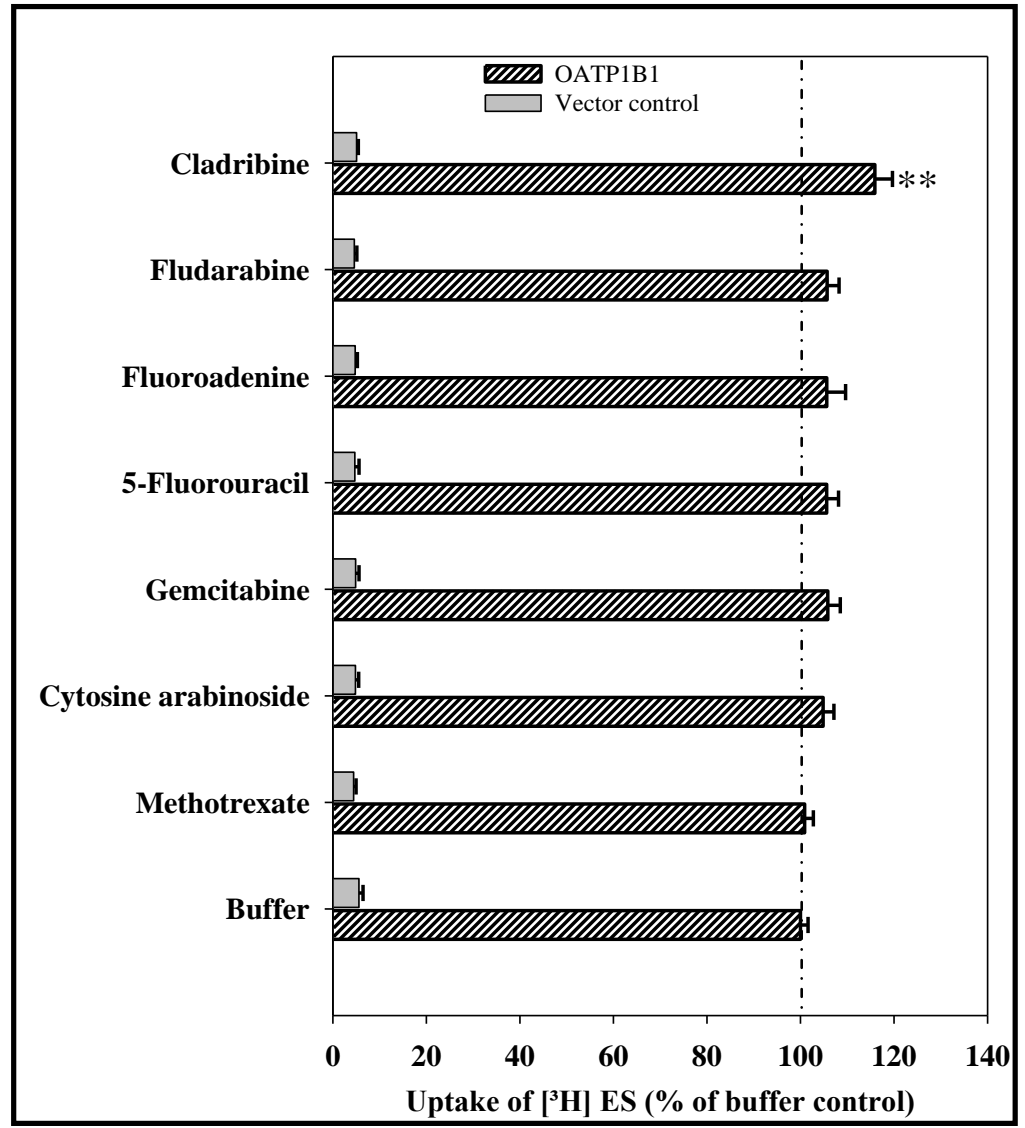

Figure 4.19 Inhibition of OATP1B1 mediated estrone-3-sulfate uptake by antimetabolites. The uptake of $\left[{ }^{3} \mathrm{H}\right]$ estrone-3-sulfate was followed in the presence of $100 \mu \mathrm{M}$ of antimetabolites. Data is represented as percentage of uptake observed in the absence of any compounds and are means \pm SEM of three individual experiments with three repeats each. $* *$ represents $p$ value $<0.01$.

\subsubsection{Inhibition of OATP1B1 mediated estrone-3-sulfate uptake by intercalating agents and mitotic inhibitors}

The intercalating agents, doxorubicin and mitoxantrone, and the mitotic inhibitor vincristine significantly reduced the OATP1B1-mediated uptake of estrone 3- sulfate by $12 \pm 2.2 \%, 18.9 \pm 2.0 \%$, and $28.1 \pm 1.4 \%$ of buffer control, respectively. The uptake 
was strongly reduced in the presence of the other mitotic inhibitors vinblastine and paclitaxel by $64.1 \pm 1.5 \%$ and $87.6 \pm 0.5 \%$, respectively (Fig. 4.20).

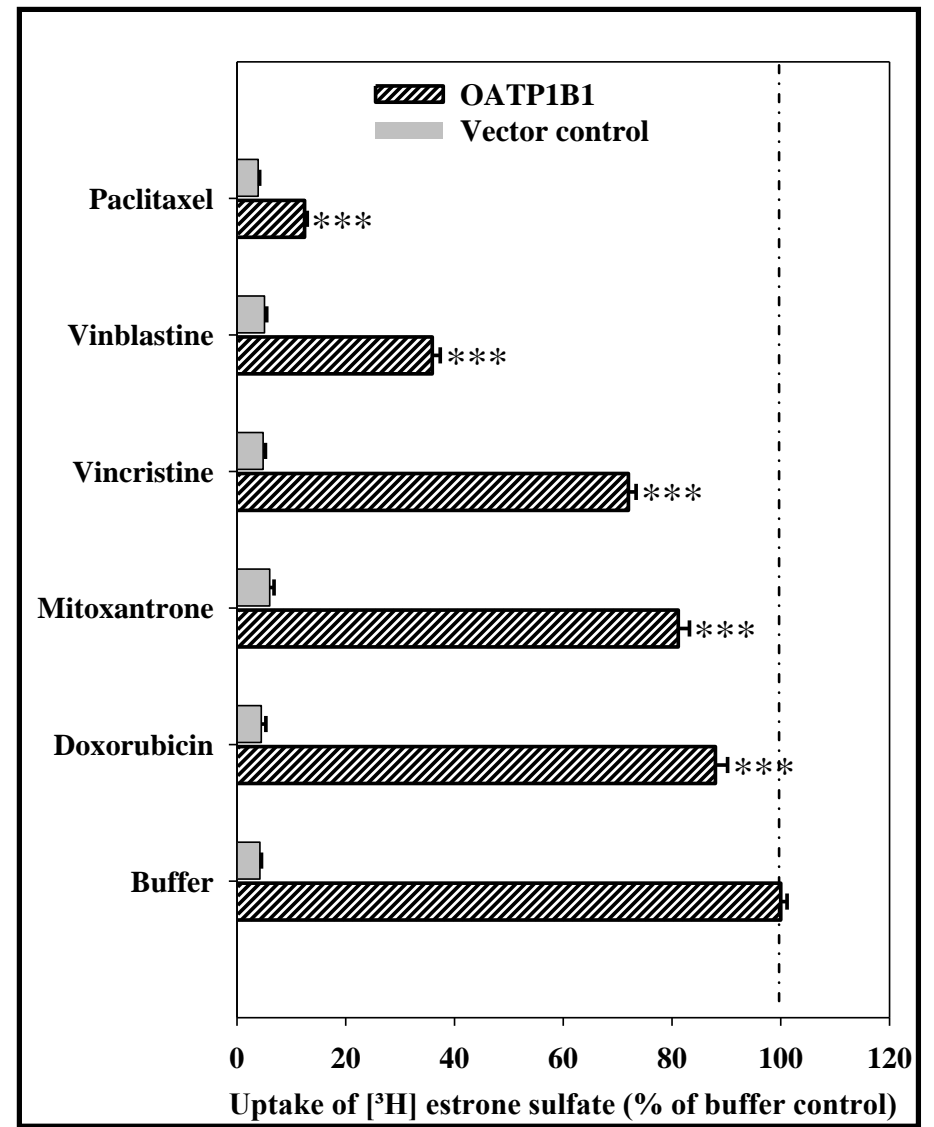

Figure 4.20 Inhibition of OATP1B1 mediated estrone-3-sulfate uptake by intercalating agents and mitotic inhibitors. The uptake of $\left[{ }^{3} \mathrm{H}\right]$ estrone-3-sulfate was followed in the presence of $100 \mu \mathrm{M}$ of intercalating agents and mitotic inhibitors. Data is represented as percentage of uptake observed in the absence of any compounds and are means \pm SEM of three individual experiments with three repeats each. * represents $p$ value $<0.05, * * *$ represents $p$ value $<0.001$.

\subsubsection{Inhibition of OATP1B1 mediated estrone-3-sulfate uptake by topoisomerase inhibitors and hormone receptor targeters}

Among the topoisomerase inhibitors, irinotecan caused a profound stimulation of the uptake of $\left[{ }^{3} \mathrm{H}\right]$ estrone-3-sulfate by $93.3 \pm 5.0 \%$ of buffer control while incubation with 
the compounds prednisone and tamoxifen resulted in a decrease of the uptake by $9.8 \pm$ $2.7 \%$ and $16.4 \pm 3.1 \%$ of buffer control, respectively (Fig. 4.21). Etoposide and clodronic acid did not cause any significant changes in the uptake.

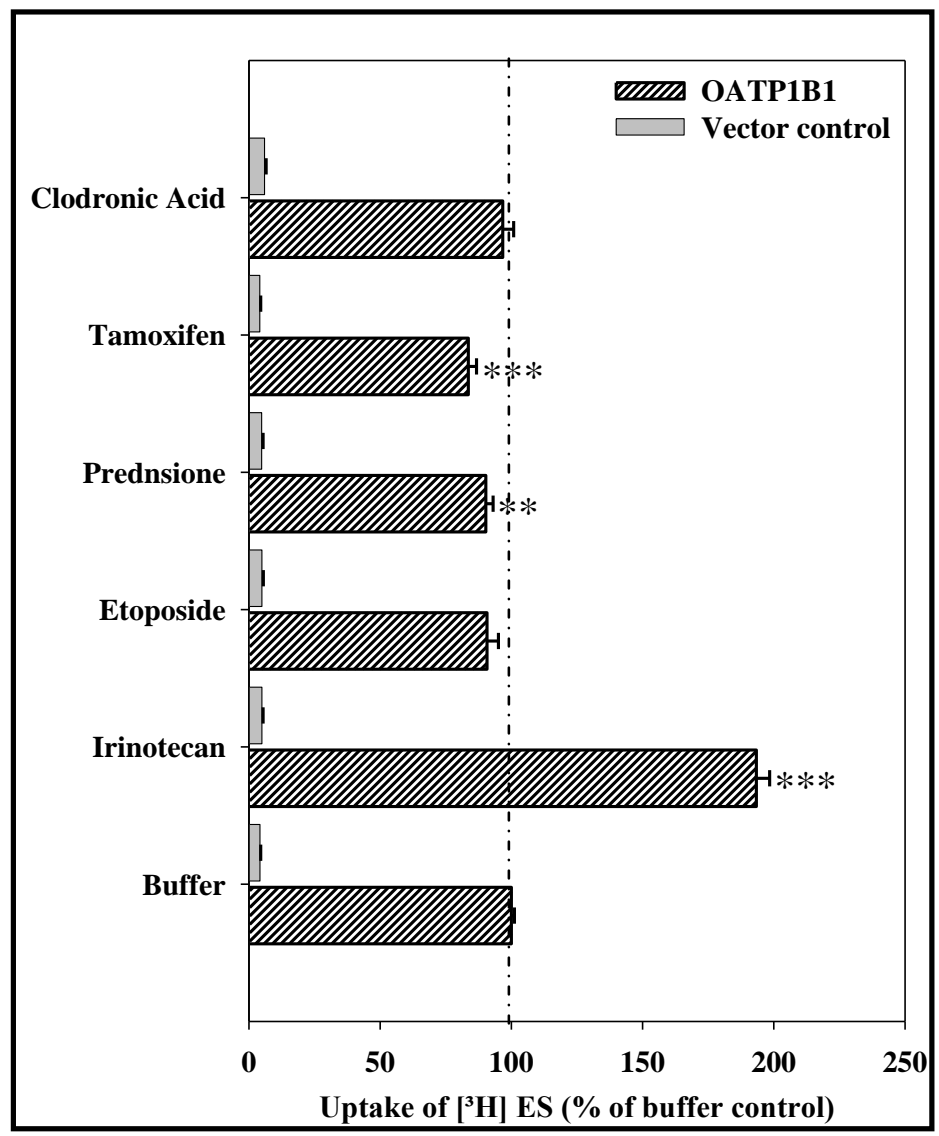

\section{Figure 4.21 Inhibition of OATP1B1 mediated estrone-3-sulfate uptake by} topoisomerase inhibitors and hormone receptor targeters. The uptake of $\left[{ }^{3} \mathrm{H}\right]$ estrone-3sulfate was followed in the presence of $100 \mu \mathrm{M}$ of topoisomerase inhibitors and hormone receptor targeters. Data is represented as percentage of uptake observed in the absence of any compounds and are means \pm SEM of three individual experiments with three repeats each. $* *$ represents $p$ value $<0.01, * * *$ represents $p$ value $<0.001$ 
4.3.2 Concentration dependent inhibition of antineoplastic compounds on OATP1B1 mediated estrone-3-sulfate uptake

As the two compounds, vinblastine and paclitaxel, strongly inhibited the uptake of OATP1B1 mediated estrone sulfate uptake to less than $40 \%$ of buffer control, the kinetic constants of inhibition of OATP1B1 were determined for these compounds.

\subsubsection{Concentration dependent inhibition of vinblastine on OATP1B1 mediated estrone-3-sulfate uptake}

Dixon plot analysis of the uptake of $\left[{ }^{3} \mathrm{H}\right]$ estrone-3-sulfate in buffer solutions containing $0.25 \mu \mathrm{M}$ or $2.5 \mu \mathrm{M}$ estrone-3-sulfate in the presence of increasing concentrations of vinblastine revealed the $K_{i}$ value of OATP1B1 for vinblastine to be $10.2 \mu \mathrm{M} \pm 0.18 \mu \mathrm{M}$.

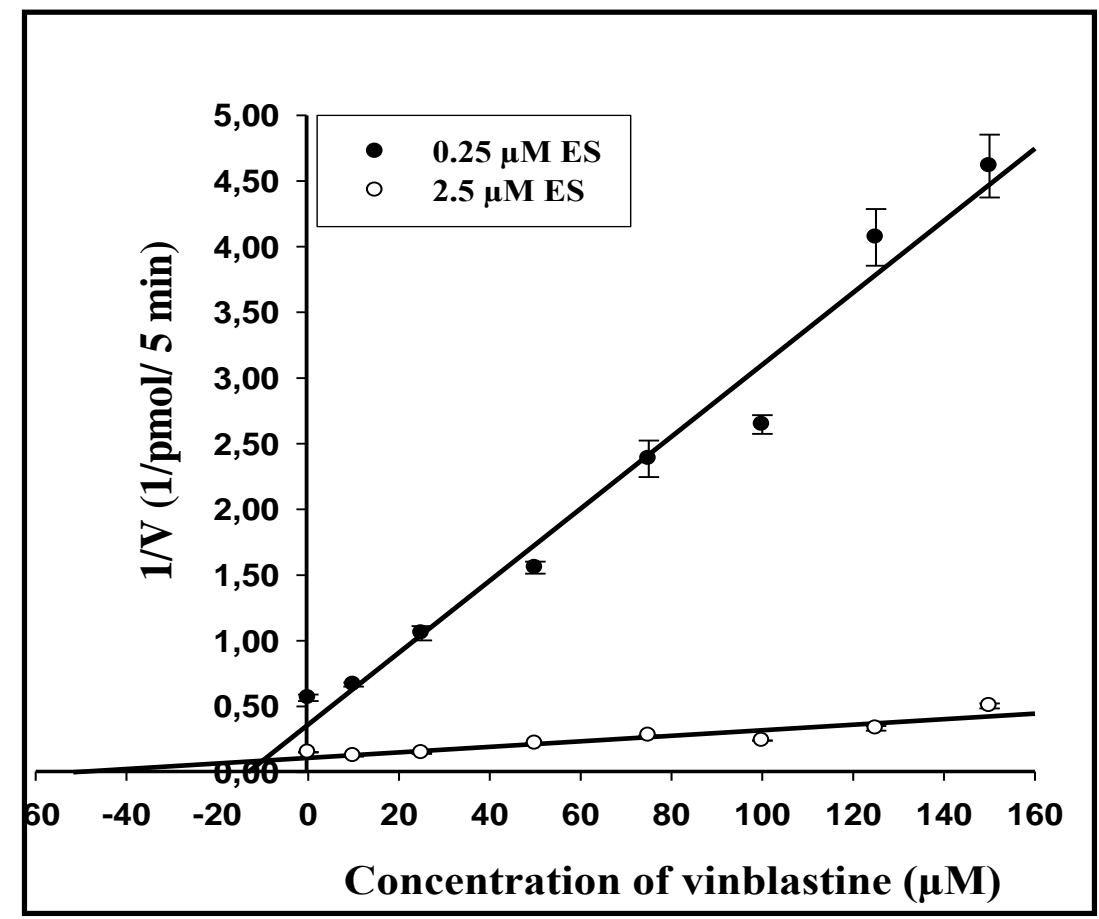

Figure 4.22 Concentration dependent inhibition of OATP1B1-mediated estrone-3-

sulfate by vinblastine. The uptake of $\left[{ }^{3} \mathrm{H}\right]$ estrone-3-sulfate was measured in the presence of 0 , $10 \mu \mathrm{M}, 25 \mu \mathrm{M}, 50 \mu \mathrm{M}, 75 \mu \mathrm{M}, 100 \mu \mathrm{M}, 125 \mu \mathrm{M}$, and $150 \mu \mathrm{M}$ vinblastine. Dark circles represent the uptake values at $0.25 \mu \mathrm{M}$ estrone-3-sulfate and clear circles represent uptake at $2.5 \mu \mathrm{M}$ 
estrone-3-sulfate. Figure is representative and $K_{i}$ value was calculated from two such experiments.

Data are means \pm SEMs of two independent experiments with three repeats each.

\subsubsection{Concentration dependent inhibition of paclitaxel on OATP1B1 mediated estrone-3-sulfate uptake}

Dixon plot analysis of the uptake of $\left[{ }^{3} \mathrm{H}\right]$ estrone-3-sulfate in solutions containing $0.25 \mu \mathrm{M}$ or $2.5 \mu \mathrm{M}$ estrone-3-sulfate in the presence of increasing concentrations of paclitaxel revealed the $K_{i}$ value of OATP1B1 for paclitaxel to be $0.84 \mu \mathrm{M} \pm 0.10 \mu \mathrm{M}$.

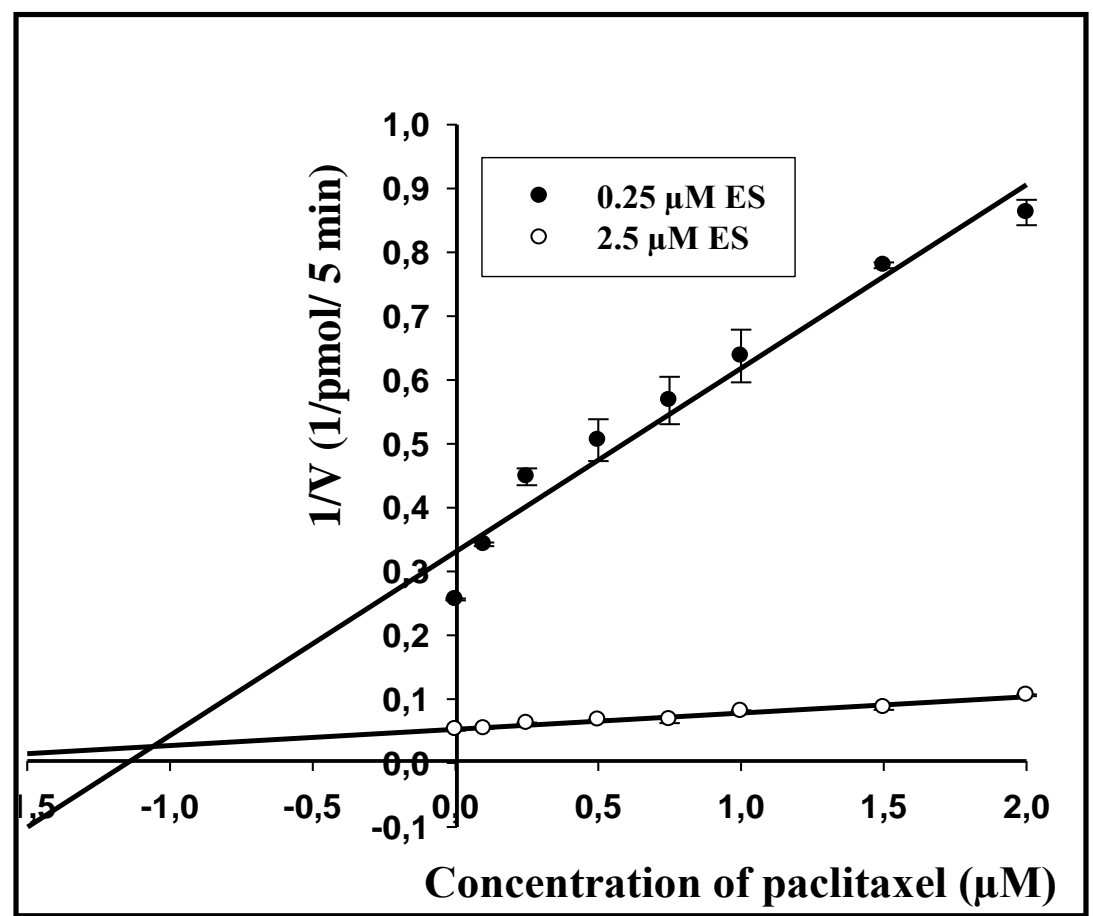

Figure 4.23 Concentration dependent inhibition of OATP1B1-mediated estrone-3-

sulfate by paclitaxel. The uptake of $\left[{ }^{3} \mathrm{H}\right]$ estrone-3-sulfate was measured in the presence of 0 , $0.1 \mu \mathrm{M}, 0.25 \mu \mathrm{M}, 0.5 \mu \mathrm{M}, 0.75 \mu \mathrm{M}, 1 \mu \mathrm{M}, 1.5 \mu \mathrm{M}$, and $2 \mu \mathrm{M}$ of paclitaxel. Dark circles represent the uptake values at $0.25 \mu \mathrm{M}$ estrone-3-sulfate and clear circles represent uptake at $2.5 \mu \mathrm{M}$ estrone-3-sulfate. Figure is representative and $K_{i}$ value was calculated from two such experiments. Data are means \pm SEMs of two independent experiments with three repeats each. 


\subsection{Interaction of organic anion transporting polypeptide $1 B 3$ (OATP1B3) with antineoplastic compounds}

To study the interactions between the antineoplastic compounds and OATP1B3, initial functional characterization was performed with human embryonic kidney cells expressing OATP1B3 as a system to measure the transport activity.

\subsubsection{Functional characterization of OATP1B3 transporter activity}

Initial functional characterization of OATP1B3 protein involved time dependent and concentration dependent uptake of the radiolabeled substrate cholecystokinin octapeptide $\left(\left[{ }^{3} \mathrm{H}\right] \mathrm{CCK}-8\right)$.

\subsubsection{Time dependent uptake of $\left[{ }^{3} \mathrm{H}\right]$ CCK-8 by OATP1B3 expressing cells}

A time course experiment was performed with OATP1B3 expressing HEK cells and vector transfected HEK cells wherein the uptake of $\left[{ }^{3} \mathrm{H}\right]$ CCK-8 was measured over a range of $30 \mathrm{~min}$. From the time course experiments, 2 min was selected for further experiments as this was in the linear range of uptake (Fig.4.24). 


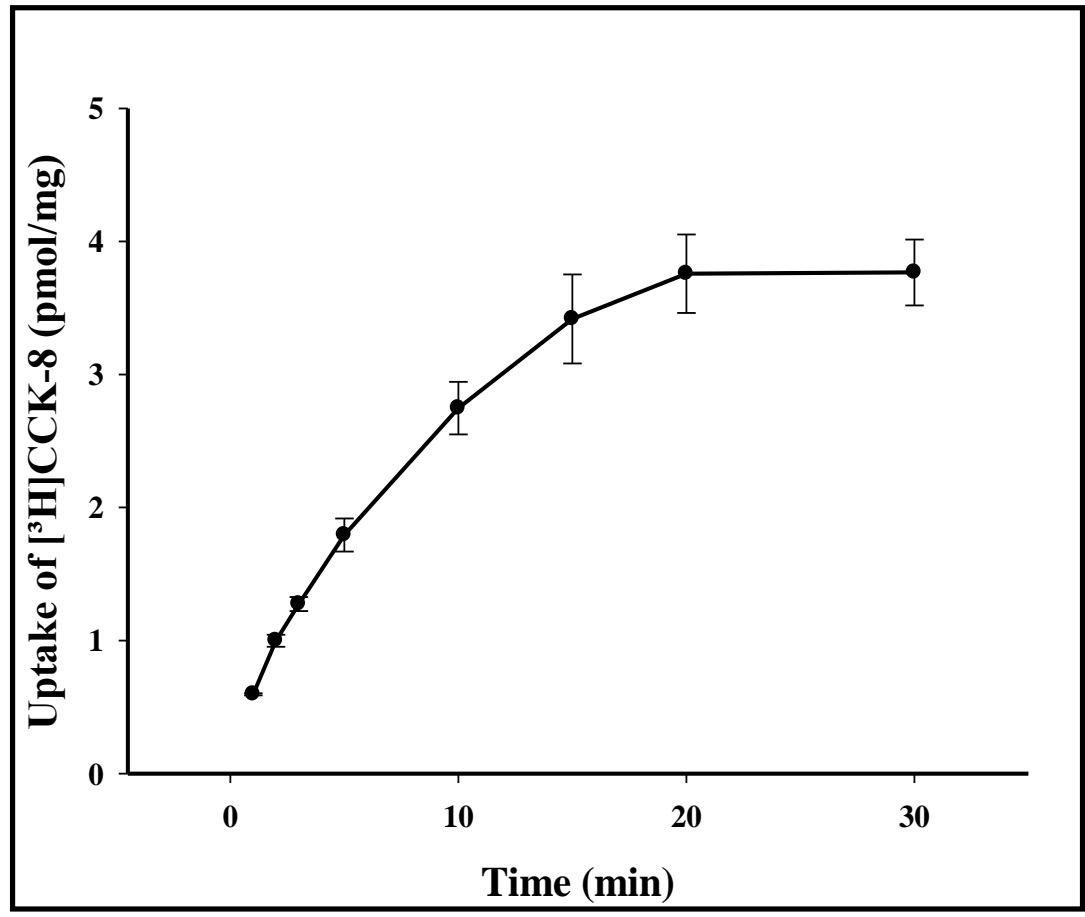

Figure 4.24. Time dependent uptake of OATP1B3. Uptake of $\left[{ }^{3} \mathrm{H}\right] \mathrm{CCK}-8$ was measured in buffer containing $5 \mathrm{nM}\left[{ }^{3} \mathrm{H}\right] \mathrm{CCK}-8$ and $245 \mathrm{nM}$ CCK-8 for 1, 2, 3, 5, 10, 15, 20, and $30 \mathrm{~min}$. The net uptake was calculated by subtracting the uptake in vector cells from the uptake in OATP1B3 expressing cells and plotted against time. Data are means \pm SEMs of three independent experiments with three repeats each.

\subsubsection{Concentration dependent uptake of $\left[{ }^{3} \mathrm{H}\right]$ CCK-8 by OATP1B3 expressing cells}

The affinity of OATP1B3 was determined by calculating the Michaelis-Menten constant $K_{m}$ for the interaction. Measurement of uptake of $\left[{ }^{3} \mathrm{H}\right] \mathrm{CCK}-8$ in the presence of increasing concentrations of unlabeled CCK-8 for 2 min revealed a $K_{m}$ of OATP1B3 for CCK-8 to be $13.2 \pm 1.6 \mu \mathrm{M}$ (Fig. 4.25$)$. 


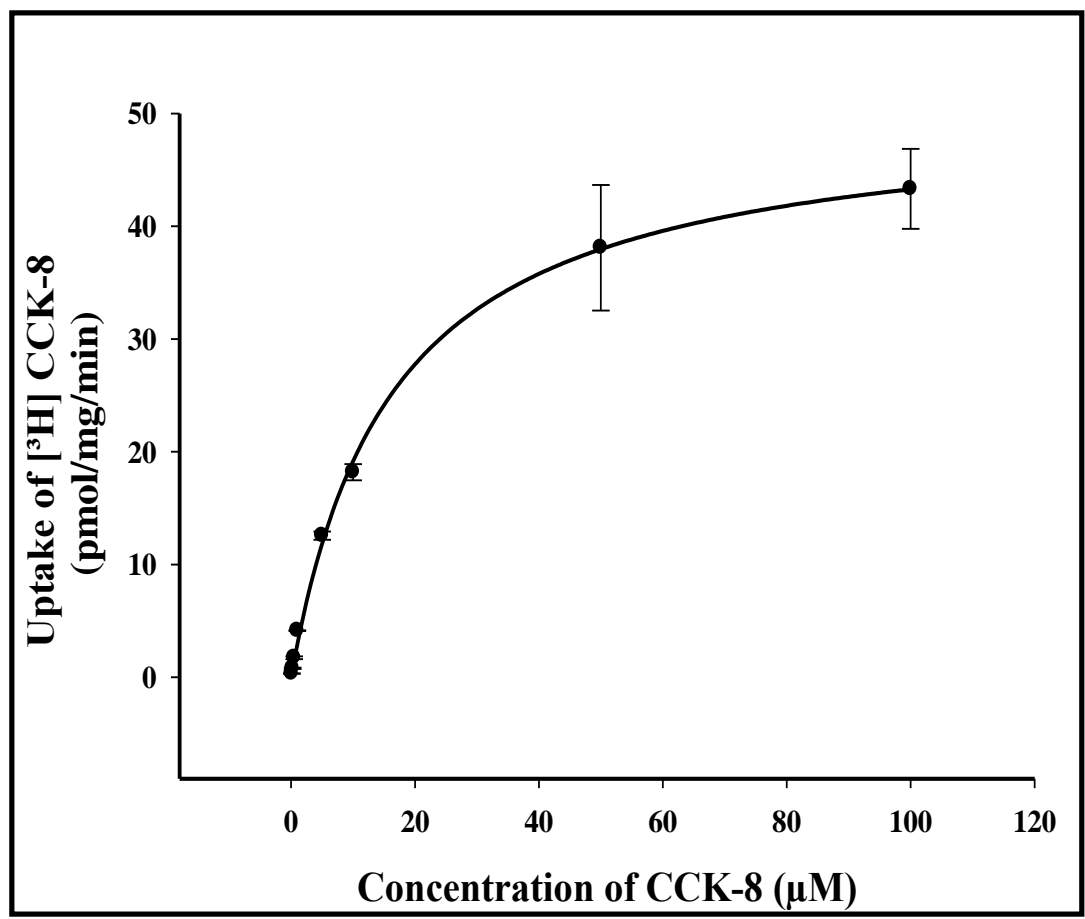

Figure 4.25. Concentration dependent uptake of OATP1B3. Uptake of $\left[{ }^{3} \mathrm{H}\right]$ CCK-8 was measured in buffer solution containing $5 \mathrm{nM}\left[{ }^{3} \mathrm{H}\right] \mathrm{CCK}-8$ mixed with unlabeled CCK-8 to a final concentration of $0.1 \mu \mathrm{M}, 0.25 \mu \mathrm{M}, 0.5 \mu \mathrm{M}, 1 \mu \mathrm{M}, 5 \mu \mathrm{M}, 10 \mu \mathrm{M}, 50 \mu \mathrm{M}$ and $100 \mu \mathrm{M}$ for $2 \mathrm{~min}$. The net uptake was calculated by subtracting the uptake in vector cells from the uptake in OATP1B3 expressing cells and plotted against concentration of CCK-8. Data are means \pm SEM of three independent experiments with three repeats each.

\subsubsection{Inhibition of OATP1B3-mediated CCK-8 uptake by antineoplastic compounds}

The uptake of $\left[{ }^{3} \mathrm{H}\right] \mathrm{CCK}-8$ was measured in the presence of $100 \mu \mathrm{M}$ of the corresponding antineoplastic compounds in buffer solutions containing $5 \mathrm{nM}\left[{ }^{3} \mathrm{H}\right] \mathrm{CCK}-8$ mixed with $995 \mathrm{nM}$ of unlabeled CCK-8 for 2 min. Uptake of $\left[{ }^{3} \mathrm{H}\right] \mathrm{CCK}-8$ by OATP1B3 in the absence of any of the compounds (buffer control) was calculated to be $2.9 \pm 0.2$ pmol CCK-8 / 2 min and the uptake in the presence of any of the antineoplastic compound tested is represented as percentage of this value. The uptake was significantly altered in the presence of a variety of compounds. 


\subsubsection{Inhibition of OATP1B3 mediated CCK-8 uptake by alkylating agents}

The alkylating agents, bendamustine and chlorambucil significantly reduced the uptake by $48.8 \pm 2.5 \%$ and $66 \pm 1.5 \%$, respectively, whereas a slight increase in the uptake was observed with cyclophosphamide by $8.7 \pm 2.0 \%$ of buffer control. There were no significant changes observed in the presence of the rest of the alkylating compounds tested (Fig. 4.26).

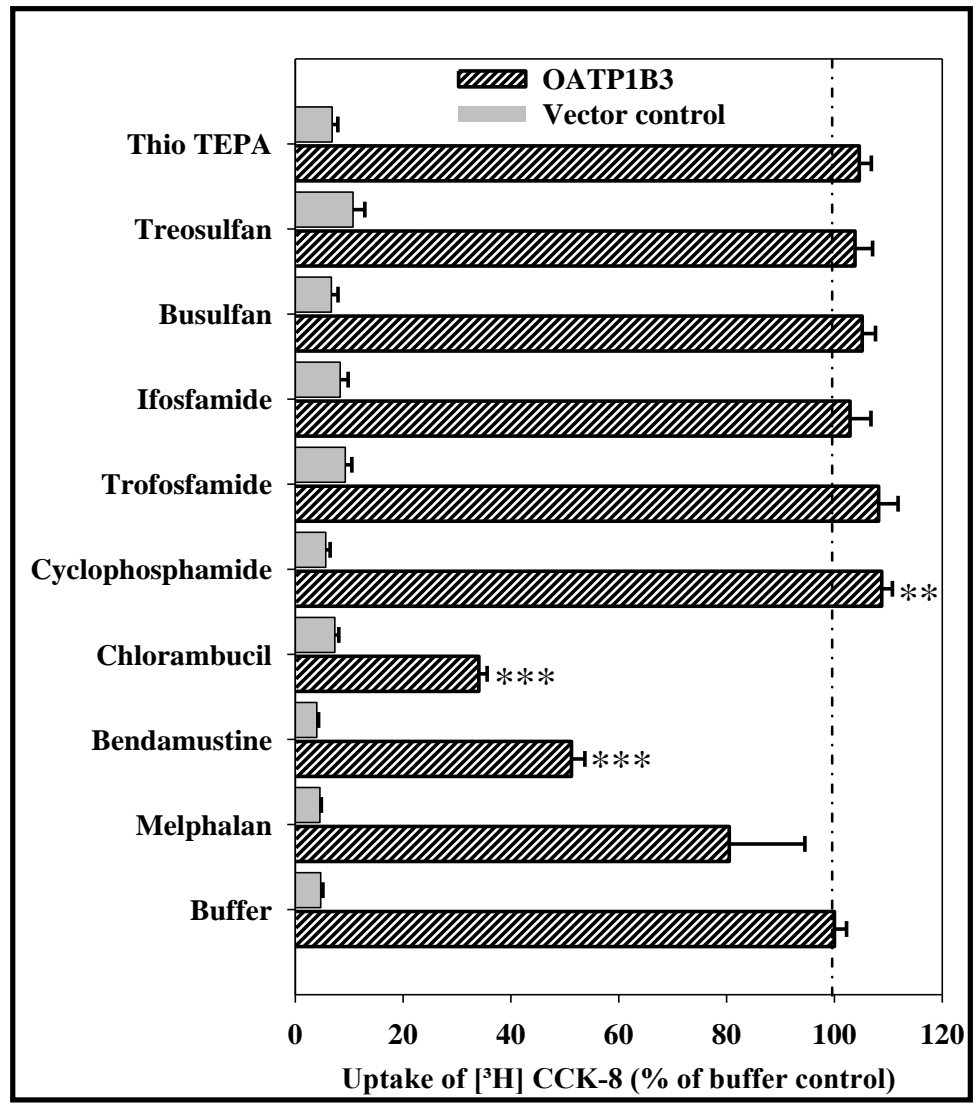

Figure 4.26 Inhibition of OATP1B3 mediated CCK-8 uptake by alkylating agents.

The uptake of $\left[{ }^{3} \mathrm{H}\right] \mathrm{CCK}-8$ was followed in the presence of $100 \mu \mathrm{M}$ of alkylating agents. Data is represented as percentages of uptake $( \pm$ SEM) observed in the absence of any compound and are means of three individual experiments with three repeats each. ** represents $p$ value $<0.01$, *** represents $p$ value $<0.001$. 


\subsubsection{Inhibition of OATP1B3 mediated CCK-8 uptake by antimetabolites}

Among antimetabolites, methotrexate, cytosine arabinoside, gemcitabine, fludarabine, and cladribine showed a weak stimulation of the $\left[{ }^{3} \mathrm{H}\right] \mathrm{CCK}-8$ uptake by $12.0 \pm 2.12 \%$, $17.7 \pm 5.9 \%, 11.1 \pm 4.6 \%, 12.0 \pm 4.2 \%$, and $10.0 \pm 1.8 \%$, respectively (Fig. 4.27).

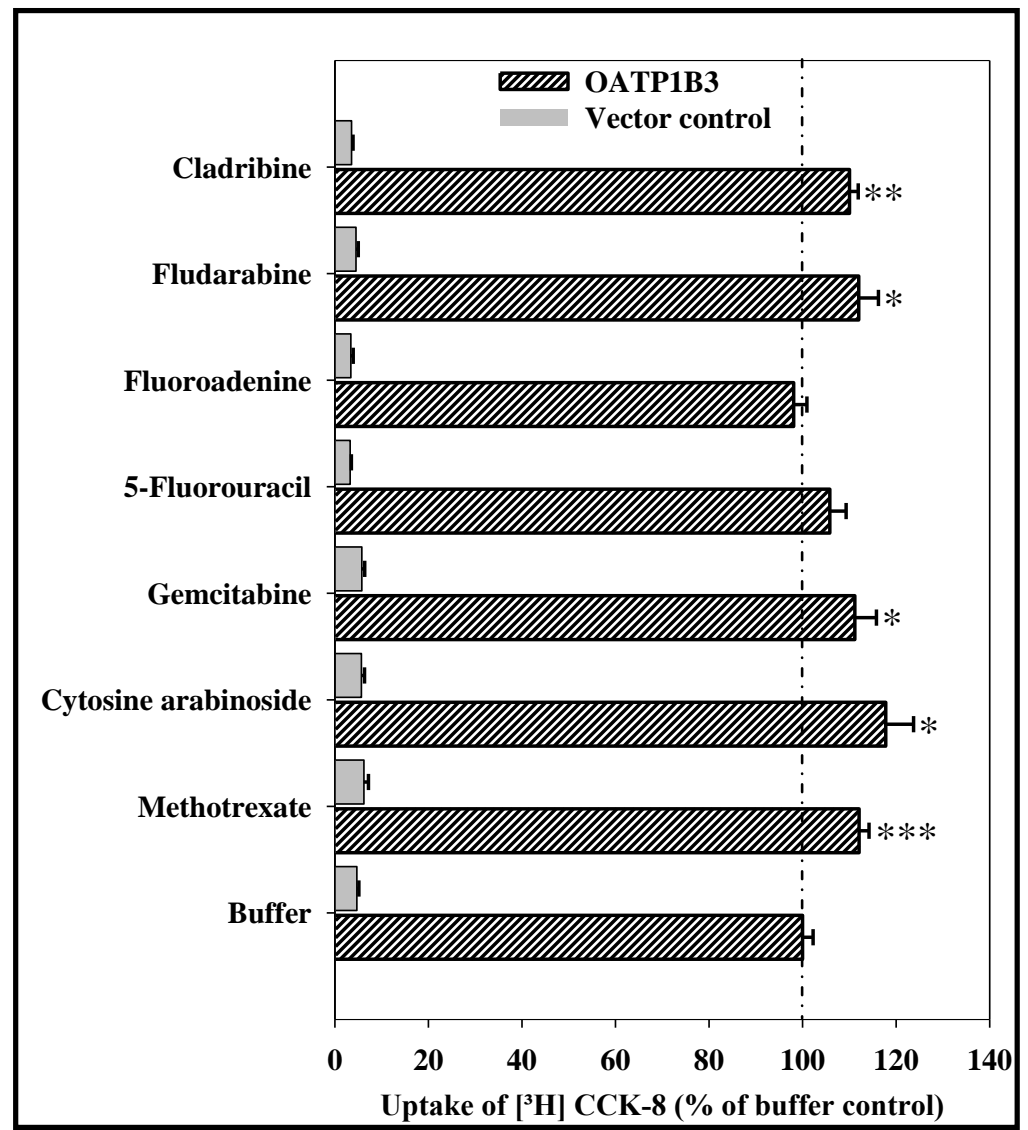

Figure 4.27 Inhibition of OATP1B3 mediated CCK-8 uptake by antimetabolites. The uptake of $\left[{ }^{3} \mathrm{H}\right] \mathrm{CCK}-8$ was followed in the presence of $100 \mu \mathrm{M}$ of antimetabolites. Data is represented as percentage of uptake observed in the absence of any compounds and are means \pm SEM of three individual experiments with three repeats each. * represents $p$ value $<0.05, * *$ represents $p$ value $<0.01$ and $* * *$ represents $p$ value $<0.001$. 


\subsubsection{Inhibition of OATP1B3 mediated CCK-8 uptake by intercalating agents and mitotic inhibitors}

The intercalating agents, doxorubicin and mitoxantrone reduced the OATP1B3-mediated

[ $\left.{ }^{3} \mathrm{H}\right]$ CCK-8 uptake by $53.6 \pm 1.6 \%$ and $84.4 \pm 1.4 \%$ of buffer control, respectively.

Similarly, the mitotic inhibitors, vincristine, vinblastine and paclitaxel reduced the uptake by $65.1 \pm 2.9 \%, 81.5 \pm 0.9 \%$, and $94.4 \pm 0.5 \%$, respectively (Fig. 4.28).

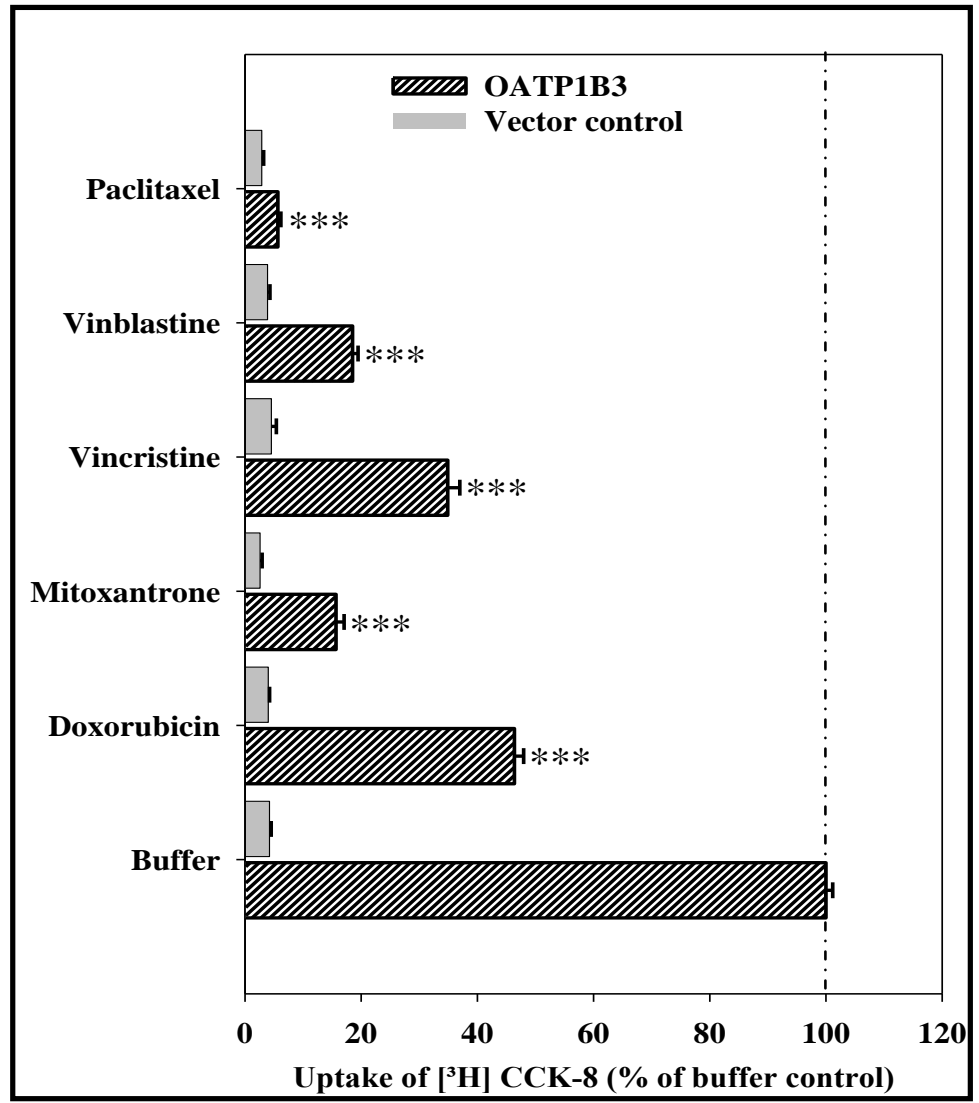

Figure 4.28 Inhibition of OATP1B3 mediated CCK-8 uptake by intercalating agents and mitotic inhibitors. The uptake of $\left[{ }^{3} \mathrm{H}\right] \mathrm{CCK}-8$ was followed in the presence of $100 \mu \mathrm{M}$ of intercalating agents and mitotic inhibitors. Data is represented as percentage of uptake observed in the absence of any compounds and are means \pm SEM of three individual experiments with three repeats each. ${ }^{* *}$ represents $p$ value $<0.01$ and $* * *$ represents $p$ value $<0.001$. 


\subsubsection{Inhibition of OATP1B3 mediated CCK-8 uptake by topoisomerase inhibitors and hormone receptor targeters}

The topoisomerase inhibitors irinotecan and etoposide reduced $\left[{ }^{3} \mathrm{H}\right] \mathrm{CCK}-8$ uptake by $34.3 \pm 3.9 \%$ and $76.3 \pm 1.6 \%$, respectively. The uptake of $\left[{ }^{3} \mathrm{H}\right] \mathrm{CCK}-8$ was reduced by $12.5 \pm 4.4 \%$ in the presence of prednisone and by $38.1 \pm 3.9 \%$ in the presence of tamoxifen, respectively (Fig. 4.29).

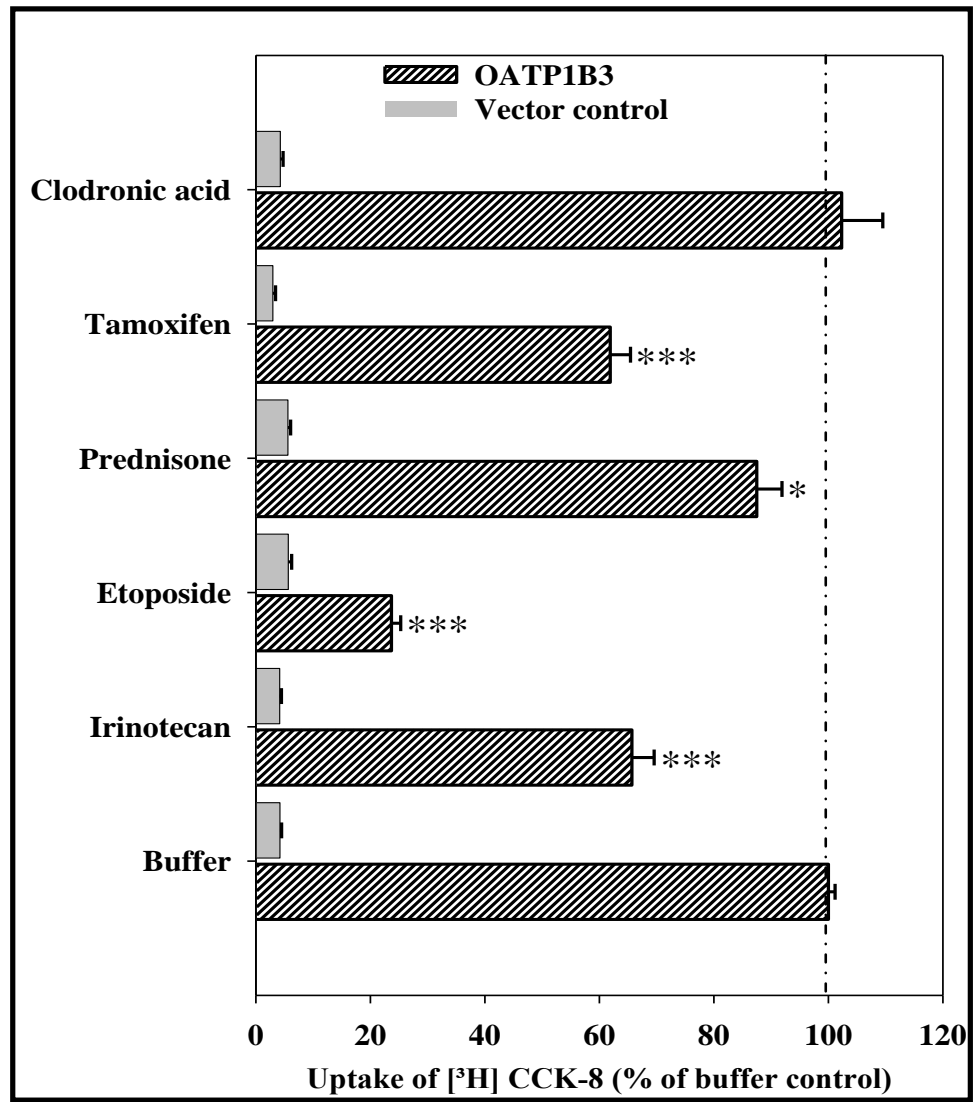

Figure 4.29 Inhibition of OATP1B3 mediated CCK-8 uptake by topoisomerase inhibitors and hormone receptor targeters. The uptake of $\left[{ }^{3} \mathrm{H}\right] \mathrm{CCK}-8$ was followed in the presence of $100 \mu \mathrm{M}$ of topoisomerase inhibitors and compounds targeting hormone receptors. Data is represented as percentage of uptake observed in the absence of any compounds and are means \pm SEM of three individual experiments with three repeats each. * represents $p$ value $<0.05$, ** represents $p$ value $<0.01$ and $* * *$ represents $p$ value $<0.001$. 
4.4.3 Concentration dependent inhibition of antineoplastic compounds on OATP1B3 mediated cholecystokinin octapeptide uptake

From the inhibition experiments, it was observed that chlorambucil, mitoxantrone, vinblastine, vincristine, paclitaxel and etoposide inhibited the uptake of OATP1B3mediated $\left[{ }^{3} \mathrm{H}\right]$ CCK-8 uptake to less than $40 \%$ of buffer control. So, these cytostatics were analyzed further for their inhibition potency by Dixon plot analysis to elucidate the affinity of OATP1B3 for them.

\subsubsection{Concentration dependent inhibition of chlorambucil on OATP1B3 mediated CCK-8 uptake}

Measurement of the uptake of $\left[{ }^{3} \mathrm{H}\right] \mathrm{CCK}-8$ at two different substrate concentrations in the presence of increasing concentration of chlorambucil revealed the $K_{i}$ value to be $37.4 \pm 1.2 \mu \mathrm{M}$ by Dixon plot analysis.

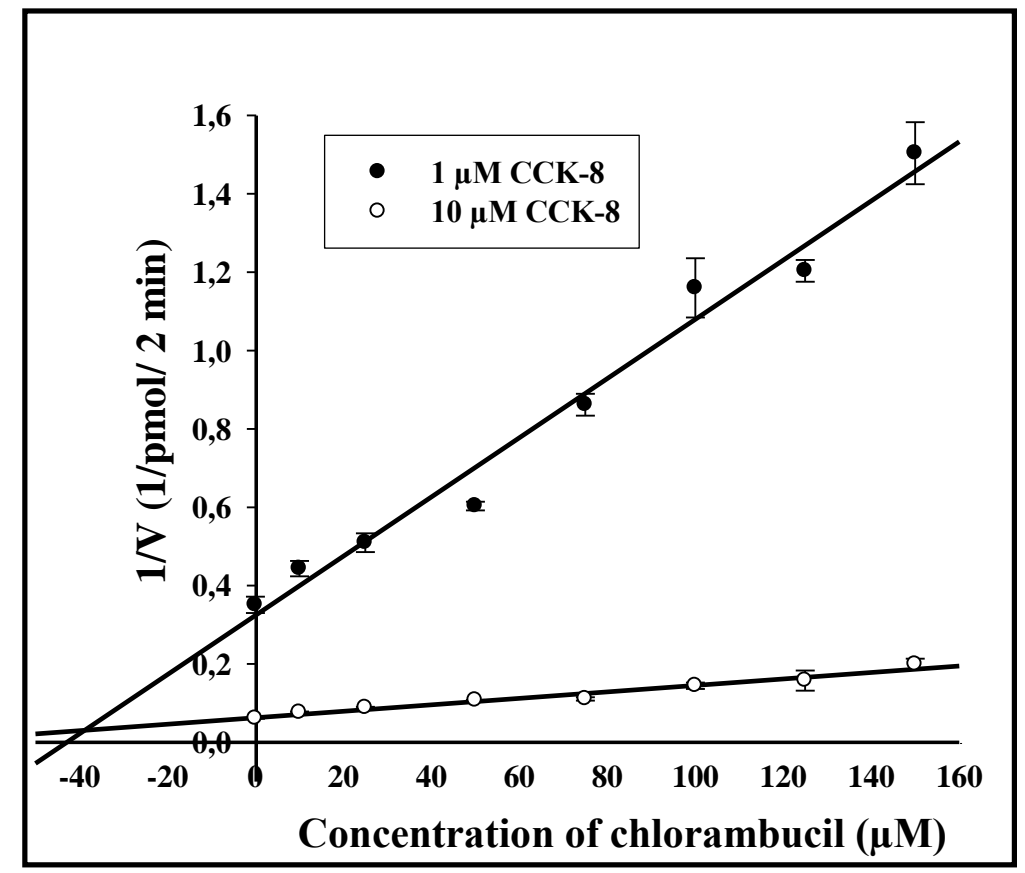

Figure 4.30 Concentration dependent inhibition of OATP1B3 mediated CCK-8 uptake by chlorambucil. The uptake of $\left[{ }^{3} \mathrm{H}\right]$ CCK- 8 was measured in Hank's buffer solution 
containing $5 \mathrm{nM}\left[{ }^{3} \mathrm{H}\right] \mathrm{CCK}-8$ and either $995 \mathrm{nM}$ or $9.995 \mu \mathrm{M}$ unlabeled CCK-8 in the presence of $0,10 \mu \mathrm{M}, 25 \mu \mathrm{M}, 50 \mu \mathrm{M}, 75 \mu \mathrm{M}, 100 \mu \mathrm{M}, 125 \mu \mathrm{M}$, and $150 \mu \mathrm{M}$ chlorambucil for 2 min. Dark circles represent the uptake values at $1 \mu \mathrm{M}$ CCK-8 and clear circles represent uptake at $10 \mu \mathrm{M}$ CCK-8. Figure is of one representative experiment and $K_{i}$ value was calculated from two such experiments. Data are means \pm SEM of two independent experiments with three repeats each.

\subsubsection{Concentration dependent inhibition of mitoxantrone on OATP1B3 mediated CCK-8 uptake}

The uptake of $\left[{ }^{3} \mathrm{H}\right]$ CCK-8 measured in buffer solutions containing $1 \mu \mathrm{M}$ and $10 \mu \mathrm{M}$ CCK-8 in the presence of increasing concentrations of mitoxantrone, revealed a $K_{i}$ value of $3.1 \pm 0.1 \mu \mathrm{M}$ for the intercalating agent, mitoxantrone (Fig. 4.31).

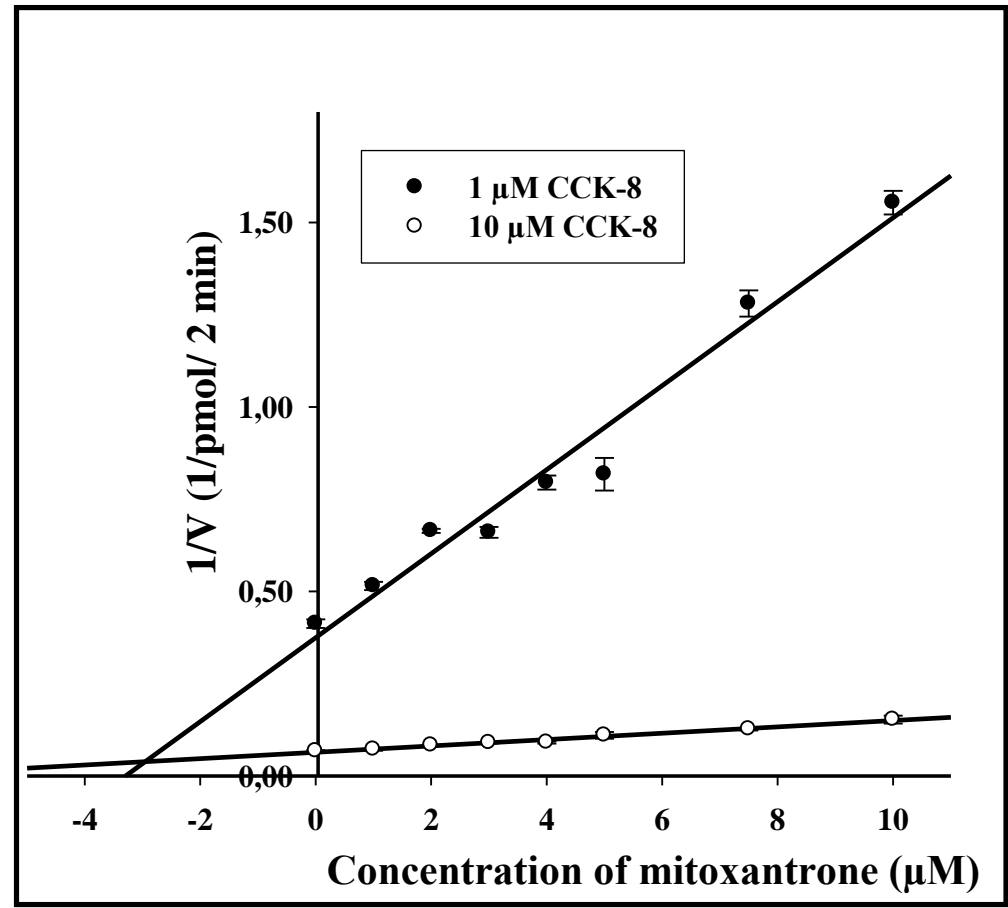

Figure 4.31 Concentration dependent inhibition of OATP1B3 mediated CCK-8 uptake by mitoxantrone. The uptake of $\left[{ }^{3} \mathrm{H}\right] \mathrm{CCK}-8$ was measured in Hank's buffer solution containing $5 \mathrm{nM}\left[{ }^{3} \mathrm{H}\right] \mathrm{CCK}-8$ and either $995 \mathrm{nM}$ or $9.995 \mu \mathrm{M}$ unlabeled CCK-8 in the presence of $0,1 \mu \mathrm{M}, 2 \mu \mathrm{M}, 3 \mu \mathrm{M}, 4 \mu \mathrm{M}, 5 \mu \mathrm{M}, 7.5 \mu \mathrm{M}$, and $10 \mu \mathrm{M}$ mitoxantrone for $2 \mathrm{~min}$. Dark circles represent the uptake values at $1 \mu \mathrm{M} \mathrm{CCK}-8$ and clear circles represent uptake at $10 \mu \mathrm{M}$ CCK-8. 
Figure is of one representative experiment representative and $K_{i}$ value was calculated from two such experiments. Data are means \pm SEM of two independent experiments with three repeats each.

\subsubsection{Concentration dependent inhibition of vinblastine on OATP1B3 mediated CCK-8 uptake}

Dixon plot analysis of the uptake of $\left[{ }^{3} \mathrm{H}\right] \mathrm{CCK}-8$ in solutions containing $1 \mu \mathrm{M}$ or $10 \mu \mathrm{M}$ CCK-8 in the presence of increasing concentrations of vinblastine revealed the $K_{i}$ value of OATP1B3 for vinblastine to be $18.6 \mu \mathrm{M} \pm 1.4 \mu \mathrm{M}$ (Fig. 4.32).

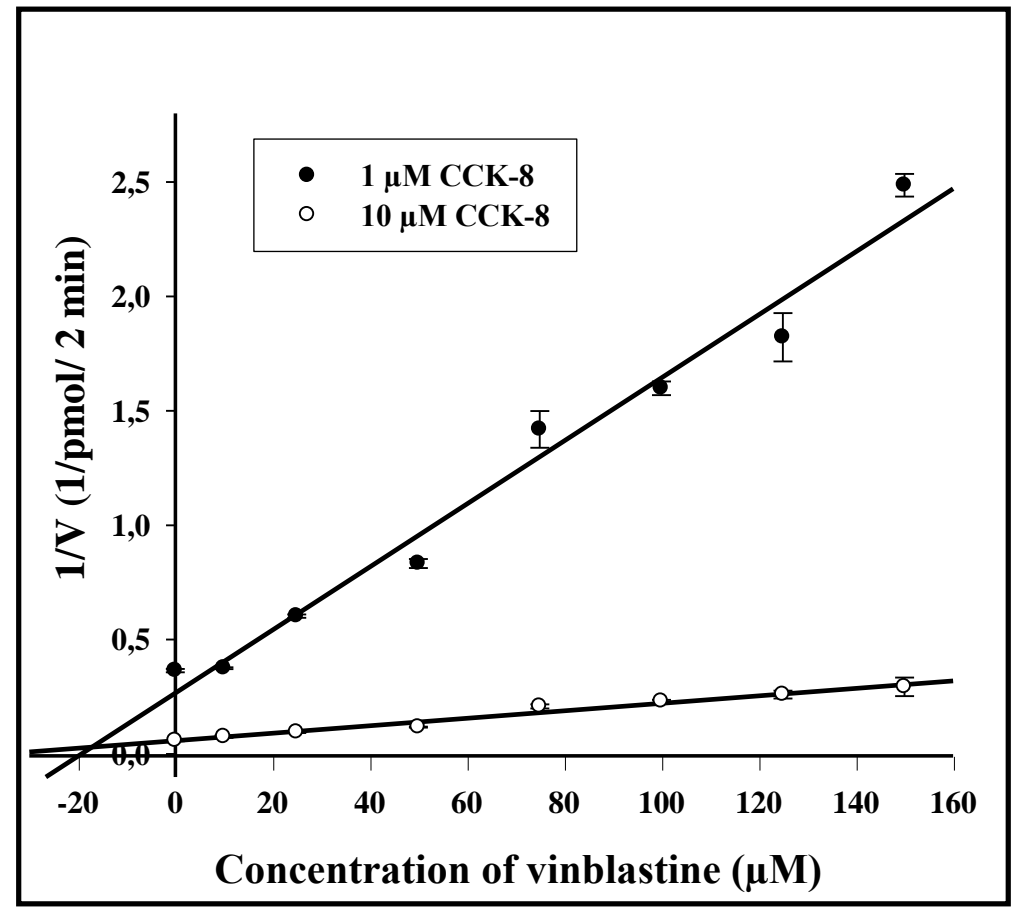

Figure 4.32 Concentration dependent inhibition of OATP1B3 mediated CCK-8 uptake by vinblastine. The uptake of $\left[{ }^{3} \mathrm{H}\right] \mathrm{CCK}-8$ was measured in Hank's buffer solution containing $5 \mathrm{nM}\left[{ }^{3} \mathrm{H}\right] \mathrm{CCK}-8$ and either $995 \mathrm{nM}$ or $9.995 \mu \mathrm{M}$ unlabeled CCK-8 in the presence of 0, $10 \mu \mathrm{M}, 25 \mu \mathrm{M}, 50 \mu \mathrm{M}, 75 \mu \mathrm{M}, 100 \mu \mathrm{M}, 125 \mu \mathrm{M}$, and $150 \mu \mathrm{M}$ vinblastine for 2 min. Dark circles represent the uptake values at $1 \mu \mathrm{M}$ CCK-8 and clear circles represent uptake at $10 \mu \mathrm{M}$ CCK-8. Figure is representative from one experiment and $K_{i}$ value was calculated from two such experiments. Data are means \pm SEM of two independent experiments with three repeats each. 


\subsubsection{Concentration dependent inhibition of vincristine on OATP1B3 mediated CCK-8 uptake}

Dixon plot analysis of the uptake of $\left[{ }^{3} \mathrm{H}\right] \mathrm{CCK}-8$ in solutions containing $1 \mu \mathrm{M}$ or $10 \mu \mathrm{M}$ CCK-8 in the presence of increasing concentrations of vincristine revealed the $K_{i}$ value of OATP1B3 for vinblastine to be $17.6 \mu \mathrm{M} \pm 0.03 \mu \mathrm{M}$ (Fig. 4.33)

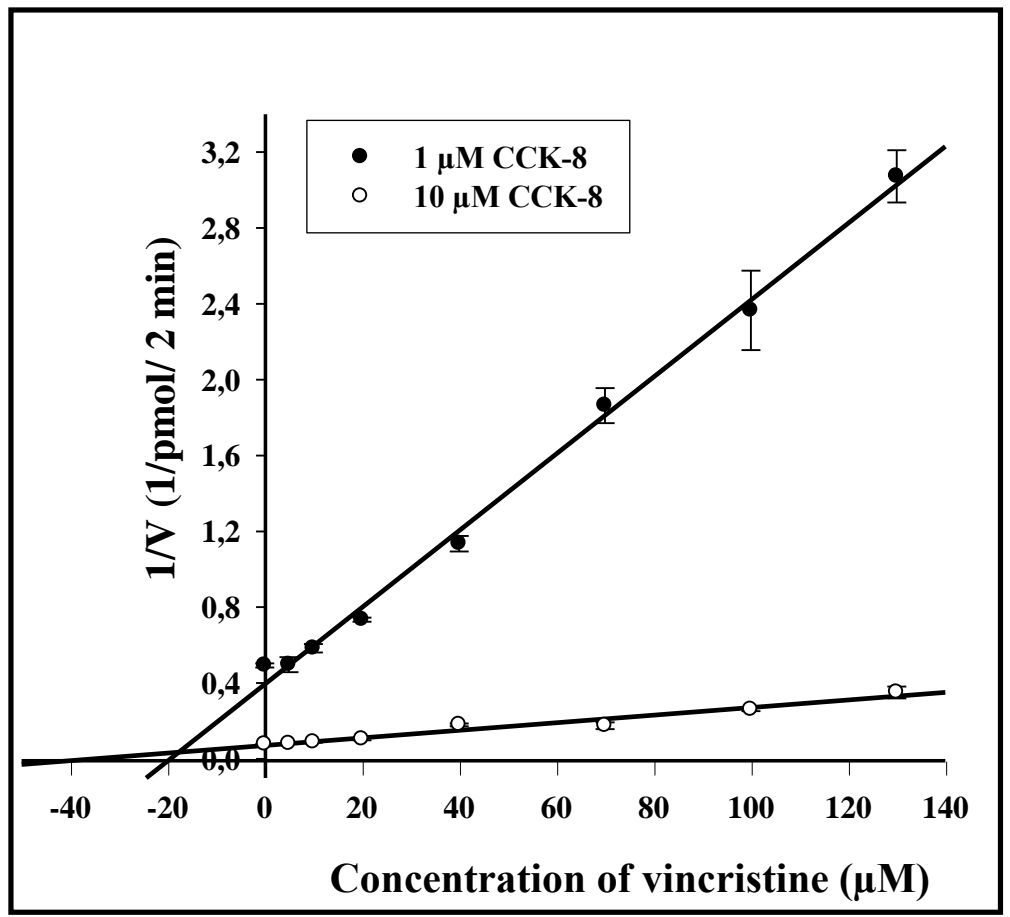

Figure 4.33 Concentration dependent inhibition of OATP1B3 mediated CCK-8 uptake by vincristine. The uptake of $\left[{ }^{3} \mathrm{H}\right] \mathrm{CCK}-8$ was measured in Hank's buffer solution containing $5 \mathrm{nM}\left[{ }^{3} \mathrm{H}\right] \mathrm{CCK}-8$ and either $995 \mathrm{nM}$ or $9.995 \mu \mathrm{M}$ unlabeled CCK-8 in the presence of $0,5 \mu \mathrm{M}, 10 \mu \mathrm{M}, 20 \mu \mathrm{M}, 40 \mu \mathrm{M}, 70 \mu \mathrm{M}, 100 \mu \mathrm{M}$, and $130 \mu \mathrm{M}$ vincristine for 2 min. Dark circles represent the uptake values at $1 \mu \mathrm{M} \mathrm{CCK}-8$ and clear circles represent uptake at $10 \mu \mathrm{M}$ CCK-8. Figure is representative from one experiment and $K_{i}$ value was calculated from two such experiments. Data are means \pm SEM of two independent experiments with three repeats each. 


\subsubsection{Concentration dependent inhibition of paclitaxel on OATP1B3 mediated CCK-8 uptake}

Measurement of the uptake of $\left[{ }^{3} \mathrm{H}\right] \mathrm{CCK}-8$ at two different substrate concentrations in the presence of increasing concentration of paclitaxel revealed the $K_{i}$ value to be $1.8 \pm$ $0.03 \mu \mathrm{M}$ by Dixon plot analysis (Fig. 4.34).

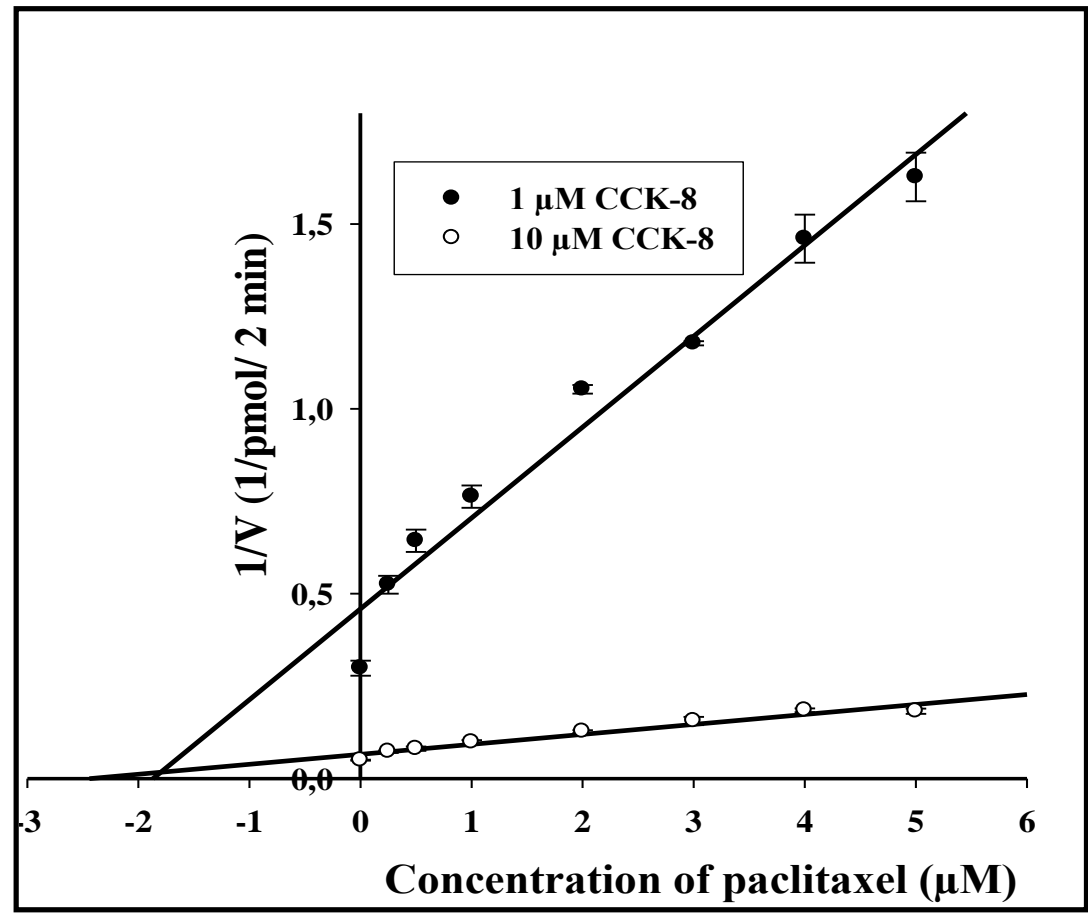

Figure 4.34 Concentration dependent inhibition of OATP1B3 mediated CCK-8 uptake by paclitaxel. The uptake of $\left[{ }^{3} \mathrm{H}\right] \mathrm{CCK}-8$ was measured in Hank's buffer solution containing $5 \mathrm{nM}\left[{ }^{3} \mathrm{H}\right] \mathrm{CCK}-8$ and either $995 \mathrm{nM}$ or $9.995 \mu \mathrm{M}$ unlabeled CCK-8 in the presence of $0,0.25 \mu \mathrm{M}, 0.5 \mu \mathrm{M}, 1 \mu \mathrm{M}, 2 \mu \mathrm{M}, 3 \mu \mathrm{M}, 4 \mu \mathrm{M}$, and $5 \mu \mathrm{M}$ paclitaxel for 2 min. Dark circles represent the uptake values at $1 \mu \mathrm{M} \mathrm{CCK}-8$ and clear circles represent uptake at $10 \mu \mathrm{M}$ CCK-8. Figure is representative from one experiment and $K_{i}$ value was calculated from two such experiments. Data are means \pm SEM of two independent experiments with three repeats each. 


\subsubsection{Concentration dependent inhibition of etoposide on OATP1B3 mediated CCK-8 uptake}

Measurement of the uptake of $\left[{ }^{3} \mathrm{H}\right] \mathrm{CCK}-8$ at two different substrate concentrations in the presence of increasing concentration of etoposide revealed the $K_{i}$ value to be $13.5 \pm$ $0.28 \mu \mathrm{M}$ by Dixon plot analysis (Fig. 4.35).

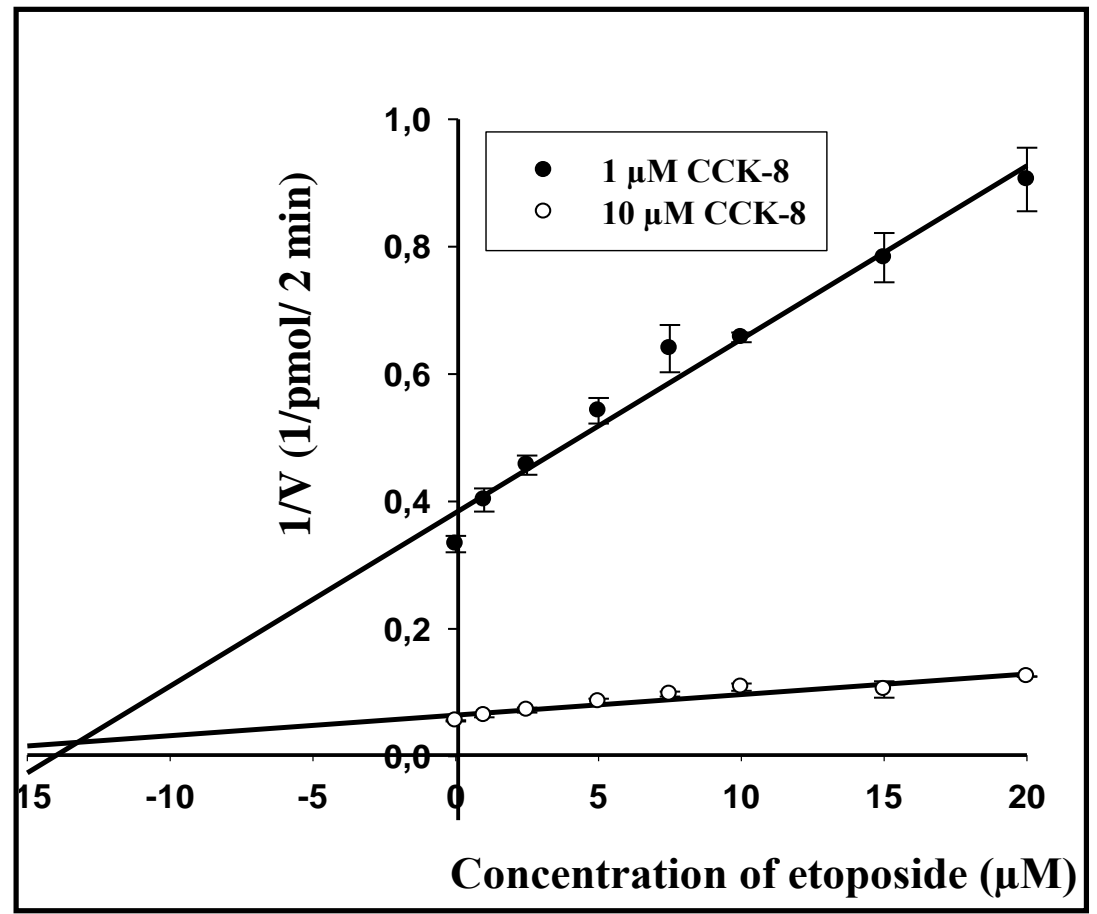

Figure 4.35 Concentration dependent inhibition of OATP1B3 mediated CCK-8 uptake by etoposide. The uptake of $\left[{ }^{3} \mathrm{H}\right] \mathrm{CCK}-8$ was measured in Hank's buffer solution containing $5 \mathrm{nM}\left[{ }^{3} \mathrm{H}\right] \mathrm{CCK}-8$ and either $995 \mathrm{nM}$ or $9.995 \mu \mathrm{M}$ unlabeled CCK-8 in the presence of $0,1 \mu \mathrm{M}, 2.5 \mu \mathrm{M}, 5 \mu \mathrm{M}, 7.5,10 \mu \mathrm{M}, 15 \mu \mathrm{M}$, and $20 \mu \mathrm{M}$ etoposide for $2 \mathrm{~min}$. Dark circles represent the uptake values at $1 \mu \mathrm{M}$ CCK-8 and clear circles represent uptake at $10 \mu \mathrm{M} \mathrm{CCK}-8$. Figure is representative from one experiment and $K_{i}$ value was calculated from two such experiments. Data are means \pm SEM of two independent experiments with three repeats each.

The results depicted so far highlight the ability of a transporter protein to interact with certain antineoplastic compounds that might lead to drug-drug interactions influencing the chemotherapy regimens of tumor treatment. There is yet another dimension in which the 
transporter proteins influence the effectiveness of a chemotherapy regimen; their expression status in the tumors. Expression of uptake transporters has been shown to vary markedly among different tumors. There are many different stages in the metabolism of a cell where the expression of a gene is regulated, the other group of experiments are focused on the regulation of a transporter protein encoded by the gene SLC22A3; the organic cation transporter 3 (OCT3).

\subsection{Expression of SLC22A3 in A498, ACHN, 786-O and LN 78 cells}

Earlier studies conducted in the lab showed a variable expression pattern of OCT3 in renal carcinoma cell lines. The current experiments are aimed to find the reason for this variable expression of OCT3. The expression pattern found was reestablished prior to experiments on the regulation aspects were performed.

Using TaqMan primers specific for OCT3 and GAPDH, the expression of OCT3 in the four renal carcinoma cells was measured. qRTPCR of cDNA prepared from RNA isolated from the four cell lines showed a clear pattern wherein the difference between the $\Delta \mathrm{Ct}$ value between A498 and ACHN cells was around 12 cycles, consistent with the earlier finding in the lab (Fig. 4.36). 


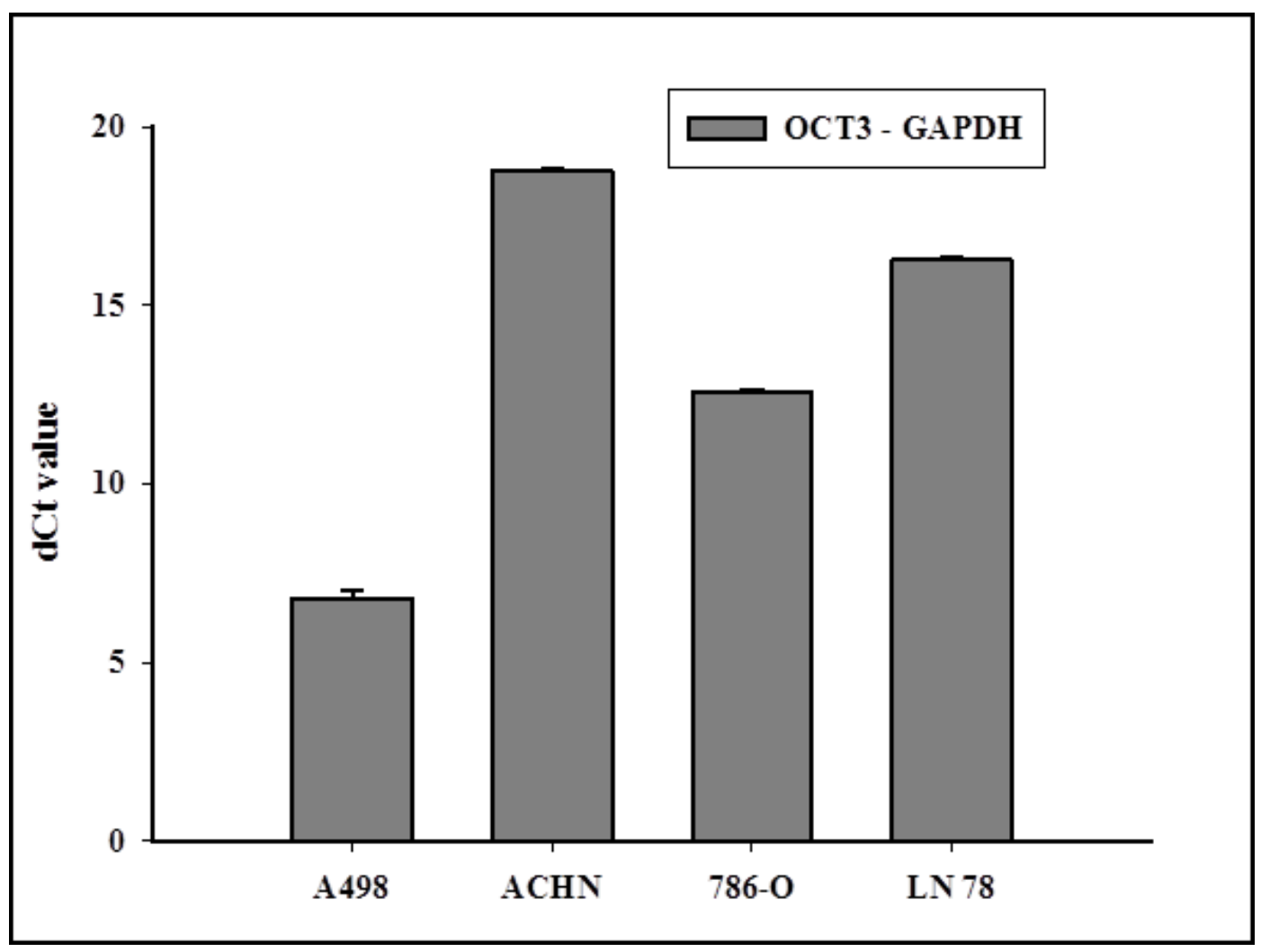

Figure 4.36 Expression of OCT3 in renal carcinoma cell lines. qRTPCR was conducted with cDNA prepared from total RNA isolated from the cells. The Ct values of OCT3 and GAPDH were obtained and the $\Delta \mathrm{Ct}$ values were obtained by subtracting the $\mathrm{Ct}$ (cycle of threshold) of GAPDH from the Ct value of OCT3.

\subsection{Effect of inhibition of DNA methylation on expression of OCT3}

To find out whether inhibition of DNA methylation would have any effect on the expression of OCT3, cells were treated with 5-aza-2'-deoxy-cytidine, an inhibitor of DNA methyltransferase. Incubation of ACHN cells with $5 \mu \mathrm{M}$ resulted in a decrease of ca. 2 in $\Delta \mathrm{Ct}$ value on the expression of OCT3 in these cells. However, there was no further increase in the increase of expression of OCT3 with increase in the concentration of 5aza-2'-deoxy-cytidine (Fig. 4.37). 


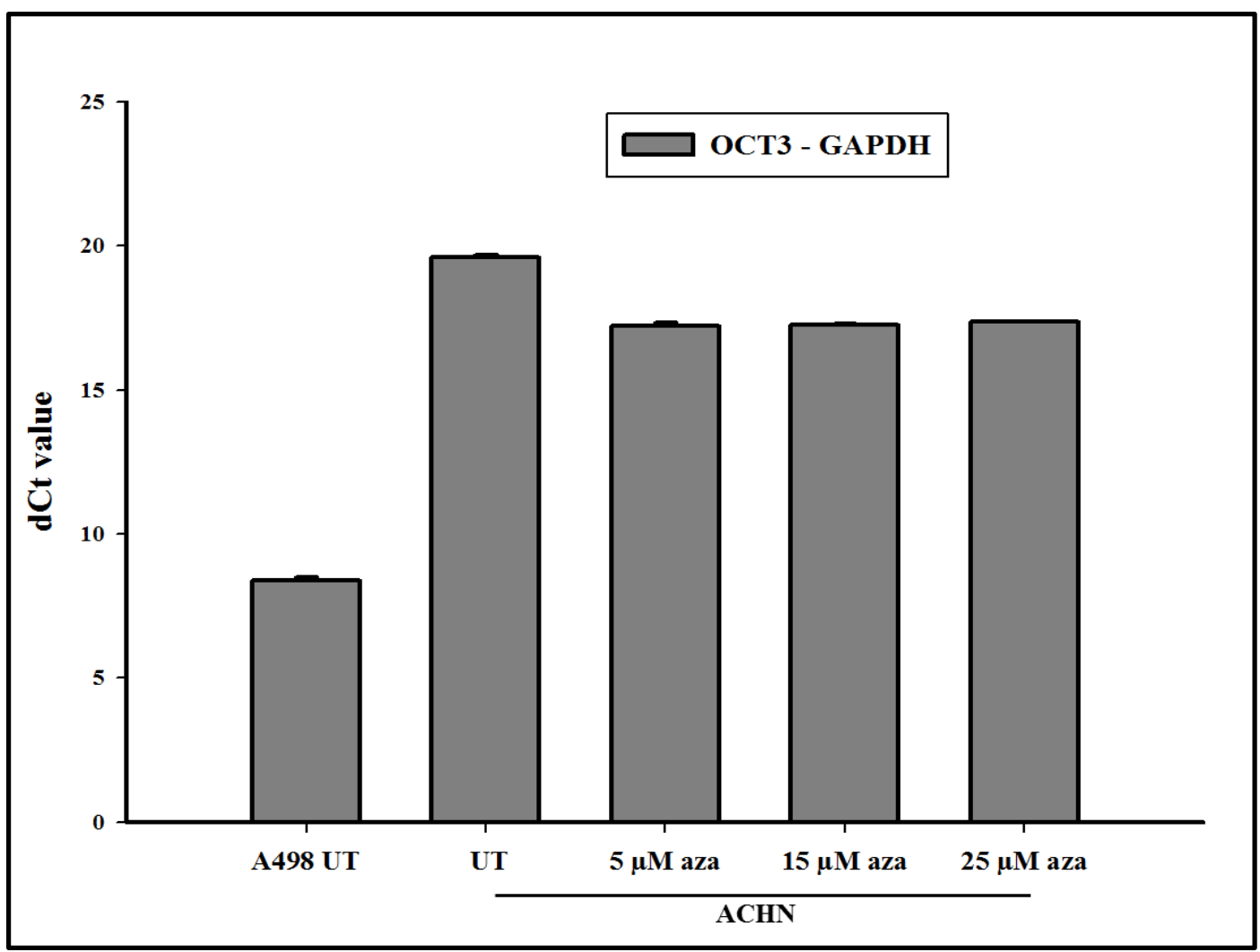

Figure 4.37 Expression of OCT3 in ACHN cells treated with 5-aza-2'-deoxy-cytidine.

ACHN cells were treated with $5 \mu \mathrm{M}, 15 \mu \mathrm{M}$, or $25 \mu \mathrm{M}$ 5-aza-2'-deoxy-cytidine for $72 \mathrm{~h}$. qRTPCR was conducted with cDNA prepared from total RNA isolated from these cells along with untreated A498 and ACHN cells. The Ct values of OCT3 and GAPDH were obtained and the $\Delta \mathrm{Ct}$ values were obtained by subtracting the $\mathrm{Ct}$ (cycle of threshold) of GAPDH from the $\mathrm{Ct}$ value of OCT3. UT- untransfected, aza- 5-aza-2'-deoxy-cytidine.

\subsection{Effect of inhibition of histone deacetylation on the expression of OCT3}

To find out whether inhibition of acetylation of histones has any effect on the expression of OCT3, cells were treated with valproic acid, an inhibitor of the enzyme histone deacetylase. Incubation of ACHN cells with $0.5 \mathrm{mM}, 5 \mathrm{mM}$ or $10 \mathrm{mM}$ valproic acid for $24 \mathrm{~h}$ did not result in any change in $\Delta \mathrm{Ct}$ value compared to the untreated ACHN cells (Fig. 4.38). 


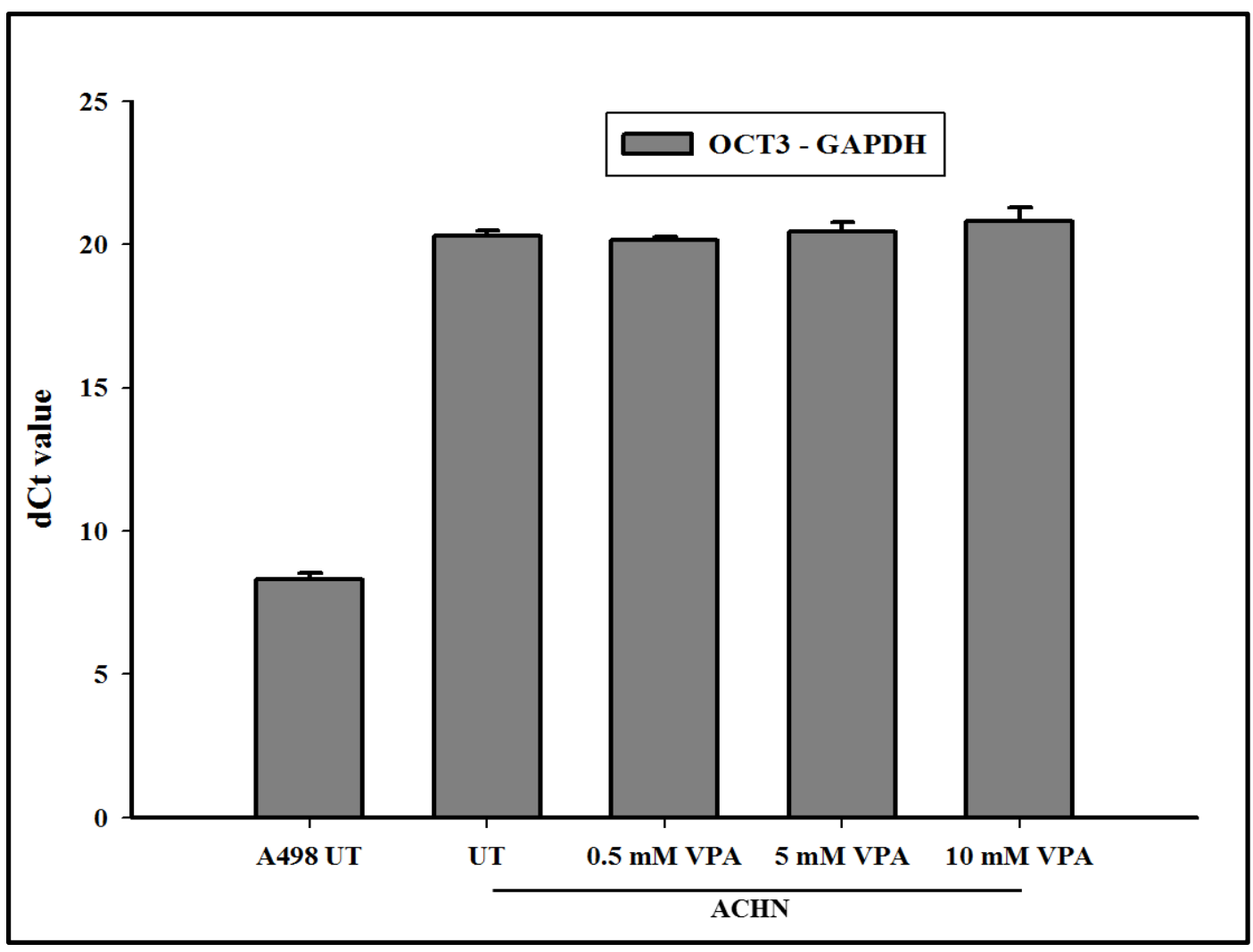

Figure 4.38 Expression of $\mathrm{OCT} 3$ in ACHN cells treated with valproic acid. ACHN cells were treated with $0.5 \mathrm{mM}, 5 \mathrm{mM}$ or $15 \mathrm{mM}$ valproic acid for $24 \mathrm{~h}$. qRTPCR was conducted with cDNA prepared from total RNA isolated from these cells along with untreated A498 and ACHN cells. The Ct values of OCT3 and GAPDH were obtained and the $\Delta \mathrm{Ct}$ values were obtained by subtracting the Ct (cycle of threshold) of GAPDH from the Ct value of OCT3. UTuntransfected. VPA-valproic acid.

\subsection{Determination of methylation status of CpG islands by Ion-Torrent sequencing of bisulfite treated DNA}

The fragments of interest were amplified, from all the cell lines, by PCR using the suitable annealing conditions, analyzed on a $2 \%$ agarose gel, and the bands were detected in a gel documentation chamber (Fig. 4.39). 
Fragment 1

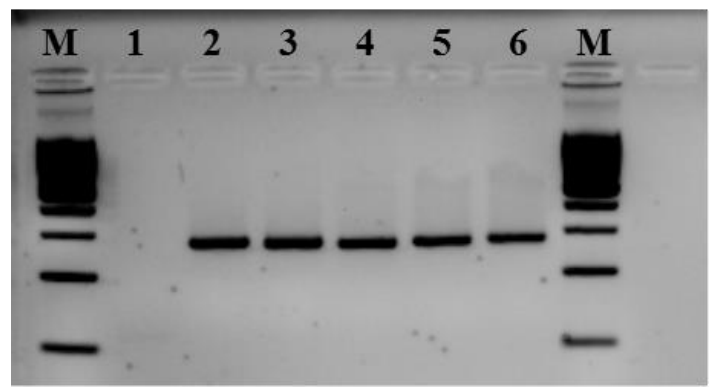

Fragment 2

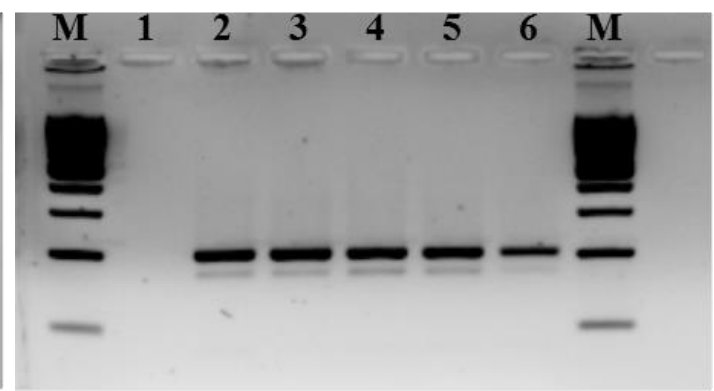

Figure 4.39 Amplification of fragments 1 and 2 from the promoter region of

SLC22A3. The fragments 1 and 2 were amplified using specific primers and analyzed on a $2 \%$ agarose gel. Lanes: M-100 bp ladder, 1 - negative control, 2 - A498, 3 - ACHN, 4 - RCCNG-1, 5 786-O, and 6 - LN78.

The obtained fragments were further subjected to adapter PCR wherein they were further amplified using specific primers which would make them distinct during the sequencing procedure (Fig. 4.40).

Fragment 1 adapter PCR

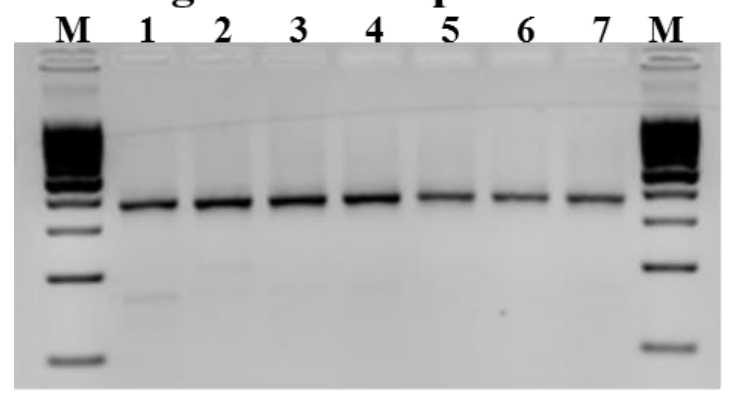

\section{Fragment 2 adapter PCR}

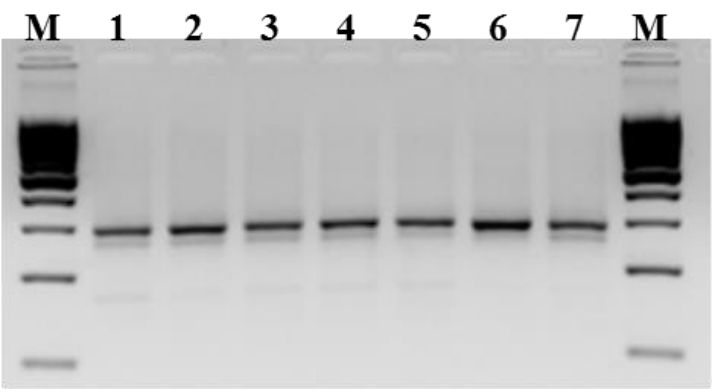

Figure 4.40 Adapter PCR of amplified fragments. The fragments 1 and 2 were further amplified using specific primers that contained barcode sequences, which make them distinctly recognized by the sequencer, and analyzed on a $2 \%$ agarose gel. Lanes: M-100 bp ladder, 1 A498, 2 - ACHN,3 - RCCNG-1, 4 - 786-O, 5 - LN78, 6 - renal epithelial cell pellet, 7 hepatocytes. 
These fragments were pooled, run on a $2 \%$ agarose gel and extracted from the gel. They were quantitated and used to prepare the template positive ion sphere particles which were sequenced. The methylation status of the $\mathrm{CpG}$ islands in the promoter fragments 1 and 2 was obtained by comparing the sequence obtained in the ion torrent sequencing run with the original sequence of the fragments amplified. There were $15 \mathrm{CpG}$ residues in the fragment 1 and they did not show a considerable difference among the renal carcinoma cells and the human renal cortical epithelial cell pellet used as a positive control. However, there was a considerable difference at the CpG positions 3-7 in LN78 cell line. The other CpG islands had similar levels of methylation as the other cell lines.

The $16 \mathrm{CpG}$ islands in fragment 2 did not show any marked differences between the four renal carcinoma cell lines. However, there was a high degree of hypomethylation in the control cells at the positions, 2, 3, and 9-16 (Fig. 4.41).

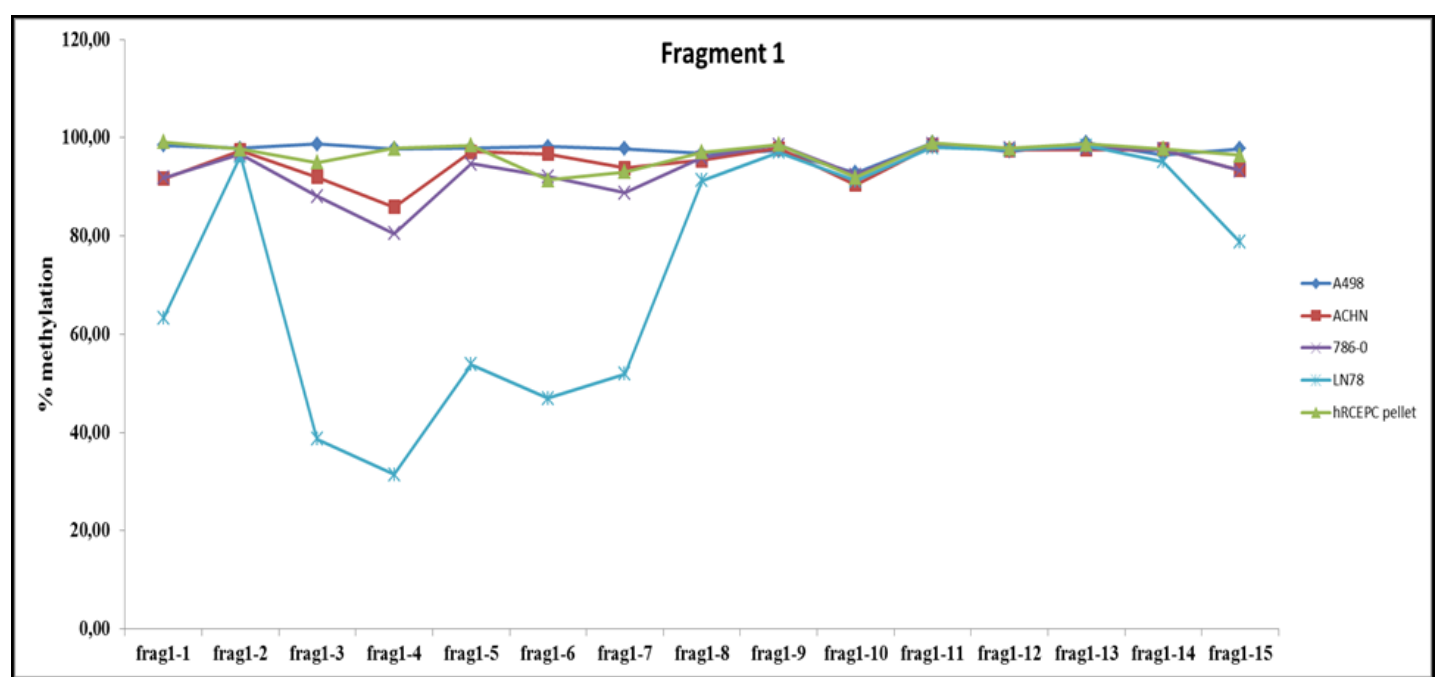




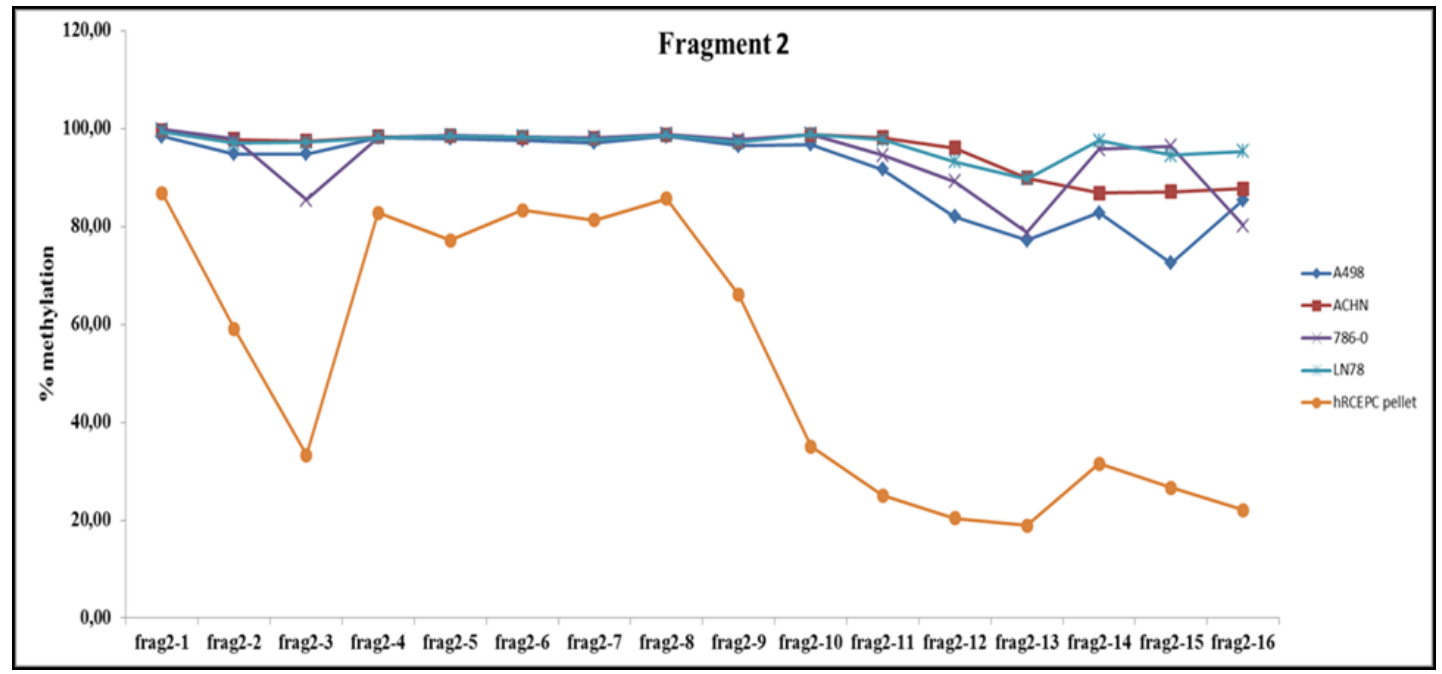

Figure 4.41 Analysis of methylation status of CpG islands in fragments 1 and 2 of the promoter region of SLC22A3. The fragments 1 and 2 in the promoter region were amplified using specific primers and subjected to ion torrent sequencing to analyze the methylation status of the $\mathrm{CpG}$ islands present in these fragments. The results were downloaded from the Torrent server within the program and \% methylation of each residue was calculated. The $\%$ methylation obtained was plotted against the number of $\mathrm{CpG}$ residue counted from the $5^{\prime}$ end of the template. hRCEPC - human renal cortical epithelial cell pellet.

\section{9. qRTPCR of expression of selected microRNAs in A498 and ACHN cells}

From the microRNA predicting programs, 11 microRNA species were selected as they were predicted from more than of the stronger prediction programs used for the study. qRTPCR of the selected microRNAs in A498 and ACHN cells revealed that two micro species hsa-mir-204 and hsa-mir-143 were highly expressed in A498 cells having the highest OCT3 expression. The small nucleolar RNAs, RNU48 and RNU43 were used as internal controls and $\Delta \mathrm{Ct}$ values were calculated by subtracting the $\mathrm{Ct}$ values of these RNAs from the corresponding microRNA. $2^{-\Delta \Delta C t}$ values were calculated by subtracting the $\triangle \mathrm{Ct}$ values of microRNAs in $\mathrm{ACHN}$ cells from that of the corresponding values in A498 cells. There were no microRNA species among the selected microRNAs which was 
highly expressed in ACHN cells which had low OCT3 expression (Fig.4.42). Two of the selected microRNAs did not show any expression in either of the cell lines.

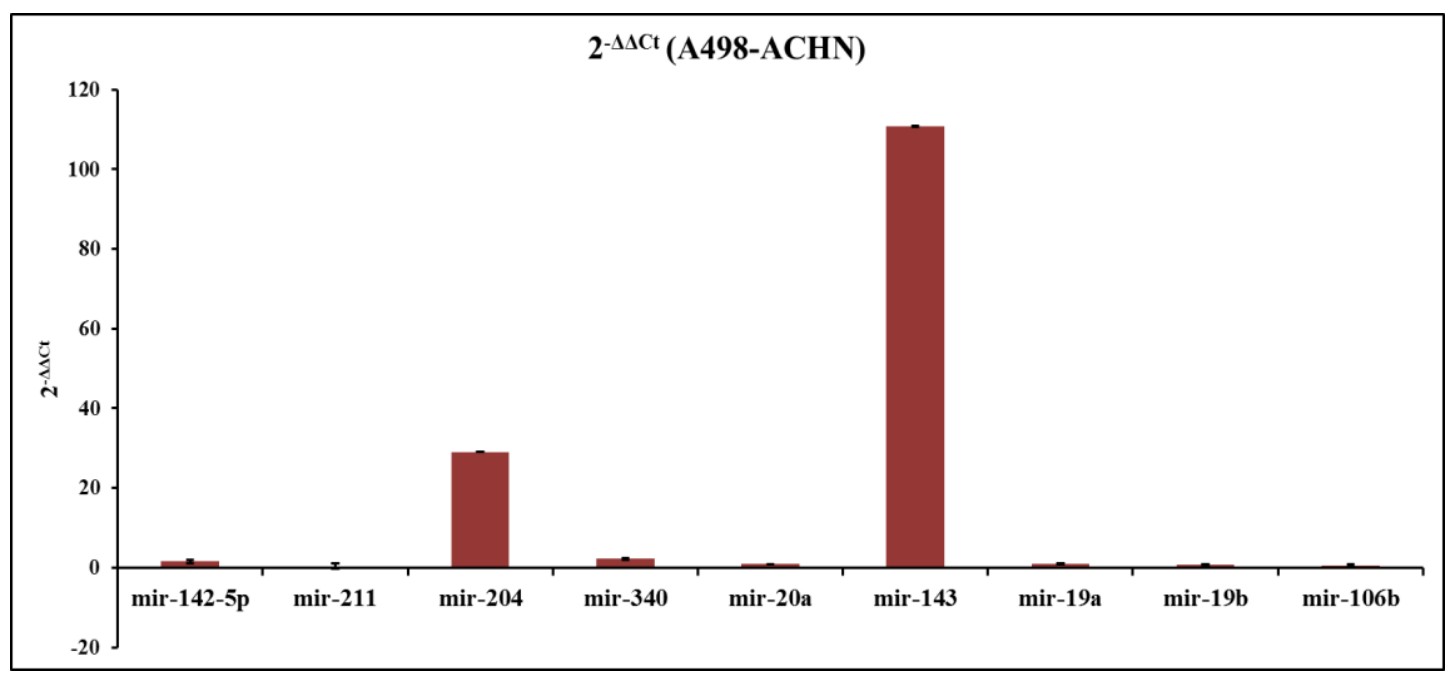

Figure 4.42 qRTPCR of microRNAs in A498 and ACHN cells. The $\Delta \mathrm{Ct}$ values were calculated by subtracting the expression of the control RNA (RNU48 and RNU43) from the corresponding microRNAs. The $\Delta \Delta \mathrm{Ct}$ values were obtained by taking A498 cells as reference.

\subsection{Manipulation of levels of hsa-mir-204 and hsa-mir-143 in A498 and ACHN cells using microRNA mimics and antimirs}

Transient transfection of microRNA mimics of hsa-mir-204 and hsa-mir-143 into ACHN cells led to an increase in the expression of mir-204 and mir-143, respectively; however, there was no consequence of this increase of the microRNAs on the expression level of OCT3. Similarly, there was a decrease in the expression levels of microRNAs 204 and 143 in A498 cells upon transfection with corresponding antimirs, but this did not lead to any change in the expression of OCT3 in these cells compared to untransfected cells (Fig. 4.43). 


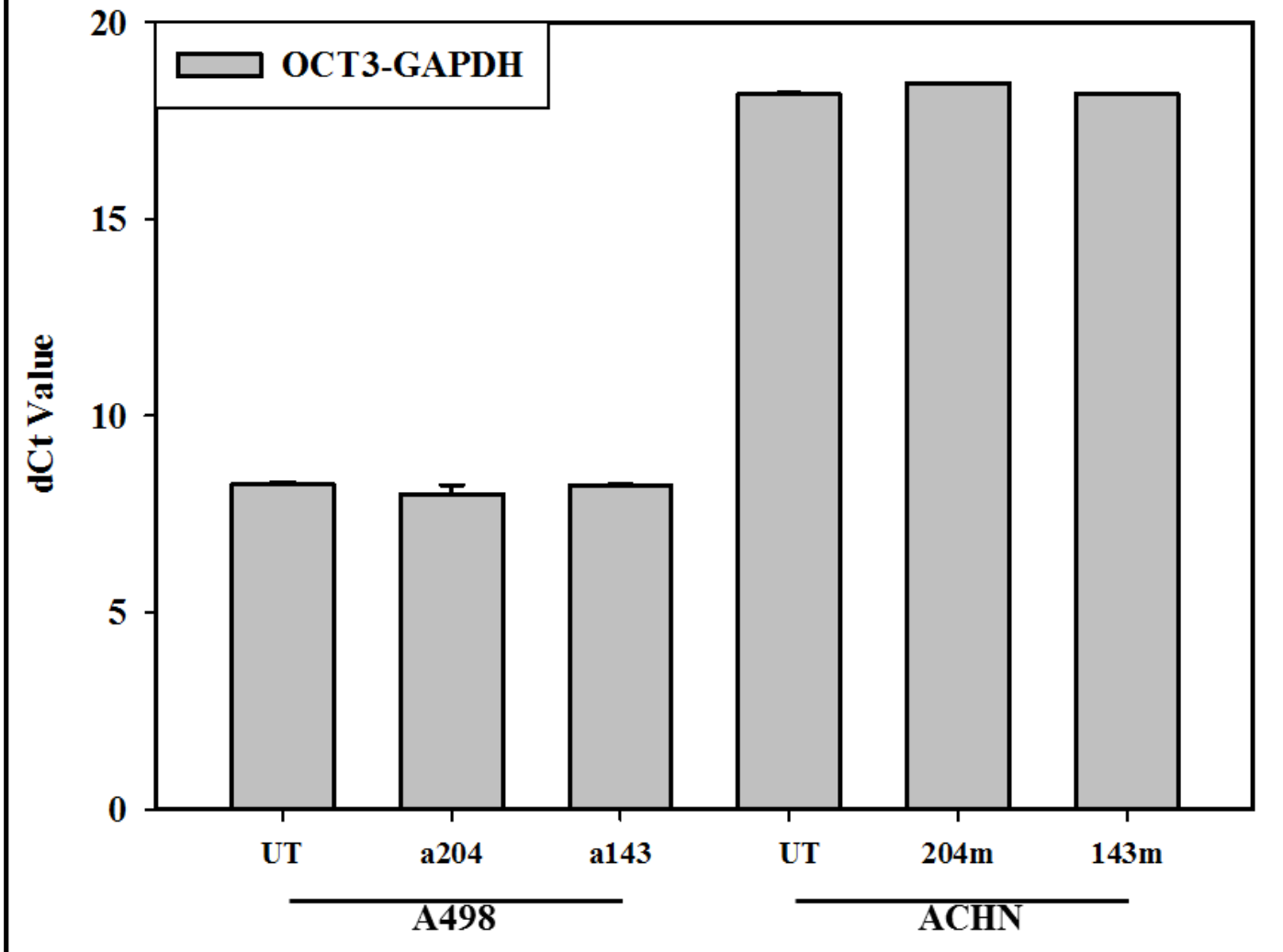

Figure 4.43 qRTPCR of SLC22A3 in A498 and ACHN cells upon transfection with microRNA mimics and antimirs, respectively. Mimics (m) and antimirs (a) directed against microRNAs hsa-mir-204 and hsa-mir-143 were transiently transfected into A498 and ACHN cells. qRTPCR was conducted with cDNA prepared from total RNA isolated from the cells. The Ct values of OCT3 and GAPDH were obtained and the $\Delta \mathrm{Ct}$ values were obtained by subtracting the $\mathrm{Ct}$ (cycle of threshold) of GAPDH from the Ct value of OCT3. UT- untransfected.

4.11. Genome wide analysis of microRNA in A498, ACHN, 786-O and LN 78 cells

Since our earlier approach of using prediction algorithms of microRNA binding to $3^{\prime}$ UTR of OCT3 to find out microRNAs potentially involved in regulating the expression of OCT3 did not yield a reliable result, we proceeded for the next generation sequencing of genome wide microRNA analysis. The run and analysis were performed by our 
colleagues at the DNA microarray and deep sequencing facility in Goettingen, under the supervision of Dr. Gabriela Salinas-Riester. For this purpose, the total RNA was isolated from A498, ACHN, 786-O and LN78 cells and subjected to next generation sequencing for genome wide analysis of microRNAs in the cells. The sequencing was performed on a HiSeq 2000 platform and the results were obtained as microRNA expression in one cell line vs microRNA present in another cell line. Many parameters were obtained such as mean expression among the triplicates, their ratios, the fold change in logarithmic scale with standard error and the significance values of the observed differences in expression between two RCCs.

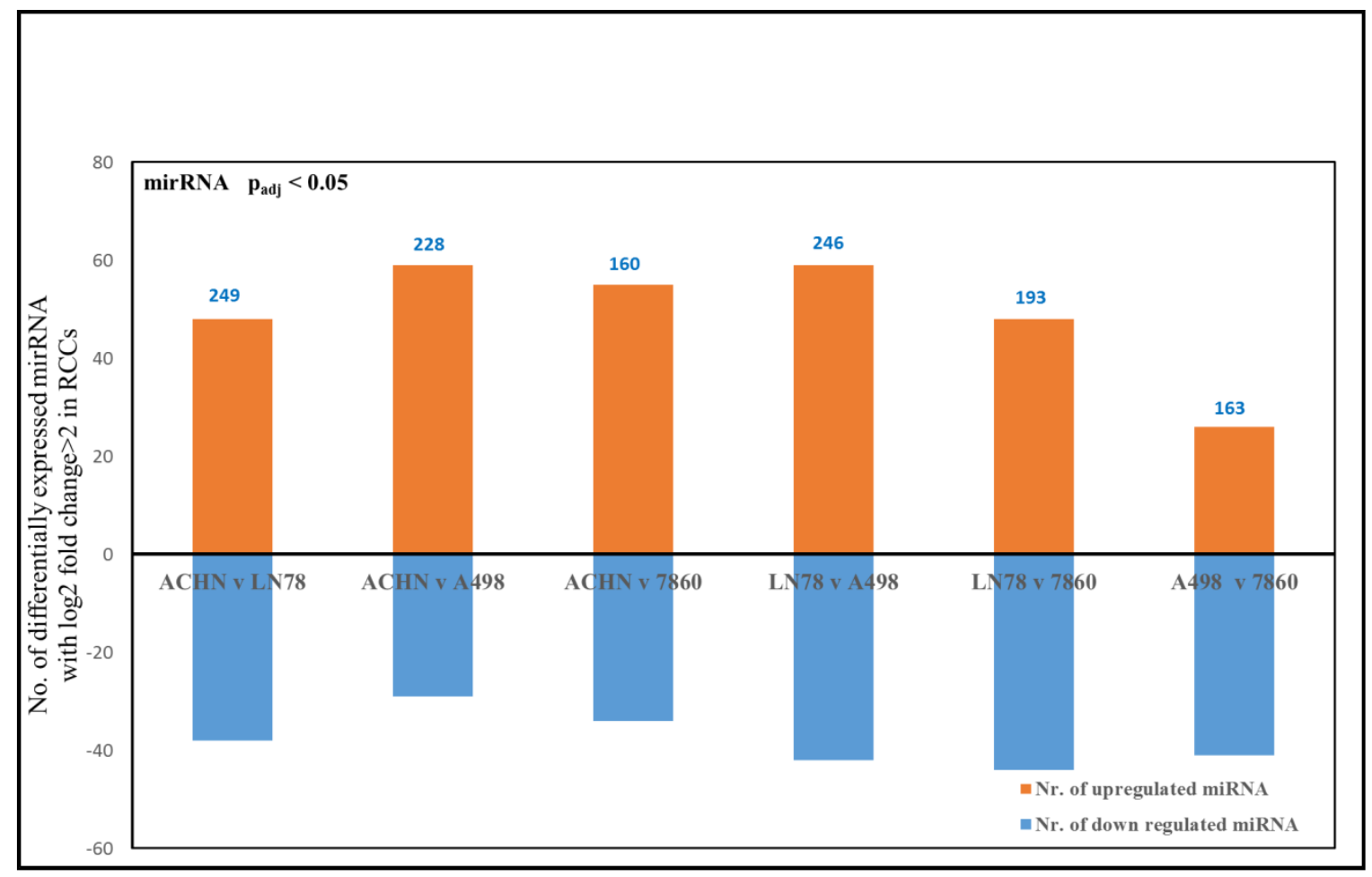

Figure 4.44. Expression patterns of various RNA species in the four cell lines.

The microRNAs which have a $\log 2$ fold change value of more than 2 are presented against each comparison of cell lines. The numbers above the bars indicate the total number of microRNAs with adjusted $p$ value of $<0.05$. The orange and blue bars depict the number of upregulated and down regulated microRNAs, respectively, in the cell line (A) in the representation of A vs B. 
As can be seen in figure 4.44 , there is a huge difference of expression of many of the small length RNAs among the cell lines. The microRNA species which have a $\log 2$ fold change of more than 2 are being analyzed further.

Furthermore, with a focus on ACHN cell line, which has least expression of OCT3, we found that a number of microRNAs are highly expressed in this cell line as depicted in figure 4.45 .

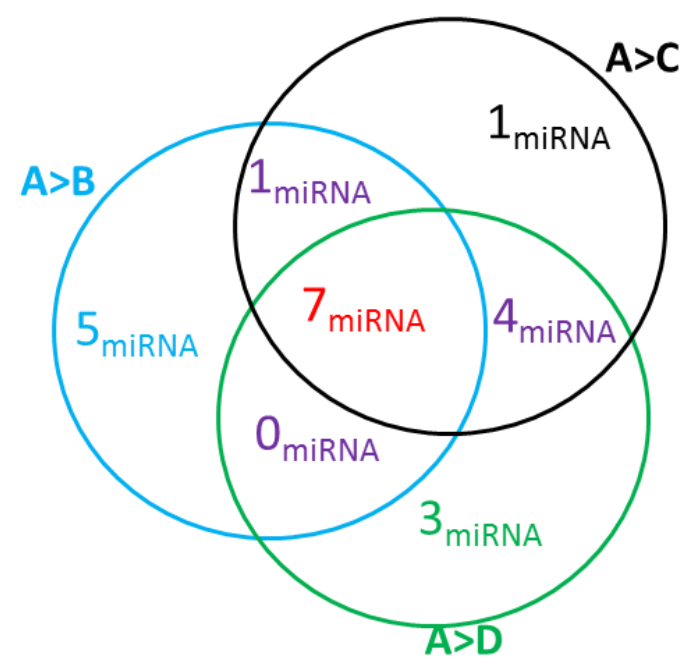

Figure 4.45 Number of microRNAs highly expressed in ACHN (A) and with zero expression in LN78 (B), A498 (C) and 7680 (D) cells.

In addition, there were some microRNAs that were found to be highly expressed in LN78, A498, and 786-O cells but not in ACHN cells as represented in figure 4.46

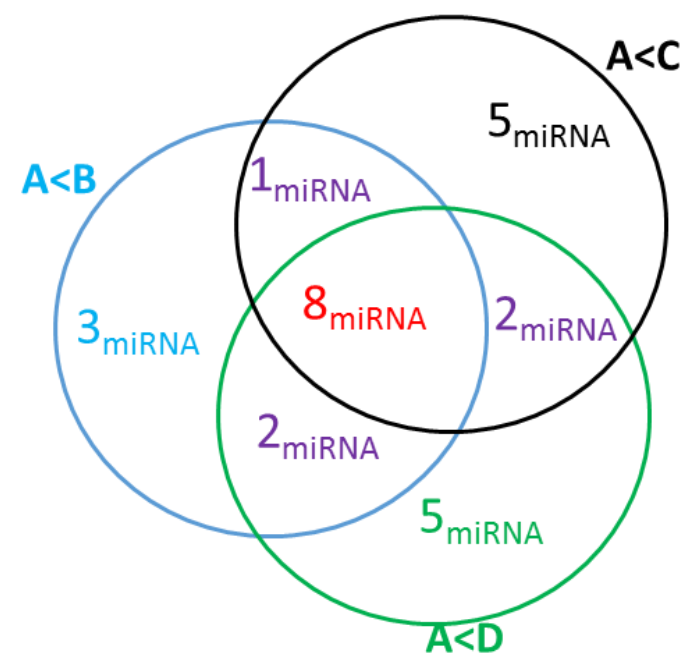

Figure 4.46 Number of microRNAs highly expressed in LN78 (B), A498 (C) and 7680 (D) cells but not in ACHN (A) cells 


\section{Discussion}

An important step in the elimination of drugs and xenobiotics is the absorption of these molecules from blood into the hepatocytes. It is not yet known, how many of the antineoplastic agents gain entry into the cells and what are the factors that influence this process. The objectives of the study were 1) To find whether the liver specific transporter proteins of SLC superfamily are involved in the interaction and eventual uptake of these compounds and 2) To understand the mechanisms of regulation of one of the SLC protein, the organic cation transporter 3 , in renal carcinoma cells.

\subsection{Interaction of OAT2, NTCP, OATP1B1 and OATP1B3 with antineoplastic compounds}

The present study is focused on four transporter proteins specifically expressed in the liver, organic anion transporter 2 (OAT2), sodium taurocholate cotransporting polypeptide (NTCP), and organic anion transporting polypeptides 1B1 (OATP1B1) and 1B3 (OATP1B3), and tested for their interaction with antineoplastic compounds. For studying these interactions, stably transfected human embryonic kidney cells expressing the corresponding transporter protein were used. The expression and function of the transporter proteins was characterized and used as a platform to study the interactions of transporter proteins with antineoplastic agents. The compounds that have been used as substrates for the transporter proteins have been described in literature and include cyclic guanosine monophosphate (cGMP) for OAT2, estrone-3-sulfate for NCTP and OATP1B1, while cholecystokinin octapeptide (CCK-8) was shown to be substrate of OATP1B3, respectively [11;152-155]. The Michaelis-Menten constant $\left(K_{m}\right)$ values generated in our expression systems were in line with the previous observations. We used one tenth of the $K_{m}$ values of the model substrate to perform the experiments under 
standardized conditions for all transporters. Using the uptake of the model substrates in the absence of any antineoplastic agent as a reference, we measured the uptake in the presence of $100 \mu \mathrm{M}$ of each one of the compounds. The high concentration of the compounds was used to find out any potential interactions. We considered, for kinetic analysis, only those interactions which led to an inhibition of the uptake (by100 $\mu \mathrm{M}$ ) to less than $40 \%$ of buffer control. We report, for the first time, a very high affinity of OAT2 for the antineoplastic drugs bendamustine and irinotecan, apart from a very strong interaction with paclitaxel as reported earlier [12]. Dixon plot analysis revealed the $K_{i}$ values of OAT2 for bendamustine, irinotecan, and paclitaxel to be $43.3 \pm 4.33 \mu \mathrm{M}, 26.4 \pm$ $2.34 \mu \mathrm{M}$ and $10.4 \pm 0.45 \mu \mathrm{M}$, respectively. None of the antineoplastic compounds studied inhibited the uptake of NTCP mediated estrone-3-sulfate to less than $40 \%$ of buffer control. Our observation of a strong interaction of OAT2 with paclitaxel is in line with a previous report [4] wherein the authors have measured the uptake of radiolabeled paclitaxel in OAT2 expressing oocytes. However, we did not see any interaction of OAT2 with 5-fluorouracil, as observed in the same report. It is not uncommon to see such differences in the substrate uptakes between those performed in oocytes and those performed in HEK cells or CHO cells. Besides OAT2, paclitaxel is also shown to be transported by OATP1B1 and OATP1B3 [156], and our experiments also show strong interaction between the two transport proteins and paclitaxel.

We observed a strong interaction of vinblastine and paclitaxel with OATP1B1. In addition, we observed a very strong stimulation of OATP1B1-mediated estrone 3-sulfate uptake by irinotecan. Similarly, OATP1B3 showed many significant interactions with the antineoplastic compounds tested. This might be an indication of its broad specificity for the substrates, and highlights its importance in drug mediated cytotoxicity and drug-drug interactions. The compounds chlorambucil, an alkylating agent; mitoxantrone, an 
intercalating agent; both the vinca alkaloids vincristine and vinblastine and paclitaxel, the other mitotic inhibitor tested; and the topoisomerase inhibitor etoposide all strongly interacted with varying effectiveness.

Until recently, there was no study showing any interactions of these antineoplastic agents other than paclitaxel with OATP1B1 and OATP1B3. However, in a quest for pharmacophore prediction, a study was conducted with as many as 225 drug-like compounds in search of their ability to interact with these two proteins $[157 ; 158]$. Although the study was conducted with stably transfected HEK cells as is the case with our experiments, there were a number of similarities as well as differences among the two. The authors used estradiol-17 $\beta$-gulucuronide as a model substrate for OATP1B1 and OATP1B3 and $20 \mu \mathrm{M}$ as the concentration of compounds whose interaction was studied. Similar to their observation, we also found comparably strong interactions of OATP1B1 and OATP1B3 with vinblastine. In addition, we did not find any interaction between methotrexate and OATP1B1 as has been previously reported [159]. However, contrary to that study, we found a very strong inhibition of OATP1B3-mediated CCK-8 uptake by mitoxantrone and etoposide, with $K_{i}$ values of $15.9 \mu \mathrm{M}$ and $3.25 \mu \mathrm{M}$, respectively, suggesting a very high affinity of the transporters for these compounds, apart from paclitaxel which seems to be the antineoplastic agent with the highest affinity of all the compounds tested in this study. Differences like these have been observed in the past and they are shown to arise from the choice of the substrate used in the experiments [160]. This is further strengthened by another study wherein the authors used sodium fluorescein as a substrate and measured the interactions in Chinese Hamster Ovary cells and observed that $10 \mu \mathrm{M}$ paclitaxel inhibited the OATP1B1 and OATP1B3 mediated uptake of sodium fluorescein to $16.4 \%$ and $52.9 \%$ of buffer control, respectively [6]. As mentioned above, using estrone-3-sulfate and CCK-8 as substrates, we observed a very strong interaction of 
paclitaxel with both the OATP transporters with $K_{i}$ values of $0.84 \mu \mathrm{M}$ and $1.8 \mu \mathrm{M}$, respectively.

Apart from the inhibition of transporter mediated uptake, we also observed stimulation of uptake of the corresponding substrates. The most pronounced stimulation was observed in the presence of irinotecan on the uptake of estrone 3-sulfate by OATP1B1. Stimulation of OATP mediated uptake by another compound has been observed earlier by Wang et al similar to our observation of increased estrone 3-sulfate uptake in the presence of irinotecan [161;162] and also in the study mentioned above [157;158]. The stimulation indicates a complex transport mechanism of OATPs in general and might be due to the presence of more than one binding site on OATPs [163]. Most of the interacting compounds are bulky and hydrophobic, a feature consistent with the notion that OATPs are involved in the transport of such compounds.

Now that the interactions are established between the antineoplastic compounds and OAT2, OATP1B1, and OATP1B3 transporters, more questions arise: firstly, whether these interactions lead to drug-drug interactions in vivo and secondly, whether these compounds are transported into the cell. To consider the obtained kinetic parameters for prediction of in vivo drug-drug interactions, it is necessary to know the unbound fractions of the antineoplastic compounds in circulation. The unbound fractions of these compounds in circulation were obtained from Goodman and Gilman's "The pharmacological basis of therapeutics" $10^{\text {th }}$ edition and literature [164] and the peak plasma concentrations were calculated as per the standard dosages of administration of these compounds during the course of chemotherapy.

The possibility of a compound interacting with OAT proteins to contribute to drug-drug interactions in vivo was described previously [66]. Applying the same principle (unbound 
$\left.\mathrm{C}_{\max } / \mathrm{IC}_{50} \geq 0.1\right)$ to the three inhibitors of OAT2 observed in our study, we found that irinotecan has the potential to contribute to drug-drug interactions in vivo, while the compounds bendamustine and paclitaxel do not. Similarly, in the case of OATPs, for a compound to be possibly involved in drug-drug interaction, it was suggested that the $\mathrm{IC}_{50}$ value shall be less than or equal to 10 times the unbound $\mathrm{C}_{\max }$ of the drug [66]. Applying the same principle with the $\mathrm{IC}_{50}$ values, the antineoplastic compound paclitaxel in the case of OATP1B1, and the compounds mitoxantrone, paclitaxel and etoposide for OATP1B3 are potential candidates to inhibit the corresponding transporter protein in vivo and contribute to drug-drug interactions. The following table summarizes the unbound fraction, and the peak plasma concentration of the antineoplastic compounds interacting with transporter proteins.

\begin{tabular}{|c|c|c|c|c|c|}
\hline $\begin{array}{c}\text { Transporter } \\
\text { protein }\end{array}$ & Compounds & $\begin{array}{c}\text { Fraction of } \\
\text { unbound } \\
\text { compound }\end{array}$ & $\begin{array}{c}\text { Peak plasma } \\
\text { concentration }\end{array}$ & IC $_{50}$ values & $\begin{array}{c}\text { Possibility } \\
\text { of drug- } \\
\text { drug } \\
\text { interaction }\end{array}$ \\
\hline OAT2 & Bendamustine & 0.05 & $14.8 \mu \mathrm{M}$ & $16.88 \mu \mathrm{M}$ & No \\
\hline OAT2 & Irinotecan & 0.51 & $2.89 \mu \mathrm{M}$ & $7.55 \mu \mathrm{M}$ & Yes \\
\hline OAT2 & Paclitaxel & 0.12 & $0.85 \mu \mathrm{M}$ & $1.44 \mu \mathrm{M}$ & No \\
\hline OATP1B1 & Vinblastine & 0.14 & $5.75 \mu \mathrm{M}$ & $46.8 \mu \mathrm{M}$ & No \\
\hline OATP1B1 & Paclitaxel & 0.12 & $0.85 \mu \mathrm{M}$ & $0.28 \mu \mathrm{M}$ & Yes \\
\hline OATP1B3 & Chlorambucil & 0.01 & $1.67 \mu \mathrm{M}$ & $80.7 \mu \mathrm{M}$ & No \\
\hline OATP1B3 & Mitoxantrone & 0.25 & $15.56 \mu \mathrm{M}$ & $3.39 \mu \mathrm{M}$ & Yes \\
\hline OATP1B3 & Vinblastine & 0.14 & $5.75 \mu \mathrm{M}$ & $43.5 \mu \mathrm{M}$ & No \\
\hline OATP1B3 & Vincristine & 0.4 & $0.56 \mu \mathrm{M}$ & $36.78 \mu \mathrm{M}$ & No \\
\hline OATP1B3 & Paclitaxel & 0.12 & $0.85 \mu \mathrm{M}$ & $0.26 \mu \mathrm{M}$ & Yes \\
\hline OATP1B3 & Etoposide & 0.12 & $45.8 \mu \mathrm{M}$ & $4.18 \mu \mathrm{M}$ & Yes \\
\hline
\end{tabular}


Table 5.1. Possibility of compounds to contribute to the transporter mediated drug-

drug interactions. "The fraction of compound unbound to protein was obtained from literature [164] and from BC cancer agency drug manual. ${ }^{\mathrm{b}}$ The peak plasma concentrations were obtained from Goodman and Gilman's "The pharmacological basis of therapeutics" $10^{\text {th }}$ edition and literature [165]. ${ }^{\mathrm{c}} \mathrm{IC}_{50}$ values were calculated from uptake values measured at $1 \mu \mathrm{M}$ cGMP substrate or $0.25 \mu \mathrm{M}$ ES or $1 \mu \mathrm{M}$ CCK- 8 as substrate, respectively, in the presence of increasing concentration of the corresponding antineoplastic compound. ${ }^{\mathrm{d}}$ Possibility of contribution of drugdrug interactions in vivo is calculated from literature[166].

To understand the selectivity of transporter proteins for some of the antineoplastic drugs, we analyzed the molecular parameters of the compounds using the MarvinSketch software (Tab. 5.2). The obtained parameters $\log \mathrm{P}, \log \mathrm{D}$, polar surface area (psa) and net charge at $\mathrm{pH} 7.4$, did not markedly vary among the compounds which interacted with OAT2 and the compounds which did not interact. Moreover, the net charge at $\mathrm{pH} 7.4$ of bendamustine, irinotecan and paclitaxel was $-1,+1$ and 0 , respectively. In addition, we obtained that $87.4 \%$ of vinblastine at $\mathrm{pH} 7.4$ exists in a "+2" ionization state (Table 5.2). Likewise, $99.5 \%$ of paclitaxel exists in an uncharged state at the same $\mathrm{pH}$. This is at odds with the fact that OATP1B1 interacts with and transports negatively charged species. It has also been proposed that high molecular weight (> $300 \mathrm{~g} / \mathrm{mol}$ ) is one of the various criteria that are responsible for distinction of a compound to be a substrate of OATPs [6]. The fact that both these compounds are bulky high molecular weight molecules (810.9 $\mathrm{g} / \mathrm{mol}$ and $853.9 \mathrm{~g} / \mathrm{mol}$, respectively) seems to support their candidature. However, the selectivity of the protein for vinblastine, but not for vincristine (also a " +2 " charged compound, with comparable molecular weight of $824.9 \mathrm{~g} / \mathrm{mol}$ ) suggests that there is some other specificity factor that drives these interactions. 
Table 5.2 Molecular parameters of the compounds used in the study

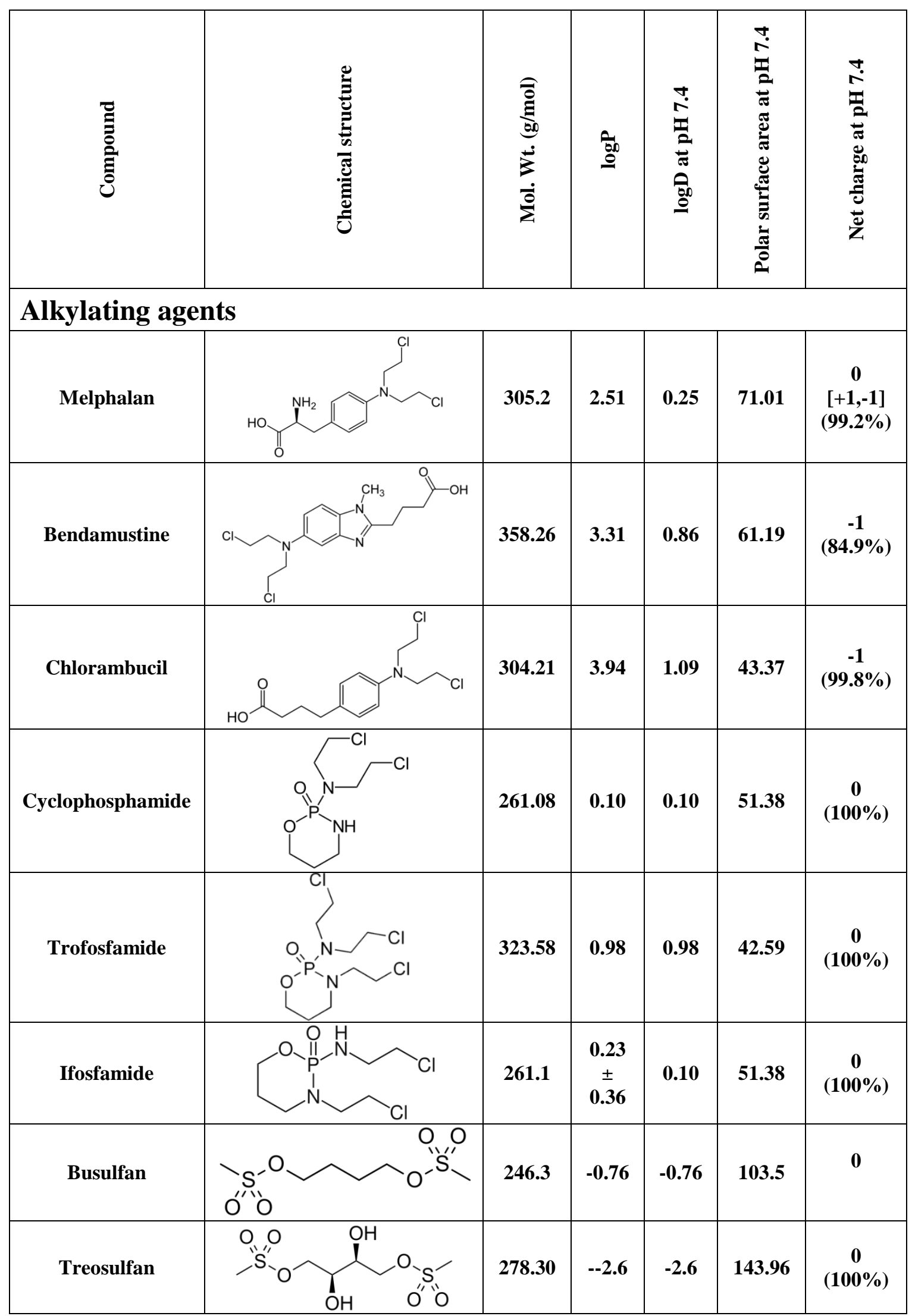


Discussion

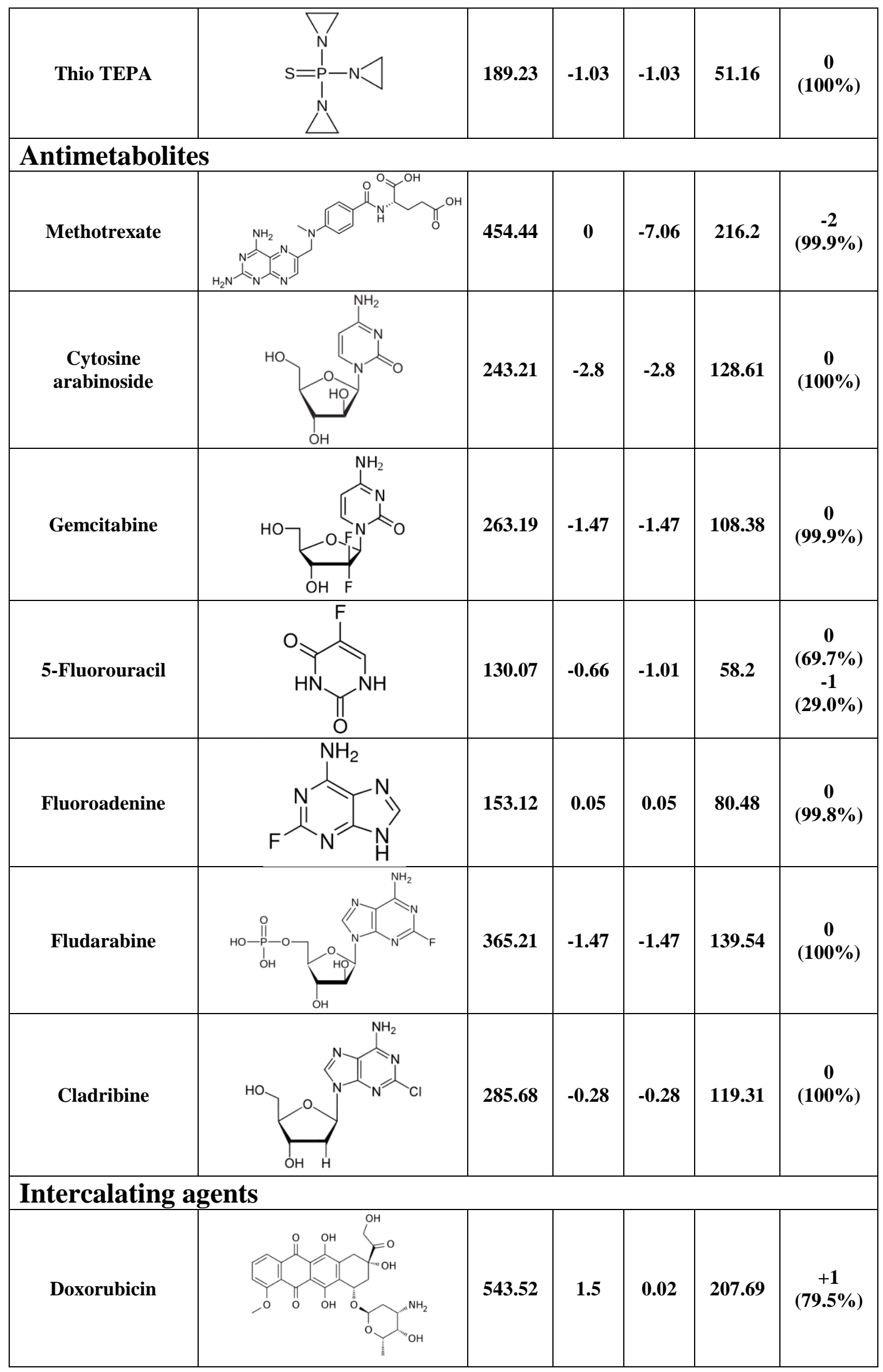




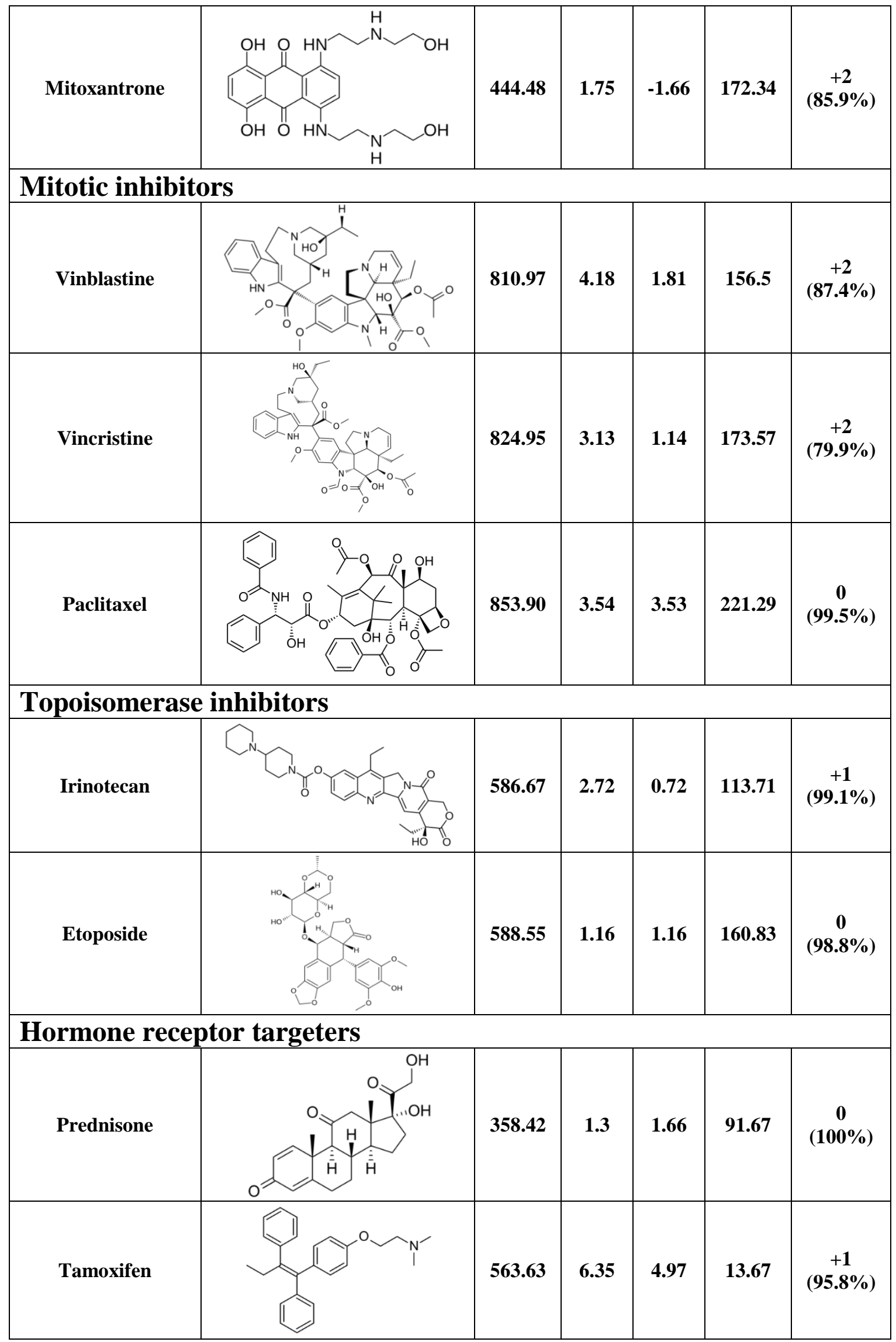




\begin{tabular}{|c|c|c|c|c|c|c|}
\hline Clodronic acid & 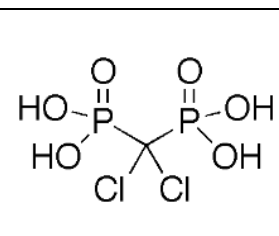 & 244.89 & -0.07 & -5.05 & 143.17 & $\begin{array}{c}-2 \\
(43 \%) ; \\
-3 \\
(48 \%) ; \\
-4 \\
(09 \%)\end{array}$ \\
\hline
\end{tabular}

The polar surface area was not markedly different either among the compounds which inhibited the transporter activity of OAT2, OATP1B1 or OATP1B3 and those which did not (Figure 5.1). Similarly the other parameters like $\log P$ value or $\log \mathrm{D}$ value were not considerably different between inhibitors and non-inhibitors and no correlation was observed between the parameters obtained from the software and the interactions observed.
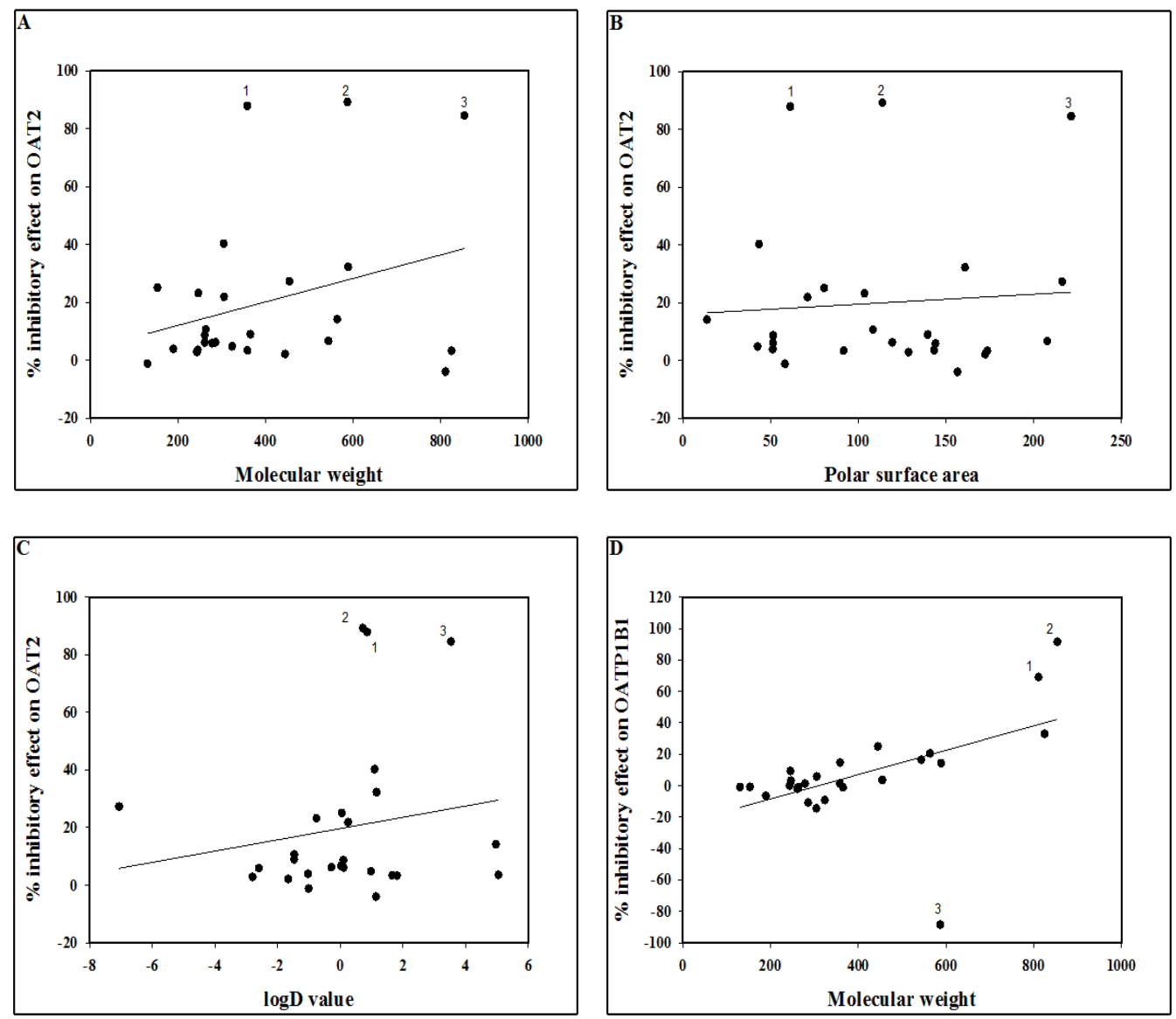

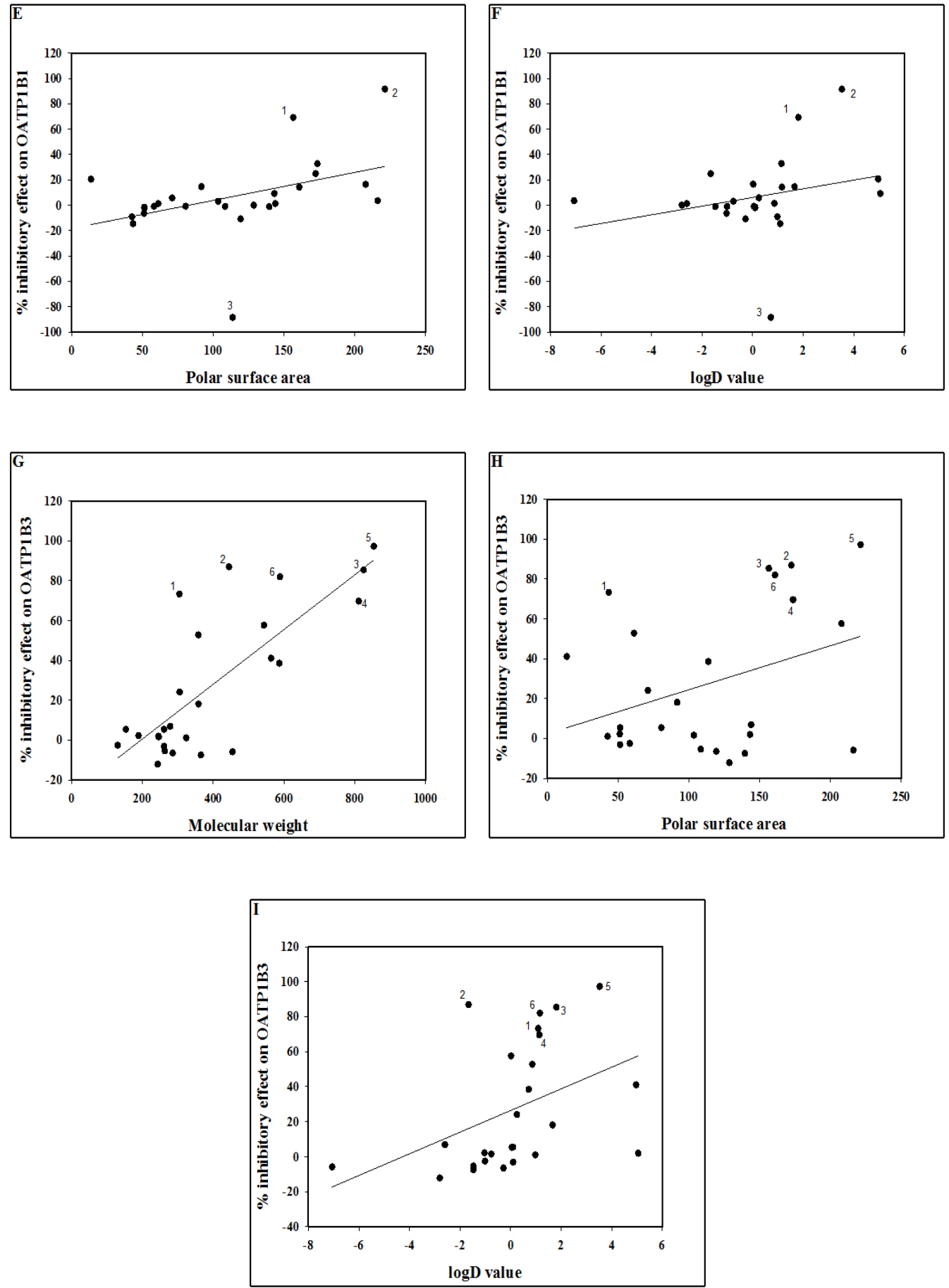

Figure 5.1 Correlation plots of inhibitory effect of antineoplastic compounds and their molecular parameters

Correlation plots of $\%$ inhibitory effect of OAT2 mediated cGMP uptake with molecular weights (A), polar surface area (at $\mathrm{pH}$ 7.4) (B), and $\log \mathrm{D}$ value (at $\mathrm{pH}$ 7.4) of the antineoplastic compounds (C); 1, 2 and 3 represent bendamustine, irinotecan and paclitaxel, respectively; 
OATP1B1 mediated ES uptake with molecular weights (D), polar surface area (at pH 7.4) (E), and $\log \mathrm{D}$ value (at $\mathrm{pH}$ 7.4) of the antineoplastic compounds $(\mathrm{F}) ; 1,2$, and 3 represent vinblastine, paclitaxel and irinotecan, respectively; OATP1B3 mediated CCK-8 uptake with molecular weights $(\mathrm{G})$, polar surface area $($ at $\mathrm{pH}$ 7.4) $(\mathrm{H})$, and $\log \mathrm{D}$ value (at $\mathrm{pH}$ 7.4) of the antineoplastic compounds;1-chlorambucil, 2-mitoxantrone, 3-vinblastine, 4-vincrsitine, 5-paclitaxel, and 6etoposide.

The other point to understand was whether the interactions observed lead to the uptake of these transporters, with a focus on OAT2. As paclitaxel has already been shown to be a substrate of OAT2 [12], we concentrated on the other two compounds, bendamustine and irinotecan.

\subsubsection{Bendamustine is a substrate of organic anion transporter 2}

As we saw an interaction between the OAT2 and the compounds, bendamustine, irinotecan and paclitaxel, we set out to find whether they are inhibitors alone or they can be transported by OAT2. Bendamustine is increasingly being recognized as the frontline therapy for chronic lymphocytic leukemia (CLL) [167-169] and also in the treatment of other lymphomas [170;171]. Structurally bendamustine contains alkylating and antimetabolite (purine analog) groups. It belongs to the nitrogen mustard group of molecules but its mode of action is predominantly as an alkylating agent, and the antimetabolite effect of this compound is not evident yet [172]. As far as we know, there is nothing known as to how bendamustine gains entry into the liver cells. Since we did not observe any interaction of OAT2 with chlorambucil which is very similar in structure to bendamustine or with any of the purine analogs tested, it is not possible with this data to conclude which functional group of bendamustine might be responsible for its interaction with OAT2. To find whether they are transported by OAT2, we focused on an 
event that would occur if the antineoplastic drugs use the transporter protein to get into the cells, i.e. apoptosis. For measuring OAT2 mediated, bendamustine uptake induced apoptosis; we performed the caspase-3 assay wherein the OAT2 expressing cells treated with bendamustine showed an increase in the caspase- 3 activity compared to the untreated OAT2 expressing cells and the control cells with or without treatment. The fact that the bendamustine induced increase in caspase- 3 activity was diminished almost completely in the presence of probenecid demonstrates the specificity of this OAT2 mediated process. Similar experiments with irinotecan showed a high increase in apoptosis in pcDNA as well as OAT2 expressing cells with or without inhibitor, suggesting strong OAT2 independent accumulation of the compound in the conditions we used. This led us to believe that a protocol needs to be employed which allows the study with shorter incubation time.

\subsubsection{Irinotecan is a substrate of organic anion transporter 2}

Irinotecan, also referred to as CPT 11 , is a water soluble derivative of camptothecin and a well-known topoisomerase inhibitor. It inhibits the topoisomerase I, an enzyme which relaxes DNA supercoils formed during the processes of DNA replication and transcription, leading to breaks in DNA that result in DNA fragmentation [32]. It is a common component of combination chemotherapeutic regimens that are in clinical trials for its efficacy in certain cancers like small cell lung cancer, colorectal cancer and pancreatic cancer $[58 ; 59 ; 173]$. There is little information as to how irinotecan is taken up into the cell. The active metabolite of irinotecan, $\mathrm{SN}-38$, but not irinotecan as such, was shown to be a substrate for the transporter protein OATP1B1 [174]. In our experiments we found that it interacted strongly with OAT2, but not with NTCP. We employed HPLC analysis as it is highly sensitive and hence can detect irinotecan uptake even at lower 
incubation periods, as described earlier [175]. A standard curve was developed for irinotecan as well as for the internal standard camptothecin and the observed amounts of irinotecan in the cell lysates were in the linear range of the curve. An interesting point to be noted is that, in our experiments, we did not find any peak for SN38, a hydrolysis product of irinotecan, which is the active metabolite of the compound mostly responsible for its in vivo activity. Accumulation of irinotecan was observed in both control cells and OAT2 expressing cells by HPLC analysis with fluorescence specific detection of irinotecan, suggesting a nonspecific accumulation in addition to the transporter mediated uptake. However, transporter mediated uptake exceeded the nonspecific accumulation of irinotecan in OAT2 expressing cells. This enabled us to determine the affinity $\left(K_{m}\right)$ of OAT2 for irinotecan, which was determined to be $42.37 \mu \mathrm{M}$. In addition, co-incubation of irinotecan with $100 \mu \mathrm{M}$ probenecid did not cause any inhibition on the OAT2 specific uptake of irinotecan. In parallel experiments, conducted by a colleague in the department, the $K_{i}$ value of OAT2 for probenecid was determined to be $778.9 \mu \mathrm{M}$. This led us to believe that as we were working with shorter time periods, we needed a stronger inhibitor of OAT2 than probenecid to see a profound effect, and for this reason, we chose unlabeled cGMP, the model substrate of OAT2. Inhibition of the accumulation of irinotecan in the presence of cGMP in OAT2 expressing cells alone confirmed that this increase was transporter specific. This strongly suggests that irinotecan is a substrate of OAT2.

To conclude, the transporters OAT2, OATP1B1 and OATP1B3 interact with many of the antineoplastic compounds tested, and there exists a possibility of these transporters to contribute to the transporter mediated drug-drug interactions in vivo. As mentioned earlier, uptake transporters contribute at the initial stages of absorption, distribution, metabolism and excretion (ADME) of an exogenous compound. The uptake transporters 
expressed in hepatocytes are especially important because liver is the center of xenobiotic metabolism. Although there is literature about many of the mechanisms involved in the activation of xenobiotic compounds, their interaction with efflux transporters, pathways of their excretion, it is not yet known how many of these compounds enter into the cells. The current study throws light on the possible roles played by the hepatic uptake transporters in the uptake of compounds found to interact with them. The contribution of these transporters to such interactions has to be verified in patients, wherein a complex network of transporter proteins works in tandem. However, such drug-drug interactions exert an influence on the combination chemotherapy of various cancers. Apart from the interactions with antineoplastic compounds, the regulation of expression of transporters also plays an essential role in the effectiveness of its interacting partner. This fact was evident from one of the earlier studies in the department, wherein the uptake of MPP was dependent on the level of expression of OCT3 in renal carcinoma cell lines [141].

\subsection{Regulation of organic cation transporter 3 in renal carcinoma cells}

In the above mentioned study focused on the expression of transporters in the renal carcinoma cell lines A498, ACHN, 786-O, RCCNG-1, and LN78, it was found that the organic cation transporter 3 (OCT3) was expressed at varying levels. While A498 had highest expression of OCT3 among the cell lines, ACHN had the least with 12 cycle difference in $\Delta \mathrm{Ct}$ values. The difference between the uptake of the model substrate MPP between A498 and ACHN cells was comparable to that observed between OCT3 transfected Chinese Hamster Ovary (CHO) cells and mock $\mathrm{CHO}$ cells. The current study is aimed to decipher the possible reasons for this variable expression pattern of OCT3 in the renal carcinoma cells. As mentioned in section 1.10, some studies have been performed on the expression of OCT3 in other cell systems at the genetic, epigenetic, 
transcriptional and post-translational levels in various model systems. In the current study, we looked at regulation of OCT3 at epigenetic and post-transcriptional levels.

\subsubsection{Epigenetic regulation of OCT3 in renal carcinoma cells}

A decrease in the expression of OCT3 in hepatocellular carcinoma compared to the tumor surrounding tissue was reported earlier [145]. Of the epigenetic mechanisms described in section 1.9.1, we looked at the impact of histone modification and DNA methylation on the expression of OCT3 in renal carcinoma cells. These two modifications play a major role in the regulation of gene expression as observed earlier [176]. While histone acetylation increases the transcriptional activity of a gene, histone deacetylation and DNA methylation reduce its expression. Inhibition of histone deacetylation has been shown to promote transcription of a gene. Treatment of cells with inhibitors of histone deacetylation was shown to increase the expression of transporters such as excitatory amino acid transporter 3 (EAAT3 or EAAC1) encoded by SLC1A1 [177].

In order to find out whether the high level of deacetylation of histones is the reason for the low expression of OCT3 in ACHN cells, we used valproic acid, an inhibitor of histone deacetylases. Treatment of ACHN cells with valproic acid did not change the expression level of OCT3 in them, suggesting that histone deacetylation is not the reason for the excessively low expression of OCT3 in ACHN cells. Similarly, hypermethylation of DNA hinders the transcription of DNA. 5-Aza-2'-deoxycytidine, also known as decitabine, is an inhibitor of DNA methyltransferase and treatment of cells with this compound was shown to restore the expression of monocarboxylate transporter 3 (MCT3) encoded by SLC16A8 [178]. To find out whether hypermethylation of DNA was the cause of low expression of OCT3 in ACHN cells, we treated the cells with 5-Aza-2'deoxycytidine. Treatment of ACHN cells with 5-Aza-2'-deoxycytidine decreased the $\Delta \mathrm{Ct}$ 
value by ca. two suggesting an increase of the expression of OCT3; however, this increase was not responsive to increasing concentrations of the compound. The increase observed does not explain the 12 cycle $\Delta \mathrm{Ct}$ difference observed between A498 and ACHN cells. Apart from exerting external perturbations on the possible regulation mechanism, we also wanted to know whether the methylation levels of $\mathrm{CpG}$ residues in the promoter are responsible for this variable expression. To achieve this, we performed a next generation sequencing based on bisulfite conversion of unmethylated cytosines to uracil, referred to as Ion Torrent Sequencing.

\subsubsection{Impact of methylation of promoter region on the expression of organic cation transporter 3 .}

Promoter methylation was previously shown to be responsible for the epigenetic downregulation of the expression of the uptake transporter organic anion/carnitine transporter 2 (OCTN2) encoded by SLC22A5, in some cancer cell lines [87]. The down-regulation of OCT3 observed in hepatocellular carcinoma compared to the tumor surrounding tissue [145] was not due to any difference in the methylation status of the promoter region of OCT3 [179]. Methylation status of the promoter regions 1 and 2 of SLC22A3 gene in the four cell lines was determined using Ion Torrent sequencing technique. It was clear from the results that there was no substantial difference in the methylation patterns in the regions 1 and 2 of promoter of OCT3 gene in the $\mathrm{CpG}$ residues in the promoter among the four cell lines. However the methylation pattern of the positive control, human cortical renal epithelial cell pellet was markedly different and showed extensive hypomethylation in many of the $\mathrm{CpG}$ residues. This observation is in line with the observations of a previous study conducted on the promoter of OCT3 in hepatocellular carcinomas [179]. In addition, the expression of OCT3 in hepatocellular carcinoma was 
not markedly different between the normal and tumor tissue, unlike what we observed comparing the RCCs with normal kidney cells. From the above results, it must be concluded that the epigenetic modifications tested, or the methylation status of promoter do not explain for the huge difference of expression of OCT3 between A498 and ACHN cells.

\subsubsection{Investigation of microRNA dependent post-transcriptional regulation of organic cation transporter 3}

MicroRNAs are being increasingly recognized as regulators of expression of a variety of genes and often engage in crosstalk between adjacent pathways. They were shown to regulate the expression of transporter proteins as well such as the SLC16A1 gene product, monocarboxylate transporter 1 (MCT1) [180]. MicroRNAs have been shown to alter the chemotherapeutic potential of antineoplastic compounds [181]. MicroRNAs are a group of non-coding RNAs that have been implicated in the regulation of many genes including transporters. As the binding of microRNA to its target messenger RNA was found to be with incomplete complementarity, programs were developed which use computational algorithms to predict possible targets of microRNA in silico. Using strong prediction algorithms, supported by correlation studies [117], a data set was generated from predicted species using various algorithms which predict microRNAs binding to $3^{\prime}$ untranslated region of OCT3 mRNA, and consensus predictions were picked up for further analysis. The expression of 11 such microRNA species was obtained by qRTPCR. While two of the microRNAs were not expressed quantifiably, there was a differential expression of the rest among the cell lines A498 and ACHN. Of these, the microRNAs hsa-mir-204 and hsa-mir-143 showed high expression in A498 cell line which had high OCT3 expression. This was against to what was expected as the expression of 
microRNAs was supposed to be in inverse correlation with the expression of their targets. Interestingly, hsa-mir-204 was shown to increase the chemosensitivity of neuroblastoma cells to cisplatin [181]. However, it has been shown that cisplatin is transported by OCT1 and OCT2, but not by OCT3 [182]. On the other hand, it was shown to be at least partially responsible for cisplatin uptake in human cervical cancer cells [183]. In addition, microRNA 204 was implicated as a tumor suppressor [184;185] and maintenance of epithelial physiology [186]. Similarly, microRNA 143 was also reported to be a tumor suppressor [187;188]. MicroRNA 143 was implicated in conferring chemosensitivity on colorectal cancers to oxaliplatin. Although the target was established, the mechanism of increase of chemosensitivity has not been explained [189]. It is worthwhile to mention here that oxaliplatin was shown to be transported by OCT3 [182].

The impact of these two microRNAs on the expression of OCT3 was tested by experiments which involved altering the levels of microRNA. This was achieved by transient transfection of miRNA mimics and antimirs into the cells and any change in the expression of OCT3 was monitored by qRTPCR. However, this approach did not work as there was no correlation found between the expression levels of microRNAs and OCT3. This prompted us to look to other strategies for finding out potential microRNAs that could regulate the expression of OCT3, one of which was genome wide analysis of microRNA expression. Novel techniques which make the study of genome wide expression of microRNAs possible have been recently developed. One such technique, the next generation sequencing analysis of genome wide expressed microRNAs was performed in the DNA microarray and deep sequencing facility in the university. The results were quite encouraging as a lot of microRNA species were found distributed among the four cell lines with highly variable expression (ca. 10 cycles). Although there are a lot of studies conducted on expression profiling of microRNAs in renal cell 
carcinoma and the impact of microRNAs on expression of transporters such as the glucose transporter 1 (GLUT1) [190], none of them so far were correlated to OCT3 expression. The genome wide expression analysis we conducted revealed different levels of expression of mir-204 and mir-143 compared to our initial observations. This led us to believe that a correlation study between the microRNA expression and mRNA expression from the same samples would give us more accurate details about the interactions in these cells as performed earlier [191]. This is an emerging trend in microRNA research with the development of databases such as MIMA (microRNA and mRNA integrated analysis). Accordingly, genome wide mRNA analysis is also being performed. Correlation of transcriptome analysis with the microRNA data obtained from the samples is the way forward to look at candidate genes and microRNAs involved in the regulation of expression of OCT3. The entire data shall be correlated with data obtained from healthy kidney cells; this approach would help us to look at factors that might regulate the expression of OCT3 at the transcriptional as well as post-transcriptional levels. 


\section{Summary and conclusions}

To summarize, we report novel interactions of the SLC transporter proteins expressed in liver. Organic anion transporter 2 interacted with the antineoplastic compounds bendamustine, irinotecan and paclitaxel. Furthermore, we proved that OAT2 can act as transporter for bendamustine and irinotecan. This is a very important observation as this is the first report which shows an uptake transporter for bendamustine and irinotecan. Irinotecan is metabolized into SN38, which was shown to be a substrate of OATP1B1; however, how irinotecan enters the cells is still a question, and our observation of OAT2 being able to transport irinotecan might provide an answer to this puzzle. We report that OATP1B1 interacts strongly with vinblastine and paclitaxel. In addition, OATP1B3 interacted with the compounds chlorambucil, mitoxantrone, vinblastine, vincristine, paclitaxel and etoposide. Other than paclitaxel, it remains to be seen whether these compounds are transported by OATP1B1 and OATP1B3. We attempted to understand the basis of the differentiation of compounds that interact with those which do not interact with the transporter proteins. However, we did not find any correlation between the molecular parameters such as molecular weight, polar surface area, $\log \mathrm{P}$ and $\log \mathrm{D}$ values and the fact whether they interact with a protein or not. From the $\mathrm{IC}_{50}$ values generated, we predict whether these interactions might lead to potential drug-drug interactions and as per the calculations, the interactions of irinotecan with OAT2, paclitaxel with OATP1B1, and the compounds mitoxantrone, paclitaxel and etoposide with OATP1B3 have the potential to cause drug-drug interactions and this needs to be looked into in in vivo situations. Considering the fact that cancerous tissues exhibit a differential expression of transporter proteins, as reported in many cases, the expression of these transporters in various cancers also needs to be evaluated. This has the potential to increase the chances of a successful chemotherapy many fold. In addition, we also looked at the causes of a 
variable pattern of expression of OCT3 in the renal carcinoma cell lines A498, ACHN, 786-O, and LN78, a study reported earlier by our group. We used compounds which essentially perturbed the DNA methylation and histone deacetylation mechanisms independently, and analyzed their effects on changes of expression of OCT3. We observed that these mechanisms could not account for the huge difference of expression of OCT3 in A498 (a high OCT3 expressing cell line) and ACHN (a low OCT3 expressing cell line). Methylation status of the promoter region of OCT3 was also analyzed and no differences were observed among the four RCCs. Using prediction algorithms that predict microRNAs able to bind to 3' UTR of OCT3, we selected those microRNAs which were predicted by at least a couple of accurate prediction programs, as reported in the literature. The expression of these microRNAs was evaluated in the cell lines A498 and ACHN and two microRNAs hsa-mir-204 and hsa-mir-143 were found to be expressed more in A498, a cell line with high OCT3 expression. Altering the levels of these microRNAs did not affect the expression of OCT3 suggesting that they are not involved in the regulation of OCT3. We broadened our search by performing a genome wide microRNA analysis in the four RCCs. Many microRNAs are found to be differentially expressed in these cell lines and a correlation between the microRNA expression data with the transcriptome data is to be done. In this direction, the transcriptome analysis is being performed. This strategy shall also shed light on those microRNAs which are targeting OCT3 indirectly, along with transcriptional regulators of OCT3.

To conclude, this study demonstrates for the first time, OAT2 as an uptake transporter for bendamustine and irinotecan, antineoplastic compounds widely used in cancer chemotherapy. In addition, novel interactions of the antineoplastic compounds with OATP1B1 and OATP1B3 are reported. Furthermore, the epigenetic mechanisms of histone deacetylation, DNA methylation, and differences in methylation status of $\mathrm{CpG}$ 
residues in the promoter region of OCT3 were not responsible for the differential expression of OCT3 in A498 and ACHN cells. A comprehensive approach of next generation sequencing of mRNAs of the cell lines is being performed, which in addition to the expression data obtained for microRNAs, would be crucial to decipher the regulators of OCT3 in renal carcinoma cells. 


\section{7. $\quad$ References}

1. Hollenstein K, Dawson RJ, Locher KP, Structure and mechanism of ABC transporter proteins. Curr Opin Struct Biol 2007;17:412-8.

2. Szakacs G, Paterson JK, Ludwig JA, Booth-Genthe C, Gottesman MM, Targeting multidrug resistance in cancer. Nat Rev Drug Discov 2006;5:219-34.

3. Luqmani YA, Mechanisms of drug resistance in cancer chemotherapy. Med Princ Pract 2005;14 Suppl 1:35-48.

4. Hediger MA, Clemencon B, Burrier RE, Bruford EA, The ABCs of membrane transporters in health and disease (SLC series): introduction. Mol Aspects Med 2013;34:95-107.

5. Leslie EM, Deeley RG, Cole SP, Multidrug resistance proteins: role of Pglycoprotein, MRP1, MRP2, and BCRP (ABCG2) in tissue defense. Toxicol Appl Pharmacol 2005;204:216-37.

6. De BT, van Westen GJ, Ijzerman AP, Stieger B, de WP, Augustijns PF, Annaert PP, Structure-based identification of OATP1B1/3 inhibitors. Mol Pharmacol 2013;83:1257-67.

7. Gupta S, Wulf G, Henjakovic M, Koepsell H, Burckhardt G, Hagos Y, Human organic cation transporter 1 is expressed in lymphoma cells and increases susceptibility to irinotecan and paclitaxel. J Pharmacol Exp Ther 2012;341:16-23.

8. Filipski KK, Loos WJ, Verweij J, Sparreboom A, Interaction of Cisplatin with the human organic cation transporter 2. Clin Cancer Res 2008;14:3875-80.

9. Sekine T, Cha SH, Tsuda M, Apiwattanakul N, Nakajima N, Kanai Y, Endou H, Identification of multispecific organic anion transporter 2 expressed predominantly in the liver. FEBS Lett 1998;429:179-82.

10. Burckhardt $\mathrm{G}$ and Burckhardt $\mathrm{BC}$, In vitro and in vivo evidence of the importance of organic anion transporters (OATs) in drug therapy. Handb Exp Pharmacol 2011;29-104.

11. Cropp CD, Komori T, Shima JE, Urban TJ, Yee SW, More SS, Giacomini KM, Organic anion transporter 2 (SLC22A7) is a facilitative transporter of cGMP. Mol Pharmacol 2008;73:1151-8.

12. Kobayashi Y, Ohshiro N, Sakai R, Ohbayashi M, Kohyama N, Yamamoto T, Transport mechanism and substrate specificity of human organic anion transporter 2 (hOat2 [SLC22A7]). J Pharm Pharmacol 2005;57:573-8.

13. Fork C, Bauer T, Golz S, Geerts A, Weiland J, Del TD, Schomig E, Grundemann D, OAT2 catalyses efflux of glutamate and uptake of orotic acid. Biochem $\mathbf{J}$ 2011;436:305-12. 
14. Sato M, Mamada H, Anzai N, Shirasaka Y, Nakanishi T, Tamai I, Renal secretion of uric acid by organic anion transporter 2 (OAT2/SLC22A7) in human. Biol Pharm Bull 2010;33:498-503.

15. Cheng Y, Vapurcuyan A, Shahidullah M, Aleksunes LM, Pelis RM, Expression of organic anion transporter 2 in the human kidney and its potential role in the tubular secretion of guanine-containing antiviral drugs. Drug Metab Dispos 2012;40:617-24.

16. Hagenbuch B and Meier PJ, Molecular cloning, chromosomal localization, and functional characterization of a human liver $\mathrm{Na}+$ /bile acid cotransporter. J Clin Invest 1994;93:1326-31.

17. Visser WE, Wong WS, van Mullem AA, Friesema EC, Geyer J, Visser TJ, Study of the transport of thyroid hormone by transporters of the SLC10 family. Mol Cell Endocrinol 2010;315:138-45.

18. Ho RH, Tirona RG, Leake BF, Glaeser H, Lee W, Lemke CJ, Wang Y, Kim RB, Drug and bile acid transporters in rosuvastatin hepatic uptake: function, expression, and pharmacogenetics. Gastroenterology 2006;130:1793-806.

19. Fujino H, Saito T, Ogawa S, Kojima J, Transporter-mediated influx and efflux mechanisms of pitavastatin, a new inhibitor of HMG-CoA reductase. J Pharm Pharmacol 2005;57:1305-11.

20. Yan H, Zhong G, Xu G, He W, Jing Z, Gao Z, Huang Y, Qi Y, Peng B, Wang H, Fu L, Song M, Chen P, Gao W, Ren B, Sun Y, Cai T, Feng X, Sui J, Li W, Sodium taurocholate cotransporting polypeptide is a functional receptor for human hepatitis B and D virus. Elife 2012;1:e00049.

21. Hagenbuch B and Meier PJ, The superfamily of organic anion transporting polypeptides. Biochim Biophys Acta 2003;1609:1-18.

22. Abe T, Kakyo M, Tokui T, Nakagomi R, Nishio T, Nakai D, Nomura H, Unno M, Suzuki M, Naitoh T, Matsuno S, Yawo H, Identification of a novel gene family encoding human liver-specific organic anion transporter LST-1. J Biol Chem 1999;274:17159-63.

23. Abe T, Unno M, Onogawa T, Tokui T, Kondo TN, Nakagomi R, Adachi H, Fujiwara K, Okabe M, Suzuki T, Nunoki K, Sato E, Kakyo M, Nishio T, Sugita J, Asano N, Tanemoto M, Seki M, Date F, Ono K, Kondo Y, Shiiba K, Suzuki M, Ohtani H, Shimosegawa T, Iinuma K, Nagura H, Ito S, Matsuno S, LST-2, a human liver-specific organic anion transporter, determines methotrexate sensitivity in gastrointestinal cancers. Gastroenterology 2001;120:1689-99.

24. Tzvetkov MV, Saadatmand AR, Lotsch J, Tegeder I, Stingl JC, Brockmoller J, Genetically polymorphic OCT1: another piece in the puzzle of the variable pharmacokinetics and pharmacodynamics of the opioidergic drug tramadol. Clin Pharmacol Ther 2011;90:143-50. 
25. Oh ES, Kim CO, Cho SK, Park MS, Chung JY, Impact of ABCC2, ABCG2 and SLCO1B1 polymorphisms on the pharmacokinetics of pitavastatin in humans. Drug Metab Pharmacokinet 2013;28:196-202.

26. Begleiter A, Mowat M, Israels LG, Johnston JB, Chlorambucil in chronic lymphocytic leukemia: mechanism of action. Leuk Lymphoma 1996;23:187-201.

27. Galaup A and Paci A, Pharmacology of dimethanesulfonate alkylating agents: busulfan and treosulfan. Expert Opin Drug Metab Toxicol 2013;9:333-47.

28. Leoni LM and Hartley JA, Mechanism of action: the unique pattern of bendamustine-induced cytotoxicity. Semin Hematol 2011;48 Suppl 1:S12-S23.

29. Pettitt AR, Mechanism of action of purine analogues in chronic lymphocytic leukaemia. Br J Haematol 2003;121:692-702.

30. Mini E, Nobili S, Caciagli B, Landini I, Mazzei T, Cellular pharmacology of gemcitabine. Ann Oncol 2006;17 Suppl 5:v7-12.

31. Longley DB, Harkin DP, Johnston PG, 5-fluorouracil: mechanisms of action and clinical strategies. Nat Rev Cancer 2003;3:330-8.

32. Pommier $\mathrm{Y}$, Leo E, Zhang H, Marchand C, DNA topoisomerases and their poisoning by anticancer and antibacterial drugs. Chem Biol 2010;17:421-33.

33. Dumontet $\mathrm{C}$ and Sikic BI, Mechanisms of action of and resistance to antitubulin agents: microtubule dynamics, drug transport, and cell death. J Clin Oncol 1999; 17:1061-70.

34. Perez EA, Microtubule inhibitors: Differentiating tubulin-inhibiting agents based on mechanisms of action, clinical activity, and resistance. Mol Cancer Ther 2009;8:2086-95.

35. Martino M, Olivieri A, Offidani M, Vigna E, Moscato T, Fedele R, Montanari M, Console G, Gentile M, Messina G, Irrera G, Morabito F, Addressing the questions of tomorrow: melphalan and new combinations as conditioning regimens before autologous hematopoietic progenitor cell transplantation in multiple myeloma. Expert Opin Investig Drugs 2013;22:619-34.

36. Jabbour P, Chalouhi N, Tjoumakaris S, Gonzalez LF, Dumont AS, Chitale R, Rosenwasser R, Bianciotto CG, Shields C, Pearls and pitfalls of intraarterial chemotherapy for retinoblastoma. J Neurosurg Pediatr 2012;10:175-81.

37. Hus I, Jawniak D, Gorska-Kosicka M, Butrym A, Dzietczenia J, Wrobel T, Grzegorz M, Lech-Maranda E, Warzocha K, Waszczuk-Gajda A, Jedrzejczak WW, Krawczyk-Kulis M, Kyrcz-Krzemien S, Poplawska L, Walewski J, Dmoszynska A, Bendamustine as Monotherapy and in Combination Regimens for the Treatment of Chronic Lymphocytic Leukemia and Non-Hodgkin Lymphoma: A Retrospective Analysis. Chemotherapy 2014;59:280-9.

38. Goede V, Fischer K, Busch R, Engelke A, Eichhorst B, Wendtner CM, Chagorova T, de la Serna J, Dilhuydy MS, Illmer T, Opat S, Owen CJ, Samoylova O, Kreuzer 
KA, Stilgenbauer S, Dohner H, Langerak AW, Ritgen M, Kneba M, Asikanius E, Humphrey K, Wenger M, Hallek M, Obinutuzumab plus chlorambucil in patients with CLL and coexisting conditions. N Engl J Med 2014;370:1101-10.

39. Hillmen P, Gribben JG, Follows GA, Milligan D, Sayala HA, Moreton P, Oscier DG, Dearden CE, Kennedy DB, Pettitt AR, Nathwani A, Varghese A, Cohen D, Rawstron A, Oertel S, Pocock CF, Rituximab plus chlorambucil as first-line treatment for chronic lymphocytic leukemia: Final analysis of an open-label phase II study. J Clin Oncol 2014;32:1236-41.

40. Masuda N, Higaki K, Takano T, Matsunami N, Morimoto T, Ohtani S, Mizutani M, Miyamoto T, Kuroi K, Ohno S, Morita S, Toi M, A phase II study of metronomic paclitaxel/cyclophosphamide/capecitabine followed by 5fluorouracil/epirubicin/cyclophosphamide as preoperative chemotherapy for triple-negative or low hormone receptor expressing/HER2-negative primary breast cancer. Cancer Chemother Pharmacol 2014;74:229-38.

41. Shien T, Iwata H, Fukutomi T, Inoue K, Aogi K, Kinoshita T, Ando J, Takashima S, Nakamura K, Shibata T, Fukuda H, Tamoxifen plus tegafur-uracil (TUFT) versus tamoxifen plus Adriamycin (doxorubicin) and cyclophosphamide (ACT) as adjuvant therapy to treat node-positive premenopausal breast cancer (PreMBC): results of Japan Clinical Oncology Group Study 9404. Cancer Chemother Pharmacol 2014;74:603-9.

42. Chen G, Gupta R, Petrik S, Laiko M, Leatherman JM, Asquith JM, Daphtary MM, Garrett-Mayer E, Davidson NE, Hirt K, Berg M, Uram JN, Dauses T, Fetting J, Duus EM, Atay-Rosenthal S, Ye X, Wolff AC, Stearns V, Jaffee EM, Emens LA, A Feasibility Study of Cyclophosphamide, Trastuzumab, and an Allogeneic GMCSF-Secreting Breast Tumor Vaccine for HER2+ Metastatic Breast Cancer. Cancer Immunol Res 2014;2:949-61.

43. Oki Y, Westin JR, Vega F, Chuang H, Fowler N, Neelapu S, Hagemeister FB, McLaughlin P, Kwak LW, Romaguera JE, Fanale M, Younes A, Rodriguez MA, Orlowski RZ, Wang M, Ouzounian ST, Samaniego F, Fayad L, Prospective phase II study of rituximab with alternating cycles of hyper-CVAD and high-dose methotrexate with cytarabine for young patients with high-risk diffuse large B-cell lymphoma. Br J Haematol 2013;163:611-20.

44. Gorn M, Habermann CR, Anige M, Thom I, Schuch G, Andritzky B, Brandl S, Burkholder I, Edler L, Hossfeld DK, Bokemeyer C, Laack E, A pilot study of docetaxel and trofosfamide as second-line 'metronomic' chemotherapy in the treatment of metastatic non-small cell lung cancer (NSCLC). Onkologie 2008;31:185-9.

45. Berghmans T, Lafitte JJ, Scherpereel A, Paesmans M, Lecomte J, Marco VG, Meert AP, Leclercq N, Sculier JP, An ELCWP phase III trial comparing ifosfamide and cisplatin regimens in advanced NSCLC. Anticancer Res 2013;33:5477-82. 
46. Khawandanah M, Baxley A, Pant S, Recurrent metastatic anal cancer treated with modified paclitaxel, ifosfamide, and cisplatin and third-line mitomycin/cetuximab. J Oncol Pharm Pract 2014.

47. Lee JH, Joo YD, Kim H, Ryoo HM, Kim MK, Lee GW, Lee JH, Lee WS, Park JH, Bae SH, Hyun MS, Kim DY, Kim SD, Min YJ, Lee KH, Randomized trial of myeloablative conditioning regimens: busulfan plus cyclophosphamide versus busulfan plus fludarabine. J Clin Oncol 2013;31:701-9.

48. Schmittel A, Schmidt-Hieber M, Martus P, Bechrakis NE, Schuster R, Siehl JM, Foerster $\mathrm{MH}$, Thiel E, Keilholz U, A randomized phase II trial of gemcitabine plus treosulfan versus treosulfan alone in patients with metastatic uveal melanoma. Ann Oncol 2006;17:1826-9.

49. Atzpodien J, Terfloth K, Fluck M, Reitz M, Cisplatin, gemcitabine, and treosulfan in relapsed stage IV cutaneous malignant melanoma patients. $\mathrm{Br} \mathrm{J}$ Cancer 2007;97:1329-32.

50. Shukla N, Kobos R, Renaud T, Steinherz LJ, Steinherz PG, Phase II trial of clofarabine with topotecan, vinorelbine, and thiotepa in pediatric patients with relapsed or refractory acute leukemia. Pediatr Blood Cancer 2014;61:431-5.

51. Kitamura H, Tsukamoto T, Shibata T, Masumori N, Fujimoto H, Hirao Y, Fujimoto K, Kitamura Y, Tomita Y, Tobisu K, Niwakawa M, Naito S, Eto M, Kakehi Y, Randomised phase III study of neoadjuvant chemotherapy with methotrexate, doxorubicin, vinblastine and cisplatin followed by radical cystectomy compared with radical cystectomy alone for muscle-invasive bladder cancer: Japan Clinical Oncology Group Study JCOG0209. Ann Oncol 2014;25:1192-8.

52. Kim M, Kim TM, Kim KH, Keam B, Lee SH, Kim DW, Lee JS, Jeon YK, Kim CW, Heo DS, Ifosfamide, methotrexate, etoposide, and prednisolone (IMEP) plus L-asparaginase as a first-line therapy improves outcomes in stage III/IV NK/T cell-lymphoma, nasal type (NTCL). Ann Hematol 2014.

53. Li W, Gong X, Sun M, Zhao X, Gong B, Wei H, Mi Y, Wang J, High-dose cytarabine in acute myeloid leukemia treatment: a systematic review and metaanalysis. PLoS One 2014;9:e110153.

54. Karp JE, Blackford A, Smith BD, Alino K, Seung AH, Bolanos-Meade J, Greer JM, Carraway HE, Gore SD, Jones RJ, Levis MJ, McDevitt MA, Doyle LA, Wright JJ, Clinical activity of sequential flavopiridol, cytosine arabinoside, and mitoxantrone for adults with newly diagnosed, poor-risk acute myelogenous leukemia. Leuk Res 2010;34:877-82.

55. Craig M, Hanna WT, Cabanillas F, Chen CS, Esseltine DL, Neuwirth R, O'Connor OA, Phase II study of bortezomib in combination with rituximab, cyclophosphamide and prednisone with or without doxorubicin followed by rituximab maintenance in patients with relapsed or refractory follicular lymphoma. Br J Haematol 2014;166:920-8. 
56. Yeo D, Huynh N, Beutler JA, Christophi C, Shulkes A, Baldwin GS, Nikfarjam $\mathrm{M}, \mathrm{He} \mathrm{H}$, Glaucarubinone and gemcitabine synergistically reduce pancreatic cancer growth via down-regulation of P21-activated kinases. Cancer Lett 2014;346:264-72.

57. Haas NB, Lin X, Manola J, Pins M, Liu G, McDermott D, Nanus D, Heath E, Wilding G, Dutcher J, A phase II trial of doxorubicin and gemcitabine in renal cell carcinoma with sarcomatoid features: ECOG 8802. Med Oncol 2012;29:761-7.

58. Zaniboni A, Aitini E, Barni S, Ferrari D, Cascinu S, Catalano V, Valmadre G, Ferrara D, Veltri E, Codignola C, Labianca R, FOLFIRI as second-line chemotherapy for advanced pancreatic cancer: a GISCAD multicenter phase II study. Cancer Chemother Pharmacol 2012;69:1641-5.

59. Deng T, Zhang L, Liu XJ, Xu JM, Bai YX, Wang Y, Han Y, Li YH, Ba Y, Bevacizumab plus irinotecan, 5-fluorouracil, and leucovorin (FOLFIRI) as the second-line therapy for patients with metastatic colorectal cancer, a multicenter study. Med Oncol 2013;30:752.

60. Geisler $\mathrm{CH}$, van $\mathrm{T}^{\prime}$ Veer MB, Jurlander J, Walewski J, Tjonnfjord G, Itala RM, Kimby E, Kozak T, Polliack A, Wu KL, Wittebol S, Abrahamse-Testroote MC, Doorduijn J, Ghidey AW, van Oers MH, Frontline low-dose alemtuzumab with fludarabine and cyclophosphamide prolongs progression-free survival in high-risk CLL. Blood 2014;123:3255-62.

61. Mey U, Strehl J, Gorschluter M, Ziske C, Glasmacher A, Pralle H, Schmidt-Wolf I, Advances in the treatment of hairy-cell leukaemia. Lancet Oncol 2003;4:86-94.

62. Tadmor T, Purine analog toxicity in patients with hairy cell leukemia. Leuk Lymphoma 2011;52 Suppl 2:38-42.

63. Chiorean EG and Von Hoff DD, Taxanes: impact on pancreatic cancer. Anticancer Drugs 2014.

64. Sabry NA and Habib EE, Zoledronic acid and clodronate in the treatment of malignant bone metastases with hypercalcaemia; efficacy and safety comparative study. Med Oncol 2011;28:584-90.

65. Kindla J, Fromm MF, Konig J, In vitro evidence for the role of OATP and OCT uptake transporters in drug-drug interactions. Expert Opin Drug Metab Toxicol 2009;5:489-500.

66. Giacomini KM, Huang SM, Tweedie DJ, Benet LZ, Brouwer KL, Chu X, Dahlin A, Evers R, Fischer V, Hillgren KM, Hoffmaster KA, Ishikawa T, Keppler D, Kim RB, Lee CA, Niemi M, Polli JW, Sugiyama Y, Swaan PW, Ware JA, Wright SH, Yee SW, Zamek-Gliszczynski MJ, Zhang L, Membrane transporters in drug development. Nat Rev Drug Discov 2010;9:215-36.

67. Karlgren M, Ahlin G, Bergstrom CA, Svensson R, Palm J, Artursson P, In vitro and in silico strategies to identify OATP1B1 inhibitors and predict clinical drugdrug interactions. Pharm Res 2012;29:411-26. 
68. Kido Y, Matsson P, Giacomini KM, Profiling of a prescription drug library for potential renal drug-drug interactions mediated by the organic cation transporter 2 . J Med Chem 2011;54:4548-58.

69. Shitara Y, Sato H, Sugiyama Y, Evaluation of drug-drug interaction in the hepatobiliary and renal transport of drugs. Annu Rev Pharmacol Toxicol 2005;45:689-723.

70. Tzvetkov MV, Vormfelde SV, Balen D, Meineke I, Schmidt T, Sehrt D, Sabolic I, Koepsell H, Brockmoller J, The effects of genetic polymorphisms in the organic cation transporters OCT1, OCT2, and OCT3 on the renal clearance of metformin. Clin Pharmacol Ther 2009;86:299-306.

71. Giacomini KM, Balimane PV, Cho SK, Eadon M, Edeki T, Hillgren KM, Huang SM, Sugiyama Y, Weitz D, Wen Y, Xia CQ, Yee SW, Zimdahl H, Niemi M, International Transporter Consortium commentary on clinically important transporter polymorphisms. Clin Pharmacol Ther 2013;94:23-6.

72. Johnstone RW, Histone-deacetylase inhibitors: novel drugs for the treatment of cancer. Nat Rev Drug Discov 2002;1:287-99.

73. Yoo CB and Jones PA, Epigenetic therapy of cancer: past, present and future. Nat Rev Drug Discov 2006;5:37-50.

74. Laird PW, Cancer epigenetics. Hum Mol Genet 2005;14 Spec No 1:R65-R76.

75. Gottlicher M, Minucci S, Zhu P, Kramer OH, Schimpf A, Giavara S, Sleeman JP, Lo CF, Nervi C, Pelicci PG, Heinzel T, Valproic acid defines a novel class of HDAC inhibitors inducing differentiation of transformed cells. EMBO J 2001;20:6969-78.

76. Phiel CJ, Zhang F, Huang EY, Guenther MG, Lazar MA, Klein PS, Histone deacetylase is a direct target of valproic acid, a potent anticonvulsant, mood stabilizer, and teratogen. J Biol Chem 2001;276:36734-41.

77. Weidle UH and Grossmann A, Inhibition of histone deacetylases: a new strategy to target epigenetic modifications for anticancer treatment. Anticancer Res 2000;20:1471-85.

78. Kostrouchova M, Kostrouch Z, Kostrouchova M, Valproic acid, a molecular lead to multiple regulatory pathways. Folia Biol (Praha) 2007;53:37-49.

79. Kazantsev AG and Thompson LM, Therapeutic application of histone deacetylase inhibitors for central nervous system disorders. Nat Rev Drug Discov 2008;7:85468.

80. Christman JK, 5-Azacytidine and 5-aza-2'-deoxycytidine as inhibitors of DNA methylation: mechanistic studies and their implications for cancer therapy. Oncogene 2002;21:5483-95.

81. Stresemann C and Lyko F, Modes of action of the DNA methyltransferase inhibitors azacytidine and decitabine. Int J Cancer 2008;123:8-13. 
82. Yang X, Noushmehr H, Han H, Andreu-Vieyra C, Liang G, Jones PA, Gene reactivation by 5-aza-2'-deoxycytidine-induced demethylation requires SRCAPmediated H2A.Z insertion to establish nucleosome depleted regions. PLoS Genet 2012;8:e1002604.

83. Eden $\mathrm{S}$ and Cedar H, Role of DNA methylation in the regulation of transcription. Curr Opin Genet Dev 1994;4:255-9.

84. Siegfried Z, Eden S, Mendelsohn M, Feng X, Tsuberi BZ, Cedar H, DNA methylation represses transcription in vivo. Nat Genet 1999;22:203-6.

85. Suzuki MM and Bird A, DNA methylation landscapes: provocative insights from epigenomics. Nat Rev Genet 2008;9:465-76.

86. Robertson KD, DNA methylation and human disease. Nat Rev Genet 2005;6:597610.

87. Qu Q, Qu J, Zhan M, Wu LX, Zhang YW, Lou XY, Fu LJ, Zhou HH, Different involvement of promoter methylation in the expression of organic cation/carnitine transporter 2 (OCTN2) in cancer cell lines. PLoS One 2013;8:e76474.

88. Kikuchi R, Kusuhara H, Hattori N, Shiota K, Kim I, Gonzalez FJ, Sugiyama Y, Regulation of the expression of human organic anion transporter 3 by hepatocyte nuclear factor 1alpha/beta and DNA methylation. Mol Pharmacol 2006;70:887-96.

89. Mitchell PJ and Tjian R, Transcriptional regulation in mammalian cells by sequence-specific DNA binding proteins. Science 1989;245:371-8.

90. Thomas $\mathrm{MC}$ and Chiang CM, The general transcription machinery and general cofactors. Crit Rev Biochem Mol Biol 2006;41:105-78.

91. Lee TI and Young RA, Transcription of eukaryotic protein-coding genes. Annu Rev Genet 2000;34:77-137.

92. Lee TI and Young RA, Transcriptional regulation and its misregulation in disease. Cell 2013;152:1237-51.

93. Yeh JE, Toniolo PA, Frank DA, Targeting transcription factors: promising new strategies for cancer therapy. Curr Opin Oncol 2013;25:652-8.

94. Saborowski M, Kullak-Ublick GA, Eloranta JJ, The human organic cation transporter-1 gene is transactivated by hepatocyte nuclear factor-4alpha. J Pharmacol Exp Ther 2006;317:778-85.

95. Popowski K, Eloranta JJ, Saborowski M, Fried M, Meier PJ, Kullak-Ublick GA, The human organic anion transporter 2 gene is transactivated by hepatocyte nuclear factor-4 alpha and suppressed by bile acids. Mol Pharmacol 2005;67:1629-38.

96. Ogasawara K, Terada T, Asaka J, Katsura T, Inui K, Hepatocyte nuclear factor$4\{$ alpha $\}$ regulates the human organic anion transporter 1 gene in the kidney. Am J Physiol Renal Physiol 2007;292:F1819-F1826. 
97. Klein K, Jungst C, Mwinyi J, Stieger B, Krempler F, Patsch W, Eloranta JJ, Kullak-Ublick GA, The human organic anion transporter genes OAT5 and OAT7 are transactivated by hepatocyte nuclear factor-1alpha (HNF-1alpha). Mol Pharmacol 2010;78:1079-87.

98. Wegner W, Burckhardt G, Henjakovic M, Transcriptional regulation of human organic anion transporter 1 (OAT1) by B-cell CLL/lymphoma 6 (BCL6). Am J Physiol Renal Physiol 2014;ajprenal.

99. Bartel DP, MicroRNAs: genomics, biogenesis, mechanism, and function. Cell 2004;116:281-97.

100. Miyoshi K, Miyoshi T, Siomi H, Many ways to generate microRNA-like small RNAs: non-canonical pathways for microRNA production. Mol Genet Genomics 2010;284:95-103.

101. Ha M and Kim VN, Regulation of microRNA biogenesis. Nat Rev Mol Cell Biol 2014;15:509-24.

102. Brummer A and Hausser J, MicroRNA binding sites in the coding region of mRNAs: extending the repertoire of post-transcriptional gene regulation. Bioessays 2014;36:617-26.

103. Ajay SS, Athey $\mathrm{BD}$, Lee I, Unified translation repression mechanism for microRNAs and upstream AUGs. BMC Genomics 2010;11:155.

104. Lee I, Ajay SS, Yook JI, Kim HS, Hong SH, Kim NH, Dhanasekaran SM, Chinnaiyan AM, Athey BD, New class of microRNA targets containing simultaneous 5'-UTR and 3'-UTR interaction sites. Genome Res 2009;19:1175-83.

105. Sen GL and Blau HM, Argonaute 2/RISC resides in sites of mammalian mRNA decay known as cytoplasmic bodies. Nat Cell Biol 2005;7:633-6.

106. Liu J, Valencia-Sanchez MA, Hannon GJ, Parker R, MicroRNA-dependent localization of targeted mRNAs to mammalian P-bodies. Nat Cell Biol 2005;7:719-23.

107. Valinezhad OA, Safaralizadeh R, Kazemzadeh-Bavili M, Mechanisms of miRNAMediated Gene Regulation from Common Downregulation to mRNA-Specific Upregulation. Int J Genomics 2014;2014:970607.

108. Vasudevan S, Tong Y, Steitz JA, Switching from repression to activation: microRNAs can up-regulate translation. Science 2007;318:1931-4.

109. Vasudevan S, Posttranscriptional upregulation by microRNAs. Wiley Interdiscip Rev RNA 2012;3:311-30.

110. Hausser $\mathbf{J}$ and Zavolan $\mathbf{M}$, Identification and consequences of miRNA-target interactions--beyond repression of gene expression. Nat Rev Genet 2014;15:599612. 
111. Lim LP, Lau NC, Garrett-Engele P, Grimson A, Schelter JM, Castle J, Bartel DP, Linsley PS, Johnson JM, Microarray analysis shows that some microRNAs downregulate large numbers of target mRNAs. Nature 2005;433:769-73.

112. Wu S, Huang S, Ding J, Zhao Y, Liang L, Liu T, Zhan R, He X, Multiple microRNAs modulate p21Cip1/Waf1 expression by directly targeting its 3' untranslated region. Oncogene 2010;29:2302-8.

113. Lewis BP, Shih IH, Jones-Rhoades MW, Bartel DP, Burge CB, Prediction of mammalian microRNA targets. Cell 2003;115:787-98.

114. Kiriakidou M, Nelson PT, Kouranov A, Fitziev P, Bouyioukos C, Mourelatos Z, Hatzigeorgiou A, A combined computational-experimental approach predicts human microRNA targets. Genes Dev 2004;18:1165-78.

115. John B, Enright AJ, Aravin A, Tuschl T, Sander C, Marks DS, Human MicroRNA targets. PLoS Biol 2004;2:e363.

116. Krek A, Grun D, Poy MN, Wolf R, Rosenberg L, Epstein EJ, Macmenamin P, da P, I, Gunsalus KC, Stoffel M, Rajewsky N, Combinatorial microRNA target predictions. Nat Genet 2005;37:495-500.

117. Alexiou P, Maragkakis M, Papadopoulos GL, Reczko M, Hatzigeorgiou AG, Lost in translation: an assessment and perspective for computational microRNA target identification. Bioinformatics 2009;25:3049-55.

118. Yue D, Liu H, Huang Y, Survey of Computational Algorithms for MicroRNA Target Prediction. Curr Genomics 2009;10:478-92.

119. Zhang $\mathrm{Y}$ and Verbeek FJ, Comparison and integration of target prediction algorithms for microRNA studies. J Integr Bioinform 2010;7.

120. Witkos TM, Koscianska E, Krzyzosiak WJ, Practical Aspects of microRNA Target Prediction. Curr Mol Med 2011;11:93-109.

121. Thomson DW, Bracken CP, Goodall GJ, Experimental strategies for microRNA target identification. Nucleic Acids Res 2011;39:6845-53.

122. Fei X, Qi M, Wu B, Song Y, Wang Y, Li T, MicroRNA-195-5p suppresses glucose uptake and proliferation of human bladder cancer T24 cells by regulating GLUT3 expression. FEBS Lett 2012;586:392-7.

123. Horie T, Ono K, Nishi H, Iwanaga Y, Nagao K, Kinoshita M, Kuwabara Y, Takanabe R, Hasegawa K, Kita T, Kimura T, MicroRNA-133 regulates the expression of GLUT4 by targeting KLF15 and is involved in metabolic control in cardiac myocytes. Biochem Biophys Res Commun 2009;389:315-20.

124. Kubitz R, Sutfels G, Kuhlkamp T, Kolling R, Haussinger D, Trafficking of the bile salt export pump from the Golgi to the canalicular membrane is regulated by the p38 MAP kinase. Gastroenterology 2004;126:541-53. 
125. Cetinkaya I, Ciarimboli G, Yalcinkaya G, Mehrens T, Velic A, Hirsch JR, Gorboulev V, Koepsell H, Schlatter E, Regulation of human organic cation transporter hOCT2 by PKA, PI3K, and calmodulin-dependent kinases. Am J Physiol Renal Physiol 2003;284:F293-F302.

126. Klaassen CD and Aleksunes LM, Xenobiotic, bile acid, and cholesterol transporters: function and regulation. Pharmacol Rev 2010;62:1-96.

127. Kuhlkamp T, Keitel V, Helmer A, Haussinger D, Kubitz R, Degradation of the sodium taurocholate cotransporting polypeptide (NTCP) by the ubiquitinproteasome system. Biol Chem 2005;386:1065-74.

128. Pelis RM, Suhre WM, Wright SH, Functional influence of N-glycosylation in OCT2-mediated tetraethylammonium transport. Am J Physiol Renal Physiol 2006;290:F1118-F1126.

129. Ciarimboli G, Struwe K, Arndt P, Gorboulev V, Koepsell H, Schlatter E, Hirsch JR, Regulation of the human organic cation transporter hOCT1. J Cell Physiol 2004;201:420-8.

130. Storch $\mathrm{CH}$, Ehehalt R, Haefeli WE, Weiss J, Localization of the human breast cancer resistance protein (BCRP/ABCG2) in lipid rafts/caveolae and modulation of its activity by cholesterol in vitro. J Pharmacol Exp Ther 2007;323:257-64.

131. Annaba F, Sarwar Z, Kumar P, Saksena S, Turner JR, Dudeja PK, Gill RK, Alrefai WA, Modulation of ileal bile acid transporter (ASBT) activity by depletion of plasma membrane cholesterol: association with lipid rafts. Am J Physiol Gastrointest Liver Physiol 2008;294:G489-G497.

132. Watanabe C, Kato Y, Sugiura T, Kubo Y, Wakayama T, Iseki S, Tsuji A, PDZ adaptor protein PDZK2 stimulates transport activity of organic cation/carnitine transporter OCTN2 by modulating cell surface expression. Drug Metab Dispos 2006;34:1927-34.

133. Sugiura T, Kato Y, Tsuji A, Role of SLC xenobiotic transporters and their regulatory mechanisms PDZ proteins in drug delivery and disposition. J Control Release 2006;116:238-46.

134. Jensen ON, Interpreting the protein language using proteomics. Nat Rev Mol Cell Biol 2006;7:391-403.

135. Grundemann D, Schechinger B, Rappold GA, Schomig E, Molecular identification of the corticosterone-sensitive extraneuronal catecholamine transporter. Nat Neurosci 1998;1:349-51.

136. Kekuda R, Prasad PD, Wu X, Wang H, Fei YJ, Leibach FH, Ganapathy V, Cloning and functional characterization of a potential-sensitive, polyspecific organic cation transporter (OCT3) most abundantly expressed in placenta. J Biol Chem 1998;273:15971-9.

137. Wu X, Kekuda R, Huang W, Fei YJ, Leibach FH, Chen J, Conway SJ, Ganapathy $\mathrm{V}$, Identity of the organic cation transporter OCT3 as the extraneuronal 
monoamine transporter (uptake2) and evidence for the expression of the transporter in the brain. J Biol Chem 1998;273:32776-86.

138. Koepsell $\mathrm{H}$ and Endou H, The SLC22 drug transporter family. Pflugers Arch 2004;447:666-76.

139. Koepsell H, Polyspecific organic cation transporters and their biomedical relevance in kidney. Curr Opin Nephrol Hypertens 2013;22:533-8.

140. Vialou V, Amphoux A, Zwart R, Giros B, Gautron S, Organic cation transporter 3 (Slc22a3) is implicated in salt-intake regulation. J Neurosci 2004;24:2846-51.

141. Shnitsar V, Eckardt R, Gupta S, Grottker J, Muller GA, Koepsell H, Burckhardt G, Hagos Y, Expression of human organic cation transporter 3 in kidney carcinoma cell lines increases chemosensitivity to melphalan, irinotecan, and vincristine. Cancer Res 2009;69:1494-501.

142. Yokoo S, Masuda S, Yonezawa A, Terada T, Katsura T, Inui K, Significance of organic cation transporter 3 (SLC22A3) expression for the cytotoxic effect of oxaliplatin in colorectal cancer. Drug Metab Dispos 2008;36:2299-306.

143. dos Santos Pereira JN, Tadjerpisheh S, Abed MA, Saadatmand AR, Weksler B, Romero IA, Couraud PO, Brockmoller J, Tzvetkov MV, The Poorly Membrane Permeable Antipsychotic Drugs Amisulpride and Sulpiride Are Substrates of the Organic Cation Transporters from the SLC22 Family. AAPS J 2014;16:1247-58.

144. Zhu HJ, Appel DI, Grundemann D, Richelson E, Markowitz JS, Evaluation of organic cation transporter 3 (SLC22A3) inhibition as a potential mechanism of antidepressant action. Pharmacol Res 2012;65:491-6.

145. Heise M, Lautem A, Knapstein J, Schattenberg JM, Hoppe-Lotichius M, Foltys D, Weiler N, Zimmermann A, Schad A, Grundemann D, Otto G, Galle PR, Schuchmann M, Zimmermann T, Downregulation of organic cation transporters OCT1 (SLC22A1) and OCT3 (SLC22A3) in human hepatocellular carcinoma and their prognostic significance. BMC Cancer 2012;12:109.

146. Chen L, Hong C, Chen EC, Yee SW, Xu L, Almof EU, Wen C, Fujii K, Johns SJ, Stryke D, Ferrin TE, Simko J, Chen X, Costello JF, Giacomini KM, Genetic and epigenetic regulation of the organic cation transporter 3, SLC22A3. Pharmacogenomics J 2013;13:110-20.

147. Schaeffeler E, Hellerbrand C, Nies AT, Winter S, Kruck S, Hofmann U, van der Kuip H, Zanger UM, Koepsell H, Schwab M, DNA methylation is associated with downregulation of the organic cation transporter OCT1 (SLC22A1) in human hepatocellular carcinoma. Genome Med 2011;3:82.

148. Massmann V, Edemir B, Schlatter E, Al-Monajjed R, Harrach S, Klassen P, Holle SK, Sindic A, Dobrivojevic M, Pavenstadt H, Ciarimboli G, The organic cation transporter 3 (OCT3) as molecular target of psychotropic drugs: transport characteristics and acute regulation of cloned murine OCT3. Pflugers Arch 2014;466:517-27. 
149. Pietig G, Mehrens T, Hirsch JR, Cetinkaya I, Piechota H, Schlatter E, Properties and regulation of organic cation transport in freshly isolated human proximal tubules. J Biol Chem 2001;276:33741-6.

150. Ciarimboli $\mathrm{G}$ and Schlatter E, Regulation of organic cation transport. Pflugers Arch 2005;449:423-41.

151. Bradford MM, A rapid and sensitive method for the quantitation of microgram quantities of protein utilizing the principle of protein-dye binding. Anal Biochem 1976;72:248-54.

152. Craddock AL, Love MW, Daniel RW, Kirby LC, Walters HC, Wong MH, Dawson PA, Expression and transport properties of the human ileal and renal sodium-dependent bile acid transporter. Am J Physiol 1998;274:G157-G169.

153. Tamai I, Nozawa T, Koshida M, Nezu J, Sai Y, Tsuji A, Functional characterization of human organic anion transporting polypeptide B (OATP-B) in comparison with liver-specific OATP-C. Pharm Res 2001;18:1262-9.

154. Hirano M, Maeda K, Shitara Y, Sugiyama Y, Contribution of OATP2 (OATP1B1) and OATP8 (OATP1B3) to the hepatic uptake of pitavastatin in humans. J Pharmacol Exp Ther 2004;311:139-46.

155. Ismair MG, Stieger B, Cattori V, Hagenbuch B, Fried M, Meier PJ, Kullak-Ublick GA, Hepatic uptake of cholecystokinin octapeptide by organic anion-transporting polypeptides OATP4 and OATP8 of rat and human liver. Gastroenterology 2001;121:1185-90.

156. Svoboda M, Wlcek K, Taferner B, Hering S, Stieger B, Tong D, Zeillinger R, Thalhammer T, Jager W, Expression of organic anion-transporting polypeptides 1B1 and 1B3 in ovarian cancer cells: relevance for paclitaxel transport. Biomed Pharmacother 2011;65:417-26.

157. Karlgren M, Ahlin G, Bergstrom CA, Svensson R, Palm J, Artursson P, In vitro and in silico strategies to identify OATP1B1 inhibitors and predict clinical drugdrug interactions. Pharm Res 2012;29:411-26.

158. Karlgren M, Vildhede A, Norinder U, Wisniewski JR, Kimoto E, Lai Y, Haglund $\mathrm{U}$, Artursson P, Classification of inhibitors of hepatic organic anion transporting polypeptides (OATPs): influence of protein expression on drug-drug interactions. J Med Chem 2012;55:4740-63.

159. van de Steeg E, van der Kruijssen CM, Wagenaar E, Burggraaff JE, Mesman E, Kenworthy KE, Schinkel AH, Methotrexate pharmacokinetics in transgenic mice with liver-specific expression of human organic anion-transporting polypeptide 1B1 (SLCO1B1). Drug Metab Dispos 2009;37:277-81.

160. Izumi S, Nozaki Y, Komori T, Maeda K, Takenaka O, Kusano K, Yoshimura T, Kusuhara H, Sugiyama Y, Substrate-dependent inhibition of organic anion transporting polypeptide 1B1: comparative analysis with prototypical probe substrates estradiol-17beta-glucuronide, estrone-3-sulfate, and sulfobromophthalein. Drug Metab Dispos 2013;41:1859-66. 
161. Wang X, Wolkoff AW, Morris ME, Flavonoids as a novel class of human organic anion-transporting polypeptide OATP1B1 (OATP-C) modulators. Drug Metab Dispos 2005;33:1666-72.

162. Gui C, Miao Y, Thompson L, Wahlgren B, Mock M, Stieger B, Hagenbuch B, Effect of pregnane $\mathrm{X}$ receptor ligands on transport mediated by human OATP1B1 and OATP1B3. Eur J Pharmacol 2008;584:57-65.

163. Noe J, Portmann R, Brun ME, Funk C, Substrate-dependent drug-drug interactions between gemfibrozil, fluvastatin and other organic anion-transporting peptide (OATP) substrates on OATP1B1, OATP2B1, and OATP1B3. Drug Metab Dispos 2007;35:1308-14.

164. Obach RS, Lombardo F, Waters NJ, Trend analysis of a database of intravenous pharmacokinetic parameters in humans for 670 drug compounds. Drug Metab Dispos 2008;36:1385-405.

165. Dubbelman AC, Rosing H, Darwish M, D'Andrea D, Bond M, Hellriegel E, Robertson P, Jr., Beijnen JH, Schellens JH, Pharmacokinetics and excretion of 14C-bendamustine in patients with relapsed or refractory malignancy. Drugs R D 2013; 13:17-28.

166. Huang SM, Zhang L, Giacomini KM, The International Transporter Consortium: a collaborative group of scientists from academia, industry, and the FDA. Clin Pharmacol Ther 2010;87:32-6.

167. Knauf WU, Lissichkov T, Aldaoud A, Liberati A, Loscertales J, Herbrecht R, Juliusson G, Postner G, Gercheva L, Goranov S, Becker M, Fricke HJ, Huguet F, Del G, I, Klein P, Tremmel L, Merkle K, Montillo M, Phase III randomized study of bendamustine compared with chlorambucil in previously untreated patients with chronic lymphocytic leukemia. J Clin Oncol 2009;27:4378-84.

168. Knauf WU, Lissitchkov T, Aldaoud A, Liberati AM, Loscertales J, Herbrecht R, Juliusson G, Postner G, Gercheva L, Goranov S, Becker M, Fricke HJ, Huguet F, Del G, I, Klein P, Merkle K, Montillo M, Bendamustine compared with chlorambucil in previously untreated patients with chronic lymphocytic leukaemia: updated results of a randomized phase III trial. $\mathrm{Br} \mathrm{J}$ Haematol 2012;159:67-77.

169. Masiello D and Tulpule A, Bendamustine therapy in chronic lymphocytic leukemia. Expert Opin Pharmacother 2009;10:1687-98.

170. Rummel MJ, Niederle N, Maschmeyer G, Banat GA, von GU, Losem C, KofahlKrause D, Heil G, Welslau M, Balser C, Kaiser U, Weidmann E, Durk H, Ballo H, Stauch M, Roller F, Barth J, Hoelzer D, Hinke A, Brugger W, Bendamustine plus rituximab versus $\mathrm{CHOP}$ plus rituximab as first-line treatment for patients with indolent and mantle-cell lymphomas: an open-label, multicentre, randomised, phase 3 non-inferiority trial. Lancet 2013;381:1203-10.

171. Cheson BD and Rummel MJ, Bendamustine: rebirth of an old drug. J Clin Oncol 2009;27:1492-501. 
172. Gandhi V and Burger JA, Bendamustine in B-Cell Malignancies: The New 46Year-Old Kid on the Block. Clin Cancer Res 2009;15:7456-61.

173. Crabb SJ, Bradbury J, Nolan L, Selman D, Muthuramalingam SR, Cave J, Johnson PW, Ottensmeier C, A phase I clinical trial of irinotecan and carboplatin in patients with extensive stage small cell lung cancer. Chemotherapy 2012;58:257-63.

174. Nozawa T, Minami H, Sugiura S, Tsuji A, Tamai I, Role of organic anion transporter OATP1B1 (OATP-C) in hepatic uptake of irinotecan and its active metabolite, 7-ethyl-10-hydroxycamptothecin: in vitro evidence and effect of single nucleotide polymorphisms. Drug Metab Dispos 2005;33:434-9.

175. de BP, Verweij J, Loos WJ, Nooter K, Stoter G, Sparreboom A, Determination of irinotecan (CPT-11) and its active metabolite $\mathrm{SN}-38$ in human plasma by reversed-phase high-performance liquid chromatography with fluorescence detection. J Chromatogr B Biomed Sci Appl 1997;698:277-85.

176. Ikehata M, Ueda K, Iwakawa S, Different involvement of DNA methylation and histone deacetylation in the expression of solute-carrier transporters in 4 colon cancer cell lines. Biol Pharm Bull 2012;35:301-7.

177. Bianchi MG, Franchi-Gazzola R, Reia L, Allegri M, Uggeri J, Chiu M, Sala R, Bussolati $\mathrm{O}$, Valproic acid induces the glutamate transporter excitatory amino acid transporter-3 in human oligodendroglioma cells. Neuroscience 2012;227:260-70.

178. Zhu S, Goldschmidt-Clermont PJ, Dong C, Inactivation of monocarboxylate transporter MCT3 by DNA methylation in atherosclerosis. Circulation 2005; 112:1353-61.

179. Schaeffeler E, Hellerbrand C, Nies AT, Winter S, Kruck S, Hofmann U, van der Kuip H, Zanger UM, Koepsell H, Schwab M, DNA methylation is associated with downregulation of the organic cation transporter OCT1 (SLC22A1) in human hepatocellular carcinoma. Genome Med 2011;3:82.

180. Pullen TJ, da S, X, Kelsey G, Rutter GA, miR-29a and miR-29b contribute to pancreatic beta-cell-specific silencing of monocarboxylate transporter 1 (Mct1). Mol Cell Biol 2011;31:3182-94.

181. Ryan J, Tivnan A, Fay J, Bryan K, Meehan M, Creevey L, Lynch J, Bray IM, O'Meara A, Tracey L, Davidoff AM, Stallings RL, MicroRNA-204 increases sensitivity of neuroblastoma cells to cisplatin and is associated with a favourable clinical outcome. Br J Cancer 2012;107:967-76.

182. Yonezawa A, Masuda S, Yokoo S, Katsura T, Inui K, Cisplatin and oxaliplatin, but not carboplatin and nedaplatin, are substrates for human organic cation transporters (SLC22A1-3 and multidrug and toxin extrusion family). J Pharmacol Exp Ther 2006;319:879-86.

183. Li Q, Peng X, Yang H, Rodriguez JA, Shu Y, Contribution of organic cation transporter 3 to cisplatin cytotoxicity in human cervical cancer cells. J Pharm Sci 2012;101:394-404. 
184. Mao J, Zhang M, Zhong M, Zhang Y, Lv K, MicroRNA-204, a direct negative regulator of ezrin gene expression, inhibits glioma cell migration and invasion. Mol Cell Biochem 2014;396:117-28.

185. Gong M, Ma J, Li M, Zhou M, Hock JM, Yu X, MicroRNA-204 critically regulates carcinogenesis in malignant peripheral nerve sheath tumors. Neuro Oncol 2012;14:1007-17.

186. Wang FE, Zhang C, Maminishkis A, Dong L, Zhi C, Li R, Zhao J, Majerciak V, Gaur AB, Chen S, Miller SS, MicroRNA-204/211 alters epithelial physiology. FASEB J 2010;24:1552-71.

187. Wu XL, Cheng B, Li PY, Huang HJ, Zhao Q, Dan ZL, Tian DA, Zhang P, MicroRNA-143 suppresses gastric cancer cell growth and induces apoptosis by targeting COX-2. World J Gastroenterol 2013;19:7758-65.

188. Zhang Y, Wang Z, Chen M, Peng L, Wang X, Ma Q, Ma F, Jiang B, MicroRNA143 targets MACC1 to inhibit cell invasion and migration in colorectal cancer. Mol Cancer 2012;11:23.

189. Qian X, Yu J, Yin Y, He J, Wang L, Li Q, Zhang LQ, Li CY, Shi ZM, Xu Q, Li W, Lai LH, Liu LZ, Jiang BH, MicroRNA-143 inhibits tumor growth and angiogenesis and sensitizes chemosensitivity to oxaliplatin in colorectal cancers. Cell Cycle 2013;12:1385-94.

190. Yamasaki T, Seki N, Yoshino H, Itesako T, Yamada Y, Tatarano S, Hidaka H, Yonezawa T, Nakagawa M, Enokida H, Tumor-suppressive microRNA-1291 directly regulates glucose transporter 1 in renal cell carcinoma. Cancer Sci 2013;104:1411-9.

191. van IM, Bervoets S, de Meijer EJ, Buermans HP, 't Hoen PA, Menezes RX, Boer $\mathrm{JM}$, Integrated analysis of microRNA and mRNA expression: adding biological significance to microRNA target predictions. Nucleic Acids Res 2013;41:e146. 


\section{Curriculum Vitae}

Venkata Vishnu Vardhan Reddy Marada

Born $28^{\text {th }}$ October, 1982 in Visakhapatnam, India

Email: venkata.marada@med.uni-goettingen.de

Education and research

2011-present.............PhD student at the institute of systemic physiology and pathophysiology, University medical Centre (PhD program Molecular Medicine)

PhD thesis: "Regulation of expression of SLC transporter family of proteins and their interaction with antineoplastic compounds"

$2010 \ldots \ldots \ldots \ldots$..............esearch assistant in the department of gastroenterology, hepatology and endocrinology, Hannover medical school, Hannover.

2006-2010 Researcher in the department of biochemistry, Indian institute of science.

2004-2006. Masters in biochemistry at the University of Hyderabad, India.

\section{Presentations}

May 2012

Poster presentation at the Bad Herrenalber Transporter- und Barriere- Tage, Bad Herrenalb, Germany

October 2012,

November 2013 Oral presentations in Göttinger transporttage, Göttingen 